\title{
Requirement of phosphoinositol-derived signals in the wounding response of Arabidopsis thaliana
}

\author{
Dissertation \\ zur Erlangung des \\ mathematisch-naturwissenschaftlichen Doktorgrades \\ "Doctor rerum naturalium" \\ der Georg-August-Universität Göttingen \\ vorgelegt von \\ Alina Mosblech \\ aus Paderborn
}

Göttingen 2010 
Mitglied des Betreuungsausschusses (1. Referent):

Prof. Dr. Ingo Heilmann, bisher: Abteilung Biochemie der Pflanze, Albrecht-von-Haller-Institut für Pflanzenwissenschaften, Georg-August-Universität Göttingen; ab 01.08.2010: Abteilung Zelluläre Biochemie, Institut für Biochemie und Biotechnologie, Martin-Luther-Universität Halle-Wittenberg

Mitglied des Betreuungsausschusses (2. Referentin):

Prof. Dr. Andrea Polle, Abteilung Forstbotanik und Baumphysiologie, Institut für Forstbotanik, Georg-August-Universität Göttingen

Mitglied des Betreuungsausschusses:

Prof. Dr. Gerhard Braus, Abteilung Molekulare Mikrobiologie und Genetik, Institut für Mikrobiologie und Genetik, Georg-August-Universität Göttingen

Tag der mündlichen Prüfung: 04. Oktober 2010 
Herewith I affirm that I wrote this thesis independently and with no other sources and aids than quoted.

Alina Mosblech 


\section{INDEX}

1 INTRODUCTION 1

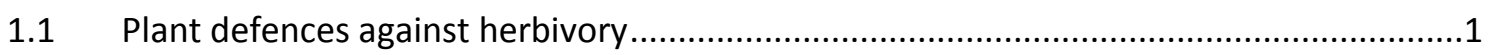

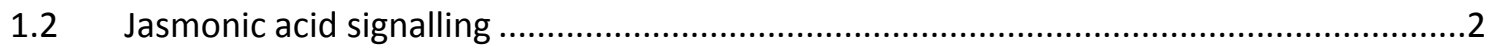

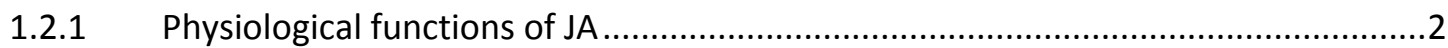

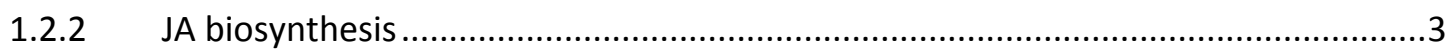

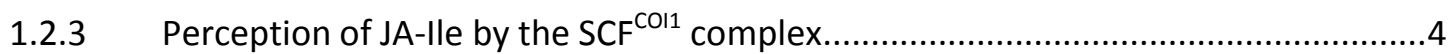

1.2.4 Manipulating JA signalling in plants...................................................................

1.3 The auxin receptor TIR1 contains an inositol polyphosphate cofactor ..........................

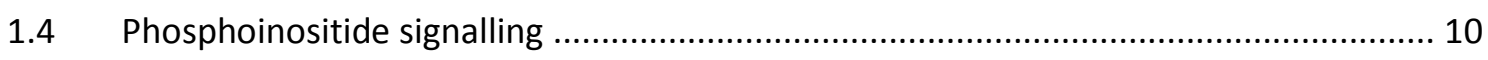

1.4.1 Signalling events involving inositol-containing factors ..........................................10

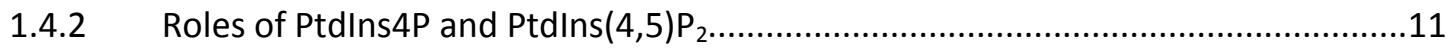

1.4.3 Differences in PLC-mediated PI metabolism between animals and plants .............12

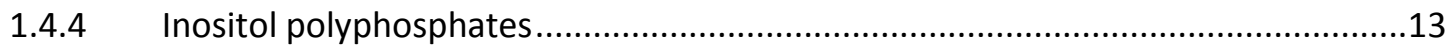

1.4.5 Manipulating PI signals in plants ……….........................................................

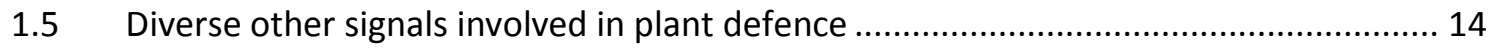

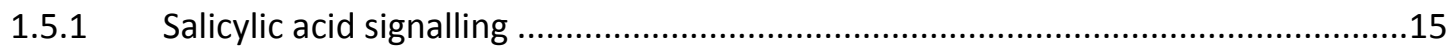

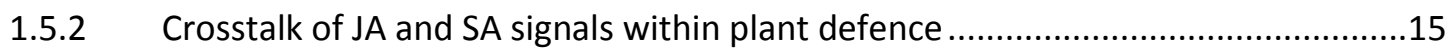

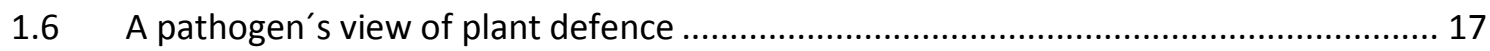

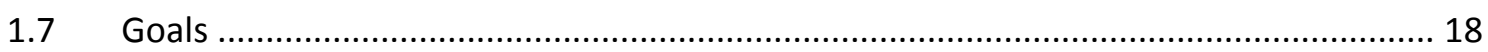

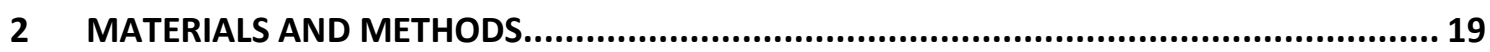

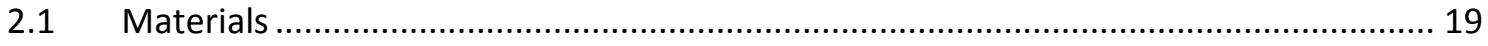

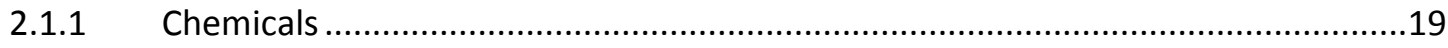

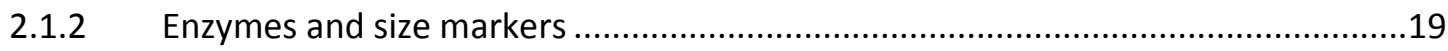

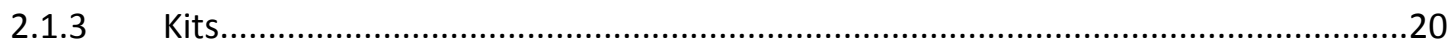

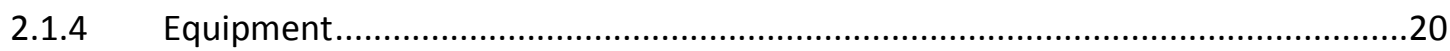

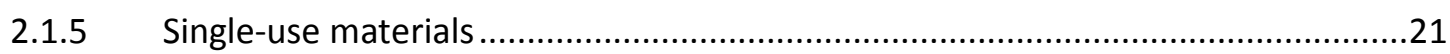

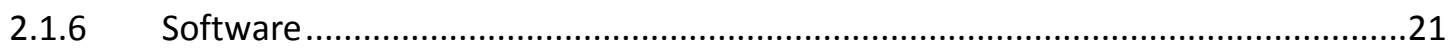

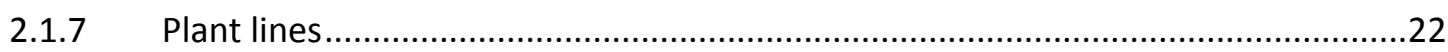

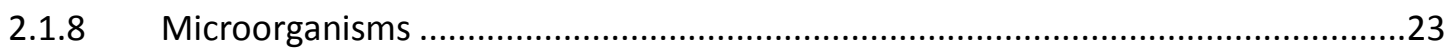

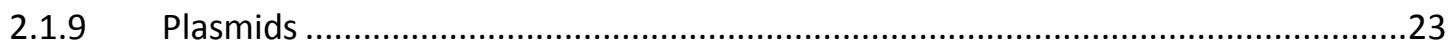

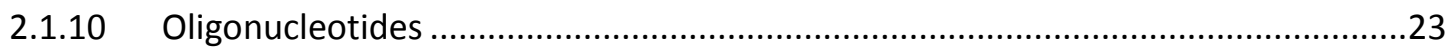


2.2 Methods. 24

2.2.1 Plant growth and cultivation....................................................................24

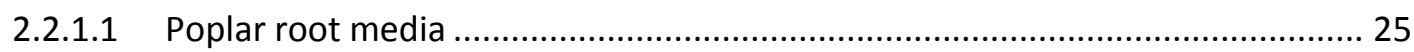

2.2.1.2 Hydroponic culture media .................................................................. 25

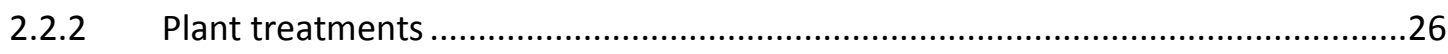

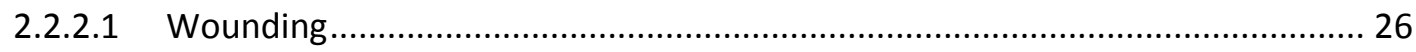

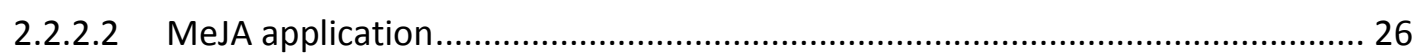

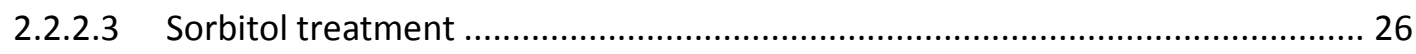

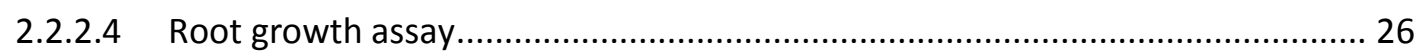

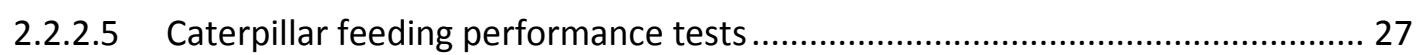

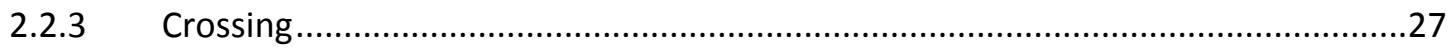

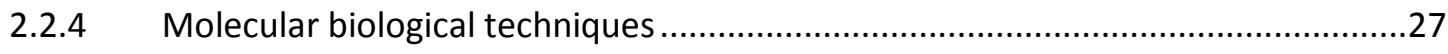

2.2.4.1 Amplification of specific sequences by PCR .......................................... 27

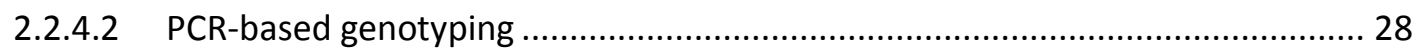

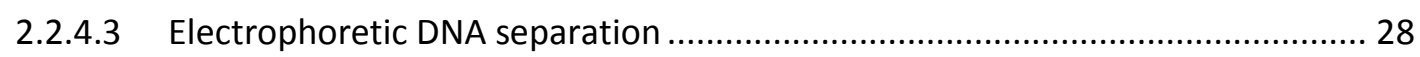

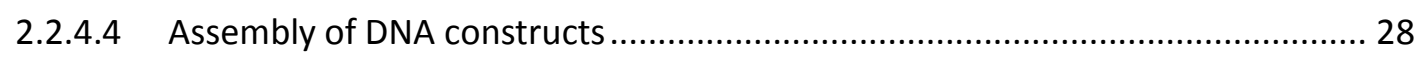

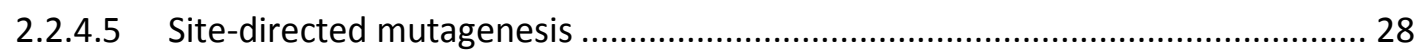

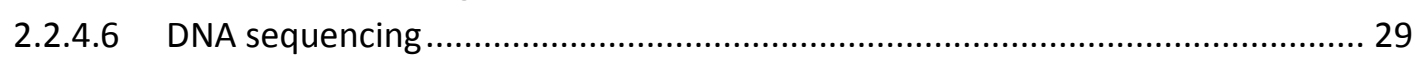

2.2.4.7 Preparation of chemically competent $E$. coli cells ......................................... 29

2.2.4.8 Transformation of $E$. coli cells ....................................................................... 29

2.2.4.9 Preparation of chemically competent $A$. tumefaciens cells............................. 30

2.2.4.10 Transformation of $A$. tumefaciens cells .................................................. 30

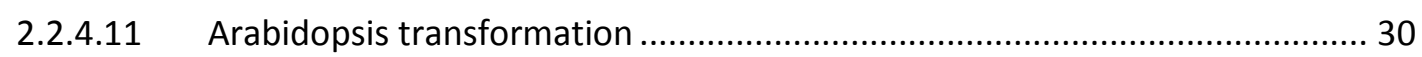

2.2.4.12 Isolation of plasmid DNA from bacterial cultures........................................ 31

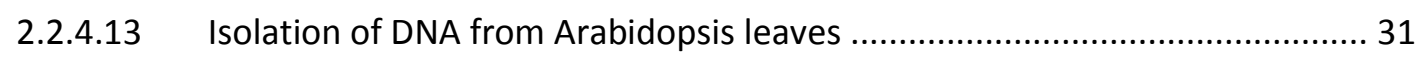

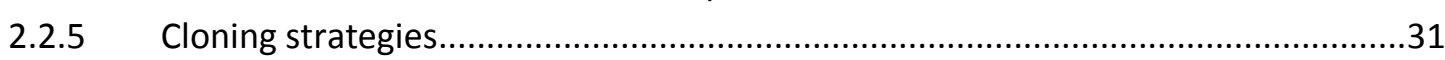

2.2.6 Determination of specific transcript levels ....................................................33

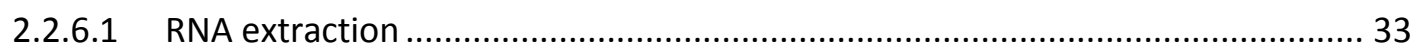

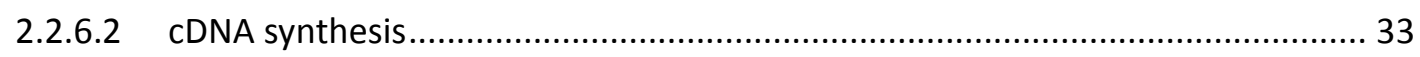

2.2.6.3 Real-time RT-PCR analysis............................................................... 34

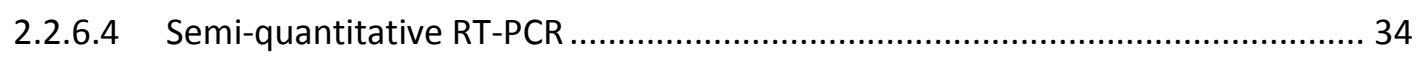

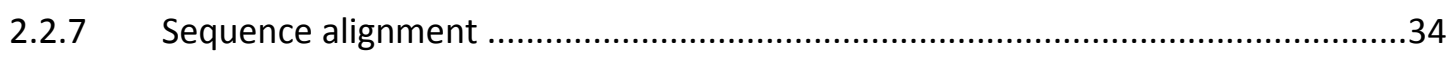

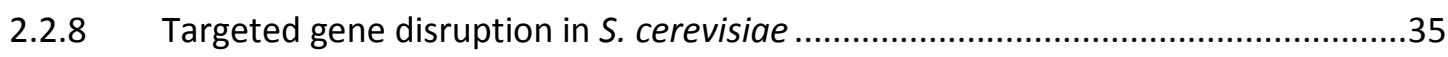

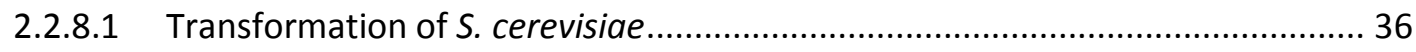

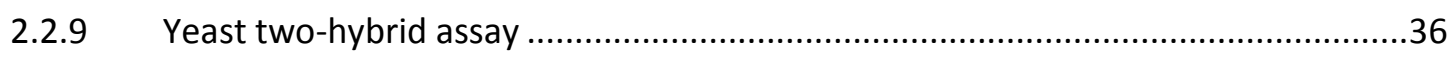

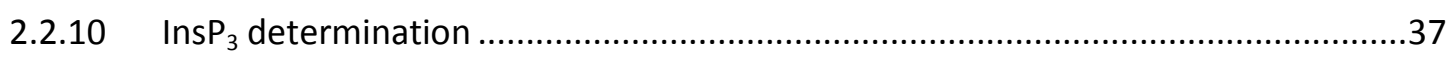

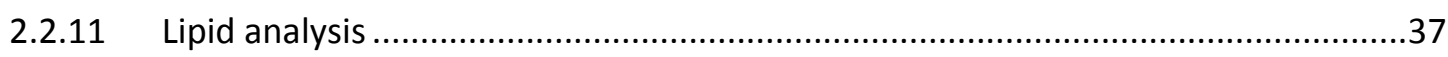

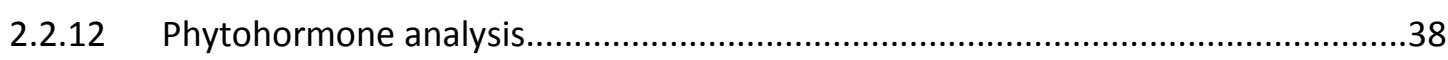

2.2.12.1 Phytohormone analysis via GC/MS .................................................. 38

2.2.12.2 Phytohormone analysis via LC/MS.................................................... 41 


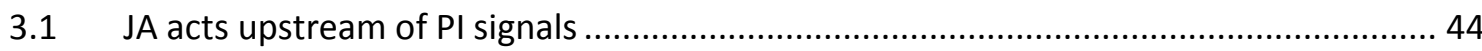

3.1.1 Sorbitol treatment induces $\mathrm{Ins}_{3}$ formation ................................................44

3.2 PI signals are required for full induction of wound-inducible genes .........................45

3.3 PI signals are required for functional defence against caterpillars ......................... 47

Oxylipins accumulate in InsP 5-ptase plants................................................... 48

3.5 A new T-DNA insertion line, coil-t ............................................................... 50

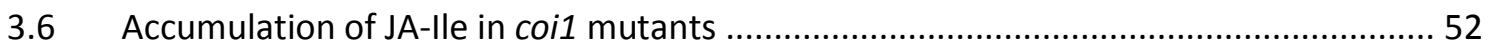

3.7 Amino acid residues coordinating an inositol polyphosphate cofactor in TIR1 are conserved in COI1 ...................................................................................... 54

3.8 Putative inositol polyphosphate coordinating residues are required for COI1/JAZ9

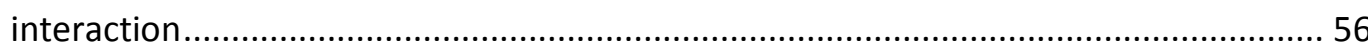

3.9 Reduced in planta functionality of COI1 variants lacking putative inositol polyphosphate binding residues.

3.10 Modulation of inositol polyphosphate biosynthesis alters COI1/JAZ9 interactions in yeast.

3.11 Modulation of inositol polyphosphate biosynthesis alters defence responses in ipk1-1

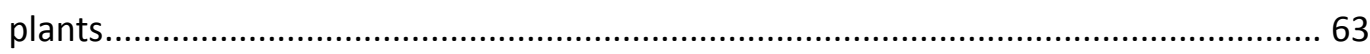

3.11.1 Biochemical characterization of ipk1-1 plants ...........................................63

3.11.1.1 Wound-induced PI signalling components in ipk1-1 plants........................63 63

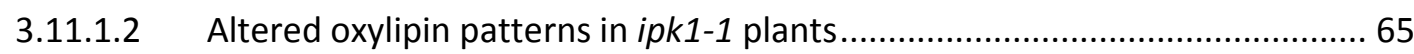

3.11.2 Arabidopsis ipk1-1 mutants are hypersensitive to JA.....................................67

3.11.2.1 Enhanced wound-induced gene expression in ipk1-1 mutants................... 67

3.11.2.2 Increased defence against caterpillars of $i p k 1-1$ plants...............................68

3.11.2.3 Enhanced root length reduction on MeJA in ipk1-1 plants ......................... 69

3.12 SA is relevant for JA as well as for PI signalling ................................................. 70

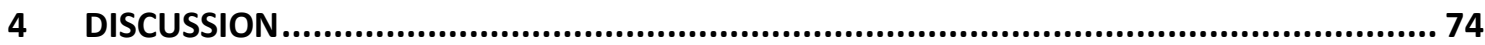

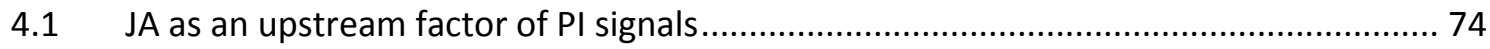

4.2 PI signals required for wound responses and defence ....................................... 74

4.3 Are PI signals required for sensitivity towards JA-Ile? ...................................... 76

4.4 Exchange of putative inositol polyphosphate coordinating amino acids reduces COI1

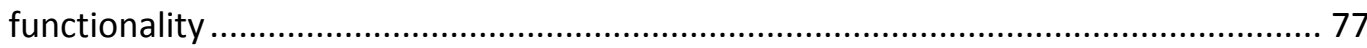

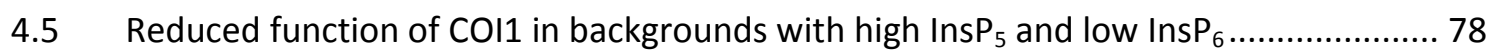

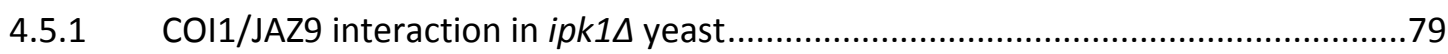

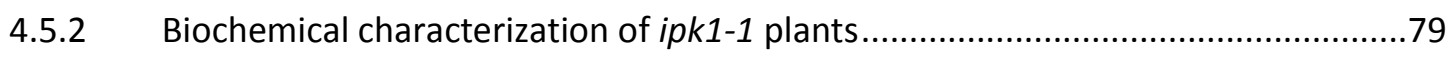




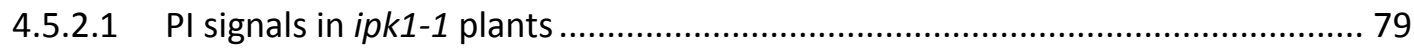

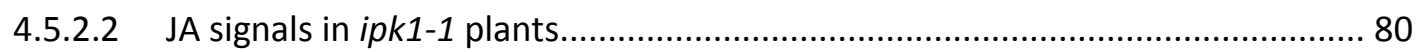

4.5.2.3 COl1-mediated responses in ipk1-1 plants ............................................... 80

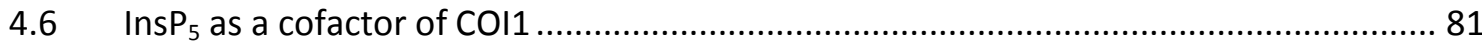

4.7 Integrating PI signals into a greater signalling network: a switch between JA and SA

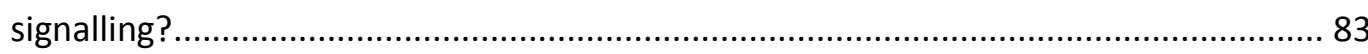

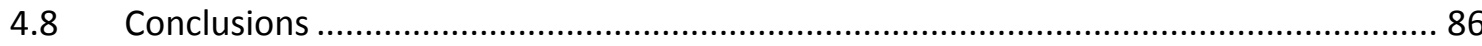

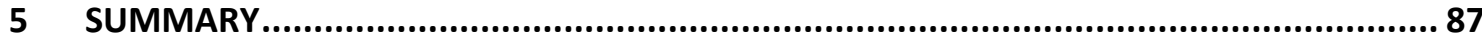

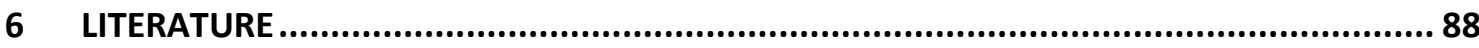

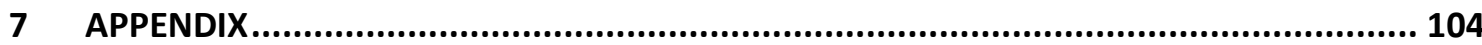

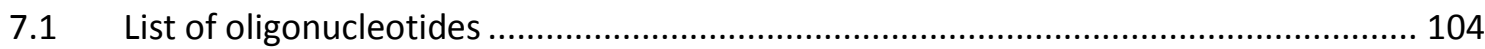

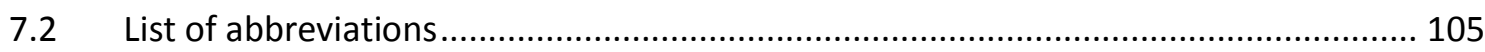

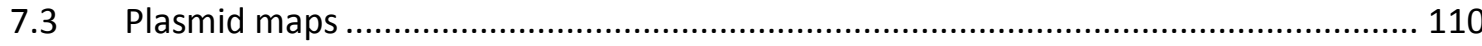

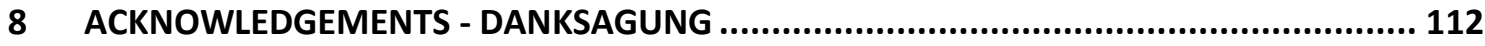

9 CURRICULUM VITAE...................................................................... 115 


\section{INTRODUCTION}

\subsection{Plant defences against herbivory}

In natural ecosystems as well as in agricultural settings, plants are exposed to frequent attacks by herbivorous insects. Crop shortfalls caused by herbivory are of enormous economical relevance and infestation with larvae and beetles may cause $10-35 \%$ of yield reduction. When rapeseed is attacked by the pollen beetle, up to $50 \%$ of loss is possible (Kirch, 2006). To avoid yield losses caused by herbivores, preventive cultivation measures are adopted as well as technical barriers, such as nets or foil. Farmers also spend substantial sums of money for chemical treatment of their crops. In Germany, the annual expenses for insecticides reach 100150 million EUR and for fungicides more than 500 million EUR (source: http://www.agrarpresseportal.de/Nachrichten/Jahrespressekonferenz-2010_article5618.html). Clearly, even in 2010 it is a major goal to minimize crop damage caused by herbivorous insects.

An alternative starting point to increase plants' resistance against herbivory and pathogens is genetic modification. So far, so-called Bt maize is the only transgenic crop plant commercially cultivated in the EU today (source: http://www.bmelv.de/cln_163/SharedDocs/Standardartikel /Landwirtschaft/Pflanze/GrueneGentechnik/StandderGentechnik.html). These plants express a toxin from the bacterium Bacillus thuringiensis (B. t.), which is poisonous to insect pests. The commercial use of transgenic plants in agriculture suffers, however, from low public acceptance, and severe legal restrictions are supposed to control possible risks of genetically modified plants concerning the environment and ecosystem as well as the consumer of the ensuing product.

Before human intervention, plants themselves have evolved to have strategies to defend against a variety of attacks by insects and microbial pathogens. By gaining a better understanding of natural plant defence reactions, it may be possible to find new starting points of herbivorous pest control, either by genetic modifications or by other external manipulation.

The stimulus a plant receives when it is attacked by herbivorous insects is a highly complex event and is composed of different aspects, such as the loss of cellular integrity, chemical substances present in the insects' saliva (Musser et al, 2006), or structural features of the insects' or pathogens' surface (Howe \& Jander, 2008; Jones \& Dangl, 2006). In the laboratory, the naturally occurring wounding event can be experimentally mimicked by the directed 
application of an herbivorous insect, but the choice of a representative species is critical in such an experiment. To keep the experimental setup simple, mechanical wounding may serve to mimic the herbivore attack. Mechanical wounding performed by squeezing with forceps is also used in this thesis as a simplified model system to investigate general aspects of plant wound reaction. Clearly, when interpreting results obtained with such experiments it has to be taken into account that such a wounding event differs from the natural situation of herbivore attack in particular by lacking the chemical aspect (Howe \& Jander, 2008).

Active wound responses of plants include those involved in healing of damaged tissue and also multiple chemical defence mechanisms. Wound responses may also serve to prevent further damage, for example by altered growth and increased trichome formation, or to limit pathogen spread by the release of antimicrobial substances. A common feature of wound responses is an alteration of gene expression patterns, which is orchestrated by a precisely adjusted signalling network, in which different phytohormones and second messengers act to sense the wounding stress and transduce this signal to manifest an appropriate response pattern. Signalling molecules important for wound responses include jasmonic acid (JA) and oxylipins, salicylic acid (SA), auxin ( $\beta$-indolyl acetic acid, IAA), ethylene (ET) and $\mathrm{Ca}^{2+}$ (Johnson \& Ecker, 1998; Kernan \& Thornburg, 1989; Leon et al, 2001; O'Donnell et al, 2003). Basic research on plant-endogenous defence mechanisms against insect herbivory might provide starting points for future approaches to fight insect pests in applied settings.

\subsection{Jasmonic acid signalling}

\subsubsection{Physiological functions of JA}

The phytohormone JA is involved in the regulation of numerous cellular processes in plants, including responses to environmental as well as developmental cues (Balbi \& Devoto, 2008; Turner et al, 2002; Wasternack, 2007). JA is present in all higher land plants examined, and the concentration of JA in plant tissue varies depending on the type of tissue, developmental stage and external stimuli (Creelman \& Mullet, 1997). High levels of JA were reported in reproductive tissues, and JA plays a crucial role in reproduction, as JA-deficient mutants exhibit a sterile phenotype (Creelman \& Mullet, 1997). Interestingly, this JA-dependent fertility is differently affected in different plant species. While JA-deficient Arabidopsis thaliana (Arabidopsis) mutants display male sterility (Feys et al, 1994; von Malek et al, 2002), JAdeficient tomato mutants display female sterility (Li et al, 2001). Besides its role in fertility, JA 
is also involved in fruit ripening, together with the ripening hormone $\mathrm{ET}$, and it is speculated to act as a scent of flowering blossoms attracting pollinating insects (Creelman \& Mullet, 1997; Pichersky \& Gershenzon, 2002). Furthermore, JA affects plant growth with respect to root elongation (Staswick et al, 1992) and tendril coiling (Devoto \& Turner, 2003).

JA represents one of the best-studied players in wound signalling and defence. JA levels increase within a few minutes upon wounding (Glauser et al, 2008), and JA-deficient mutants fail to express a variety of wound-inducible genes (Creelman \& Mullet, 1997; Park et al, 2002; Reymond et al, 2000). Moreover, JA plays a crucial role in defence against herbivorous insects (McConn et al, 1997) and against necrotrophic pathogens (Browse \& Howe, 2008; Li et al, 2005; Thomma et al, 1999). Most relevant for data presented in this thesis with regard to the manifested wounding response is the fact that solanaceous plants express wound-induced genes encoding protease inhibitors active in the gut of insects to interfere with herbivore digestion (Pearce et al, 1991).

Clearly, JA is involved in numerous aspects of plant life. In this thesis, the role of JA during Arabidopsis wound response in crosstalk with other wound-induced signals, in particular to phosphoinositide (PI) signals described further down, has been investigated.

\subsubsection{JA biosynthesis}

JA biosynthesis via the octadecanoid pathway starts in the chloroplast (Fig. 1; Delker et al, 2006), where lipases release the triple-unsaturated C-18 fatty acid $\alpha$-linolenic acid ( $\alpha$-LeA) from membranes of the inner plastidial envelope (Creelman \& Mullet, 1997; Delker et al, 2006; Narvaez-Vasquez et al, 1999). By the lipoxygenase (LOX)-mediated introduction of molecular oxygen to the C-13 atom of $\alpha$-LeA (Feussner et al, 1995), a hydroperoxy $\alpha$-linolenic acid (HPOT) is produced, and allene oxide synthase (AOS), a key enzyme of JA production, forms an unstable intermediate, epoxy octadecatrienoic acid (EOT). This epoxy intermediate is transformed by allene oxide cyclase $(A O C)$ to the cyclic compound, oxo phytodienoic acid (OPDA; Hamberg \& Fahlstadius, 1990). After export from the plastid and transfer to the peroxisome, oPDA is activated and subsequently reduced by oPDA reductase 3 (OPR3) to oxo cyclopentane octanoic acid (OPC 8:0), which is converted to JA by three rounds of $\beta$-oxidation (Creelman \& Mullet, 1995; Vick \& Zimmerman, 1984). Alternatively, JA can be formed via the hexadecanoid pathway, which starts with the triple-unsaturated C-16 fatty acid hexadecatrienoic acid and produces JA via dinor-oPDA (dn-oDPA) and oxo pentenyl cyclopentane hexanoic acid (OPC 6:0) intermediates. JA formed by either pathway is transported from the peroxisome to the cytosol, where the JA amino acid synthetase 
JASMONIC ACID RESISTANT 1 (JAR1) forms the bioactive jasmonoyl-isoleucin conjugate (JA-lle; Fonseca et al, 2009; Staswick et al, 2002). Biosynthetic pathways involved in JA biosynthesis are, thus, in part localized in plastids, in peroxisomes and in the cytosol. JA, its precursors oPDA and dn-oPDA and the bioactive form JA-lle are often and also in this thesis collectively referred to as jasmonates.

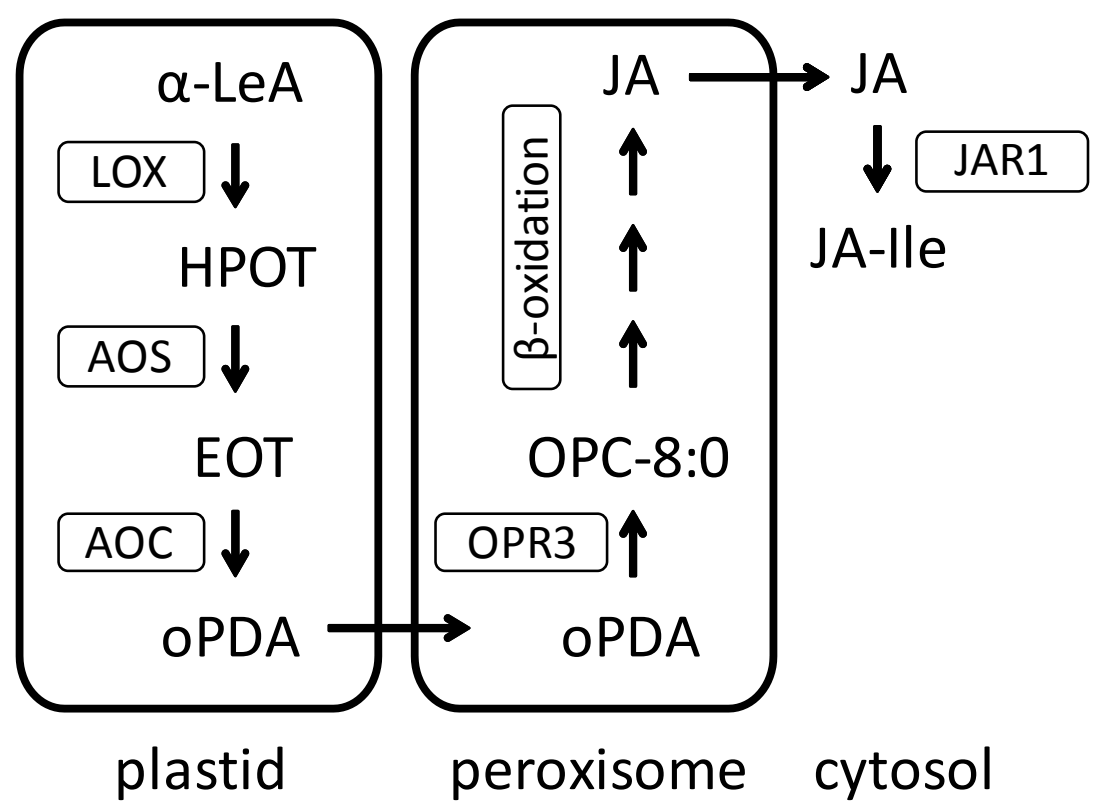

Fig. 1: Subcellular compartmentation of JA biosynthesis. The formation of jasmonic acid (JA) starts with the lipase-mediated release of $\alpha$-linolenic acid ( $\alpha$-LeA) from membrane lipids. Lipoxygenases (LOX) transform the fatty acid into a hydroperoxy $\alpha$-linolenic acid (HPOT). Allene oxide synthase (AOS) converts HPOT to an instable intermediate, epoxy octadecatrienoic acid (EOT), which is the substrate for allene oxide cyclase (AOC), yielding oxo phytodienoic acid (oPDA). oPDA is exported from the plastid and transferred to the peroxisome. There, oPDA is activated by and subsequently reduced by oPDAreductase 3 (OPR3) to oxo pentenyl cyclopentane octanoic acid (OPC 8:0), which is transformed to JA by three rounds of $\beta$-oxidation. JA is exported to the cytosol by an unknown mechanism where it can be conjugated to isoleucine (Ile) by jasmonate amino acid transferase, JAR1, forming the biologically active JA-Ile. Illustration according to Mosblech et al (2009).

\subsubsection{Perception of JA-Ile by the $\mathrm{SCF}^{\mathrm{CO} 1}$ complex}

JA-lle is perceived by binding to the F-box protein CORONATINE INSENSITIVE 1 (COI1). F-box proteins contain at least one F-box motif, which was first identified in the protein cyclin F. The F-box motif consists of approximately 50 amino acids and functions as a site of protein-protein interaction (Kipreos \& Pagano, 2000). Together with other proteins, such as ARABIDOPSIS SKP1-LIKE 1 or 2 (ASK1 or ASK2), CULLIN 1 (CUL1) and RING-BOX PROTEIN 1 (RBX1), COI1 forms an $\mathrm{SCF}^{\mathrm{COI1}} \mathrm{E} 3$ ubiquitin ligase complex (Xu et al, 2002). In this complex, the F-box motif of COI1 
interacts with ASK proteins. E3 ubiquitin ligase complexes are well known in plants to be involved in protein degradation via the ubiquitin-proteasome system (Moon et al, 2004; Santner \& Estelle, 2010). The ubiquitin monomer is a highly conserved protein consisting of 76 amino acids, which is attached to target proteins by the sequential action of three enzymes: The ubiquitin activating enzyme E1 activates ubiquitin in an ATP-dependent manner and the ubiquitin conjugating enzyme E2 conjugates it to a lysine residue of a target protein, which is recruited and correctly positioned by the ubiquitin ligase complex E3 (Pickart, 2001). COI1 is, thus, part of an E3 ubiquitin ligase complex responsible for presenting specific target proteins for ubiquitination. While attachment of a single ubiquitin monomer modifies protein activity or localization of a target protein (Mukhopadhyay \& Riezman, 2007), poly-ubiquitination initiates protein degradation by the $26 \mathrm{~S}$ proteasome (Santner \& Estelle, 2010). The $26 \mathrm{~S}$ proteasome is a large ATP-dependent proteolytic complex that unfolds and degrades poly-ubiquitinated proteins (Voges et al, 1999). The ubiquitin-proteasome system is involved in numerous aspects of plant growth, including cell cycle regulation, embryogenesis, senescence, defence and hormone signalling via JA and auxin (Vierstra, 2009). While in Arabidopsis only two CUL proteins have been shown to assemble in SCF complexes and only two RBX and 21 ASK proteins are encoded in the Arabidopsis genome, over 700 genes encoding putative F-box proteins have been annotated for Arabidopsis. The large diversity enables a possibly modular assembly of specific F-box proteins with E3 ubiquitin ligase complexes (Moon et al, 2004), which denote specific protein targets for degradation. Thus, a key role in hormone perception can be attributed to F-box proteins such as COI1. Specifically, it has been demonstrated that COI1 defines the binding of target proteins determined for ubiquitination and subsequent degradation that have roles in JA signalling (Xie et al, 1998; Xu et al, 2002; Yan et al, 2009). Target proteins of COI1 are jasmonate ZIM-domain (JAZ) proteins, which are transcriptional repressors of the MYC2 transcription factor required for JA-inducible gene expression (MYC transcription factors are named after myelocytomatosis, caused by the virus in which they were first discovered; Chini et al, 2007; Katsir et al, 2008; Thines et al, 2007). In the absence of JA-Ile, JAZ proteins repress MYC2 from activating gene expression (Fig. 2 A). Upon stimulation, JA-lle is formed and promotes the interaction between COI1 and JAZ proteins, thereby initiating JAZ degradation via the ubiquitin-proteasome system (Fig. 2 B; Thines et al, 2007). The now released MYC2 is able to activate JA-responsive genes (Fig. $2 \mathrm{C}$ ).

The Arabidopsis JAZ protein family consists of 12 members, all of which contain the ZIM domain in the central part of the protein and the Jas motif at the $C$ terminus (Staswick, 2008). The ZIM motif is comprised of 28 conserved amino acids and confers the ability for homo- or heteromeric interactions among JAZ proteins independent of the presence of JA-Ile (Chini et al, 
2009a; Chung \& Howe, 2009). Furthermore, the ZIM domain recruits transcriptional corepressors (Pauwels et al, 2010). The 26 amino acid comprising Jas motif displays the JA-lle dependent COI1 binding site, presenting the "degron" of JAZ proteins, a protein sequence that acts as a starting point for degradation (Dohmen et al, 1994). Furthermore, the Jas motif mediates JAZ interaction with MYC2 in a JA-lle independent manner (Fonseca et al, 2009). It has been proposed that both COI1 and MYC2 compete for interaction with the Jas motif of JAZ proteins, and the presence or absence of JA-lle determines the outcome of this competition (Chini et al, 2009b; Chini et al, 2007).

Cellular processes relying on JA signalling are diverse. Likewise, different JAZ proteins display diverse tissue- and stage-specific expression patterns (Chini et al, 2009b) and furthermore are

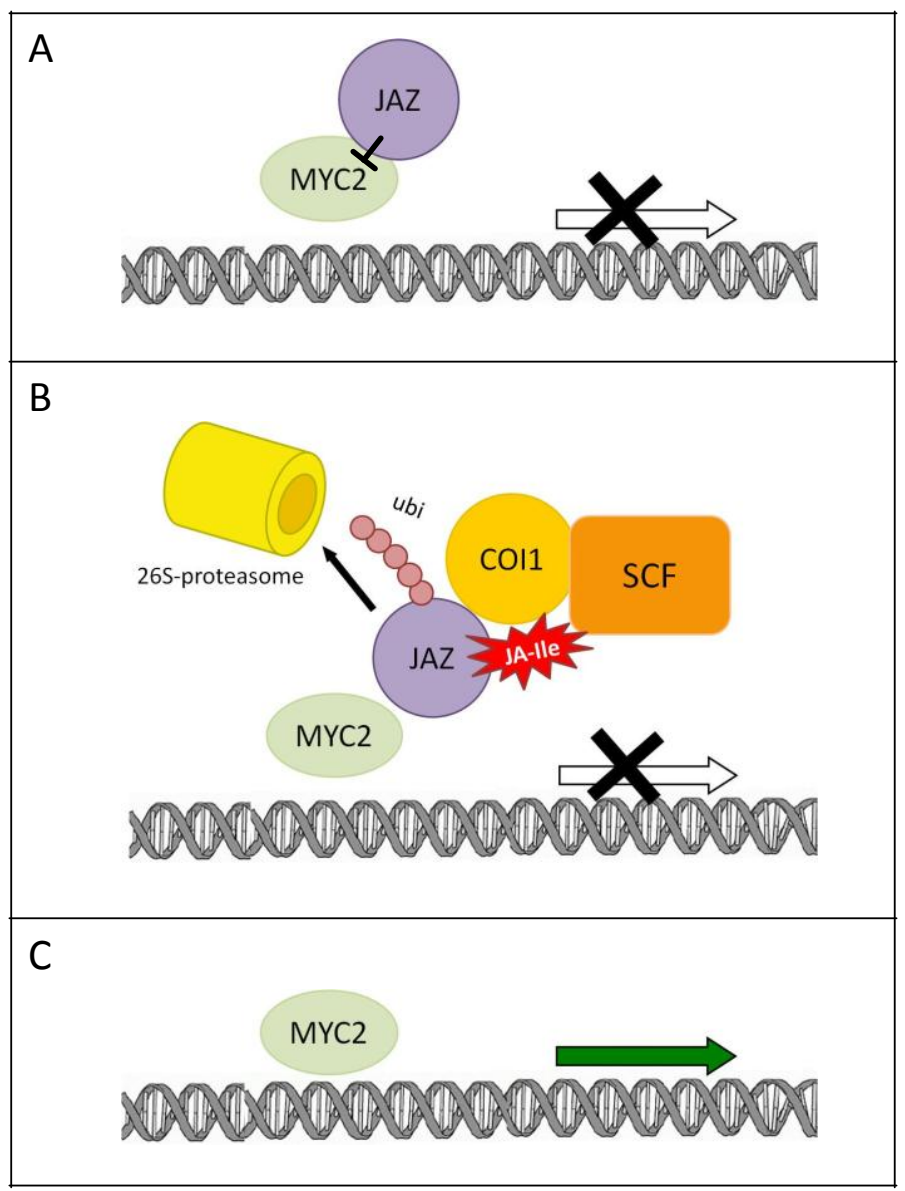

Fig. 2: JA-Ile perception via SCF ${ }^{\mathrm{COI1}}$-mediated JAZ degradation. (A) In the uninduced state, the transcription factor MYC2 is repressed by JAZ. JA-inducible genes are not transcribed, indicated by the crossed-out white arrow. (B) Upon stimulation, JA-lle promotes the interaction of JAZ and SCF ${ }^{\mathrm{COI1}}$, JAZ is poly-ubiquitinated by the $\mathrm{E} 3$ ubiquitin ligase complex $\mathrm{SCF}^{\mathrm{CO} 11}$ and subsequently degraded by the 26Sproteasome. (C) MYC2 is now capable of activating JA-responsive gene expression, indicated by the green arrow. Illustration according to Mosblech et al (2010). 
differently induced by insect feeding and wounding (Chung et al, 2008). However, individual jaz knockout mutants (except jaz10) lack JA-related phenotypes (Thines et al, 2007; Yan et al, 2007), indicating functional redundancy among JAZ family proteins (Chini et al, 2009b). The proposed diversity of JAZ actions can further be expanded by homo- and heteromeric interactions among JAZ proteins as mentioned above (Chini et al, 2009a).

The basic helix-loop-helix transcriptional activator MYC2 (Boter et al, 2004) mentioned above is the so far only identified target of JAZ repressors. Nevertheless, JAZ proteins are expected to target also other transcription factors, since MYC2 does not regulate all JA-responsive genes. Different families of transcription factors are involved in JA signalling, including ET response factors (ERFs; Lorenzo et al, 2003; McGrath et al, 2005; Pauwels et al, 2008; Pre et al, 2008), WRKYs (named after their WRKY domain, defined by the conserved amino acid sequence WRKYGQK at its N-terminal end; Li et al, 2004; Rushton et al, 1995; Xu et al, 2006) and MYBs (MYB transcription factors are named after myeloblastosis, caused by the virus in which they were first discovered; Mandaokar \& Browse, 2009). Recently, JA-Ile-dependent interaction of JAZ1 with MYC3, a close relative of MYC2, was also shown (Pauwels et al, 2010), indicating an alternative candidate of JAZ targets.

As mentioned above, JA-lle-dependent JAZ degradation is mediated by SCF complexes, which are themselves modified by addition or removal of the small ubiquitin-like peptide NEURAL PRECURSOR CELL EXPRESSED DEVELOPMENTALLY DOWNREGULATED PROTEIN 8, NEDD8 (de/neddylation). Active cycles of neddylation and de-neddylation are required to sustain SCF activity towards its protein substrates (Cope et al, 2002; Schwechheimer \& Deng, 2001). Deneddylation takes place via the COP9 signalosome (CSN), a multi protein complex that hydrolyses NEDD8 from SCFs (Schwechheimer \& Isono). Interaction of CSN and SCF ${ }^{\mathrm{CO} 11}$ was shown by (Feng et al, 2003), and it was shown that both complexes are required for JAresponsive gene expression.

\subsubsection{Manipulating JA signalling in plants}

Knockout mutants are important tools to experimentally elucidate functions of single proteins or whole pathways. Two different JA-related Arabidopsis mutants were used in this thesis. The Arabidopsis delayed dehiscence 2-2 (dde2-2) mutant is defective in AOS gene expression and exhibits reduced levels of all oxylipin metabolites downstream of AOS (Fig. 1; Park et al, 2002). As a consequence, these plants are defective in wound-induced JA accumulation as well as in JA-dependent wound-induced gene expression. Furthermore, dde2-2 plants are male sterile, 
since stamen elongation and anther development stall early and pollen fail to dehisce (Park et al, 2002). This phenotype is rescued by exogenous application of methyl-JA (MeJA).

The Arabidopsis coronatine insensitive 1-1 (coi1-1) mutant was isolated in a screen for mutants displaying insensitivity towards the Pseudomonas syringae-derived toxin coronatine and towards MeJA (Feys et al, 1994). coi1-1 plants lack the JA receptor COI1 and exhibit defects in JA-mediated processes, including reduced expression of JA-responsive defence genes and male sterility (Feys et al, 1994; Xie et al, 1998), similar to dde2-2 plants. The coi1-1 mutant also displays a flower phenotype similar to that of the dde2-2 mutants, with shortened stamen and retarded pollen development. In contrast to dde2-2 plants, sterility of coi1-1 mutants cannot be rescued by treatment with exogenous MeJA. Therefore, only heterozygous coi1-1 plants produce offspring and coi1-1 mutant populations are maintained in a heterozygous state. When wild type seedlings are grown on agar plates containing MeJA, they react with reduced growth and especially shortened root growth. As coi1-1 plants are impaired in JA perception, they display decreased root growth inhibition on MeJA and develop long roots (Feys et al, 1994). This response can be utilized to select for homozygous coi1-1 individuals in a heterozygous population and is also employed in this thesis. Heterozygous coi1-1 individuals are required for seed production and exhibit an intermediate root growth phenotype on MeJA. Both the dde2-2 and the coi1-1 mutants carry point mutations and are not easily genotyped. Therefore, in this thesis another allele of coil was established, in which the coil gene is disrupted by a T-DNA insertion, allowing genotyping by PCR.

\subsection{The auxin receptor TIR1 contains an inositol polyphosphate cofactor}

The principle of hormone perception via SCF ubiquitin ligases outlined above is prevalent in plant signalling and has been demonstrated to mediate the effects of JA, but also of auxins (Ruegger et al, 1998), gibberellins (McGinnis et al, 2003), ET (Gagne et al, 2004; Guo \& Ecker, 2003; Potuschak et al, 2003), abscisic acid (ABA; Zhang et al, 2008) and blue light (Demarsy \& Fankhauser, 2009). A large and well-studied familiy of F-box proteins are those involved in auxin signalling. The crystal structure of the auxin receptor F-box protein, TRANSPORT INHIBITOR RESPONSE 1 (TIR1), revealed the unexpected presence of an inositol hexakisphosphate $\left(\operatorname{InsP}_{6}\right)$ cofactor (Fig. 3), the functional relevance of which so far has not been fully assessed (Tan et al, 2007). The TIR1 structure consists of a large leucin-rich repeat (LRR) domain, responsible for auxin perception and substrate recruitment, and an F-box motif. 

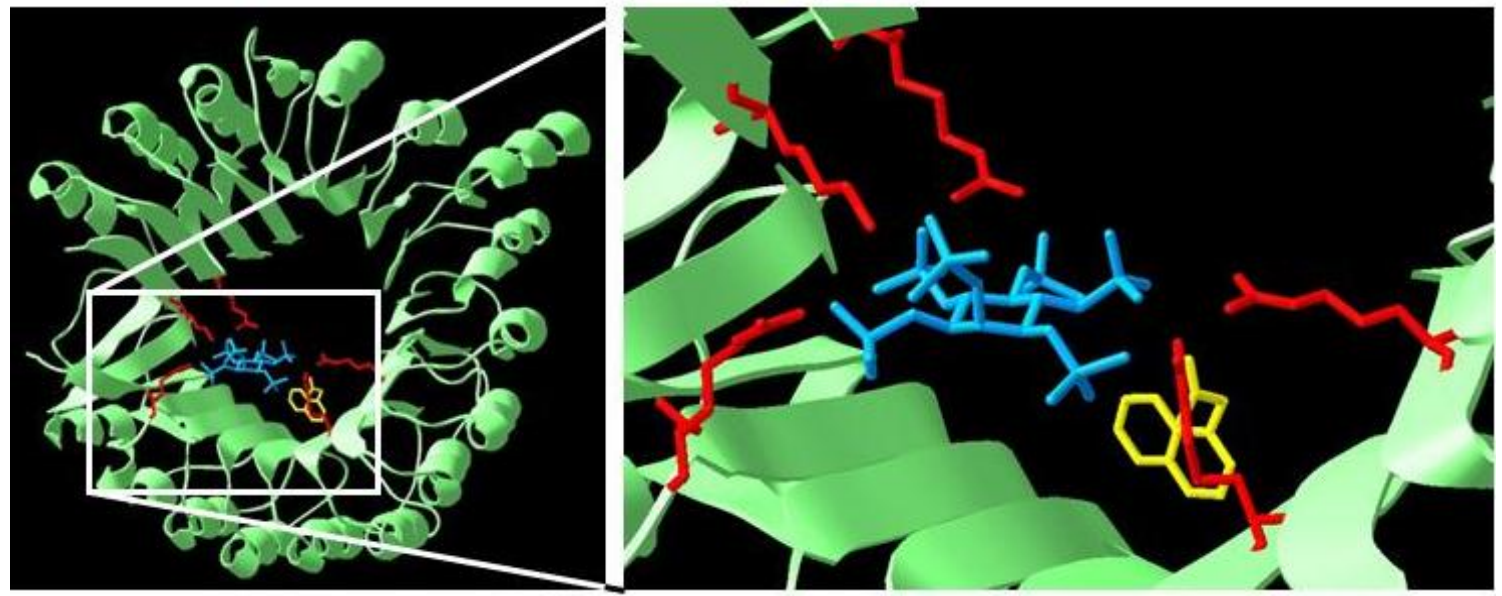

Fig. 3: Partial structure model of TIR1 LRR domain. Auxin is indicated in yellow, inositol hexakisphosphate $\left(\mathrm{InsP}_{6}\right)$ in blue, $\mathrm{InsP}_{6}$ coordinating amino acids also conserved in COI1 are highlighted in red. Left side, overview; right side, close up of $\mathrm{InsP}_{6}$ binding site. Illustration generated by Prof. Dr. Ingo Heilmann.

At the bottom of a surface pocket within the LRR domain, auxin is recognized, and InsP $\mathrm{P}_{6}$ supports a key arginine residue pivotally involved in auxin binding (Tan et al, 2007). The physiological role of InsP $_{6}$ within TIR1 is not clear. However, recent molecular dynamics simulations suggest that $\operatorname{InsP}_{6}$ functions as a structural cofactor, stabilizing the local conformation of the LRR domain by a complicated hydrogen-bonding network between Ins $\mathrm{P}_{6}$ and the surrounding residues of the receptor (Hao and Yang, 2010).

The COI1 protein involved in JA perception is related in sequence to F-box proteins involved in auxin perception, and COI1 and TIR1 show $33 \%$ sequence identity (Yan et al, 2009). Like TIR1, COI1 contains an LRR domain and an F-box motif. The comparison of the primary structures (see also Fig. 12), revealed that the amino acid residues coordinating $\operatorname{lns} \mathrm{P}_{6}$ are not only conserved between TIR1 and other auxin signalling F-box proteins, but also largely in the JA receptor F-box protein, COI1. A cavity in the horseshoe-like structure of the LRR domain has been identified as the JA-lle binding pocket (Yan et al, 2009). This binding pocket can be divided into four distinct areas with specific surface properties, each interacting with a different functional group of JA-lle. One of these areas, called P1 (Yan et al, 2009), interacts with the keto group of the JA cyclopentanone ring by forming hydrogen bonds; the amino acid arginine 409 (R409), involved in forming P1, is one of the conserved amino acid residues that coordinate the $\mathrm{InsP}_{6}$ within TIR1. Based on the similarity in sequence and structure between TIR1 and COI1, it can be hypothesized that an inositol polyphosphate plays a role in JA perception. 


\subsection{Phosphoinositide signalling}

\subsubsection{Signalling events involving inositol-containing factors}

The PI pathway is involved in numerous cellular processes in all eukaryotes (Michell, 2008). The membrane lipid phosphatidylinositol (Ptdlns) is sequentially phosphorylated by specific kinases (Fig. 4). Ptdlns 4-kinases (PI4-kinases) form phosphatidylinositol 4-monophosphate (Ptdlns4P) which can then be further phosphorylated by Ptdlns4P 5-kinases (PIP5-kinases) to phosphatidylinositol 4,5-bisphosphate (Ptdlns $(4,5) \mathrm{P}_{2}$; Drobak et al, 1999). PI lipids act as ligands for partner proteins and display signalling function themselves. PtdIns $(4,5) \mathrm{P}_{2}$ can also be cleaved by phospholipase $C$ (PLC) into diacyl glycerol (DAG), which remains in the membrane, and the soluble inositol 1,4,5-trisphosphate (InsP $P_{3}$; Fig. 4; Lee et al, 1996; Munnik et $\mathrm{al}, 1998)$. InsP $\mathrm{P}_{3}$ has been proposed to induce the release of $\mathrm{Ca}^{2+}$ from intracellular stores.

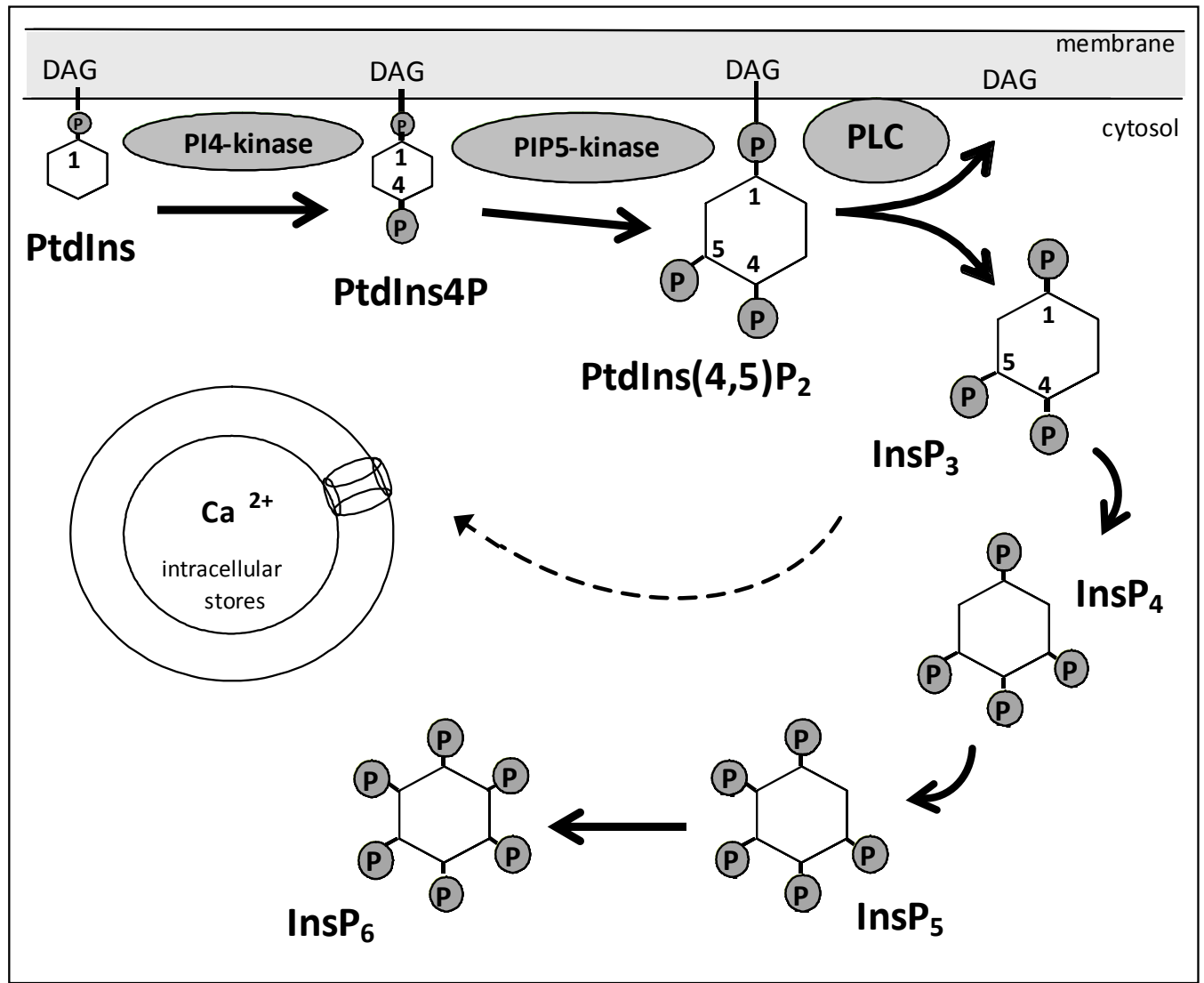

Fig. 4: The PI signalling pathway. Phosphatidylinositol (Ptdlns) is phosphorylated to phosphatidylinositol 4-monophosphate (Ptdlns4P) by Ptdlns 4-kinases (PI4-kinase). Phosphatidylinositol 4,5-bisphosphate (PtdIns $(4,5) \mathrm{P}_{2}$ ), formed by further phosphorylation via Ptdlns4P 5-kinases (PIP5-kinase), is cleaved by phospholipase $C$ (PLC) to form diacyl glycerol (DAG) and the soluble messenger inositol 1,4,5-trisphosphate $\left(\operatorname{Ins}_{3}\right)$. Ins $\mathrm{P}_{3}$ can induce $\mathrm{Ca}^{2+}$ release from intercellular stores and $\mathrm{Ins}_{3}$ can be further phosphorylated to form additional soluble inositol polyphosphates, such as inositol 1,3,4,5-tetrakisphosphate $\left(\right.$ InsP $\left._{4}\right)$, inositol 1,3,4,5,6-pentakisphosphate (InsP $\mathrm{P}_{5}$ ) or inositol 1,2,3,4,5,6-hexakisphosphate (InsP 6 ). 
Alternatively, $\operatorname{Ins}_{3}$ can be further phosphorylated to form different inositol polyphosphates, such as inositol 1,3,4,5-tetrakisphosphate $\left(\operatorname{InsP}_{4}\right)$, inositol 1,3,4,5,6-pentakisphosphate (InsP $\left.\mathrm{P}_{5}\right)$ and inositol 1,2,3,4,5,6-hexakisphosphate ( $\left.\operatorname{InsP}_{6}\right)$.

In previous experiments, the involvement of PIs and inositol polyphosphate signals in the Arabidopsis wounding response was shown (Mosblech et al, 2008), indicated by a 6-fold increase of $\mathrm{InSP}_{3}$ levels over a period of at least six hours after wounding. Based on the information available for the COI 1 homologue TIR1 and those earlier results, it was the working hypothesis of this thesis that wound-induced formation of inositol polyphosphates is important for JA perception by COI1. To test this hypothesis, it is important to understand the metabolism of PIs and inositol polyphosphates in plants and their acknowledged roles in signalling and development.

\subsubsection{Roles of PtdIns4P and PtdIns(4,5) $\mathrm{P}_{2}$}

As intact lipids, PtdIns4P and PtdIns $(4,5) \mathrm{P}_{2}$ exhibit diverse signalling functions, partly due to their high density of negative charges in their head groups that are extending from the hydrophobic bilayer into the cytoplasm (Sansom et al, 2005). These special features allow the recruitment of proteins to the membrane, for example via pleckstrin homology $(\mathrm{PH})$ domains. $\mathrm{PH}$ domains were shown to interact with a variety of different PI head groups, in some cases with high specificity towards particular PI isomers, but in most cases not discriminating between different PIs (Lemmon \& Ferguson, 2000). By various indirect mechanisms, Ptdlns $(4,5) \mathrm{P}_{2}$ was shown to be involved in the regulation of the actin cytoskeleton, for example via actin binding proteins, such as profilin (Braun et al, 1999; Dong et al, 2001; Gungabissoon et al, 1998; Witke, 2004). Furthermore, Ptdlns $(4,5) \mathrm{P}_{2}$ is involved in ion channel regulation, and for instance $\mathrm{K}^{+}$channels are activated upon binding to Ptdlns $(4,5) \mathrm{P}_{2}$ (Hilgemann \& Ball, 1996; Wigoda et al, 2010). It has been postulated that Ptdlns(4,5) $P_{2}$ is involved in the fusion of secretory vesicles with the plasma membrane of yeast (Strahl \& Thorner, 2007), and in neuronal cells PtdIns4P and PtdIns $(4,5) \mathrm{P}_{2}$ are suggested to stimulate exocytosis (Berwin et al, 1998; Hay et al, 1995; Hay \& Martin, 1993). Additionally, Ptdlns(4,5) $P_{2}$ could be important in endocytosis, as many proteins of the endocytotic machinery are targeted to the plasma membrane by Ptdlns (4,5) $P_{2}$ in yeast and mammalian cells (Ford et al, 2001; Itoh \& Howe, 2001; Jost et al, 1998). Dynamin proteins, crucially involved in endocytosis, interact with PIs via their $\mathrm{PH}$ domain (Lemmon \& Ferguson, 2000). In plants, association of $\operatorname{Ptd} \ln (4,5) \mathrm{P}_{2}$ with clathrincoated vesicles during stress-induced endocytosis has been shown by (König et al, 2008). Moreover, vesicle transport and pectin secretion in growing pollen tubes was suggested to be 
influenced by PtdIns4P and Ptdlns $(4,5) \mathrm{P}_{2}$, regulated by the action of specific lipid kinases (Ischebeck et al, 2008; Ischebeck et al, 2010). While the list of regulatory roles of intact PIs in eukaryotic cells could be expanded in much more detail, for the purpose of this thesis a focus shall be placed on the cleavage of PIs by PLC and the generation of soluble inositol polyphosphates.

\subsubsection{Differences in PLC-mediated PI metabolism between animals and plants}

All PI-specific PLCs (PI-PLCs) identified in plants hydrolyze Ptdlns $(4,5) \mathrm{P}_{2}$ in a $\mathrm{Ca}^{2+}$-dependent manner, and G-protein-coupled PLCs, which are present in animals, were not described (Meijer \& Munnik, 2003; Mueller-Roeber \& Pical, 2002). While transcription of some Arabidopsis PIPLCs can be induced by drought, low temperature or salt stress (Hirayama et al, 1997; Parre et al, 2007), others are constitutively expressed in different plant organs (Yamamoto et al, 1995). Overexpression of PI-PLC2 in Brassica napus resulted in increased InsP $\mathrm{P}_{6}$ levels and also in altered phytohormone patterns, including those of $A B A$, auxins and cytokinins, supporting an important role for the PI system in phytohormone signalling (Georges et al, 2009).

PLC-derived DAG displays different functions in animals and plants. While DAG activates protein kinase C (PKC) in mammalian cells and therefore displays signalling function by itself, no homolog of PKC has been reported in plants (Meijer \& Munnik, 2003). In contrast, in plants DAG is rapidly phosphorylated by DAG kinases to phosphatidic acid (PtdOH). PtdOH has been shown to display signalling function in plants, and increased levels of $\mathrm{PtdOH}$ have been reported after osmotic stress, ABA treatment, drought stress, pathogen attack and wounding (Bargmann et al, 2009; Lee et al, 2001; Munnik, 2001; Wang et al, 2000).

An InsP $_{3}$ receptor, as it was found in animals to mediate $\mathrm{Ca}^{2+}$ release upon stimulation, is absent in all so far sequenced genomes of land plants (Krinke et al, 2007a), and in general, the regulation of the plant PI signalling pathway appears to be different from that in animals. For instance, in animals production of $\operatorname{InsP}_{3}$ and DAG is driven by increased activation of PLC (Berridge \& Irvine, 1984), whereas in plants enhanced availability of the PLC substrate PtdIns $(4,5) \mathrm{P}_{2}$ seems to promote this process, provided by increased activity of PIP5-kinases (Stevenson et al, 2000). Compared to mammalian cells, higher plants exhibit only low levels of PtdIns $(4,5) \mathrm{P}_{2}$. Upon stimulation, Ptdlns $(4,5) \mathrm{P}_{2}$ levels increase locally and/or transiently, highlighting the important regulatory role of the respective lipid kinases involved in stress adaptation (Heilmann et al, 1999; Heilmann et al, 2001; Perera et al, 1999). 


\subsubsection{Inositol polyphosphates}

InsP 3 signals have been reported to occur upon gravistimulation in maize and oat, accompanied by an increase of specific PIP5-kinase activity (Perera et al, 1999; Perera et al, 2001). A similar effect was reported during responses to salt and osmotic stress in plants, algae and plant cell cultures (Drobak \& Watkins, 2000; Heilmann et al, 1999; Heilmann et al, 2001; König et al, 2008; König et al, 2007; Pical et al, 1999), displaying increased synthesis of Ptdlns $(4,5) \mathrm{P}_{2}$ accompanied by Ins $\mathrm{P}_{3}$ accumulation.

An increasing number of reports indicates that signalling functions can also be attributed to inositol polyphosphates other than $\mathrm{Ins}_{3}$, which are predominantly derived from the $\mathrm{PI}$ pathway via an $\operatorname{Ins}_{3}$ intermediate. In yeast, $\operatorname{InsP}_{6}$ is required for mRNA export from the nucleus, and involved in the recruitment of protein complexes from the cytosol to the nuclear pore (Alcazar-Roman et al, 2006; Seeds \& York, 2007; Weirich et al, 2006; York et al, 1999). $I_{n s} P_{4}$ InsP $P_{5}$ and $I_{n s} P_{6}$ have been shown to be involved in chromatin remodelling in yeast, thereby regulating transcription (Shen et al, 2003). Additionally, inositol polyphosphates and inositol pyrophosphates control telomer length and cell death in yeast (Saiardi et al, 2005).

In plants, several reports indicate further roles for inositol polyphosphates other than InsP $\mathrm{P}_{3}$. Besides its acknowledged role as an important phosphate store in plant seeds (Raboy, 2003), Ins $\mathrm{P}_{6}$ has been shown to play a role in maintaining resistance to plant pathogens. For instance, potato plants with altered inositol polyphosphate metabolism and deficient in $\operatorname{lns}_{6}$ formation exhibit reduced resistance to viruses, bacteria and fungal pathogens (Murphy et al, 2008). Furthermore, the involvement of $\operatorname{InsP}_{6}$ in $A B A$-mediated guard cell signalling was demonstrated in Arabidopsis, and has been attributed either to complexing of divalent cations, such as $\mathrm{Mg}^{2+}$ or $\mathrm{Ca}^{2+}$, or to the triggering of a continuous $\mathrm{Ca}^{2+}$ flux into the cytosol via binding to ion channels, affecting $\mathrm{K}^{+}$currents (Nagy et al, 2009). Considering its presence in F-box proteins with roles in plant hormone perception, clearly roles of $\operatorname{InsP}_{6}$ and other inositol polyphosphates in signalling must be further explored.

Three pathways of InsP $\mathrm{P}_{6}$ biosynthesis have been proposed in plants, with two of them emerging from $\mathrm{PI}$ lipids and the third being lipid-independent through sequential phosphorylation of myo-inositol or inositol-3-phosphate (Stevenson-Paulik et al, 2005). The lipid dependent pathways originate from PLC-mediated hydrolysis of $\operatorname{Ptdlns}(4,5) \mathrm{P}_{2}$, generating InsP $_{3}$, which can be sequentially phosphorylated by the inositol polyphosphate kinases, IPK1 and IPK2. While the last step of InsP $_{6}$ synthesis in the lipid-dependent pathways is mediated by IPK1, the lipid-independent pathway may alternatively use IPK2 in this step. 


\subsubsection{Manipulating PI signals in plants}

Two plant lines altered in different steps of PI metabolism were used in this thesis. Due to the expression of a human type I inositol polyphosphate 5-phosphatase (InsP 5-ptase), in transgenic InsP 5-ptase plants Ins $\mathrm{P}_{3}$ accumulation is suppressed and, as a consequence of the "pull" on the PI pathway, upstream lipid precursors are also down regulated (König et al, 2007; Perera et al, 2006; Perera et al, 2002). These plants were used in this thesis as a tool to investigate how plants with a globally downregulated PI signalling pathway would respond to wounding and herbivore attack.

To study the PI pathway with a more precise modification, ipk1-1 plants were used. These plants lack the enzyme IPK1 and are impaired in the last step of $\operatorname{InsP}_{6}$ biosynthesis and, thus, exhibit strongly reduced levels of InsP $_{6}$, accompanied by accumulation of metabolic precursors, such as $\operatorname{InsP}_{5}$ and $\operatorname{InsP}_{4}$ (Stevenson-Paulik et al, 2005).

For the purpose of this thesis, it is important to note that InsP 5-ptase plants display a reduction of all PI signalling components, whereas ipk1-1 plants are only diminished in InsP $_{6}$ levels while accumulating inositol polyphosphate precursors.

\subsection{Diverse other signals involved in plant defence}

Wounding not only harms the plant by reducing tissue functionality, but a plant's wounding site is also likely to be attacked by opportunistic pathogenic microorganisms. Therefore, it is necessary for the plant to distinguish between different attackers and to defend itself against different species of feeding insects as well as different species of pathogens. This complex task is orchestrated by a tight regulatory network of various phytohormones, with JA, SA and ET being the best studied examples (del Pozo et al, 2004; Howe \& Jander, 2008; Koornneef \& Pieterse, 2008; Lorenzo \& Solano, 2005; von Dahl et al, 2007). The specific blend of hormones, varying in quantity, composition, and timing, results in a specific signal signature, the integration of which allows for a specific response effective against partially distinct classes of attackers (Koornneef \& Pieterse, 2008). In general, SA-mediated defences are often effective against pathogens with a biotrophic lifestyle, whereas JA-mediated defences are mostly effective against necrotrophic pathogens and herbivorous insects (Glazebrook, 2005; Kessler \& Baldwin, 2002; Thomma et al, 2001). 


\subsubsection{Salicylic acid signalling}

SA is one of the best-known defence hormones involved in responses to pathogen attack and in mediating disease resistance. SA biosynthesis starts with the Shikimate pathway, in which chorismate is converted to isochorismate via isochorismate synthase (ICS; Wildermuth et al, 2001). Arabidopsis SA induction-defective 2 (sid2) mutants are defective in ICS and fail to accumulate SA or to induce SA-mediated gene expression upon pathogen attack (Dewdney et al, 2000; Wildermuth et al, 2001). An alternative way to produce SA requires phenylalanine and phenylalanine ammonia lyase (PAL) activity. While the ICS-dependent pathway provides the bulk synthesis of SA, the PAL-dependent pathway only produces minor amounts (Chen et al, 2009). It has been speculated that SA derived from the PAL-dependent pathway is required to induce cell death in response to particular pathogens or fungal elicitors (Wildermuth et al, 2001). Besides sid2 mutants, transgenic NahG plants expressing the bacterial salicylate hydroxylase (nahG) gene that encodes an enzyme degrading SA to catechol also exhibit reduced SA accumulation and increased susceptibility to viral, fungal, or bacterial pathogens (Delaney et al, 1994; Vernooij et al, 1994).

The transcriptional activator, NONEXPRESSOR OF PR GENES 1 (NPR1), represents a key node of SA signal transduction. Upon SA induction, a redox change of the cellular milieu leads to the reduction of NPR1 disulfide-bound oligomers into active monomers, which are translocated from the cytosol to the nucleus (Dong, 2004; Lu et al, 2009; Mou et al, 2003; Tada et al, 2008; Wang et al, 2006). There, NPR1 activates SA-induced gene expression by interacting with transcription factors of the TGA family (TGA transcription factors are named after their ability to bind TGACG motifs; Rochon et al, 2006). It was shown that also WRKY transcription factors are controlled by NPR1 (Niggeweg et al, 2000; Wang et al, 2006). npr1 mutants, although accumulating elevated levels of SA after pathogen infection, display decreased disease resistance and abolished SA-responses (Cao et al, 1997; Dong, 2004), whereas NPR1 overexpressors exhibit broad resistance against diverse bacterial and fungal pathogens (Fitzgerald et al, 2004; Lin et al, 2004a; Lu et al, 2009; Makandar et al, 2006).

\subsubsection{Crosstalk of JA and SA signals within plant defence}

Crosstalk between different signalling pathways can be either mutually antagonistic or synergistic. For instance, SA is capable of suppressing the expression of various JA-inducible genes, thereby working as a negative regulator of JA-dependent defence pathways and representing the antagonistic aspect of the JA-SA relation (Bostock, 2005; Cui et al, 2005; Doares et al, 1995; Kloek et al, 2001; Pieterse \& van Loon, 1999; Stout et al, 2006). The 
expression of JA biosynthesis genes is suppressed by SA treatment, indicating that JA biosynthesis is a target of SA action in the suppression of JA signals (Doares et al, 1995; Spoel et al, 2003). SA seems to also target the JA pathway downstream of JA biosynthesis by interfering with the function of the $\mathrm{SCF}^{\mathrm{COI} 1}$ complex (Beckers \& Spoel, 2006).

It was shown that infection with biotrophic pathogens, inducing elevation of SA levels, enhances the susceptibility of plants to necrotrophic pathogens by suppressing the JA signalling pathway (Spoel et al, 2007). In line with this observation, caterpillar induced JAmediated defences were strongly suppressed by infection with a biotrophic pathogen (LeonReyes and Pieterse, unpublished data, mentioned in (Koornneef \& Pieterse, 2008). Furthermore, JA treatment increases number and density of trichomes, whereas SA treatment results in decreased trichome number (Traw \& Bergelson, 2003). The antagonistic relation between SA and JA is also reciprocally indicated by JA repressing SA signals. For example, JA signals in P. syringae-infected Arabidopsis leaves abolish SA accumulation and SA-mediated downstream signalling through NPR1. Furthermore, the suppression of JA-inducible gene expression by SA signals is blocked in Arabidopsis npr1 mutants, indicating the crucial role of NPR1 in the crosstalk between SA and JA (Kloek et al, 2001; Spoel et al, 2003).

Mitogen-activated protein (MAP) kinases (MPKs) are important signal transducers in all eukaryotes, and they are also involved in plant defence responses (Menke et al, 2004; Nakagami et al, 2005). In Arabidopsis, MPK4 was found to negatively regulate SA signals while positively regulating JA signals (Petersen et al., 2000), indicated by increased SA levels and enhanced SA-responsive gene expression in Arabidopsis mpk4 mutants. At the same time, mpk4 mutants exhibit decreased JA-responsive gene expression. Interestingly, this suppression was independent of SA accumulation (Brodersen et al, 2006; Petersen et al, 2000).

WRKY transcription factors are important regulators of SA-dependent defence responses (Maleck et al, 2000; Wang et al, 2006), and WRKY70 acts as a positive regulator of SA-mediated defences while repressing JA-mediated responses (Li et al, 2004). Depending on the kind of attack, the specific signal signature enables these transcription factors to modulate the primary JA signal and to differentially activate either JA-responsive defence against necrotrophic pathogens or wound responses against insect herbivores (Koornneef \& Pieterse, 2008). It has been speculated that the SA antagonism of JA signalling could be achieved by interfering with JA-mediated JAZ degradation or SCF E3 ligase components (Loake \& Grant, 2007; Robert-Seilaniantz et al, 2007). However, convincing proof for this concept has not been presented to date.

Simultaneous application of SA and JA in high concentrations seems to cause antagonistic effects, which may lead to the production of reactive oxygen and cell death (Loake \& Grant, 
2007; Mur et al, 2006). However, application of SA and JA at low concentrations results in a synergistic effect, indicated by the expression of PR1, a typical SA-regulated gene, and simultaneous expression of classical JA-mediated defence markers (Loake \& Grant, 2007; Mur et al, 2006). Positive crosstalk between JA and SA signals was reported, when JA signals were required ahead of SA and ET accumulation in disease response of tomato plants to bacterial pathogen infection (O'Donnell et al, 2003).

Clearly, the hormonal network during defence reactions is complex and highly interconnected. Transcription factors, such as MYC2 and ERF1, represent important regulatory nodes and are influenced by a variety of signalling components. Without giving any detail, at this point it should be mentioned that also JA and ABA synergistically induce MYC2-dependent gene expression after wounding, and ERF1-dependent gene induction is controlled by a combination of JA and ET in response to pathogen attack (Anderson et al, 2004; Dombrecht et al, 2007; Lorenzo et al, 2004; Lorenzo \& Solano, 2005). To keep the system assessable, the focus of this thesis is on crosstalk between JA and PI signals with an outlook on the three-way interactions between JA, PI and SA signals.

\subsection{A pathogen's view of plant defence}

During evolution, not only plants developed a tight signalling network of hormones to defend themselves against herbivores and pathogens; insects and microorganisms also co-evolved mechanisms to exploit these signalling cascades for their own benefit (Koornneef \& Pieterse, 2008; Pieterse \& Dicke, 2007). One of the best known examples is the virulent bacterium P. syringae, which produces coronatine, a potent mimic of JA-lle already mentioned above (Nomura et al, 2005). Coronatine activates JA-mediated responses, which alter the initially activated defence by suppressing SA-responses and, thus, allow enhanced growth of the pathogen (Brooks et al, 2005; Cui et al, 2005; Laurie-Berry et al, 2006; Zhao et al, 2003). By actively interfering with the plant's hormonal network, the pathogen overcomes the plant's defence mechanisms and enables its own spreading. In JA-related research, coronatine is frequently used as JA-lle analogue. 


\subsection{Goals}

In previous experiments, JA and InsP $\mathrm{P}_{3}$ signals were shown to occur in parallel upon wounding in Arabidopsis. As JA-deficient dde2-2 plants did not accumulate Ins $\mathrm{P}_{3}$ upon wounding, JA was indicated as upstream factor of PI signals.

It was the aim of this thesis to elucidate the impact of PI signals during Arabidopsis wound responses and defence reactions, and to test the hypothesis that there is crosstalk of JA and PI signals, including an inositol polyphosphate required for COI1 function in JA perception. Therefore, it was one goal to test InsP 5-ptase plants with globally reduced PI signalling pathway for wound-induced gene expression and their resistance to herbivore attack. Another goal was to further investigate the partial insensitivity of InsP 5-ptase-plants towards JA-lle in comparison with JA-insensitive coi1 mutants. Based on these results, it was the goal to test whether an inositol polyphosphate, such as $\operatorname{InsP}_{6}$ or $\operatorname{InsP}_{5}$, has a role in COI1-mediated JA responses. The effects of manipulating the putative inositol polyphosphate binding site in COI1 were to be tested in yeast two-hybrid assays as well as in complementation assays of coil plants. Furthermore, the function of wild type COI1 was to be assessed in yeast and plant backgrounds altered in their inositol polyphosphate composition. Finally, it was the goal of this thesis to investigate the implementation of PI signals in a broader context of plant defence signals. Therefore, crosstalk between SA and PI signals was to be investigated using SAdeficient Arabidopsis mutants sid2 and NahG.

The results of this thesis highlight the PI pathway as an important regulatory node in the defensive phytohormone signalling network. 


\section{Materials AND Methods}

\subsection{Materials}

\subsubsection{Chemicals}

$\begin{array}{ll}\text { Agar } & \text { Invitrogen, Karlsruhe, Germany } \\ \text { Agarose } & \text { Duchefa Biochemie, Haarlem, The Netherlands } \\ \text { Carbenicillin } & \text { Duchefa Biochemie, Haarlem, The Netherlands } \\ \text { Diisopropylamin } & \text { Aldrich, Steinheim, Germany } \\ \text { Desoxynucleotide triphosphate (dNTPs) } & \text { Roche Molecular Biochemicals, Mannheim, } \\ & \text { Germany } \\ \text { Fluorescein } & \text { Bio-Rad, Hercules, CA, USA } \\ \text { Kanamycin } & \text { Duchefa Biochemie, Haarlem, The Netherlands } \\ \text { Murashige \& Skoog medium } & \text { Duchefa Biochemie, Haarlem, The Netherlands } \\ \text { Peptone } & \text { Invitrogen, Karlsruhe, Germany } \\ \text { Phospholipid standards } & \text { Avanti Polar Lipids, Inc., Alabaster, AL, USA } \\ \text { Rifampicin } & \begin{array}{l}\text { Duchefa Biochemie, Haarlem, The Netherlands } \\ \text { Scintillation fluid } \\ \text { Silwet-Copolymer } \\ \text { SYBR Green I solution }\end{array} \\ \text { Zinsser Analytics, Frankfurt, Germany } \\ \text { OSi Specialties Inc., South Charleston, WI, USA } \\ \text { Cambrex, Wiesbaden, Germany }\end{array}$

All other chemicals were obtained from the companies Roth (Karlsruhe, Germany), Merck (Darmstadt, Germany), Fluka (Steinheim, Germany) or Sigma (Deisenhofen, Germany).

\subsubsection{Enzymes and size markers}

BIOTaq DNA Polymerase

GeneRuler $^{\mathrm{TM}} 1 \mathrm{~kb}$ DNA-Ladder

MasterAmp TfI-DNA-Polymerase

Pfu-Polymerase ${ }^{\mathrm{TM}}$

Phusion High Fidelity DNA-Polymerase

Restriction endonucleases
Bioline, Luckenwalde, Germany

MBI Fermantas, St. Leon Rot, Germany

EPICENTRE Biotechnologies, Madison, WI, USA

MBI Fermantas, St. Leon Rot, Germany

Finnzymes, Espoo, Finland

MBI Fermantas, St. Leon Rot, Germany 
RevertAid H Minus M-MuLV Reverse

Transcriptase

T4-DNA-Ligase

Takara Ex Taq ${ }^{\text {TM }}$ DNA Polymerase

\subsubsection{Kits}

Big Dye Terminator v1.1 Cycle

Sequencing-Kit

$\left[{ }^{3} \mathrm{H}\right]$ Biotrak Assay System for D-myoinositol 1,4,5-trisphosphat

Nucleospin Plasmid Kit

Nucleospin Extract II Kit

pGEM-T Easy Ligation Kit

\subsubsection{Equipment}

\author{
Agilent 1100 HPLC system \\ Agilent 1100 HPLC system \\ Applied Biosystems 3200 hybrid triple \\ quadrupole/linear ion trap mass \\ spectrometer \\ $\mathrm{C}_{18}$ column (EC 250/2 Nucleosil 120-5 $\mathrm{C}_{18}$ ) \\ Capillary Rtx-5MS column \\ Chip ion source TriVersa NanoMate \\ DB-23 capillary column \\ EC 50/2 Nucleodure $C_{18}$ gravity column \\ Fluorescence Stereo Microscope \\ Leica MZ16 FA \\ Leica DFC480 camera \\ GC6890 Gas chromatograph with Flame \\ ionization detection \\ iCycler System \\ Polaris $\mathrm{Q}$ mass selective detector \\ Shaking mill MM200
}

MBI Fermantas, St. Leon Rot, Germany

MBI Fermantas, St. Leon Rot, Germany

Takara Bio Inc, Madison, WI, USA

Applied Biosystems, Darmstadt, Germany

GE Healthcare/Amersham, Düren, Germany

Machery \& Nagel, Düren, Germany

Machery \& Nagel, Düren, Germany

Promega, Heidelberg, Germany

Agilent, Waldbronn, Germany

Agilent, Waldbronn, Germany

MDS Sciex, Ontario, Canada

Macherey \& Nagel, Düren, Germany

Resteck, Bad Homburg, Germany

Advion BioSciences, Ithaca, NY, USA

J\&W, Agilent, Waldbronn, Germany

Macherey and Nagel, Düren, Germany

Leica, Wetzlar, Germany

Leica, Wetzlar, Germany

Agilent, Waldbronn, Germany

BioRad, Hercules, CA, USA

ThermoFinnigan, Austin, Texas, USA

Retsch, Haan, Germany 
Stereo microscope SZX12

Trace gas chromatograph

Ultra Turrax

UV imager raytest IDA

\subsubsection{Single-use materials}

Bakerbond spe ${ }^{\mathrm{TM}}$ Silica Gel columns

Glass beads $2.85-3.3 \mathrm{~mm}$

Silica thin layer chromatography

plates Si-60, $20 \times 20 \mathrm{~cm}$

SuperQ column SDB-L Strata

\subsubsection{Software}

analySIS Docu 3.2

Applied Biosystems Analyst software

Chromas Lite v 2.0

GC ChemStation software

Image J

LSM 510 software $v 4.0$

Photoshop v 7.0

Xcalibur software v1.4
Olympus, Hamburg, Germany

ThermoFinnigan, Austin, Texas, USA

Ika, Staufen, Germany

Herolab, Wiesloch, Germany

J.T. Baker, Deventer, The Netherlands

Roth, Karlsruhe, Germany

Merck, Darmstadt, Germany

Phenomenex, Aschaffenburg, Germany

Soft Imaging Systems GmbH, Münster, Germany

Foster City, California, USA

Technelysium, Tewantin, Australia

Agilent, Waldbronn, Germany

freely available at http://rsbweb.nih.gov/ij/

Carl Zeiss Inc., Jena, Germany

Adobe Systems, Munich, Germany

ThermoFinnigan, Austin, Texas, USA 


\subsubsection{Plant lines}

\begin{tabular}{|c|c|c|c|}
\hline Name & Species & Transgenes & Obtained from \\
\hline $\begin{array}{l}\text { Arabidopsis } \\
\text { wild type } \\
\text { Col-0 }\end{array}$ & $\begin{array}{l}\text { Arabidopsis thaliana } \\
\text { Ecotype Columbia } 0\end{array}$ & - & $\begin{array}{l}\text { Dr. Imara Perera, North } \\
\text { Carolina State University, } \\
\text { Raleigh, NC, USA }\end{array}$ \\
\hline coil-1 & $\begin{array}{l}\text { Arabidopsis thaliana } \\
\text { Ecotype Columbia } 0\end{array}$ & $\begin{array}{l}\text { EMS line, carrying a stop codon } \\
\text { in the gene encoding for the JA } \\
\text { receptor coronatin insensitive } 1 \\
\text { (COI1; Xie et al, 1998) }\end{array}$ & $\begin{array}{l}\text { Dr. Jane Glazebrook, St. } \\
\text { Paul, MN, USA }\end{array}$ \\
\hline coi1- $t$ & $\begin{array}{l}\text { Arabidopsis thaliana } \\
\text { Ecotype Columbia } 0\end{array}$ & $\begin{array}{l}\text { T-DNA insertion into the gene } \\
\text { encoding for the JA receptor } \\
\text { coronatin insensitive } 1 \text { (COI1); } \\
\text { SALK No. } 035548\end{array}$ & $\begin{array}{l}\text { SALK Institute Genomic } \\
\text { Analysis Laboratory }\end{array}$ \\
\hline dde2-2 & $\begin{array}{l}\text { Arabidopsis thaliana } \\
\text { Ecotype Columbia } 0\end{array}$ & $\begin{array}{l}\text { delayed-dehiscence2-2 (dde2- } \\
\text { 2); En1/Spm1-transposon } \\
\text { mutagenesis of gene encoding } \\
\text { for allene oxide synthase (AOS), } \\
\text { frame shift (von Malek et al, } \\
\text { 2002) }\end{array}$ & $\begin{array}{l}\text { Dr. Michael Stumpe, } \\
\text { Georg August University, } \\
\text { Göttingen, Germany }\end{array}$ \\
\hline $\begin{array}{l}\text { InsP 5- } \\
\text { ptase }\end{array}$ & $\begin{array}{l}\text { Arabidopsis thaliana } \\
\text { Ecotype Columbia } 0\end{array}$ & $\begin{array}{l}\text { HsInP 5-ptase, human type I } \\
\text { InsP 5-ptase transgene line 2-8; } \\
\text { Kan }^{\mathrm{R}} \text { (Perera et al, 2006) }\end{array}$ & $\begin{array}{l}\text { Dr. Imara Perera, North } \\
\text { Carolina State University, } \\
\text { Raleigh, NC, USA }\end{array}$ \\
\hline ipk1-1 & $\begin{array}{l}\text { Arabidopsis thaliana } \\
\text { Ecotype Columbia } 0\end{array}$ & $\begin{array}{l}\text { T-DNA insertion into the gene } \\
\text { encoding for inositol } \\
\text { polyphosphate kinase } 1 \text { (IPK1; } \\
\text { Stevenson-Paulik et al, 2005) }\end{array}$ & $\begin{array}{l}\text { Dr. John York, Duke } \\
\text { University, Durham, NC }\end{array}$ \\
\hline NahG & $\begin{array}{l}\text { Arabidopsis thaliana } \\
\text { Ecotype Columbia } 0\end{array}$ & $\begin{array}{l}\text { Pseudomonas putida nahG } \\
\text { gene, encoding an SA } \\
\text { hydroxylase, which degrades } \\
\text { SA to catechol (Delaney et al, } \\
\text { 1994) }\end{array}$ & $\begin{array}{l}\text { Dr. Christiane Gatz, Georg } \\
\text { August University, } \\
\text { Göttingen, Germany }\end{array}$ \\
\hline sid2 & $\begin{array}{l}\text { Arabidopsis thaliana } \\
\text { Ecotype Columbia } 0\end{array}$ & $\begin{array}{l}\text { EMS line, causing a stop codon } \\
\text { in the gene encoding for } \\
\text { isochorismate synthase (ICS1), } \\
\text { involved in SA biosynthesis. SA } \\
\text { induction-deficient } 2 \text { (sid 2; } \\
\text { Nawrath \& Metraux, 1999). }\end{array}$ & $\begin{array}{l}\text { Dr. Christiane Gatz, Georg } \\
\text { August University, } \\
\text { Göttingen, Germany }\end{array}$ \\
\hline
\end{tabular}




\subsubsection{Microorganisms}

\begin{tabular}{|c|c|c|c|c|}
\hline Organism & Strain & Genotype & Reference & Obtained from \\
\hline E. coli & XL1-Blue & $\begin{array}{l}\text { recA1endA1gyrA96 thi-1hsdR17 } \\
\text { supE44 relA1lac[F'proAB } \\
\text { lac9zM15 Tn19(Tetr)] }\end{array}$ & $\begin{array}{l}\text { (Bullock et } \\
\text { al, 1987) }\end{array}$ & $\begin{array}{l}\text { Stratagene, } \\
\text { Heidelberg, } \\
\text { Germany }\end{array}$ \\
\hline A. tumefaciens & pEHA105 & pTiBo542 $\Delta$ T-DNA RifR & $\begin{array}{l}\text { (Hood et al, } \\
1993)\end{array}$ & - \\
\hline S. cerevisiae & PJ69-4A & $\begin{array}{l}\text { MATa trpl-901 leu2-3,112 ura3- } \\
52 \text { his3-200 ga14A ga180A } \\
\text { LYSZ::GALI-HIS3 GAL2-ADE2 } \\
\text { metZ::GAL7-lacZ }\end{array}$ & $\begin{array}{l}\text { (James et al, } \\
1996)\end{array}$ & $\begin{array}{l}\text { Dr. Corinna } \\
\text { Thurow, Georg } \\
\text { August University, } \\
\text { Göttingen, } \\
\text { Germany }\end{array}$ \\
\hline
\end{tabular}

\subsubsection{Plasmids}

\begin{tabular}{|l|l|l|l|}
\hline Vector & Selection marker & Obtained from & Plasmid structure \\
\hline pGEM-T Easy & Amp $^{\mathrm{R}}$ & $\begin{array}{l}\text { Promega, Mannheim, } \\
\text { Germany }\end{array}$ & \\
\hline 0GC & Kan $^{\mathrm{R}}$ & $\begin{array}{l}\text { Dr. Ellen Hornung, } \\
\text { Göttingen, Germany }\end{array}$ & $\begin{array}{l}\text { Plasmid contains a BASTA } \\
\text { resistence under a 35S promoter }\end{array}$ \\
\hline pAG25 & $\begin{array}{l}\text { Amp }{ }^{\mathrm{R}} ; \\
\text { nourseothricin }\end{array}$ & $\begin{array}{l}\text { Dr. Martin Fulda and } \\
\text { Dr. Michael }\end{array}$ & $\begin{array}{l}\text { nourseothricin resistance cloNAT- } \\
\text { MX4 cassette }\end{array}$ \\
\hline pGBKT7 & $\begin{array}{l}\text { Kan }{ }^{\text {G }} \text {, TRP1 } \\
\text { nutritional marker } \\
\text { for selection in } \\
\text { yeast }\end{array}$ & $\begin{array}{l}\text { Dr. Corinna Thurow, } \\
\text { Göttingen, Germany }\end{array}$ & $\begin{array}{l}\text { Plasmid expresses proteins fused } \\
\text { to amino acids 1-147 of the GAL4 } \\
\text { DNA binding domain under the } \\
\text { constitutive ADH1 promoter. }\end{array}$ \\
\hline
\end{tabular}

\subsubsection{Oligonucleotides}

All oligonucleotides were obtained from Invitrogen, Karlsruhe, Germany. A complete list and the respective sequences are comprised in appendix. 


\subsection{Methods}

\subsubsection{Plant growth and cultivation}

For wounding experiments, caterpillar performances or treatment with MeJA, Arabidopsis plants were sown on soil (Frühstorfer Erde type: T25 Str. 1, Fein, Industrie Erdwerk Archut, Lauterbach-Wallenrod, Germany), vernalized over night at $4{ }^{\circ} \mathrm{C}$ in the dark and grown under short day conditions with $8 \mathrm{~h}$ of light $\left(\sim 130-150 \mu \mathrm{mol}\right.$ photons $\mathrm{m}^{-2} \mathrm{~s}^{-1}, 4 \times 1,5 \mathrm{~m}$ fluorescent lamps, $58 \mathrm{~W}$ ) and $16 \mathrm{~h}$ of darkness in climate chambers (YORK Refrigeration, YORK Industriekälte GmbH \& Co. KG, Mannheim, Germany) with about $60 \%$ humidity. Single plants were grown in pots of $6 \mathrm{~cm}$ in diameter for 7-8 weeks. For seed propagation, plants were grown in the greenhouse under $16 \mathrm{~h}$ of light $\left(\sim 130-150 \mu \mathrm{mol}\right.$ photons $\left.\mathrm{m}^{-2} \mathrm{~s}^{-1}\right)$.

For sorbitol treatment, Arabidopsis plants were precultured under sterile conditions. Seeds were surface sterilized by exposing them to chloric gas for $4-7 \mathrm{~h}$ generated by adding $5 \%(\mathrm{v} / \mathrm{v})$ of $10 \mathrm{M} \mathrm{HCl}$ to a $12 \%(\mathrm{v} / \mathrm{v}) \mathrm{NaClO}$ solution in a closed exsiccator. Vacuum of about $850 \mathrm{mbar}$ was applied. After 3-4 weeks of growth on sterile poplar root media (see below) in closed glass containers in Percival climate chambers under a regime of $14 \mathrm{~h}$ of light ( 130$150 \mathrm{mmol}$ photons $\mathrm{m}^{-2} \mathrm{~s}^{-1}, 4 \times 1,5 \mathrm{~m}$ fluorescent lamps, $58 \mathrm{~W}$ ) and $10 \mathrm{~h}$ of darkness, plants were transferred to 12 I hydroponic cultures, first in $\mathrm{ddH}_{2} \mathrm{O}$ for 2-3 days, afterwards in nutrient solution (see below), purged with air of $\sim 0.1$ bar. If necessary, cultures were fertilised with 1$2 \mathrm{ml} \mathrm{Fe-Na-EDTA}$ und $\mathrm{KNO}_{3}$. Growth conditions correspond to those described for soil cultures. For vertical root growth assays, plants were cultured under sterile conditions in rectangular Petri dishes, oriented vertically, containing MS growth medium $(0.22 \%(w / v)$ Murashige \& Skoog medium, $1.5 \%(\mathrm{w} / \mathrm{v})$ sucrose, $1 \%(\mathrm{w} / \mathrm{v})$ agar) under $8 \mathrm{~h}$ of light ( $130-150 \mu \mathrm{mol}$ photons $\mathrm{m}^{-2} \mathrm{~s}^{-1}$ ) and $16 \mathrm{~h}$ of darkness in Percival climate chambers.

To select JA-insensitive mutants, plants were cultured under sterile conditions in round Petri dishes containing media as described above with additional $50 \mu \mathrm{M}$ MeJA, dissolved in ethanol. After 2-3 weeks of growth, homozygous JA-insensitive individuals were identified by normal growth, JA-sensitive wild type individuals were identified by strongly reduced growth and heterozygous individuals by an intermediate phenotype. Desired individuals were transferred to soil and grown as described above. For wound experiments, homozygous coi1-1 and coi1-t plants were grown on soil for another six weeks after selection. Wild type control plants were cultured the same way on agar plates without MeJA. 


\subsubsection{Poplar root media}

Macro elements $\left(\mathrm{KNO}_{3} 0.25 \mathrm{M} ; \mathrm{CaCl}_{2} \times 2 \mathrm{H}_{2} \mathrm{O} 3.6 \mathrm{mM}\right.$; $\mathrm{MgSO}_{4} \times 7 \mathrm{H}_{2} \mathrm{O} 16.2 \mathrm{mM}$; $\left(\mathrm{NH}_{4}\right)_{2} \mathrm{HPO}_{4}$ $26 \mathrm{mM})$, micro elements $\left(\mathrm{H}_{3} \mathrm{BO}_{3} 9.7 \mathrm{mM} ; \mathrm{Na}_{2} \mathrm{MoO}_{4} \times 2 \mathrm{H}_{2} \mathrm{O} 0.21 \mathrm{mM} ; \mathrm{MnSO}_{4} \times \mathrm{H}_{2} \mathrm{O} 0.9 \mathrm{mM}\right.$; $\mathrm{ZnSO}_{4} \times 7 \mathrm{H}_{2} \mathrm{O} 11.8 \mathrm{mM}$; $\mathrm{CoCl}_{2} \times 6 \mathrm{H}_{2} \mathrm{O} 2.1 \mathrm{mM}$; $\mathrm{CuSO}_{4} \times 5 \mathrm{H}_{2} \mathrm{O} 0.2 \mathrm{mM}$ ), vitamin solution (nicotinic acid $0.4 \mathrm{mM}$; pyridoxine- $\mathrm{HCl} 0.24 \mathrm{mM}$; thiamin- $\mathrm{HCl} 29.6 \mu \mathrm{M}$; glycine $2.6 \mathrm{mM}$ ) myoinositol (22.2 mM), $\mathrm{C}_{10} \mathrm{H}_{12} \mathrm{FeN}_{2} \mathrm{NaO}_{8}(4 \mathrm{mM})$ and saccharose $(73 \mathrm{mM})$ were sterile filtered (pore size $0.2 \mu \mathrm{m}$ ) and mixed as follows: macro elements $100 \mathrm{ml} \mathrm{I}^{-1}$; micro elements $1 \mathrm{ml} \mathrm{I}^{-1}$; vitamin solution $1 \mathrm{ml} \mathrm{I}^{-1}$; myo-inositol $5 \mathrm{ml} \mathrm{l}^{-1} ; \mathrm{C}_{10} \mathrm{H}_{12} \mathrm{FeN}_{2} \mathrm{NaO}_{8} 5 \mathrm{ml} \mathrm{l}^{-1}$. $\mathrm{pH}$ was adjusted to 5.8 using $\mathrm{NaOH}$. For solid media $2.8 \%$ (w/v) Gelrite was added.

\subsubsection{Hydroponic culture media}

Stock solutions were prepared according to Randall \& Bouma (1973). Nutrient solutions: $\mathrm{KH}_{2} \mathrm{PO}_{4} / \mathrm{K}_{2} \mathrm{HPO}_{4} 1 \mathrm{M}$, pH 7.2; $\mathrm{MgCl}_{2} \times 6 \mathrm{H}_{2} \mathrm{O} 1 \mathrm{M} ; \mathrm{MgSO}_{4} \times 7 \mathrm{H}_{2} \mathrm{O} 1 \mathrm{M} ; \mathrm{Ca}\left(\mathrm{NO}_{3}\right)_{2} \times 4 \mathrm{H}_{2} \mathrm{O} 1 \mathrm{M} ; \mathrm{KNO}_{3}$ $1 \mathrm{M} ; \mathrm{CaCl}_{2} 1 \mathrm{M} ; \mathrm{KCl} 1 \mathrm{M}$; trace element solution $\mathrm{H}_{3} \mathrm{BO}_{3} 46.2 \mathrm{mM}, \mathrm{MnCl}_{2} \times 2 \mathrm{H}_{2} \mathrm{O} 9 \mathrm{mM}, \mathrm{ZnSO}_{4} \times$ $7 \mathrm{H}_{2} \mathrm{O} 750 \mu \mathrm{M}, \mathrm{CuSO}_{4} \times 5 \mathrm{H}_{2} \mathrm{O} 318 \mu \mathrm{M}, \mathrm{Na}_{2} \mathrm{MoO}_{4} \times 2 \mathrm{H}_{2} \mathrm{O} 120 \mu \mathrm{M}$; Fe-Na-EDTA solution $\mathrm{FeCl}_{3} \times$ $6 \mathrm{H}_{2} \mathrm{O} 80 \mathrm{mM}, \mathrm{Na}_{2} \mathrm{EDTA} \times 2 \mathrm{H}_{2} \mathrm{O} 45.64 \mathrm{mM}$. Solutions were mixed according to the following scheme:

\begin{tabular}{lcc} 
Stock solution & Volume $[\mathrm{ml}]$ & Final concentration \\
\hline $\mathrm{KH}_{2} \mathrm{PO}_{4} / \mathrm{K}_{2} \mathrm{HPO}_{4}$ & 30 & $0.5 \mathrm{mM}$ \\
$\mathrm{MgCl}_{2} \times 6 \mathrm{H}_{2} \mathrm{O}$ & 120 & $2 \mathrm{mM}$ \\
$\mathrm{MgSO}_{4} \times 7 \mathrm{H}_{2} \mathrm{O}$ & 60 & $1 \mathrm{mM}$ \\
$\mathrm{Ca}\left(\mathrm{NO}_{3}\right)_{2} \times 4 \mathrm{H}_{2} \mathrm{O}$ & 210 & $3.5 \mathrm{mM}$ \\
$\mathrm{KNO}_{3}$ & 180 & $3 \mathrm{mM}$ \\
$\mathrm{Trace}$ elements & 50 & \\
$\mathrm{H}_{3} \mathrm{BO}_{3}$ & & $38.5 \mu \mathrm{M}$ \\
$\mathrm{MnCl}_{2} \times 2 \mathrm{H}_{2} \mathrm{O}$ & & $7.5 \mu \mathrm{M}$ \\
$\mathrm{ZnSO}_{4} \times 7 \mathrm{H}_{2} \mathrm{O}$ & & $0.625 \mu \mathrm{M}$ \\
$\mathrm{CuSO}_{4} \times 5 \mathrm{H}_{2} \mathrm{O}$ & & $0.265 \mu \mathrm{M}$ \\
$\mathrm{Na}_{2} \mathrm{MoO}_{4} \times 2 \mathrm{H}_{2} \mathrm{O}$ & & $0.1 \mu \mathrm{M}$ \\
$\mathrm{Fe}_{\mathrm{Na}-\mathrm{EDTA} \text { solution }}$ & & \\
$\mathrm{FeCl}_{3}$ & 36 & $48 \mu \mathrm{M}$ \\
$\mathrm{Na}_{2} \mathrm{EDTA}$ & & $27.4 \mu \mathrm{M}$
\end{tabular}

filled with $\mathrm{ddH}_{2} \mathrm{O}$ to final volume

601 


\subsubsection{Plant treatments}

\subsubsection{Wounding}

7-8-week-old Arabidopsis plants were wounded by squeezing each rosette leave 3-8 times with forceps, crossing the mid vain (Stenzel et al, 2003a). Whole rosettes were harvested at different time points and immediately frozen in liquid $\mathrm{N}_{2}$. To account for biological variation, rosettes of 6-10 plants were pooled for each time point. Wound treatment was started in the early light phase and, if possible, completed before shift to dark phase. Frozen plant material was ground to fine powder and samples were stored at $-80^{\circ} \mathrm{C}$.

\subsubsection{MeJA application}

External application of MeJA was carried out by carefully cutting whole rosettes of 6-week-old plants and placing them on $100 \mathrm{ml}$ of $\mathrm{H}_{2} \mathrm{O}$ or $\mathrm{H}_{2} \mathrm{O}$ containing $50 \mu \mathrm{M}$ MeJA (Sigma; solved in ethanol) in glass Petri dishes, as described (Stenzel et al, 2003a). After various times, rosettes were quickly dried on tissue and immediately frozen in liquid $\mathrm{N}_{2}$. To account for biological variation, rosettes of four to five plants were pooled for each time point.

\subsubsection{Sorbitol treatment}

8-10-week-old plants grown in hydroponic cultures (as described above) were treated by adding a final concentration of $0.8 \mathrm{M}$ sorbitol to the nutrient media. After indicated time, rosettes were cut and immediately frozen in liquid $\mathrm{N}_{2}$. To account for biological variation, rosettes of 4-5 plants were pooled for each time point.

\subsubsection{Root growth assay}

Petri dishes of vertically grown seedlings were scanned with a flatbed scanner (CanoScan $8000 \mathrm{~F}$, Canon, Krefeld, Germany) and root lengths were determined using the freely available software ImageJ (http://rsbweb.nih.gov/ij/).

For root length determination of complemented coi1-t seedlings, Petri dishes were first scanned, then seedlings were transferred on soil, coil-t homozygous individuals were identified by PCR-based genotyping, and root lengths of only those homozygous seedlings were determined. 


\subsubsection{Caterpillar feeding performance tests}

Diamondback moth (Plutella xylostella) caterpillars of approximately $1 \mathrm{mg}$ each were collected $3 \mathrm{~d}$ after oviposition, and 20-40 individuals were placed on the leaf surface of 5-week-old Arabidopsis plants. For the duration of the experiment, 5-6 plants were separated in closed containers, allowing gas exchange and exposition to $80-100 \mu \mathrm{mol}$ photons $\mathrm{m}^{-1} \mathrm{~s}^{-1}$ in a regime of $12 \mathrm{~h}$ light and $12 \mathrm{~h}$ darkness. After various times, caterpillars were collected and weighed. After weighing, caterpillars were allowed to continue feeding on the respective plants, in order to monitor a continuous defensive response. Care was taken not to harm caterpillars during the weighing process; individuals damaged during collection were eliminated from subsequent evaluation.

\subsubsection{Crossing}

For easier handling, the receptor inflorescence was carefully fixed beneath the stereo microscope using linen tape. Sepals and petals of young buds, not showing any white petals yet, were carefully removed. Immature anthers, which had not released any pollen yet, were removed as well, exposing the ovary with the stigma. Mature flowers of the donor plant were slightly squeezed with forceps until pollen-carrying anthers were showing, which then were rubbed on the uncovered stigma of the mother plant. After pollen transfer, the stigma was covered with a loose bag of plastic wrap, which was removed 3-5 days after crossing procedure. All other non-treated siliques, flowers and buds were removed in order to avoid confusion.

\subsubsection{Molecular biological techniques}

\subsubsection{Amplification of specific sequences by PCR}

For DNA amplification from cDNA or genomic DNA for application in cloning procedures Phusion High-Fidelity PCR Master Mix was used following manufacturer's recommendations. For the reaction the following temperature program was applied: $30 \mathrm{~s}$ at $98{ }^{\circ} \mathrm{C}, 35$ cycles of $15 \mathrm{~s}$ at $98^{\circ} \mathrm{C}, 30 \mathrm{~s}$ at $60^{\circ} \mathrm{C}$ and $1 \mathrm{~min}$ per $1000 \mathrm{bp}$ gene length at $72{ }^{\circ} \mathrm{C} ; 5 \mathrm{~min}$ at $72^{\circ} \mathrm{C}$.

For PCR-based genotyping, TaKaRa Ex Taq ${ }^{\mathrm{TM}}$ polymerase was used according to manufacturer's recommendations. For the reaction the following temperature program was used: $3 \mathrm{~min}$ at $95^{\circ} \mathrm{C} ; 28$ cycles of $15 \mathrm{~s}$ at $95^{\circ} \mathrm{C}, 30 \mathrm{~s}$ at $60^{\circ} \mathrm{C}, 1 \mathrm{~min}$ per 1000 bp length at $72{ }^{\circ} \mathrm{C} ; 4$ min at $72{ }^{\circ} \mathrm{C}$. Alternatively, MasterAmp TfI DNA Polymerase, was used following manufacturer's 
recommendations and the following temperature program was used: $1 \mathrm{~min}$ at $95^{\circ} \mathrm{C} ; 28$ cycles of $30 \mathrm{~s}$ at $95^{\circ} \mathrm{C}, 45 \mathrm{~s}$ at $60^{\circ} \mathrm{C}, 1 \mathrm{~min}$ per $1000 \mathrm{bp}$ length at $72{ }^{\circ} \mathrm{C} ; 5$ min at $72{ }^{\circ} \mathrm{C}$.

\subsubsection{PCR-based genotyping}

coi1- $t$ T-DNA insertion mutants were genotyped by PCR using genomic DNA (isolated as described in section 2.2.4.13) as a template. PCR was performed using either TaKaRa Ex Taq ${ }^{\mathrm{TM}}$ Polymerase or MasterAmp Tfl DNA Polymerase according to manufacturer's recommendations. The PCR program described above was used. To identify mutant and wild type coi1 alleles present in the plants, the primer combination P1 and P2 (5'tggaccatataaattcatgcagtc-3' / 5'-ctgcagtgtgtaacgatgctc-3') was used. For identification of mutant or wild type ipk1 alleles present in yeast, the primer combination P3 and P4 (5'tcatcatcaatgtggctgct-3' / 5'-gatacatcgggcaaagcaag-3') was used.

\subsubsection{Electrophoretic DNA separation}

DNA was separated after addition of $1 / 5$ volume of sample buffer ( $250 \mathrm{mM}$ EDTA, $0.58 \mathrm{M}$ sucrose, $50 \%(\mathrm{w} / \mathrm{v})$ glycerol and $0.4 \%(\mathrm{w} / \mathrm{v})$ Orange $\mathrm{G}$ ) on TAE agarose gels ( $40 \mathrm{mM}$ TRIS/HCl, pH 7.0, $20 \mathrm{mM}$ acetic acid, $1 \mathrm{mM}$ EDTA solidified with $1 \%(\mathrm{w} / \mathrm{v})$ agarose) using GeneRuler $1 \mathrm{~kb}$ DNA Ladder as a size marker and subsequently stained for $10 \mathrm{~min}$ in a $2 \mu \mathrm{g} / \mathrm{ml}$ ethidium bromide bath. DNA bands were then visualized using a UV-imager.

\subsubsection{Assembly of DNA constructs}

For conventional DNA construct assembly, plasmids were restricted and ligated according to the recommendations of the enzyme manufacturer. For cloning of PCR products into the PGEM-T Easy vector, an adenosine nucleotide was added to the $3^{\prime}$-end of the purified PCR products by using $0.5 \mu \mathrm{l}$ of MasterAmp TfI DNA Polymerase and dATP at a final concentration of $100 \mathrm{pM}$ in a total volume of $50 \mu \mathrm{l}$ buffered solution. Ligation was carried out using the pGEM-T Easy vector system Kit according to manufacturer's recommendations.

\subsubsection{Site-directed mutagenesis}

Base pair exchanges were introduced into cDNA clones using QuickChange technology (Stratagene, La Jolla, CA, USA). In this method the template plasmid is completely replicated by a DNA polymerase starting from the primers that contain the desired base pair exchanges. In one reaction, $50 \mathrm{ng}$ of plasmid DNA were used in a total volume of $25 \mu$ containing $10 \mathrm{pmol}$ of 
each primer, $0.75 \mu \mathrm{l}$ DMSO and $12.5 \mu \mathrm{l}$ of $2 \times$ Phusion High-Fidelity PCR Master Mix. For the reaction the following temperature cycle was used: $30 \mathrm{~s}$ at $95^{\circ} \mathrm{C} ; 21$ cycles of $30 \mathrm{~s}$ at $95^{\circ} \mathrm{C}$, $1 \mathrm{~min}$ at $55^{\circ} \mathrm{C}$, $1 \mathrm{~min}$ per $1000 \mathrm{bp}$ length at $72{ }^{\circ} \mathrm{C} ; 5 \mathrm{~min}$ at $72{ }^{\circ} \mathrm{C}$. Alternatively $\mathrm{Pfu} \mathrm{DNA}$ Polymerase was used in a total volume of $25 \mu \mathrm{l}$ containing $10 \times$ Pfu DNA Polymerase buffer including $\mathrm{MgCl}_{2}, 0,2 \mathrm{mM}$ dNTPs, $10 \mathrm{pmol}$ 3'-primer, 10 pmol 5'-primer, 2,5 $\mathrm{U} \mathrm{\mu l}^{-1} \mathrm{Pfu}$ DNA polymerase und 5-50 ng dsDNA. The mixture of product and template was subsequently restricted over night with $10 \mathrm{U}$ of $D p n /$ that recognizes and cleaves the methylated restriction site Gm6ATC. This led to the elimination of most of the methylated template leaving the unmethylated product intact which was transformed into $E$. coli as described.

\subsubsection{DNA sequencing}

DNA was sequenced by the didesoxy termination method using $50 \mathrm{ng}$ of plasmid in a total volume of $10 \mu \mathrm{l}$ containing $1.5 \mu \mathrm{l}$ sequencing buffer, $1.5 \mu \mathrm{l}$ reaction mix and $10 \mathrm{pmol}$ of primer. For the reaction the following temperature cycle was used: 2 min at $95^{\circ} \mathrm{C} ; 25$ cycles of $30 \mathrm{~s}$ at $95^{\circ} \mathrm{C}, 15 \mathrm{~s}$ at $55^{\circ} \mathrm{C}, 4 \mathrm{~min}$ at $60^{\circ} \mathrm{C}$. The reaction product was separated by Andreas Nolte (Georg August University Göttingen, Germany) using capillary electrophoresis. Sequence analysis was performed using Chromas Lite v 2.0 software (Technelysium, Tewantin, Australia).

\subsubsection{Preparation of chemically competent $E$. coli cells}

In preparation of transformation experiments, Escherichia coli XL1-Blue cells were made chemically competent (Inoue et al, 1990). Cells were picked from plates and precultured in $2 \mathrm{ml}$ SOB medium (2\% peptone, $0.5 \%(\mathrm{w} / \mathrm{v})$ yeast extract, $10 \mathrm{mM} \mathrm{NaCl}, 2.5 \mathrm{mM} \mathrm{KCl}$ ) overnight. Cultures were diluted 1:100, $1 \mathrm{ml}$ was transferred to $250 \mathrm{ml}$ of SOB medium and cells were grown at $37^{\circ} \mathrm{C}$, until an $\mathrm{OD}_{600}$ of $0.45-0.75$ was reached. Cells were collected via centrifugation at $1000 \times \mathrm{g}$ and $4{ }^{\circ} \mathrm{C}$ for $10 \mathrm{~min}$ and resuspended in $80 \mathrm{ml}$ of TFP buffer $(10 \mathrm{mM}$ pipes, $\mathrm{pH} 6.7,15 \mathrm{mM} \mathrm{CaCl}_{2}, 250 \mathrm{nM} \mathrm{KCl}, 55 \mathrm{mM} \mathrm{MnCl}$ ) and incubated on ice for $10 \mathrm{~min}$. Afterwards, centrifugation was repeated and cells were resuspended in $21.5 \mathrm{ml}$ TFB buffer containing $7 \%(\mathrm{v} / \mathrm{v})$ DMSO and incubated again for $10 \mathrm{~min}$ on ice prior to aliquoting, shock freezing in liquid nitrogen and storage at $-80^{\circ} \mathrm{C}$.

\subsubsection{Transformation of $E$. coli cells}

For transformation according to Inoue et al (1990), $100 \mu$ l of E. coli cells were thawed on ice and added to the plasmid DNA in a $2 \mathrm{ml}$ reaction tube. After incubation on ice for $20 \mathrm{~min}$, the 
cells were heat shocked at $42{ }^{\circ} \mathrm{C}$ for $45 \mathrm{~s}$ and immediately incubated on ice for $5 \mathrm{~min}$. After addition of $300 \mu \mathrm{l} \mathrm{SOC}$ medium ( $1 \%(\mathrm{w} / \mathrm{v})$ peptone, $0.5 \%(\mathrm{w} / \mathrm{v})$ yeast extract, $1 \%(\mathrm{w} / \mathrm{v}) \mathrm{NaCl}$, $20 \mathrm{mM}$ sucrose, $20 \mathrm{mM} \mathrm{MgCl}$ ) cells were incubated at $37^{\circ} \mathrm{C}$ for $1 \mathrm{~h}$ under constant shaking and plated on solid LB medium (1\% (w/v) peptone, $0.5 \%(\mathrm{w} / \mathrm{v})$ yeast extract, $1 \%(\mathrm{w} / \mathrm{v}) \mathrm{NaCl}$ solidified with $1.5 \%(\mathrm{w} / \mathrm{v})$ agar) containing the adequate selection antibiotic (carbenicillin $100 \mu \mathrm{g} \mathrm{ml}^{-1}$, kanamycin $50 \mu \mathrm{g} \mathrm{ml}^{-1}$ ). In liquid culture, E. coli cells were grown in LB medium (as above but without agarose; antibiotics were used in the same concentrations as in agar plates).

\subsubsection{Preparation of chemically competent $A$. tumefaciens cells}

The Agrobacterium tumefaciens strain EH 105 (Hood et al, 1993) was made competent as follows: Precultures containing $50 \mu \mathrm{g} \mathrm{ml}^{-1}$ rifampicin were grown in a $2 \mathrm{ml}$ YEB $(0.5 \%(\mathrm{w} / \mathrm{v})$ beef extract, $0.1 \%(\mathrm{w} / \mathrm{v})$ yeast extract, $0.5 \%(\mathrm{w} / \mathrm{v})$ peptone, $0.5 \%(\mathrm{w} / \mathrm{v})$ saccharose, $5 \mathrm{mM}$ $\mathrm{MgSO}_{4}$ ) culture at $28^{\circ} \mathrm{C}$ over night. This culture was transferred to a flask containing $50 \mathrm{ml}$ YEB and grown at $28^{\circ} \mathrm{C}$ for approximately $4 \mathrm{~h}$ until an $\mathrm{OD}_{600}$ of 0.5 was reached. Cells were collected by centrifugation at $5000 \times \mathrm{g}$ and $4{ }^{\circ} \mathrm{C}$ for $5 \mathrm{~min}$ and resuspended in $10 \mathrm{ml}$ of ice cold $0.15 \mathrm{M} \mathrm{NaCl}$ solution. After another identical centrifugation step, cells were resuspended in $1 \mathrm{ml}$ of ice cold $75 \mathrm{mM} \mathrm{CaCl}_{2}$ solution, aliquoted, shock frozen in liquid nitrogen and stored at $80^{\circ} \mathrm{C}$.

\subsubsection{Transformation of $A$. tumefaciens cells}

For transformation according to Hofgen \& Willmitzer (1988), $100 \mu \mathrm{l}$ of competent $A$. tumefaciens cells were thawed on ice and $3 \mu \mathrm{g}$ of plasmid DNA were added. After incubation for $5 \mathrm{~min}$, the cells were shock frozen in liquid nitrogen for $5 \mathrm{~min}$ and immediately heat shocked for $5 \mathrm{~min}$ in a $37^{\circ} \mathrm{C}$ water bath. After addition of $900 \mu \mathrm{l}$ of YEB medium, cells were incubated at $28^{\circ} \mathrm{C}$ for $4 \mathrm{~h}$ under constant shaking and plated on solid YEB medium (solidified with $1.5 \%(\mathrm{w} / \mathrm{v})$ agarose) containing $50 \mathrm{\mu g} \mathrm{ml}^{-1}$ rifampicin and $50 \mu \mathrm{g} \mathrm{ml}^{-1}$ kanamycin.

\subsubsection{Arabidopsis transformation}

Recombinant constructs were introduced into Arabidopsis plants through Agrobacteriummediated transformation using the floral dip method (Clough and Bent, 1998). Agrobacteria were precultured over night $\left(30^{\circ} \mathrm{C}\right.$ and shaking at $200 \mathrm{rpm}$ ) in $5 \mathrm{ml}$ liquid YEB medium with $100 \mu \mathrm{g} \mathrm{ml}{ }^{-1}$ carbenicillin or $50 \mu \mathrm{g} \mathrm{ml}^{-1}$ kanamycin and $50 \mu \mathrm{g} \mathrm{ml}^{-1}$ rifampicin. Precultures were 
used to inoculate $400 \mathrm{ml}$ of the same medium and grown over night at identical conditions. Cells were collected by centrifugation at $10000 \mathrm{~g}$ for $20 \mathrm{~min}$ and resuspended in a total volume of $600 \mathrm{ml} 5 \%(\mathrm{w} / \mathrm{v})$ sucrose and $0.025 \%(\mathrm{v} / \mathrm{v})$ Silwet-Copolymer. Arabidopsis flowers were dipped in the bacterial suspension and plants hooded over night. The procedure was repeated one week later. Positive transformants of T1 generation were identified by DsRed fluorescence using a fluorescence stereomicroscope (Leica MZ16FA) and a Leica DFC480 camera. Fluorescence intensities were determined using the freely available software ImageJ (http://rsbweb.nih.gov/ij/).

\subsubsection{Isolation of plasmid DNA from bacterial cultures}

Plasmids were isolated from small scale $(4 \mathrm{ml})$ liquid E. coli cultures using the NucleoSpin Plasmid Kit as recommended by the manufacturer. For purification of DNA from solutions or agarose gel pieces, the NucleoSpin Extract II Kit was used following manufacturer's recommendations.

\subsubsection{Isolation of DNA from Arabidopsis leaves}

DNA was extracted from Arabidopsis material as follows: One medium-sized leaf per sample was frozen in liquid nitrogen and pulverized in a $2 \mathrm{ml}$ reaction tube containing three $3 \mathrm{~mm}$ glass beads using a type MM200 shaking mill. Material was kept frozen during the whole procedure until $500 \mu \mathrm{l}$ of CTAB extraction solution $(2 \%$ (w/v) CTAB (Cetyltrimethylammoniumbromid), $100 \mathrm{mM}$ Tris- $\mathrm{HCl}, \mathrm{pH}$ 8.0, $20 \mathrm{mM}$ EDTA, $1.4 \mathrm{M} \mathrm{NaCl}$ ) were added, followed by immediate agitation. The samples were heated to $65^{\circ} \mathrm{C}$ for $15 \mathrm{~min}$ and cooled before an equal volume of $\mathrm{CHCl}_{3}$ :isoamyl alcohol $(24: 1, \mathrm{v} / \mathrm{v})$ was added. Samples were mixed followed by a centrifugation step of $20000 \times \mathrm{g}$ for $2 \mathrm{~min} .400 \mu \mathrm{l}$ of the upper (aqueous) phase were transferred to a new reaction tube containing $40 \mu \mathrm{l}$ of an aqueous solution of $10 \%$ $(\mathrm{w} / \mathrm{v}) \mathrm{CTAB}$ and $0.7 \%(\mathrm{w} / \mathrm{v}) \mathrm{NaCl}$ and mixed. After a 2-minute-incubation, $500 \mu \mathrm{l}$ of isopropanol were added and the samples were mixed. To precipitate DNA, samples were centrifuged at $20000 \mathrm{xg}$ for $15 \mathrm{~min}$ and the supernatant was carefully removed. After a washing step with $70 \%$ ethanol, the pellets were dried briefly and dissolved over night at $4{ }^{\circ} \mathrm{C}$ in $100 \mu$ of $\mathrm{ddH}_{2} \mathrm{O}$.

\subsubsection{Cloning strategies}

COI1 coding region was amplified using Arabidopsis CDNA and primers P5 and P6 (5'gattccatggaggatcctgatatcaagaggtgtaaattg- $3^{\prime}$ and $5^{\prime}$-gattcccgggtcagtggtggtggtggtggtgtattggctcc 
ttcaggactcta-3'), and ligated into the pGEM-T Easy vector (Promega). QuickChange PCR was used to mutate the COI1 sequence revealing coi1 $1_{\text {mut }}$ variants. coi $1_{\mathrm{K} 81 \mathrm{~A}}$ was generated with primers P7 and P8 (5'-ggtcgctcaaacttgcaggcaagcctagag-3' and 5'-ctctaggcttgcctgcaagtttgag cgacc- $\left.3^{\prime}\right)$, coi1 $1_{\mathrm{R} 348 \mathrm{~A}}$ with primers P9 and P10 (5'-cagttgaagcggctggcgattgaacgcggtgc-3' and $5^{\prime}$ gcaccgcgttcaatcgccagccgcttcaactg-3'), coi1 $1_{\mathrm{R} 516 \mathrm{~A}}$ with primers P11 and P12 (5'gccttcactggcatacttgtgggtacaagg- $3^{\prime}$ and $5^{\prime}$-ccttgtacccacaagtatgccagtgaaggc- $\left.3^{\prime}\right)$, coi $1_{\mathrm{R} 121 \mathrm{~A}}$ with primers P13 and P14 (5'-cggtgcacttccgagcgatgattgtcagtg-3' and 5'-cactgacaatcatcgctcggaagtgca ccg-3'), coi1 ${ }_{\text {R409A }}$ with primers P15 and P16 (5'-cctctgtgacttcgcccttgtcttactcg-3' and $5^{\prime}$ cgagtaagacaagggcgaagtcacagagg- $\left.3^{\prime}\right)$. Multiple exchange variants were successively generated with the same primer pairs. COI1 and mutated coil variant sequences were transferred to pCAMBIA vector (kindly provided by Dr. Ellen Hornung, Georg August University Göttingen, Germany) via Ncol and Xmal sites, integrated between a p35S Cauliflower mosaic virus (CaMV) promoter and a $35 \mathrm{~S}$ polyA terminator.

DsRed sequence including cassava vein mosaic virus (CVMV) promoter and a terminator was amplified from pPHAS-DsRed (kindly provided by Dr. John Shanklin, Brookhaven Natl. Lab., Upton, NY, USA) using primers P17 and P18 (5'-gatcaagcttggccgcaacagaggtggatg-3' and 5'gatcaagcttagaaggtaattatccaagat-3'), and ligated into the pGEM-T Easy vector (Promega). For reasons of cloning strategy, two $\mathrm{Ncol}$ sites were destroyed within the DsRed sequence using primer pairs P19 and P20 (5'-gaaagtggatcgaaacgatggcctcctccgag-3' and 5'ctcggaggaggccatçgtttcgatccactttc-3') for the first, and primers P21 and P22 (5'gatgcagaagaagacgatgggctgggaggcc- $3^{\prime}$ and $5^{\prime}$-ggcctcccagcccatcgtctt cttctgcatc- $3^{\prime}$ ) for the second. The resulting sequence was introduced to the PCAMBIA vector via HindIII restriction sites. All final sequences were verified by 2 rounds of sequencing with consistent results. The pCAMBIA vector carrying the DsRed as well as the COI1 sequence was first introduced to Agrobacterium tumefaciens, which was then used for Arabidopsis transformation.

COI1 and coil $1_{\text {mut }}$ coding regions for yeast interaction tests were amplified from PCAMBIA constructs using primers P5 and P23 (5'-gattccatggaggatcctgatatcaagaggtgtaaattg-3' and 5'gatcgtcgactcagtggtggtggtggtggtgtattggc- $3^{\prime}$ ) and ligated to the $\mathrm{Ncol}$ and Sall site of pGBKT7 to obtain in frame fusion proteins with GBD. JAZ9 coding region was ligated to pDEST-GAD-HA (Dr. Barry Causier and Dr. Brandan Davies, University of Leeds, UK) via gateway cloning (Invitrogen) to obtain in frame fusion proteins with GAD, performed by Dr. Corinna Thurow and Anna Hermann (Georg August University, Göttingen, Germany) 
For yeast mutagenesis, the cloNAT-MX4 cassette (kindly provided by Dr. Martin Fulda, Georg August University, Göttingen, Germany) was used as template for introduction of the selection marker to the flanking sequences. IPK1 flanking sequences for knock-out primer design (P24 and P25, 5'-aaaattgtcagagataagttccttttttgaaaagaaagatcgatgcgtacgctgcaggtcgac-3' and 5'gtgcatctgccagtaccaaaggtggaaagaaaagtatacagtttaatcgatgaattcgagctcg-3') were obtained from the yeast deletion web page (http://www-sequence.stanford.edu/group/ yeast_deletion_project/downloads.html).

\subsubsection{Determination of specific transcript levels}

\subsubsection{RNA extraction}

Total RNA was extracted from 150 to $300 \mathrm{mg}$ of rosette leaf material using the TRIZOL method (Chomczynski \& Mackey, 1995). Frozen plant powder was thawed by adding $1 \mathrm{ml} \mathrm{TRIZOL} \mathrm{(38 \%}$ $(\mathrm{v} / \mathrm{v})$ Roti-Phenol, $0.8 \mathrm{M}$ guanidinium thiocyanate, $0.4 \mathrm{M}$ ammonium thiocynanate, $133.6 \mathrm{mM}$ sodium acetate $\mathrm{pH} 5.0,5 \%(\mathrm{v} / \mathrm{v})$ glycerol) and vigorously shaking. After incubation for $5 \mathrm{~min}$ at room temperature and centrifugation for $10 \mathrm{~min}$ at $4{ }^{\circ} \mathrm{C}$ and $20000 \mathrm{xg}$, the supernatant was transferred to a new tube and $200 \mu \mathrm{l}$ of chloroform were added. Samples were shaken by hand for $15-20 \mathrm{sec}$, and after 2-3 min of incubation at room temperature centrifuged for $15 \mathrm{~min}$ at $4{ }^{\circ} \mathrm{C}$ and $20000 \times \mathrm{g}$. The upper phase was transferred to a new tube and half a volume of isopropanol and half a volume of high salt precipitation buffer $(0.8 \mathrm{M}$ sodium citrate, $1.2 \mathrm{M}$ $\mathrm{NaCl}$ ) were added. Mixture by inverting was followed by $10 \mathrm{~min}$ incubation at room temperature. After spinning the samples for $10 \mathrm{~min}$ at $4{ }^{\circ} \mathrm{C}$ and $20000 \mathrm{x}$, the supernatant was removed and the pellet was washed twice with $900 \mu$ l of $75 \%$ ethanol (centrifugation for $5 \mathrm{~min}$ at $4{ }^{\circ} \mathrm{C}$ and $10000 \times \mathrm{g}$ ). Pellet was dried briefly at room temperature and resuspended in $20 \mu$ l of RNAse-free $d_{d H_{2}} \mathrm{O}$ by heating to $65^{\circ} \mathrm{C}$ for $5 \mathrm{~min}$. During the whole procedure, care was taken to exclusively use RNAse-free equipment. Precipitation buffer was treated with diethylpyrocarbonate (DEPC) in $0.1 \%(\mathrm{v} / \mathrm{v})$ concentration, stirred over night and autoclaved.

\subsubsection{2 cDNA synthesis}

Reverse transcription was performed using $1 \mu \mathrm{g}$ of total RNA, 20 pmol of oligo(dT) (18 dT), and $200 \mathrm{pmol}$ of random nonamer oligonucleotides. Water was added to a final reaction volume of $12.5 \mu \mathrm{l}$. The mixture was heated to $70^{\circ} \mathrm{C}$ for $10 \mathrm{~min}, 20 \mathrm{nmol}$ deoxynucleotide triphosphate, $4 \mu \mathrm{l} 5 \times$ reaction buffer, and 30 units of ribonuclease inhibitor were added (final volume $20 \mu \mathrm{l}$ ), and the mixture was incubated at $37^{\circ} \mathrm{C}$ for $10 \mathrm{~min} .100 \mathrm{U}$ of RevertAid H Minus M-MuLV 
reverse transcriptase were added to a final volume of $20 \mu \mathrm{l}$ and the mixture was incubated at $42{ }^{\circ} \mathrm{C}$ for $70 \mathrm{~min}$ and then heated to $70^{\circ} \mathrm{C}$ for $10 \mathrm{~min}$. The resulting cDNA was diluted $1: 10$ and $1 \mu \mathrm{l}$ was used as a PCR template in a $25 \mu \mathrm{l}$ reaction for Real Time RT-PCR analysis. $1 \mu \mathrm{l}$ of undiluted CDNA was used for semi-quantitative RT-PCR.

\subsubsection{Real-time RT-PCR analysis}

Real-time RT-PCR analysis was performed as described by Fode et al (2008) using the iCycler System (BioRad). The amplification mix contained $1 \mathrm{x} \mathrm{NH}_{4}$ reaction buffer (Bioline), $2 \mathrm{mM}$ $\mathrm{MgCl}_{2}, 100 \mathrm{mM}$ deoxynucleotide triphosphate, $0.4 \mu \mathrm{M}$ primers, $0.25 \mathrm{U}$ BIOTaq DNA Polymerase (Bioline), $10 \mathrm{nM}$ fluorescein (Bio-Rad), 100000 times diluted SYBR Green I solution (Cambrex), $1 \mu$ of 1:10 diluted cDNA as template, and $\mathrm{ddH}_{2} \mathrm{O}$ filled to a total volume of $25 \mu \mathrm{l}$. For the reaction, the following temperatur programm was used: 3 min of $95^{\circ} \mathrm{C}, 40$ cycles of $20 \mathrm{~s}$ at $95^{\circ} \mathrm{C}, 20 \mathrm{~s}$ at $55^{\circ} \mathrm{C}, 40 \mathrm{~s}$ at $72{ }^{\circ} \mathrm{C}$. Quantitect Primers for AOS (At5g42650), OPR1 (At1g76680), VSP1 (At5g24780), RNS1 (At2g02990), T18K17.7 (At1g73260) and WRKY70 (At3g56400) were obtained from Qiagen. Calculations were made according to the $2_{T}^{-\triangle C}$ method (Livak and Schmittgen, 2001). Protein phosphatase type 2 (PP2A, At1g13320, Czechowski et al., 2005) served as internal reference when transcript levels of InsP 5-ptase plants were determined. Ubiqutin5 (UBI5, At3g62250) served as internal reference (Kesarwani et al., 2007) when transcript levels of ipk1-1 plants were determined.

\subsubsection{Semi-quantitative RT-PCR}

To determine coi1 transcript levels in complemented coi1-t plants via semi-quantitative RTPCR, $1 \mu$ l of cDNA was used as template in TaKaRa Ex Taq ${ }^{\text {TM }}$ PCR reactions of 27, 30 or 34 cycles with primers P26 and P27 (5'-gtcgcgacggttgatgat-3' and 5'-ggtggtggtggtggtgtatt-3').

To determine coi1 transcript levels in coi1-t plants via semi-quantitative RT-PCR, $1 \mu$ l of cDNA was used as template in TaKaRa Ex Taq ${ }^{\mathrm{TM}}$ PCR reactions of 32 cycles with the primers P28 and P29 (5'-gattatggaggatcctgatatcaagaggt-3' and 5'-gatttcatattggctccttcaggactcta-3').

\subsubsection{Sequence alignment}

Sequence alignments were performed using EXPASY Proteomics Server (www.expasy.org). Conserved residues were visualized using Swiss pdb Viewer, Deep View v 3.7 (Guex \& Peitsch, 1997) http://www.expasy.org/spdbv/). 


\subsubsection{Targeted gene disruption in S. cerevisiae}

For gene deletion in the yeast Saccharomyces cerevisiae, the PCR-based method described by Wach et al (1994) was used, exploiting the fact that yeast efficiently performs homologous recombination when exposed to linear DNA fragments. Linear fragment are supposed to contain $5^{\prime}$-upstream regions including start codon and $3^{\prime}$-downstream regions including stop codon of the gene of interest, embracing the resistance cassette. Using such fragments for yeast transformation, the entire open reading frame of the gene of interest will be deleted (Fig. 5). DNA fragments for IPK1 deletion were designed as follows: IPK1 flanking sequences for knock-out primer design were obtained from the yeast deletion web page (http://wwwsequence.stanford.edu/group/yeast_deletion_project/downloads.html). Knock-out primers contained 18 bases complementary to the resistance cassette and 45 bases complementary to IPK1 flanking sequences of the yeast genome (5'aaaattgtcagagataagttcctttttgaaaagaagatcgatgcgtacgctgcaggtcgac-3' and ${ }^{\prime}{ }^{\prime}$ gtgcatctgccagtaccaaaggtggaaagaaaagtatacagtttaatcgatgaattcgagctcg- $\left.3^{\prime}\right)$. Using these primers together with plasmid DNA (pAG25) carrying the nourseothricin resistance cloNAT-MX4 cassette (kindly provided by Dr. Martin Fulda and Dr. Michael Scharnewski, Georg August University, Göttingen, Germany) as template, the yielded PCR product was purified (Nucleospin Extract II Kit) and utilized for yeast transformation resulting in an ipk1 deficient yeast strain resistant to nourseothricin, named ipk1 $\Delta$.

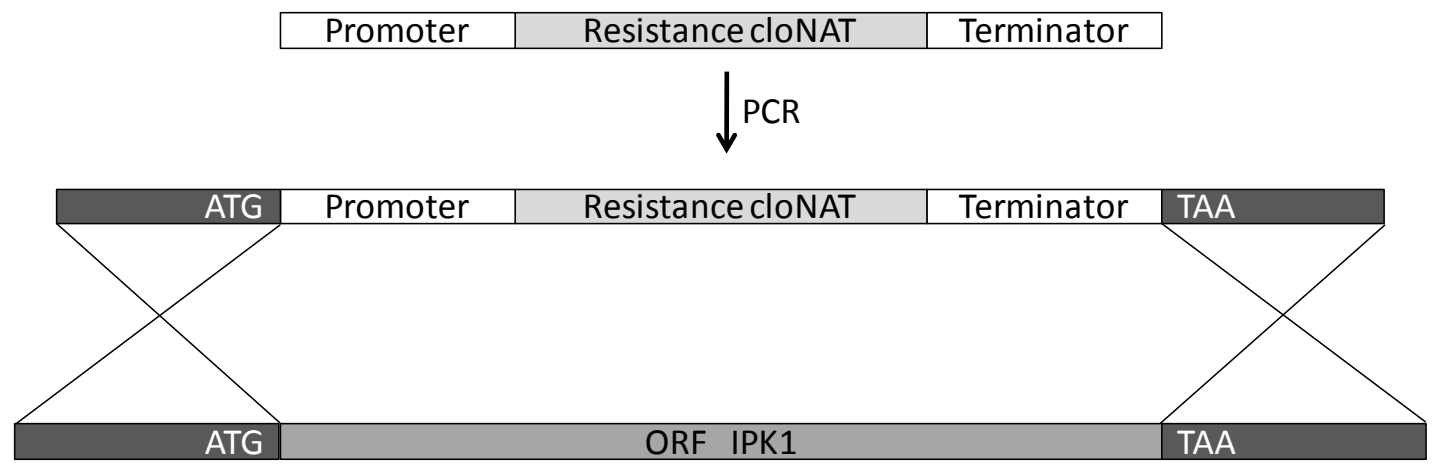

Fig. 5: Scheme of gene deletion in yeast via homologous recombination. A linear fragment containing the resistance cassette flanked by the $5^{\prime}$-upstream regions including start codon (ATG) and the $3^{\prime}$ downstream regions including stop codon (TAA) of the gene of interest is generated by PCR. By chromosomal intergration via homologous recombination the gene of interest is replaced and knocked out. Illustration according to Dr. Michael Scharnewski. 


\subsubsection{Transformation of S. cerevisiae}

To obtain yeast cells competent for DNA uptake, an overnight culture (in liquid YPD media of $1 \%$ yeast extract, $2 \%$ peptone, $2 \%$ glucose, $0.01 \%$ adenine hemisulfate, shaking at $30{ }^{\circ} \mathrm{C}$ at $200 \mathrm{rpm}$ ) was diluted in $10 \mathrm{ml}$ YPD to an $\mathrm{OD}_{600}$ of 0.3 and grown to an $\mathrm{OD}_{600}$ of 0.8 to 1.0. Cells were pelletized for $3 \mathrm{~min}$ at room temperature with $1500 \times \mathrm{g}$ and washed with sterile $\mathrm{dd}_{2} \mathrm{O}$. The obtained cell pellet was resuspended in $400 \mu \mathrm{l}$ of $0.1 \mathrm{M}$ lithium acetate and divided into two $200 \mu$ l aliquots of competent cells.

For transformation, $25 \mu \mathrm{l}$ of carrier DNA were preheated for $5 \mathrm{~min}$ to $65^{\circ} \mathrm{C}$ and together with 50-80 $\mu \mathrm{l}$ of purified PCR product added to competent cells. $\mathrm{ddH}_{2} \mathrm{O}$ was added to a control sample. $800 \mu$ I PEG solution (40 \% PEG4000, 100 mM lithium acetate, 10 mM TRIS HCl, pH 7.5; sterile) were added, the samples were inverted and pivoted for $30 \mathrm{~min}$ at $30^{\circ} \mathrm{C}$. After heat shock of $42{ }^{\circ} \mathrm{C}$ for $25 \mathrm{~min}$, cells were sedimented for $1 \mathrm{~min}$ at $4500 \mathrm{xg}$, resuspended in YPD and pivoted at $30{ }^{\circ} \mathrm{C}$ for $1-2 \mathrm{~h}$. Subsequently, cells were centrifuged for $1 \mathrm{~min}$ at $1500 \times \mathrm{g}$, resuspended in $200 \mu \mathrm{l}$ of YPD and plated on nourseothricin containing YPD dishes, which were incubated at $30^{\circ} \mathrm{C}$ for 3-4 days.

\subsubsection{Yeast two-hybrid assay}

The principle of a yeast two-hybrid test is based on the activity of a transcription factor, split into a DNA binding domain and an activation domain, which is only active upon interaction between two proteins of interest, each fused to one of the two domains. If the proteins of interest interact, the two domains are brought to close proximity and the transcription factor activates expression of a reporter gene. In this study, the Gal4 transcription factor, activating the lacZ gene which encodes for $\beta$-galactosidase, was used. Therefore, the JAZ9 sequence was fused to the Gal4 DNA binding domain (GBD), and the COI1 sequence was fused to the Gal4 activation domain (GAD). Upon JAZ9/COI1 interaction, $\beta$-galactosidase activity was followed by the conversion of o-nitrophenyl- $\beta$-D-galactopyranoside (ONPG), structurally similar to lactose, into galactose and o-nitrophenol, a yellow compound. $\beta$-galactosidase assays were performed in yeast strain PJ69-4A (James et al, 1996) as well as in the corresponding deletion strain ipk1 . The interaction of JAZ9 and COI 1 was tested in the presence of $30 \mu \mathrm{M}$ coronatin, which served as JA-lle analogue. Measurement of $\beta$-galactosidase activity was performed as described by Niggeweg et al (2000).

Yeast two-hybrid tests were kindly conducted by Dr. Corinna Thurow and Anna Hermann (Georg August University, Göttingen, Germany). 


\subsubsection{Ins $\mathrm{P}_{3}$ determination}

Plant material was ground with liquid nitrogen to a fine powder. Ins $\mathrm{P}_{3}$ levels were determined from ground powder using the $\left[{ }^{3} \mathrm{H}\right] \mathrm{Ins} \mathrm{P}^{3}$ receptor binding assay system (GE Healthcare/Amersham, Düren, Germany), as previously described (Perera et al, 1999). 100$150 \mathrm{mg}$ of frozen plant powder was thawed by adding $400 \mu \mathrm{l}$ of $20 \%$ perchloric acid and mixing vigorously. All following steps were conducted on ice. After incubation for 20 min on ice, samples were spun for $10 \mathrm{~min}$ at $4{ }^{\circ} \mathrm{C}$ and $20000 \times \mathrm{g}$ and the supernatant was transferred to a new tube. $\mathrm{pH}$ was adjusted to $6.5-7.5$ using $1.5 \mathrm{M} \mathrm{KOH} / 60 \mathrm{mM}$ HEPES including $\mathrm{pH}$ indicator dye $\left(0.5 \mathrm{ml}\right.$ Fisherdye $/ 10 \mathrm{ml}$ buffer). Following centrifugation for $10 \mathrm{~min}$ at $4{ }^{\circ} \mathrm{C}$ and $20000 \times \mathrm{g}$, the supernatant was transferred to a new tube and the volume was determined for later calculations. InsP $\mathrm{P}_{3}$ determination was performed with $25 \mu \mathrm{l}$ of binding protein and appropriate down scaled reaction volumes instead of $100 \mu \mathrm{l}$ as recommended in the manual. All other processes were conducted according to the manual. Processed samples were incubated over night and measured in a scintillation counter (Liquid Scintillation Analyzer Tricarb 1900 TR, Canberra Packard, Dreieich, Germany).

\subsubsection{Lipid analysis}

Phosphoinositides were extracted from powdered plant material by using an acidic extraction protocol (Cho et al, 1992). $1.5 \mathrm{ml} \mathrm{CHCl}: \mathrm{CH}_{3} \mathrm{OH}$ (1:2), $250 \mu \mathrm{l} 0.5 \mathrm{M} \mathrm{EDTA}, 500 \mu \mathrm{l} 2.4 \mathrm{M} \mathrm{HCl}$ and $500 \mu \mathrm{l}$ of chloroform were added to frozen plant powder, the samples were mixed after addition of each compound and subsequently shaken for $3-4 \mathrm{~h}$ at $4{ }^{\circ} \mathrm{C}$. The lower organic phase was collected and the upper aqueous phase reextracted twice with $1 \mathrm{ml}$ of chloroform. The combined organic phases were washed with $1.5 \mathrm{ml} 0.5 \mathrm{M} \mathrm{HCl}$ in $\mathrm{CH}_{3} \mathrm{OH}: \mathrm{H}_{2} \mathrm{O}$ (1:1), dried under streaming nitrogen and solubilised in $500 \mu \mathrm{l}$ of chloroform. The samples were separated by thin layer chromatography (TLC) using silica 560 plates (Merck, Darmstadt, Germany) and $\mathrm{CHCl}_{3}: \mathrm{CH}_{3} \mathrm{OH}: \mathrm{NH}_{4} \mathrm{OH}: \mathrm{H}_{2} \mathrm{O}$ (57:50:4:11 v/v/v/v) as a developing solvent for separation of Ptdlns4P, PtdlnsP $P_{2}$ and $\mathrm{PtdOH}$ (Perera et al, 2005), and methyl acetate:isopropanol: $\mathrm{CHCl}_{3}: \mathrm{CH}_{3} \mathrm{OH}: 0.25 \%$ aqueous $\mathrm{KCl}$ solution $(25: 25: 25: 10: 9 \mathrm{v} / \mathrm{v} / \mathrm{v} / \mathrm{v} / \mathrm{v})$ as a developing solvent for separation of Ptdlns (Christie, 2003). Lipids were identified by comigration of authentic standards ( $5 \mu \mathrm{g}$; Avanti Polar Lipids, Alabaster, AL, USA). Lanes with lipid standards that were run next to the plant samples were cut and visualized by the application of aqueous $10 \%(\mathrm{w} / \mathrm{w}) \mathrm{CuSO}_{4}$ containing $8 \%(\mathrm{w} / \mathrm{v}) \mathrm{H}_{3} \mathrm{PO}_{4}$ followed by heating to $180^{\circ} \mathrm{C}$ (König et al, 2007). Lipid bands on the unstained remaining part of the TLC plates were 
scraped according to the comigrated standards, and quantified via their fatty acid content, which was determined by gas chromatography (GC) analysis.

Therefore, the lipids were re-dissolved from the scraped powder to their respective developing solvents, dried under a stream of nitrogen and transmethylated according to Hornung et al (2002). $333 \mu \mathrm{l} \mathrm{MeOH/toluol} \mathrm{(2:1)} \mathrm{and} 167 \mu \mathrm{l} 0.5 \mathrm{M}$ sodium methoxide were added to the dried lipid coat with sodium methoxide acting as nucleophile, attacking the ester bound between fatty acid and lipid backbone. Furthermore, $5 \mu \mathrm{g}$ of tripentadecanoin as internal fatty acid standard were added to each sample and co-transmethylated. The mixture was shaken for $30 \mathrm{~min}$ at room temperature and afterwards stopped by adding $0.5 \mathrm{ml} 5 \mathrm{M} \mathrm{NaCl}$ and $50 \mu \mathrm{l}$ of $32 \% \mathrm{HCl}$. Obtained fatty acid methyl esters were extracted with $2 \mathrm{ml}$ hexane, and the hexane phase was washed twice with $2 \mathrm{mlddH_{2 }} \mathrm{O}$ and dried under a stream of nitrogen. The remaining lipid coat was resuspended in $100 \mu$ acetonitrile and transferred to plastic inlays of GC vials, in which the volume was narrowed down to $10 \mu$ l. Samples were overlayered with argon and stored at $-20^{\circ} \mathrm{C}$ until $\mathrm{GC}$ analysis.

Compound separation via GC is based on the molecules' different chemical characteristics, resulting in different binding properties to the GC column, which in this case contained polyimide covered silica glass as stationary phase. A continuous temperature gradient applied to the GC column changes the binding conditions and results in sequential release of polar substances in the first place and nonpolar substances afterwards. For detection, molecules are thermically ionized resulting in an electric signal.

GC analysis was performed using a GC6890 gas chromatograph with flame ionization detection (Agilent, Waldbronn, Germany) fitted with a DB-23 capillary column (30 m x $250 \mu \mathrm{m}, 0.25 \mu \mathrm{m}$ coating thickness; J\&W, Agilent, Waldbronn, Germany). Helium flowed as a carrier gas at $1 \mathrm{ml} \mathrm{min}{ }^{-1}$. Samples were injected at $220^{\circ} \mathrm{C}$. The temperature gradient was $150^{\circ} \mathrm{C}$ for $1 \mathrm{~min}$, $150-200^{\circ} \mathrm{C}$ at $8{ }^{\circ} \mathrm{C} \mathrm{min}^{-1}, 200-250^{\circ} \mathrm{C}$ at $25^{\circ} \mathrm{C} \mathrm{min}^{-1}$ and $250^{\circ} \mathrm{C}$ for $6 \mathrm{~min}$ (König et al, 2007). Fatty acids were identified according to authentic standards, and quantified according to internal tripentadecanoic acid standards of known concentration using GC ChemStation software (Agilent, Waldbronn, Germany).

\subsubsection{Phytohormone analysis}

\subsubsection{Phytohormone analysis via GC/MS}

Leaf material of InsP 5-ptase and dde2-2 plants and corresponding wild type was extracted as described by Schmelz et al (2004) with some modifications. Frozen ground plant material (50 mg) was mixed with $1 \mathrm{ml}$ diisopropylamine containing $100 \mathrm{ng}$ of D6-JA, $100 \mathrm{ng}$ of D6-OPDA 
(kindly provided by Dr. Otto Miersch, Martin Luther University, Halle, Germany), and $50 \mathrm{ng}$ of D5-SA (Icon Genetics) as internal standards. The mixture was sonified for $15 \mathrm{~min}, 1 \mathrm{ml}$ of chloroform was added followed by additional sonification for $15 \mathrm{~min}$. For detection, compounds were converted to their pentafluorobenzyl esters according to Mueller \& Brodschelm (1994) by adding $17 \mathrm{mg}$ pentafluorbenzylbromide and incubating for $1 \mathrm{~h}$ at $60^{\circ} \mathrm{C}$. After evaporation under streaming nitrogen, residues were dissolved in $1 \mathrm{ml}$ diethyl ether and filtrated through filter paper. For complete recovery of the pentafluorobenzyl esters, the sample tube was washed with $1 \mathrm{ml}$ of hexane, which was also filtered and combined with the diethyl ether filtrate. The filtered solution was evaporated under a stream of nitrogen. Vapor phase extraction was carried out at $270^{\circ} \mathrm{C}$ for $5 \mathrm{~min}$, with argon as a carrier gas. Vaporized substances absorbed by the SuperQ column ( $100 \times 4.6 \mathrm{~mm}$ SDB-L Strata, pore size $260 \mathrm{~A}^{\circ}$; Phenomenex) were eluted from the SuperQ columns subsequently with $3 \mathrm{ml}$ hexane and $3 \mathrm{ml}$ ethyl acetate. The solution was concentrated with a rotating evaporator. The remainder was dissolved in $40 \mu \mathrm{l}$ dichlormethane and subjected to GC coupled to mass spectrometry (GC/MS; see section 2.2.12.1.4).

\subsection{HIP extraction method}

For phytohormone analysis of opr3 plants and corresponding wild type, $0.5 \mathrm{~g}$ of frozen plant powder were homogenized in $10 \mathrm{ml}$ of hexane/isopropanol (HIP) solution (hexane:isopropanol (3:2), $0.0025 \%$ 2-butyl-6-hydroxytoluen) and $300 \mu \mathrm{l}$ glacial acetic acid together with $100 \mathrm{ng}$ of D6-JA, 100 ng of D6-oPDA (kindly provided by Dr. Otto Miersch, Martin Luther University, Halle, Germany), and $50 \mathrm{ng}$ of D5-SA (Icon Genetics) as internal standards, using an Ultra Turrax (13000 rpm, Ika, Staufen, Germany) under argon atmosphere for $45 \mathrm{~s}$. The extract was shaken at $4{ }^{\circ} \mathrm{C}$ for $10 \mathrm{~min}$ and centrifuged for $10 \mathrm{~min}$ at $4{ }^{\circ} \mathrm{C}$ and $450 \mathrm{xg}$. The supernatant was added to $8.1 \mathrm{ml}$ of $0.38 \mathrm{M}$ potassium sulphate solution, shaken for $10 \mathrm{~min}$ at $4{ }^{\circ} \mathrm{C}$ and centrifuged for $10 \mathrm{~min}$ at $4{ }^{\circ} \mathrm{C}$ and $450 \mathrm{xg}$. The upper hexane-rich phase was dried under streaming nitrogen, dissolved in $200 \mu \mathrm{M} \mathrm{MeOH}$ and separated by Reversed-Phase High Performance Liquid Chromatography (RP-HPLC).

\subsection{RP-HPLC}

This HPLC technique allows the separation of compound mixtures with high efficiency, forcing analytes through a stationary phase (column) by the liquid mobile phase under high pressure. Separation using RP-HPLC depends on the hydrophobic binding interactions between the dissolved compounds in the polar mobile phase and the nonpolar stationary phase. Interacting 
compounds elute from the column based on their polarity and the applied gradient, resulting in separation according to individual hydrophobicities. Eluted compounds are detected by recording their UV spectra.

Here, RP-HPLC was employed for the separation of phytohormones depending on their carbon chain length and their functional groups. An Agilent 1100 HPLC system (Agilent, Waldbronn, Germany) coupled to a diode array detector, equipped with a nonpolar $\mathrm{C}_{18}$ column (EC 250/2 Nucleosil 120-5 $\mathrm{C}_{18}, 250 \times 2.1 \mathrm{~mm}, 5 \mu \mathrm{m}$ particle size; Macherey \& Nagel, Düren, Germany) was used, applying a binary gradient of solvent $\mathrm{A}\left(\mathrm{CH}_{3} \mathrm{OH}: \mathrm{H}_{2} \mathrm{O}\right.$ :acetate, 75:25:0.1, v/v/v) and solvent $\mathrm{B}\left(\mathrm{CH}_{3} \mathrm{OH}\right.$ :acetate, 100:0.1, v/v) with the following gradient parameter: $80 \%$ solvent $A$, $20 \%$ solvent B for $10 \mathrm{~min}$, followed by a linear increase of solvent B to $100 \%$ within $5 \mathrm{~min}$. The flow rate increased at this point from 0.18 to $0.36 \mathrm{ml} / \mathrm{min}$. After a run of $100 \%$ solvent $B$ for 10 min, the gradient changed within 2 min to $80 \%$ solvent $A$ and $20 \%$ solvent $B$ and ran with this properties for another $3 \mathrm{~min}$. The absorbance at $224 \mathrm{~nm}$ was recorded, and the fraction from starting at 3 min till behind the oPDA peak was collected (Fammartino et al, 2007). Prior to injection, the lipid extract was dissolved in $80 \mu$ l of solvent A.

Separated phytohormones were converted to their pentafluorobenzyl esters for GC/MS analysis to allow for better ionization.

\subsection{Derivatisation to pentafluoroesters}

RP-HPLC fractions were dried under streaming nitrogen and dissolved in $200 \mu \mathrm{l}$ of $\mathrm{CHCl}_{3}$ :diisopropylamin (1:1) and $10 \mu \mathrm{l}$ of pentafluorbenzylbromide. Samples were heated to $50^{\circ} \mathrm{C}$ in a water bath for $1 \mathrm{~h}$ and subsequently dried under a stream of nitrogen. Bakerbond spe $^{\mathrm{TM}}$ Silica Gel columns (J.T. Baker, Deventer, Netherlands) were pre-rinsed twice with $2.5 \mathrm{ml}$ of hexane. Afterward the dried samples were loaded onto the column, solved in $5 \mathrm{ml}$ of hexane, and eluted by rinsing the column with $7 \mathrm{ml}$ of hexane:diethylether (2:1). Eluate was dried under streaming nitrogen, dissolved in $10 \mu \mathrm{l}$ acetonitrile and subjected to GC/MS analysis.

\subsection{GC/MS analysis}

The combination of GC and MS enables the separation of compound mixtures according to their chemical characteristics, resulting in different binding properties to the GC column, and subsequent characterization and quantification of individual molecules by MS, converting each molecule into its ionized form due to electron impact (EI) ionization or chemical ionization (CI) and detecting these ions using their mass to charge ratio $(\mathrm{m} / \mathrm{z})$. Transferred to the MS, the 
molecules get ionized either directly by electrons emitted from a thermionic cathode (EI) or by electrons emitted from a thermionic cathode ionized ammonia gas, which detaches a proton from the sample molecule, resulting in an anion $(\mathrm{Cl})$. Using $\mathrm{Cl}$, the energy transfer to the molecule of interest is lower; therefore the molecules remain intact allowing for analysis of whole molecules. This technique is well suitable for quantification of known substances and was used in this study in GC-coupled MS analysis. Ionized molecules are subsequently send through an electromagnetic field, in this case the ion trap, and separated via their $(\mathrm{m} / \mathrm{z})$ ratio. Due to an electric current, generated by the ions, the molecules are detected.

GC/MS analysis was carried out using a ThermoFinnigan (Austin, Texas, USA) Polaris Q mass selective detector connected to ThermoFinnigan Trace gas chromatograph equipped with a capillary Rtx-5MS column (15 m x 0.25 mm, $0.25 \mu \mathrm{m}$ coating thickness; Resteck, Bad Homburg, Germany). Helium was used as carrier gas at a flow rate of $1 \mathrm{ml} \mathrm{min}^{-1}$. The temperature gradient was $100{ }^{\circ} \mathrm{C}$ for $1 \mathrm{~min}, 100-300{ }^{\circ} \mathrm{C}$ at $8{ }^{\circ} \mathrm{C} \mathrm{min}{ }^{-1}$ and $300{ }^{\circ} \mathrm{C}$ for $5 \mathrm{~min}$. The phytohormone derivates were detected by negative chemical ionization, with ammonia as ionization gas. For quantification, the diagnostic ions m/z 215 (D6-JA; Rf = 14.09, $14.45 \mathrm{~min}$ ), $209(\mathrm{JA} ; \mathrm{Rf}=14.15,14.52 \mathrm{~min}), 141(\mathrm{D} 5-\mathrm{SA} ; \mathrm{Rf}=9.16 \mathrm{~min})$, and $137(\mathrm{SA} ; \mathrm{Rf}=9.20 \mathrm{~min}), 296$ ( $D_{5}$-oPDA, $R_{f}=20.79,21.17,21.51$ ), 291 (oPDA, $R_{f}=20.81,21.21,21.57$ ), 263 (dn-oPDA, $R_{f}=$ 18.94, 19.36, 19.70), $325\left(D_{3}\right.$-JA-Leu, $\left.R_{f}=20.87\right)$ and 322 (JA-lle, $\left.R_{f}=21.06\right)$ were used. Peaks were smoothened and data were assessed using Xcalibur software (ThermoFinnigan, Austin, Texas, USA).

\subsubsection{Phytohormone analysis via LC/MS}

Extraction of coi1-1, coi1-t and corresponding wild type material for LC/MS-based analysis (RPHPLC coupled to MS) of phytohormones was conducted according to Matyash et al (2008) as follows: $200 \mathrm{mg}$ of frozen plant powder were thawed in $0.75 \mathrm{ml}$ of methanol containing $10 \mathrm{ng}$ $\mathrm{D}_{6}$-SA (CDN Isotopes, Quebec, Canada), $10 \mathrm{ng} \mathrm{D}_{6}$-JA, 30 ng $\mathrm{D}_{5}$-OPDA, 10 ng $\mathrm{D}_{4}$-jasmonic acidleucine ( $\mathrm{D}_{4}$-JA-Leu) (all three kindly provided by Dr. Otto Miersch, Martin Luther University, Halle, Germany), 10 ng $D_{5}$-IAA (Eurisotop, Freising, Germany) each as internal standard. After vigorous mixing, $2.5 \mathrm{ml}$ of methyl-tert-butyl ether (MTBE) were added and the extract was shaken for $1 \mathrm{~h}$ at room temperature. For phase separation, $0.625 \mathrm{ml}$ water was added. The mixture was incubated for $10 \mathrm{~min}$ at room temperature and centrifuged for $15 \mathrm{~min}$ with $450 \times \mathrm{g}$. The upper phase was collected and the lower phase was reextracted with $0.7 \mathrm{ml}$ methanol and $1.3 \mathrm{ml}$ MTBE as described above. The combined upper phases were dried under 
streaming nitrogen and resuspended in $100 \mu \mathrm{l}$ of acetonitrile/dd $\mathrm{H}_{2} \mathrm{O} /$ acetic acid (20:80:0.1, $\mathrm{v} / \mathrm{v} / \mathrm{v})$.

Phytohormone analysis via LC/MS, allows the separation followed by identification and quantification of molecules, similar to GC/MS analysis, with the difference of separation in gaseous phase via GC/MS and separation in liquid phase via LC/MS.

In contrast to MS used in GC-coupled MS analysis, the HPLC-separated compounds using LC/MS exist already as ions in the liquid surrounding of HPLC. Atmospheric pressure ionisation technique is used to eliminate the solvent and to generate ions in the gaseous phase (Agilent Technologies, 2001). Electrospray ionisation (Fenn et al, 1989) generates different precursor ions, so-called parent ions, that may form different adducts like protonated ions $\left([\mathrm{M}+\mathrm{H}]^{+}\right)$, deprotonated ions $\left([\mathrm{M}-\mathrm{H}]^{-}\right)$and ammonium adducts $\left(\left[\mathrm{M}+\mathrm{NH}_{4}\right]^{+}\right)$, sodium adducts $\left([\mathrm{M}+\mathrm{Na}]^{+}\right)$, chloride adducts $\left([\mathrm{M}+\mathrm{Cl}]^{-}\right)$and acetate adducts $\left(\left[\mathrm{M}+\mathrm{CH}_{3} \mathrm{COO}\right]^{-}\right)$, depending on the solvent used. These parent ions are selected using either positive or negative ionization mode.

\subsection{HPLC/ QLIT-MS analysis}

Quadrupole-linear ion trap (QLIT)-MS consists of a quadrupole and a linear ion trap separated by a collision cell. Therefore, the analyte ions move from the source to the detector passing through first quadrupole, second collision cell and later ion trap, where they can be analyzed by different types of MS/MS experiments (Agilent Technologies, 2001). The quadrupole is employed as a mass filter and composed of four metallic rods arranged in a square. The two opposite rods are set at positive potential and the other two opposite rods at negative potential. The analyte ions generated in the source are directed to the centre of the four rods, where a combination of direct voltage and radio frequency controls the trajectory of the analyte ions through the quadrupole and just ions with certain values of $\mathrm{m} / \mathrm{z}$ are able to pass through the quadrupole for detection, while all other ions are thrown out of the original path. The passed ions are fragmented in the collision cell by collision-induced dissociation using argon or helium as a collision gas to produce the particular fragments, which are then separated by a linear ion trap and detected due to the electric current they cause.

An Agilent 1100 HPLC system (Agilent, Waldbronn, Germany) coupled to an Applied Biosystems 3200 hybrid triple quadrupole/linear ion trap mass spectrometer (MDS Sciex, Ontario, Canada) was used. Nanoelectrospray (nanoESI) analysis was achieved using a chip ion source (TriVersa NanoMate; Advion BioSciences, Ithaca, NY, USA). RP-HPLC separation was performed on an EC 50/2 Nucleodure $C_{18}$ gravity $1.8 \mu \mathrm{m}$ column $(50 \times 2.1 \mathrm{~mm}, 1.8 \mu \mathrm{m}$ particle size; Macherey and Nagel, Düren, Germany). The binary gradient system consisted of solvent $A$, acetonitrile/water/acetic acid (20:80:0.1, v/v/v) and solvent $B$, acetonitrile/acetic 
acid (100:0.1, v/v) with the following gradient program: $10 \%$ solvent $B$ for 2 min, followed by a linear increase of solvent B up to $90 \%$ within 6 min and an isocratic run at $90 \%$ solvent B for

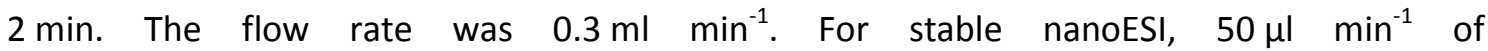
isopropanol/acetonitrile/water/formic acid (70:20:10:0.1, v/v/v/v) delivered by a 2150 HPLC pump (LKB, Bromma, Sweden) were added just after the column via a mixing tee valve. By using another post column splitter $740 \mathrm{nl} \mathrm{min}^{-1}$ of the eluent were directed to the nanoESI chip. Ionization voltage was set to $-1.7 \mathrm{kV}$. Phytohormones were ionized in a negative mode and determined in multiple reaction monitoring mode. Mass transitions were as follows: 141/97 [declustering potential (DP) $-45 \mathrm{~V}$, entrance potential (EP) $-7 \mathrm{~V}$, collision energy (CE) $22 \mathrm{~V}$ ] for $D_{6}-\mathrm{SA}, 137 / 93$ (DP -45 V, EP -7 V, CE -22 V) for SA, 215/59 (DP -45 V, EP -9.5 V, CE 22 V) for $D_{6}-\mathrm{JA}, 209 / 59$ (DP -45 V, EP -9.5 V, CE -22 V) for JA, 296/170 (DP -70 V, EP -8.5 V, CE $28 \mathrm{~V}$ ) for $D_{5}$-OPDA, 291/165 (DP -70 V, EP -8.5 V, CE -28 V) for OPDA, 263/59 (DP -70 V, EP 8.5 V, CE -28 V) for dinor-oPDA, 325/133 (DP -80 V, EP -4 V, CE -30 V) for $\mathrm{D}_{4}$-JA-Leu and $322 / 130$ (DP $-80 \mathrm{~V}, \mathrm{EP}-4 \mathrm{~V}, \mathrm{CE}-30 \mathrm{~V}$ ) for JA-lle. The mass analyzers were adjusted to a resolution of $0.7 \mathrm{amu}$ full width at half-height. The ion source temperature was $40^{\circ} \mathrm{C}$, and the curtain gas was set at 10 (given in arbitrary units). The data were smoothed and peak areas were integrated using Applied Biosystems Analyst software. The quantification was carried out by comparison to internal standards using a calibration curve (unlabeled/deuterium-labeled) vs. molar amounts of unlabeled (0.3-1000 pmol). 


\section{RESULTS}

In previous experiments, it had been shown that both $\mathrm{JA}$ and $\operatorname{Ins} \mathrm{P}_{3}$ signals occur in parallel during the Arabidopsis wound response. dde2-2 mutants, deficient in JA biosynthesis, were not able to accumulate $\operatorname{Ins}_{3}$ upon wounding, indicating $\mathrm{JA}$ as an upstream factor of Ins $\mathrm{P}_{3}$. It was the aim of this study to elucidate the impact of PI signals during the Arabidopsis wound response and defence reactions, and to further characterize the relation and dependency between $\mathrm{JA}$ and $\mathrm{PI}$ signalling.

\subsection{JA acts upstream of PI signals}

\subsubsection{Sorbitol treatment induces Ins $\mathrm{P}_{3}$ formation}

To test whether JA treatment is sufficient to induce $\mathrm{InsP}_{3}$ signals, whole Arabidopsis rosettes were floated on a $50 \mu \mathrm{M}$ MeJA solution for different time spans up to $4 \mathrm{~h}$ and $\operatorname{lnsP}_{3}$ levels were determined. Control plants were floated on water. As depicted in Fig. $6 \mathrm{~A}$, an increase of InsP $\mathrm{P}_{3}$ levels was neither detectable upon floatation on $\mathrm{H}_{2} \mathrm{O}$ nor after MeJA application. Since technical problems of MeJA application, preventing MeJA from reaching its target within the plant leaves, cannot be excluded, endogenous JA release was triggered by exposing hydroponically cultured plants to $0.8 \mathrm{M}$ sorbitol (Fig. 6 B; Reinbothe et al, 1994; Stenzel et al, 2003b; Weichert et al, 2000). While water treated plants displayed InsP $\mathrm{P}_{3}$ levels of $3.6 \pm 1.9$ to $7.8 \pm 4.0 \mathrm{nmol} \mathrm{g}^{-1}$ fresh weight, $\operatorname{InsP}_{3}$ levels in sorbitol treated plants increased to $39.6 \pm 7.9 \mathrm{nmol} \mathrm{g}^{-1}$ fresh weight already $15 \mathrm{~min}$ after application and found their maximum $30 \mathrm{~min}$ after application with $49.3 \pm 24.8 \mathrm{nmol} \mathrm{g}^{-1}$ fresh weight. After one hour of treatment, Ins $_{3}$ levels declined to $34.8 \pm 16.0 \mathrm{nmol} \mathrm{g}^{-1}$ fresh weight and still strongly exceeded water treated controls, in which only amounts of $4.5 \pm 3.4 \mathrm{nmol} \operatorname{lnsP}_{3} \mathrm{~g}^{-1}$ fresh weight were detectable. While exogenous application of MeJA did not induce substantial $\operatorname{lns}_{3}$ formation, sorbitol treatment caused strong $\operatorname{InsP}_{3}$ accumulation even exceeding that previously observed with $1 \mathrm{~h}$ of wound treatment, which had resulted in $\mathrm{InsP}_{3}$ amounts of $19.6 \pm 6.4 \mathrm{nmol} \mathrm{g}{ }^{-1}$ (Mosblech et al, 2008). 
A

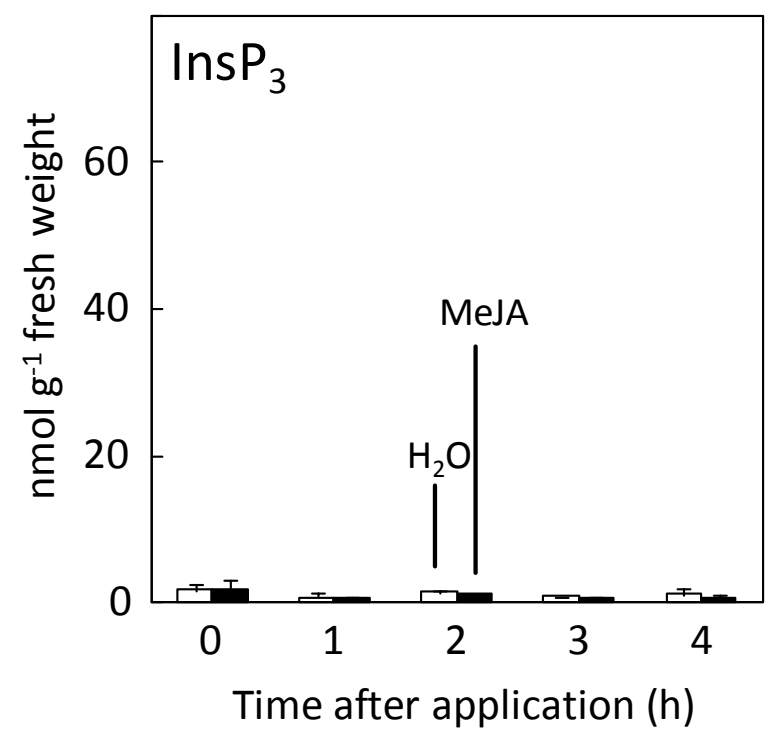

B

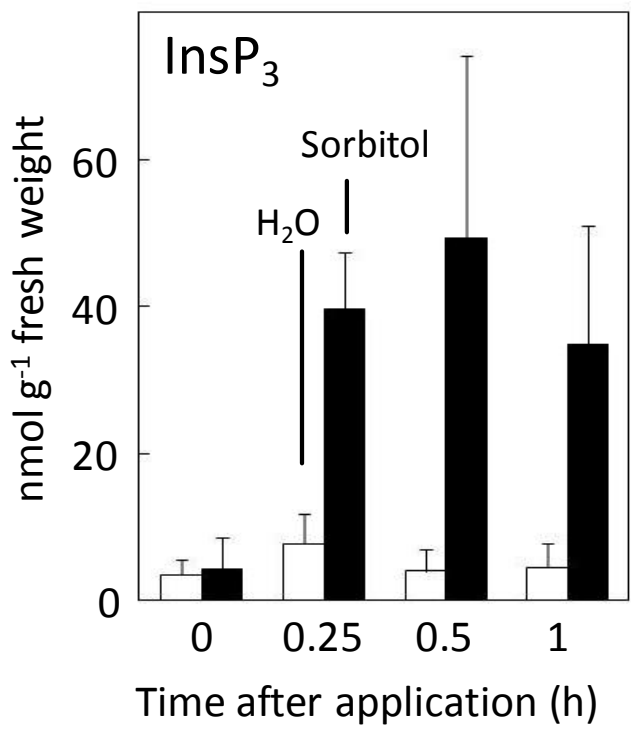

Fig. 6: InsP $\mathrm{P}_{3}$ induction with application of MeJA or sorbitol. (A) 5-week-old plants were floated on a $50 \mu \mathrm{M}$ MeJA solution (black bars) and harvested after times indicated. Controls were floated on water (white bars). (B) Hydroponically grown plants were treated by addition of sorbitol to the nutrient solvent (black bars). Controls were treated with water (white bars). Data are the means of two independent experiments, each assayed in duplicates, \pm SD.

\subsection{PI signals are required for full induction of wound-inducible genes}

It was shown in experiments performed during my diploma thesis that PI signals are involved in the Arabidopsis wound response, indicated by the accumulation of $\operatorname{Ins} \mathrm{P}_{3}$. To investigate the impact of PI signals, Ins P 5-ptase plants with global reduction of PI signalling components (König et al, 2007; Perera et al, 2006) were now wounded and analysed for downstream responses.

A number of wound-inducible genes was selected for analysis of their specific transcript levels by real-time RT-PCR (Fig. 7): AOS (Park et al, 2002) and VSP1, encoding the vegetative storage protein1 (Benedetti et al, 1995; Liu et al, 2005), both require JA for wound induction. In contrast, OPR1 and RNS1, encoding OPDA reductase and ribonuclease1, respectively, are both induced by wounding independently of JA (Reymond et al, 2000). Also investigated were the transcription factor WRKY7O ( $\mathrm{Li}$ et al, 2006) and the Kunitz-family (Bauw et al, 2006) protease inhibitor T18K17.7 encoded by the gene locus At1g73260.

Real-time RT-PCR analysis of wild type plants confirmed that transcript levels for AOS, OPR1, RNS1, VSP1, WRKY70, and T18K17.7 were all wound-inducible (Fig. 7, white bars). In InsP 5ptase plants, wound induction of the genes tested was either transiently or overall reduced 
(Fig. 7, black bars) in comparison to that observed in wild type plants. Altered gene expression patterns in InsP 5-ptase plants included attenuated wound induction early after wounding $(A O S)$, delayed wound induction (OPR1), or attenuated wound induction at later time points (RNS1, WRKY70, T18K17.7).
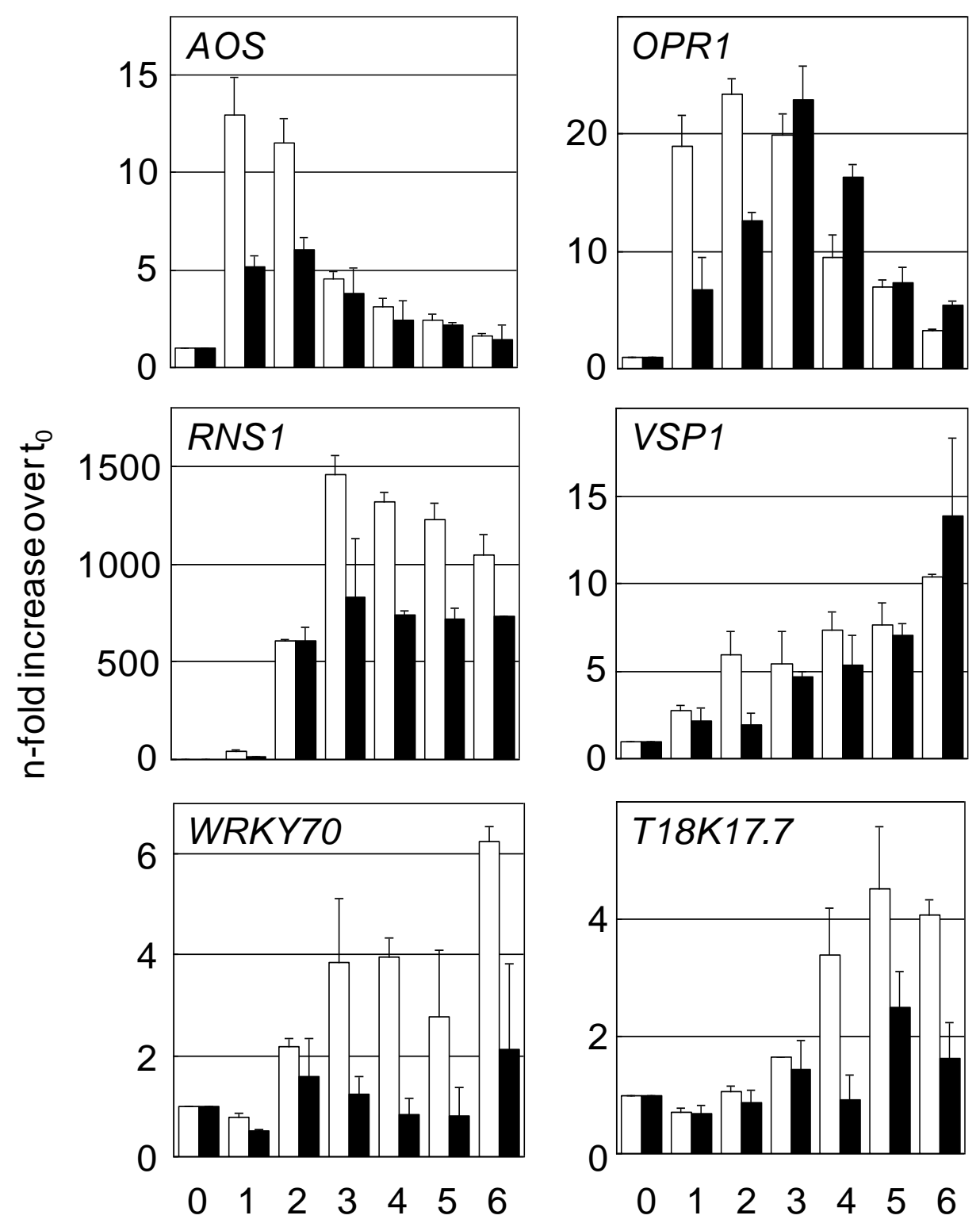

\section{Time after wounding $(\mathrm{h})$}

Fig. 7: Reduced induction of wound-inducible genes in InsP 5-ptase plants. Wild type (white bars) and InsP 5-ptase (black bars) plants were mechanically wounded and transcript levels were determined vie real-time RT-PCR over $6 \mathrm{~h}$ at time points indicated. Data are the mean of two biological replicates and given as the fold increase over transcript levels in non-wounded control plants, \pm SD. AOS, allene oxide synthase; OPR1, OPDA reductase; RNS1, ribonuclease $1 ;$ VSP1, vegetative storage protein1; WRKY70, WRKY-family transcription factor; T18K17.7, Kunitz-family trypsin and protease inhibitor. 


\subsection{PI signals are required for functional defence against caterpillars}

In addition to changes in transcript levels of wound-inducible genes, active defence of Arabidopsis plants against insect herbivory was assessed by monitoring caterpillar growth performance during feeding on wild type plants, InsP 5-ptase plants, or dde2-2 plants (Fig. 8). P. xylostella caterpillars of approximately equal developmental stages and weight were placed on leaves of 6-week-old plants and allowed to feed. The increase in caterpillar weight was then monitored over several days. Fig. 8 illustrates the relative caterpillar weight increase over 56 h; absolute values are summarized in Table 1. Caterpillars feeding on InsP 5-ptase plants or on dde2-2 plants exhibited significantly increased mean growth rates of $53 \pm 8 \mu \mathrm{g} \mathrm{h}^{-1}$ and $68 \pm 38 \mu \mathrm{g} \mathrm{h}^{-1}$, respectively, and a weight increase to $328 \%$ and $334 \%$ of initial weight,

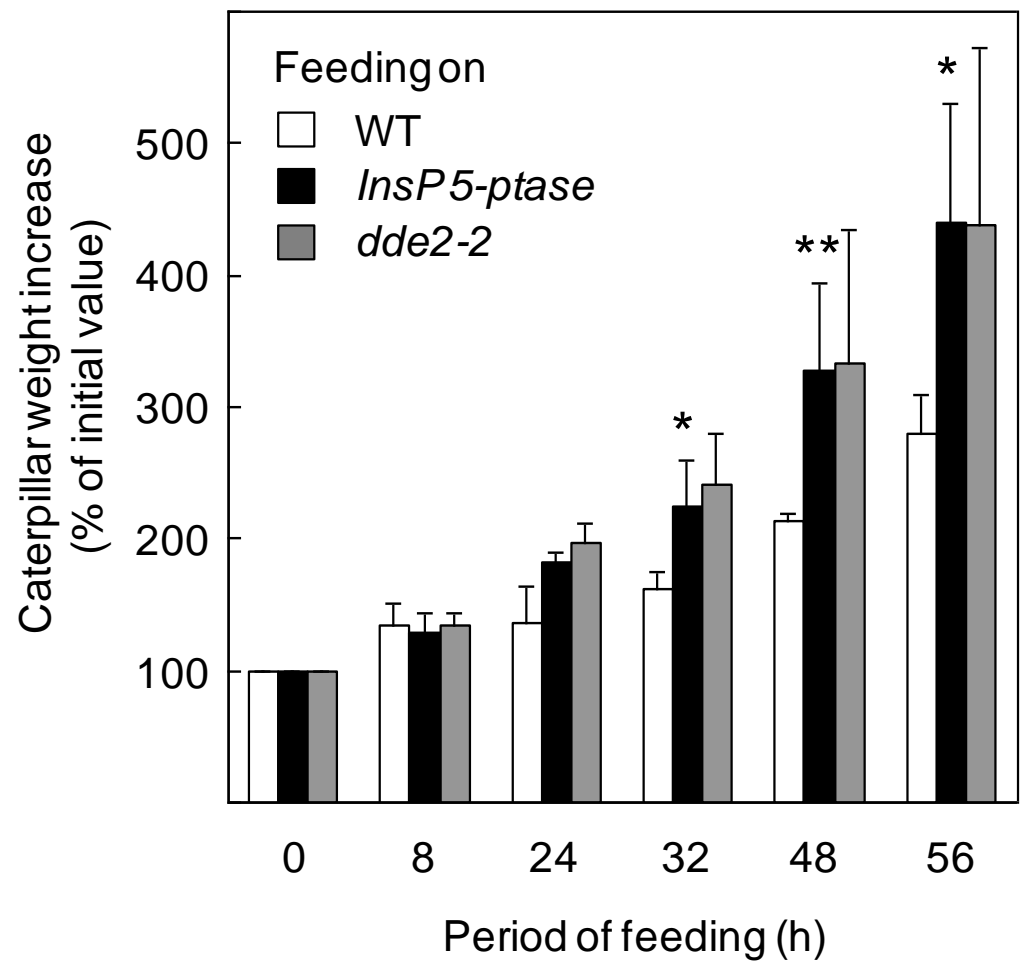

Fig. 8: Caterpillar growth performance with feeding on wild type, InsP 5-ptase or dde2-2 plants. 10-12 diamondback moth caterpillars (Plutella xylostella) of initially $\sim 1 \mathrm{mg}$ were allowed to feed on wild type plants (white bars), on InsP 5-ptase plants (black bars) or on dde2-2 plants (grey bars) for time periods indicated. Caterpillar weight was determined and they were allowed to continue feeding afterwards. Data were normalized against caterpillar weights at time zero and are given as percent increase over the time zero value. Data are presented from three independent biological experiments, \pm SD, with 30-36 caterpillars per experiment and plant line. Asterisks indicate significant increases in caterpillar growth with feeding on transgenic plants compared with feeding on wild type plants, according to a student's $t$ test $(*, p, 0.05 ; * *, p, 0.01)$. 
Table 1. Weight increase of Plutella xylostella caterpillars feeding on different Arabidopsis lines. Ten to twelve caterpillars of initially $\sim 1 \mathrm{mg}$ were allowed to feed on wild type, InsP 5-ptase, or dde2-2 plants for various time periods. Caterpillar weight was determined at the times indicated, and caterpillars were allowed to continue feeding. Data are the mean of three independent biological experiments, each conducted with 30-36 caterpillars per plant line. Numbers represent mean weight per caterpillar in mg \pm SD. Rates of weight increase calculated from caterpillar net weight increases are given as $\mu \mathrm{g} \mathrm{h}^{-1}$.

\begin{tabular}{cccccccc}
\hline $\begin{array}{c}\text { Period } \\
\text { of } \\
\text { feeding }\end{array}$ & 0 & $8 \mathrm{~h}$ & $24 \mathrm{~h}$ & $32 \mathrm{~h}$ & $48 \mathrm{~h}$ & $56 \mathrm{~h}$ & $\begin{array}{c}\text { Rate of } \\
\text { increase } \\
{\left[\mu \mathrm{h} \mathrm{h}^{-1}\right]}\end{array}$ \\
\hline $\begin{array}{c}\text { wild } \\
\text { type }\end{array}$ & $0.95 \pm 0.13$ & $1.30 \pm 0.35$ & $1.26 \pm 0.16$ & $1.53 \pm 0.18$ & $2.03 \pm 0.35$ & $2.69 \pm 0.67$ & $31 \pm 10$ \\
$\begin{array}{c}\text { InsP 5- } \\
\text { ptase }\end{array}$ & $0.96 \pm 0.26$ & $1.25 \pm 0.39$ & $1.76 \pm 0.53$ & $1.97 \pm 0.49$ & $2.98 \pm 0.33$ & $3.95 \pm 0.37$ & $53 \pm 8$ \\
dde2-2 & $1.30 \pm 0.42$ & $1.76 \pm 0.62$ & $2.60 \pm 1.00$ & $3.24 \pm 1.27$ & $4.48 \pm 1.99$ & $5.09 \pm 2.40$ & $68 \pm 38$ \\
\hline
\end{tabular}

respectively, within $48 \mathrm{~h}$. In comparison, caterpillars feeding on wild type plants reached only $213 \%$ of initial weight during this time span, which corresponds to a growth rate of only $31 \pm 10 \mu \mathrm{g} \mathrm{h}^{-1}$. Caterpillar weight increase with feeding on InsP 5-ptase plants was, thus, similar to that observed on dde2-2 plants, and both these data sets differed significantly from that observed with feeding on wild type plants (Fig. 8).

\subsection{Oxylipins accumulate in InsP 5-ptase plants}

The first obvious difference between caterpillars feeding on wild type plants and feeding on InsP 5-ptase plants was observed after $24 \mathrm{~h}$ of feeding (Fig. 8). To investigate how oxylipins were affected in InsP 5-ptase plants during this extended period, JA precursors, JA and JA-lle were determined by GC/MS, covering the time span of $24 \mathrm{~h}$ after wounding (Fig. 9).

All oxylipins measured displayed stronger wound-induced accumulation in InsP 5-ptase plants compared to wild type controls. OPDA levels of InsP 5-ptase plants exceeded those from wild type plants on average by about one third up to 2.5 -fold, while dn-oPDA levels of InsP 5-ptase plants exceeded wild type levels much stronger by about two thirds till 6-7-fold. For both compounds, the oxylipin levels of wild type plants displayed a pronounced increase $4 \mathrm{~h}$ after wounding from $0.17 \pm 0.08$ to $3.63 \pm 1.06$ in oPDA and from $0.03 \pm 0.01$ to $1.44 \pm 0.97 \mathrm{nmol} \mathrm{g}^{-1}$ 

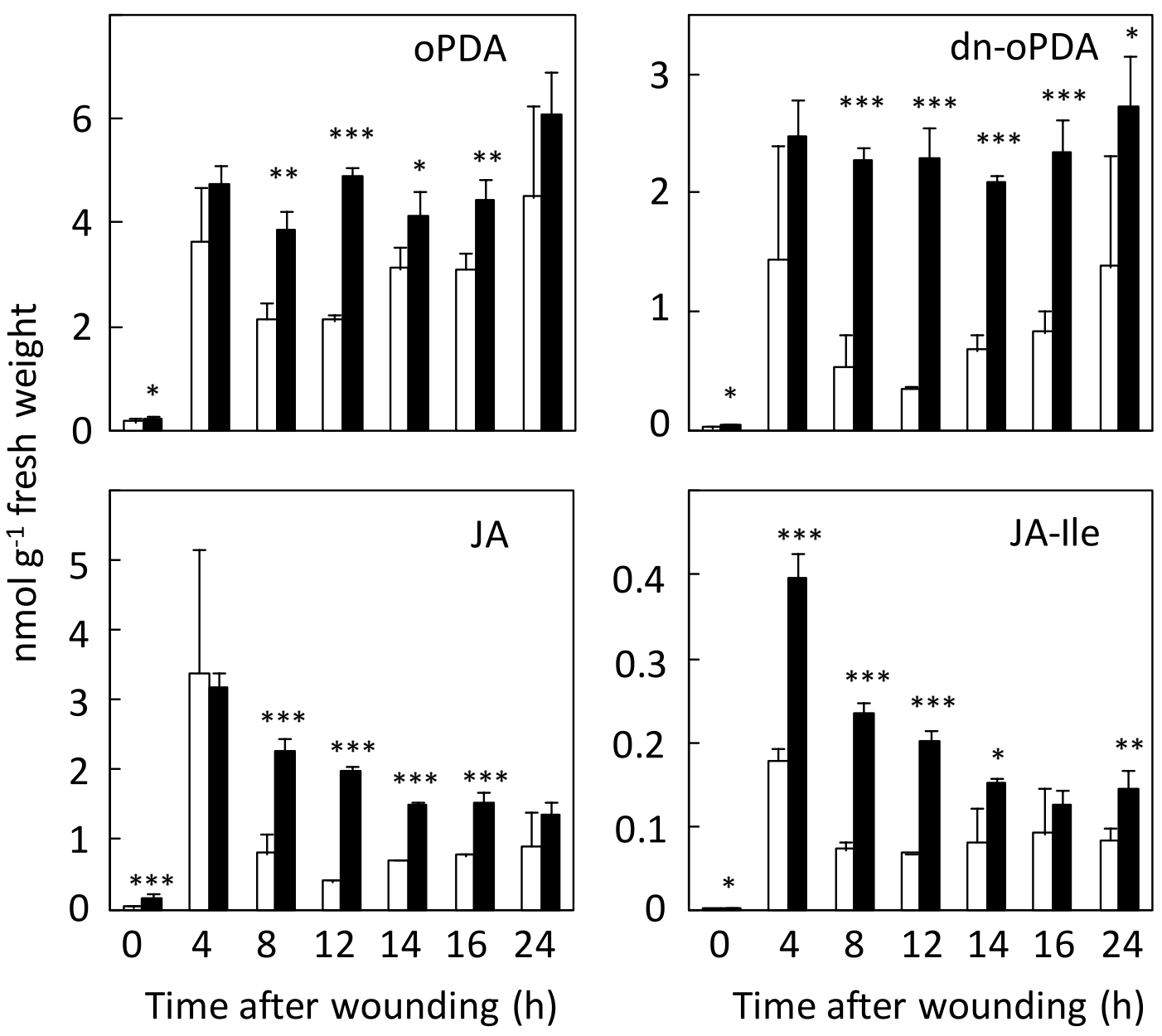

Fig. 9: Wound-induced oxylipins in InsP 5-ptase plants, impaired in PI signalling. Rosette leaves of 7week-old plants were wounded with forceps and harvested after the indicated times. Oxylipins were determined via GC/MS in wild type plants (white columns) and InsP 5-ptase (black columns) over $24 \mathrm{~h}$. The mean values of two independent wounding experiments are shown, each assayed in duplicates, and each duplicate measured twice, \pm SD. Missing error bars are too small to appear. Asterisks indicate significant differences between level detected in wild type and in InsP 5-ptase plants at the respective time point, according to a student's $t$-test $(*, p \leq 0.1 ; * *, p \leq 0.01 ; * * *, p \leq 0.001)$.

fresh weight in dn-oPDA, which declined until $12 \mathrm{~h}$ after wounding to $2.13 \pm 0.09 \mathrm{nmol} \mathrm{g}^{-1}$ fresh weight of OPDA and to $0.35 \pm 0.02 \mathrm{nmol} \mathrm{g}^{-1}$ fresh weight of dn-oPDA. Afterwards, the levels rose again to reach their maximum of $4.50 \pm 1.75 \mathrm{nmol} \mathrm{g}^{-1}$ fresh weight of OPDA and $1.38 \pm 0.93 \mathrm{nmol} \mathrm{g}^{-1}$ fresh weight of dn-oPDA $24 \mathrm{~h}$ after wounding. In contrast, InsP 5-ptase plants displayed a rather constant pattern after wound induction of in average $4.69 \pm 0.71$ of oPDA and $2.37 \pm 0.20 \mathrm{nmol} \mathrm{g}^{-1}$ fresh weight of dn-oPDA (Fig. 9).

As reported before in my diploma thesis, JA levels were similar between wild type and InsP 5ptase plants at early time points also in the experiments of this thesis (here: $4 \mathrm{~h}$ after wounding, $3.39 \pm 0.02 \mathrm{nmol} \mathrm{g}^{-1}$ fresh weight in wild type, $3.18 \pm 0.22 \mathrm{nmol} \mathrm{g}^{-1}$ fresh weight in 
InsP 5-ptase). By $8 \mathrm{~h}$ after wounding, wild type JA levels dropped by about three quarters to $0.81 \pm 0.27 \mathrm{nmol} \mathrm{g}^{-1}$ fresh weight, whereas JA levels in InsP 5-ptase plants only dropped by less than one third to $2.26 \pm 0.20 \mathrm{nmol} \mathrm{g}^{-1}$ fresh weight, thereby exceeding wild type levels for all later time points monitored (Fig. 9). Wound-induced JA-lle levels increased in InsP 5-ptase plants over wild type levels by about one third to 3.5 times, with the strongest differences in early time points (Fig. 9). $4 \mathrm{~h}$ after wounding, wild type JA-lle levels were $0.18 \pm 0.02 \mathrm{nmol} \mathrm{g}^{-1}$ fresh weight, while InsP 5-ptase plants exhibited JA-lle levels of $0.40 \pm 0.03 \mathrm{nmol} \mathrm{g}^{-1}$ fresh weight. JA and JA precursors showed only minor differences to wild type levels in InsP 5-ptase plants during $6 \mathrm{~h}$ of wound stimulus (Mosblech et al, 2008), in contrast the levels of these oxylipins and importantly the bioactive form JA-lle substantially exceeded wild time levels in the time period of $24 \mathrm{~h}$ after wounding.

The data obtained from InsP 5-ptase plants indicate a combination of lowered wound-induced gene expression and reduced defence against caterpillars accompanied by increased accumulation of JA-lle over wild type levels. This pattern suggests partial JA insensitivity of the InsP 5-ptase plants. To test this concept, control experiments were conducted with coi1 mutants, which represent established JA-insensitive plants.

\subsection{A new T-DNA insertion line, coi1-t}

The commonly used EMS line coi1-1 (Feys et al, 1994) carries a point mutation within the last exon of the COI1 gene, resulting in a premature stop codon. coi1-1 mutants are male sterile and are propagated heterozygously. Homozygous, heterozygous and wild type individuals can be distinguished by phenotypes manifesting when grown on media containing MeJA. Whereas wild type plants respond to MeJA treatment with severely reduced growth in both roots and green parts (Feys et al, 1994; Xie et al, 1998), individuals homozygous for coi1 display normal growth and heterozygous plants exhibit an intermediate phenotype under these conditions. Since the point mutation of coi1-1 mutants is difficult to genotype, an Arabidopsis T-DNA insertion line was established and named coi1-t (Fig. 10). This line carries a T-DNA insertion in the first exon of the coil gene at base pair 67 (Fig. 10 A). RT-PCR analysis revealed no detectable coi1 transcript in these plants (Fig. 10 B). 
A

T-DNA insertion

ATG

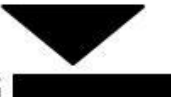

67 bp

B

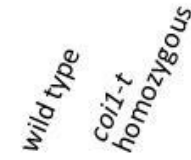

C

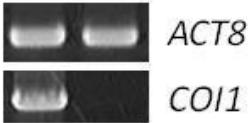

D

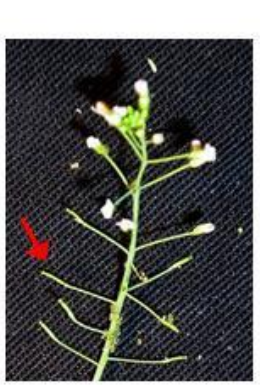

E
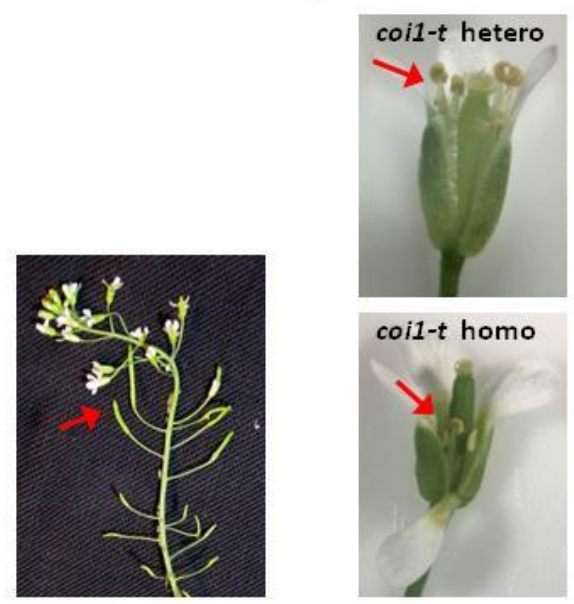

F

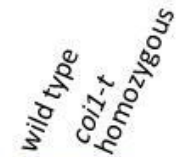

G
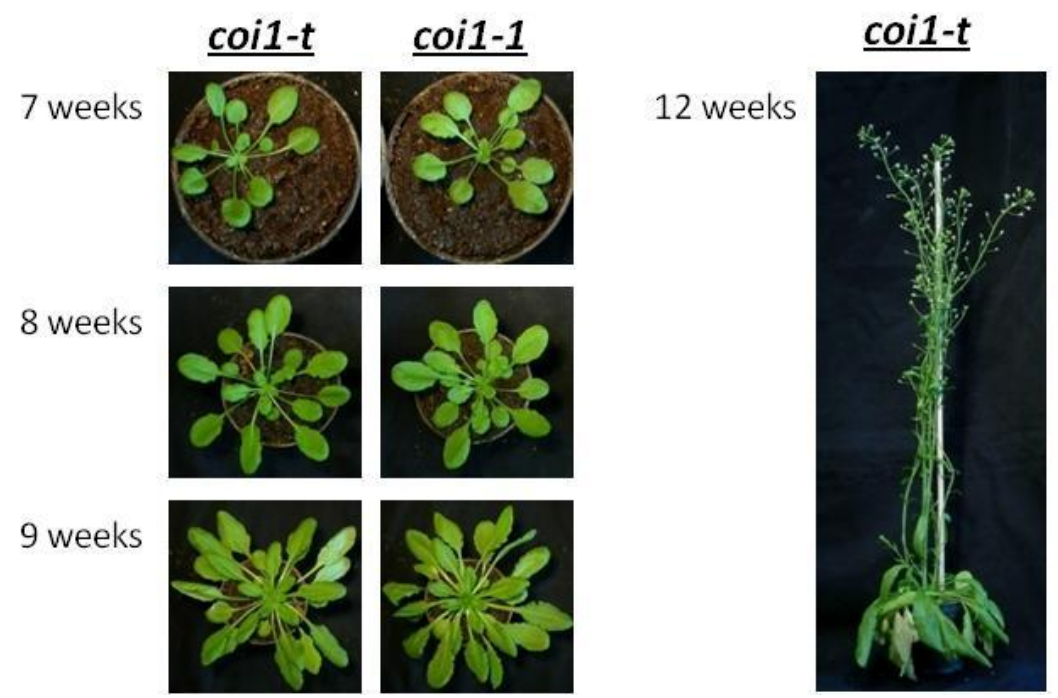

\section{coi1-1}

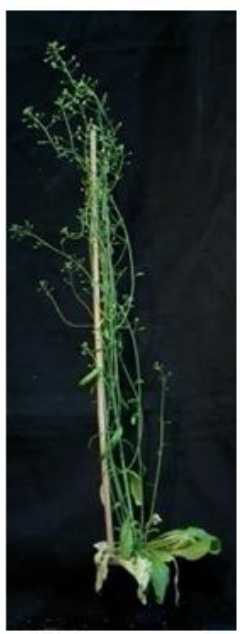

Fig. 10: coi1-t, a T-DNA insertion line lacking the JA receptor COI1. (A) COI1 gene structure with location of T-DNA insertion at base pair (bp) 67 within the first exon. The exact location of the insertion was determined by sequencing of the genomic locus. (B) COI1 transcript is present in wild type but absent in coi1-t plants. Transcript levels were determined by performing PCR with specific primers using CDNA as template. Control PCR was performed with specific primers for actin (ACT8). (C) Flower phenotype of coi1- $t$ stamina. Stamina of heterozygous coi1- $t$ plants (coi1- $t$ hetero) exhibiting normal length and stamina of homozygous coi1-t plants (coi1-t homo) exhibiting reduced length are highlighted by red arrows. (D+E) Sterility of coi1-t is restricted to male part. (D) coi1-t plants do not produce offspring, as their siliques do not carry seeds, see red arrow. (E) coi1-t plants produce offspring when pollinated with wild type pollen, see red arrow. (F) Impaired JA sensitivity of coi1-t when growing on agar plates containing $50 \mu \mathrm{M}$ MeJA. 4-week-old wild type seedlings exhibit reduced root growth (left side), while coi1-t seedlings exhibit normal root length (right side), see white arrow. (G) coi1-t plants (left side) exhibit similar growth compared to the established coi1-1 line (right side). 
To ensure that coi1-t plants can be used as a tool equivalent to the coi1-1 mutant described in the literature, JA-related phenotypes of coi1- $t$ were first characterized. As described for coi1-1 (Feys et al, 1994; Xie et al, 1998), coi1-t plants displayed male sterility, indicated by shortened stamina as depicted in Fig. $10 \mathrm{C}$, and abolished silique development, as depicted in Fig. $10 \mathrm{D}$. Female fertility was not affected, as flowers pollinated with wild type pollen developed normal siliques (Fig. $10 \mathrm{E}$ ). coi1-t seedlings vertically grown on media containing $50 \mu \mathrm{M}$ MeJA displayed normal growth (Fig. 10 F). In contrast, wild type seedlings grown under these conditions exhibited reduced growth and especially shortened roots, as indicated by white arrows in Fig. $10 \mathrm{~F}$. When further growth of coi1-1 and coi1-t on soil was monitored over a period of 12 weeks, no obvious growth differences were recorded (Fig. $10 \mathrm{G}$ ).

The obtained data indicate coi1- $t$ as a new COI1-deficient line, representing a valuable tool for JA-related studies.

\subsection{Accumulation of JA-lle in coi1 mutants}

The data obtained using InsP 5-ptase plants indicated a combination of lowered woundinduced gene expression and reduced defence against caterpillars accompanied by substantially increased accumulation of JA-lle over wild type levels. This pattern suggests partial JA insensitivity of the InsP 5-ptase plants.

In order to test this concept, and because no data on oxylipin levels are currently available for JA-insensitive plants, two independent Arabidopsis coi1 mutants lacking a functional JA receptor were tested for wound-induced JA-lle levels: the widely used EMS line coi1-1 (Feys et al, 1994) and the new T-DNA insertion line, coi1-t. In both COI1-deficient Arabidopsis lines, wound-induced levels of JA and its precursors OPDA and dn-OPDA showed induction upon wounding, but were reduced compared to wild type levels (Fig. 11). Wild type oPDA levels increased from $0.50 \pm 0.15$ to $3.77 \pm 0.51 \mathrm{nmol} \mathrm{g}^{-1}$ fresh weight $2 \mathrm{~h}$ after wounding and to $4.36 \pm 0.48 \mathrm{nmol} \mathrm{g}^{-1}$ fresh weight $4 \mathrm{~h}$ after wounding, whereas coi1-1 plants exhibited an increase from $0.29 \pm 0.02$ to $1.58 \pm 0.18$ and $1.27 \pm 0.28 \mathrm{nmol} \mathrm{g}^{-1}$ fresh weight, $2 \mathrm{~h}$ and $4 \mathrm{~h}$ 


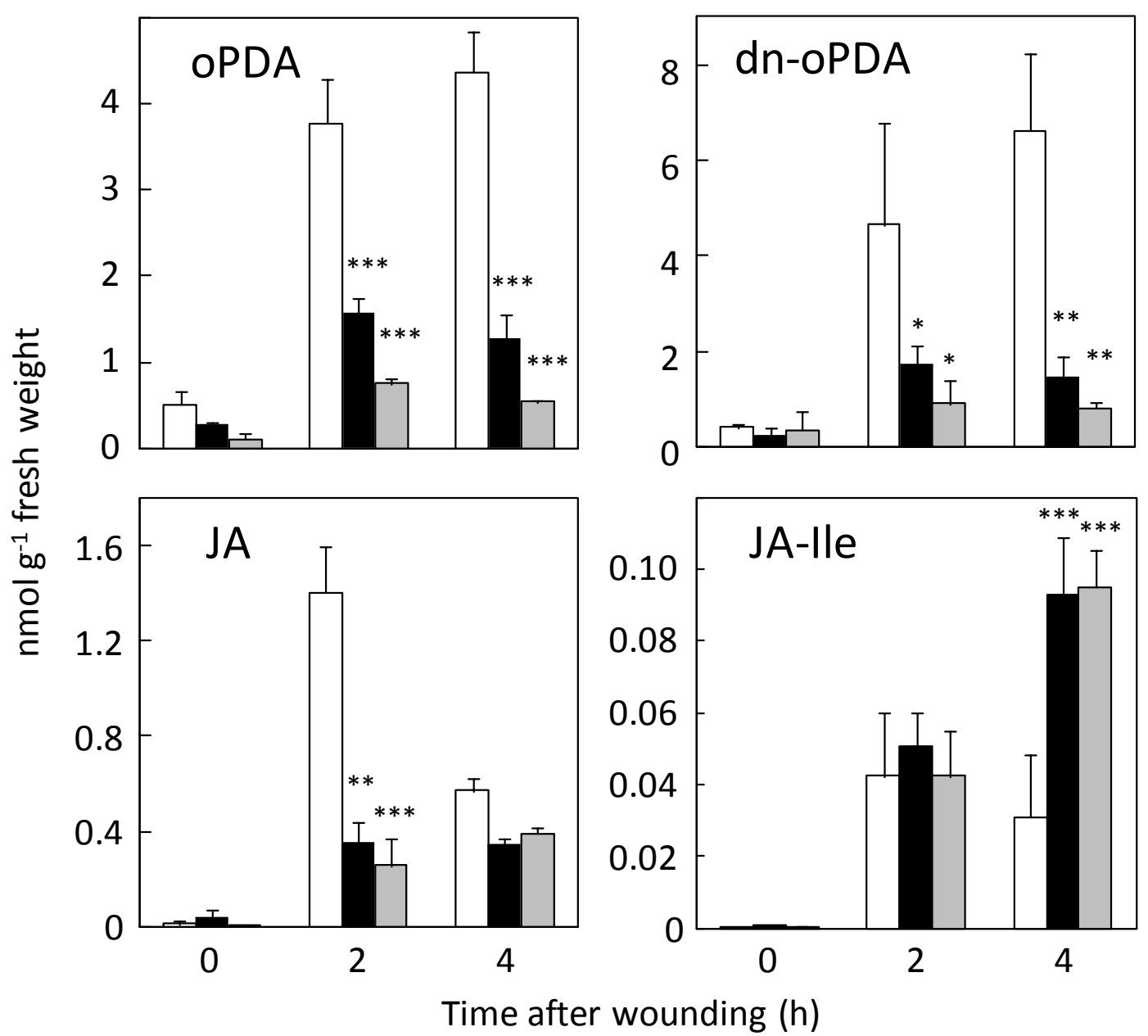

Fig. 11: Wound-induced oxylipin levels of JA-insensitive coi1 mutants. Rosette leaves of 7-week-old plants were wounded with forceps and harvested after indicated time spans. Oxylipins were determined via LC/MS in wild type plants (white columns), coi1-1 (black columns) and coi1-t (grey columns) over $24 \mathrm{~h}$. The mean values of two independent wounding experiments are shown assayed in duplicates, and each duplicate measured twice, \pm SD. Missing error bars are too small to appear. Asterisks indicate significant differences between levels detected in wild type and in coi1-1 or coi1-t plants, respectively, at the indicated time point, according to a student's $t$-test $\left(*, p \leq 0.1 ;{ }^{* *}, \mathrm{p} \leq 0.01 ;{ }^{* * *}, \mathrm{p} \leq 0.001\right)$.

after wounding, respectively. The oPDA rise in coi1-t was even slower, starting with $0.11 \pm 0.08 \mathrm{nmol} \mathrm{g}^{-1}$ fresh weight, increasing to $0.75 \pm 0.05$ and $0.54 \pm 0.02 \mathrm{nmol} \mathrm{g}^{-1}$ fresh weight. The described pattern closely resembled the induction of dn-OPDA, and also the JA induction pattern was similar, but instead of still rising from $2 \mathrm{~h}$ to $4 \mathrm{~h}$, JA levels declined in wild type plants from $1.40 \pm 0.19$ to $0.57 \pm 0.05 \mathrm{nmol} \mathrm{g}^{-1}$ fresh weight. Both coil mutant lines displayed a JA induction with wounding from levels close to detection limit (coi1-t, $0.04 \pm 0.03$, coi1-1, $0.00 \pm 0.00 \mathrm{nmol} \mathrm{g}^{-1}$ fresh weight) to nearly constant levels of $0.34 \pm 0.05 \mathrm{nmol} \mathrm{g}^{-1}$ fresh weight. Whereas levels of oPDA, dn-oPDA and JA were reduced in both coi1 mutant lines, JAIle levels were clearly elevated over wild type levels with wounding. Without stimulus, JA-Ile levels were close to detection limit in wild type, coi1-1 and coi1-t plants. After showing JA-lle 
levels similar to wild type $2 \mathrm{~h}$ after wounding $\left(0.042 \pm 0.018 \mathrm{nmol} \mathrm{g}^{-1}\right.$ fresh weight in wild type, $0.051 \pm 0.093 \mathrm{nmol} \mathrm{g}^{-1}$ fresh weight in coi1-1 and $0.042 \pm 0.095 \mathrm{nmol} \mathrm{g}^{-1}$ fresh weight in coi1-t), both coil mutants displayed a strong and prolonged further increase of JA-lle to a maximum of $0.093 \pm 0.016 \mathrm{nmol} \mathrm{g}^{-1}$ fresh weight in coi1-1 and $0.095 \pm 0.010 \mathrm{nmol} \mathrm{g}^{-1}$ fresh weight in coi1-t, whereas wild type levels dropped to $0.031 \pm 0.017 \mathrm{nmol} \mathrm{g}^{-1}$ fresh weight. Thereby coil mutants exceeded wild type JA-lle levels about 3-fold (Fig. 11).

To summarize this aspect of the data, in both InsP 5-ptase and coil mutant lines the levels of the bioactive JA-lle were highly abundant, but JA-mediated responses were reduced (Feys et al, 1994; Mosblech et al, 2008; Xie et al, 1998). The increased JA-lle levels in the JA-lleinsensitive coi1 mutants resemble the JA-lle pattern observed for InsP 5-ptase plants, thus supporting the notion of partial JA-Ile insensitivity of these plants. However, whereas in InsP 5ptase plants oxylipin precursors of JA-Ile were also elevated over wild type levels, these oxylipins displayed reduced wound induction in coi1 mutant plants. In coi1 plants the JA amino acid synthetase JAR1 seems to be activated while the other enzymes of JA biosynthesis seem to be suppressed, whereas all these enzymes seem to be similarly activated in InsP 5-ptase plants. To elucidate the link between JA metabolism and inositol-containing signalling factors, further experiments were performed.

\subsection{Amino acid residues coordinating an inositol polyphosphate cofactor in TIR1 are conserved in COI1}

Based on the notion that the crystal structure of the auxin receptor F-box protein, TIR1, contains InsP $_{6}$ as a cofactor (Tan et al, 2007), structural information of different F-box proteins was evaluated to delineate how inositol metabolites might be bound. An alignment of the amino acid sequences of TIR1, various AUXIN SIGNALLING F-BOX (AFB) proteins homologous to TIR1, and COI1 illustrates the sequence similarity between F-box proteins involved in auxin and JA perception (Fig. 12 A). The amino acid residues coordinating the Ins $\mathrm{P}_{6}$ cofactor in TIR1 are strictly conserved in all proteins involved in auxin perception. Importantly, five of these residues are also conserved in COI1. These findings led to the hypothesis that an inositol polyphosphate is also bound in COI1, and that altered JA sensitivity in InsP 5-ptase plants is mediated by an effect of an inositol polyphosphate cofactor on COI1 function. 
A

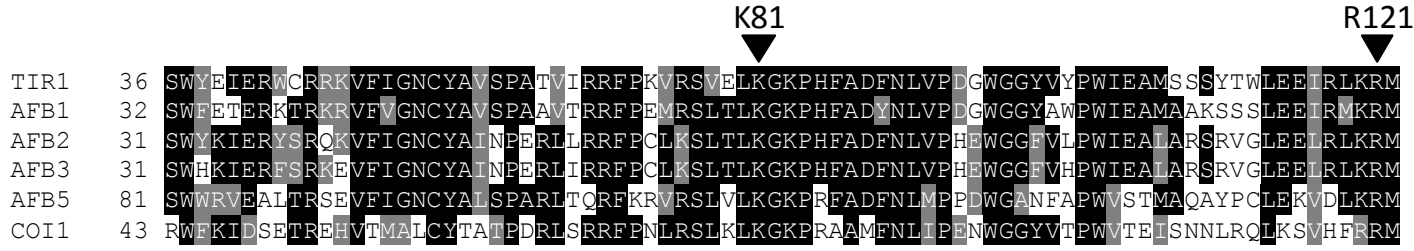

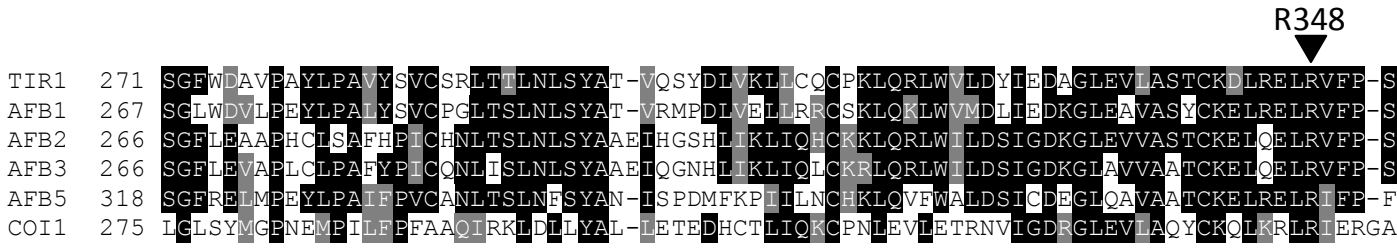

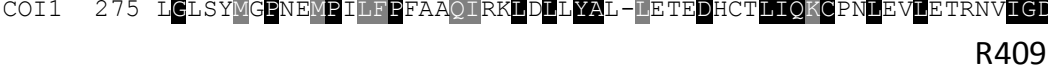

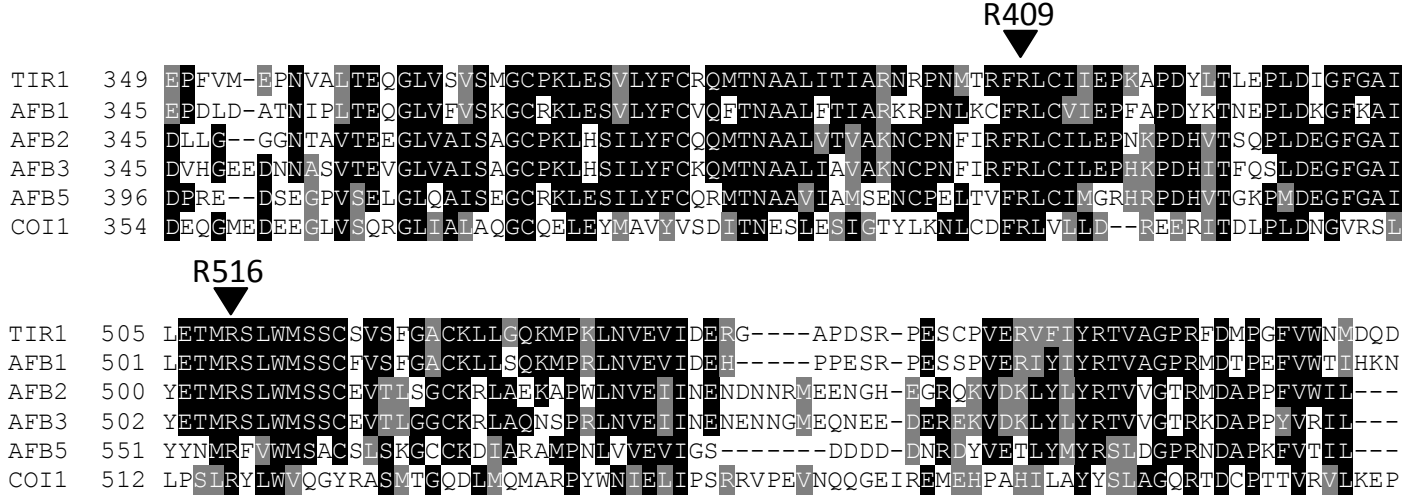

B

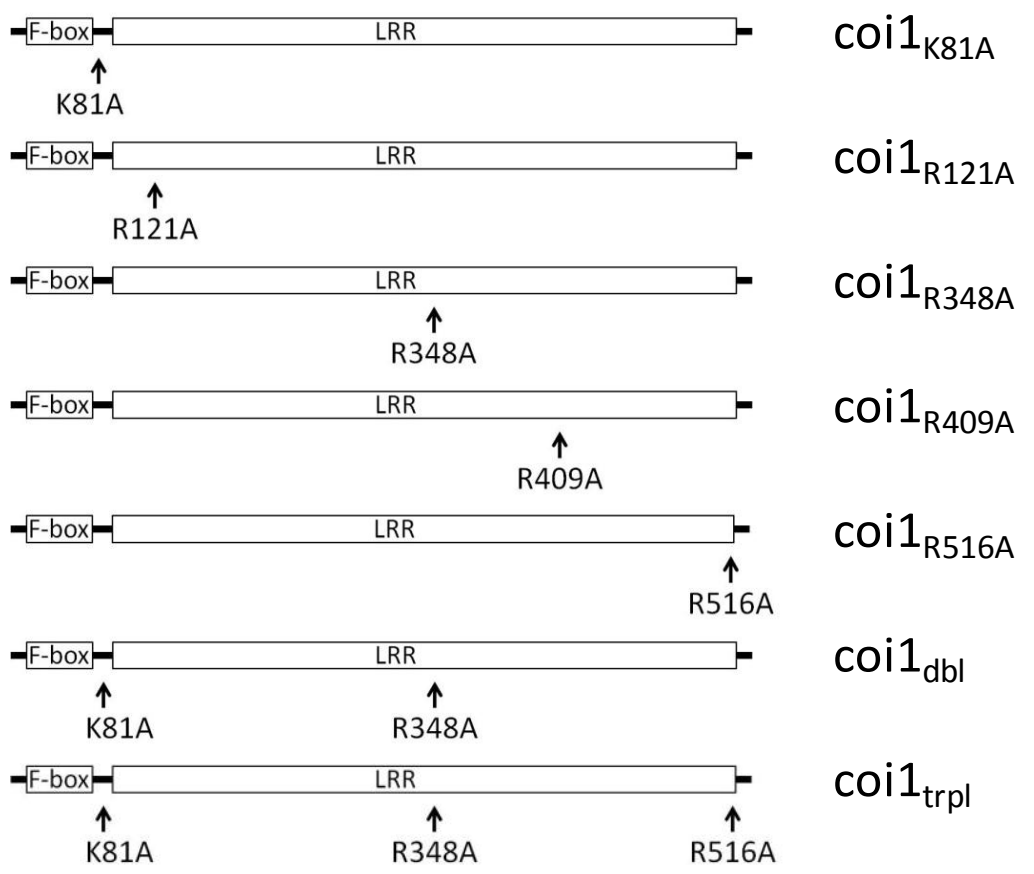

Fig. 12. Amino acid residues coordinating an inositol polyphosphate cofactor in TIR1 are conserved in COI1. (A) Partial sequence alignment of auxin binding E3 ubiquitin ligases TIR1, TIR1 homologues AFB1, 2, 3 and 5, and JA binding E3 ubiquitin ligase COI1. Putative inositol polyphosphate binding residues are marked with arrowheads. (B) Amino acid exchanges introduced into the COI1 protein. Graphical representation of COI1 with F-box domain and leucin-rich repeat (LRR) domain. Arrow heads indicate the individual positions altered in the different coi $1_{\text {mut }}$ variants, as indicated. 


\subsection{Putative inositol polyphosphate coordinating residues are required for COI1/JAZ9 interaction}

To test this hypothesis, cDNAs encoding various mutated variants of COI1 (coi $1_{\text {mut }}$ ) were created, in which single or multiple putative inositol polyphosphate coordinating amino acid residues of COI1 were exchanged to alanine residues (Fig. 12 B). These variants were first tested in yeast two-hybrid assays for their capability to interact with the COI1 target, JAZ9. The interaction was tested in the presence of coronatine, a potent JA-lle analogue (Fig 13). The

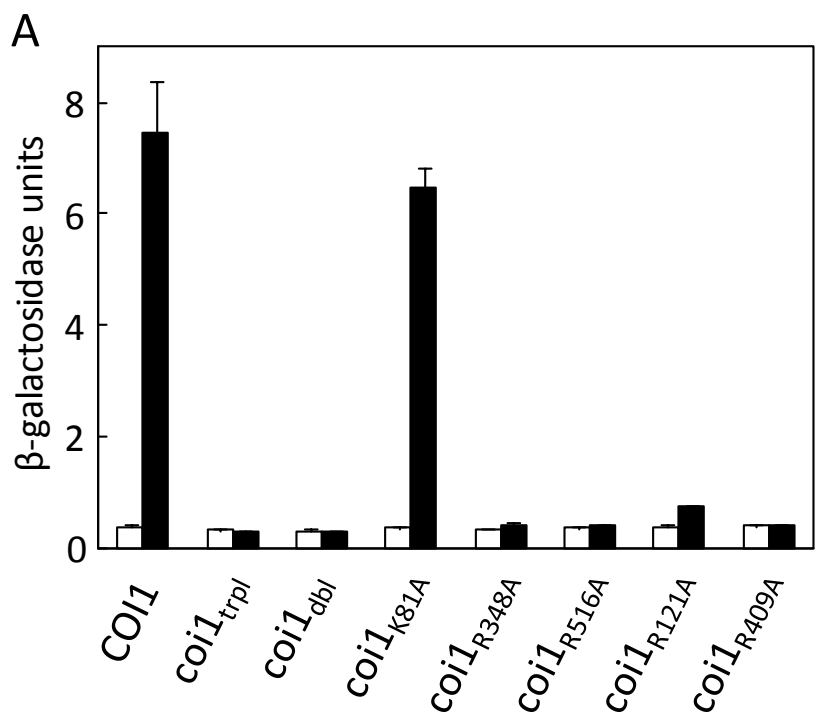

B

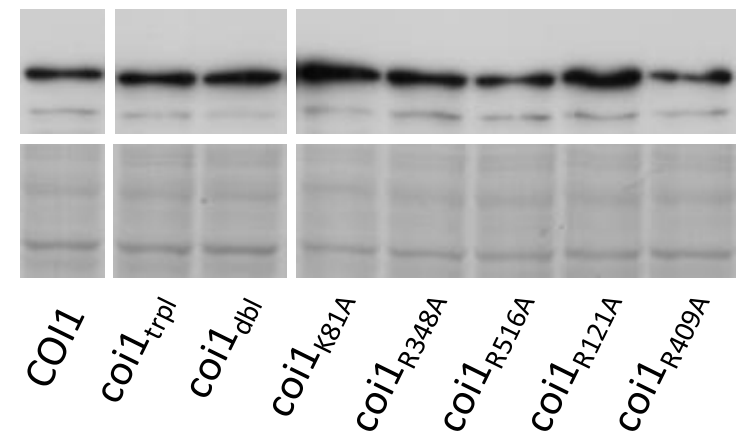

Fig 13: Putative inositol polyphosphate coordinating residues are required for the COI1/JAZ9 interaction. Constructs encoding COI1 variants with single and multiple exchanges in amino acid positions possibly involved in inositol polyphosphate binding (coi $1_{\text {mut }}$ ) were created and used in yeast two-hybrid tests for interaction with the COI1 target, JAZ9. (A) $\beta$-galactosidase activities indicating the

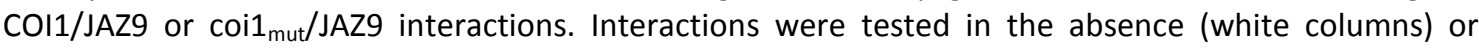
presence of $30 \mu \mathrm{M}$ coronatin (black columns). Data represent mean values of four replicates \pm SD. (B) Western blot analysis of the MYC-tagged COI1- or coi1 $1_{\text {mut }}$-GBD fusions. $2 \mu \mathrm{g}$ of total protein of 4 individual clones induced with coronatin were pooled and loaded per lane. Only the specific immunodetection band of 89 kDa is shown. Top, detection of MYC-tags; bottom, coomassie-stained gel. Experiments shown in $A$ and $B$ were repeated once in quadruples with similar results. Yeast two-hybrid experiments and Western blot analysis were kindly performed by Dr. Corinna Thurow and Anna Hermann. 
data indicate that the exchange of putative inositol polyphosphate binding residues profoundly affected the COI1/JAZ9 interaction (Fig. 13). $\beta$-galactosidase activity resulting from the interaction of the Gal4 DNA binding domain (GBD) and Gal4 activation domain (GAD) fusions was slightly lowered for the GBD-JAZ9/GAD-coi1 $1_{\mathrm{K} 81 \mathrm{~A}}$ interaction ( $87 \%$ of the activity obtained with GBD-JAZ9 and GAD-COI1; Fig. 13 A). The GBD-JAZ9/GAD-coi1 $1_{\mathrm{R} 121 \mathrm{~A}}$ interaction was severely reduced and showed only $10 \%$ of the $\beta$-galactosidase activity achieved with wild type COI1. The interaction of JAZ9 with all other coi1 $1_{\text {mut }}$ variants tested, including that of variants carrying other single as well as multiple exchanges, was fully abolished and displayed $\beta$-galactosidase activities as low as the negative controls without coronatine (Fig. $13 \mathrm{~A}$ ). To confirm that the effects observed were not due to uneven levels of the altered coi $1_{\text {mut }}$ proteins, Western blot analysis was performed (Fig. 13 B). Similar expression levels of the GAD-COI1 and GAD-coi1 $1_{\text {mut }}$ fusion proteins were detected in all samples and no variations in expression levels were observed.

\subsection{Reduced in planta functionality of COI1 variants lacking putative inositol polyphosphate binding residues}

After the exchange of putative inositol polyphosphate coordinating amino acid residues in COI1 led to reduced COI1/JAZ9 interaction in yeast, the same mutated COI1 variants were used to test their capability to complement the Arabidopsis coi1-t mutant phenotypes. Heterozygous coi1-t mutant plants were transformed with either wild type COI1 or the different coil $1_{\text {mut }}$ variants and JA sensitivity was determined first on 3-week-old T1 seedlings by a vertical root growth assay. Transformants were selected by the fluorescence of a seedexpressed DsRed marker and the root lengths of seedlings growing on media containing $50 \mu \mathrm{M}$ MeJA were determined (Fig. $14 \mathrm{~A}$ ). Homozygous coi1-t backgrounds were subsequently identified by PCR-based genotyping and just these plants were considered. 10-66 plants were analyzed for each transformation construct. As positive and negative controls the root lengths of untransformed wild type and coi1-t plants were determined. Wild type roots reached an average length of $14.3 \pm 3.4 \mathrm{~mm}$, whereas coi1-t roots were substantially longer with $63.2 \pm 17.9 \mathrm{~mm}$ (Fig. 14 A), indicating the discrimination of plants carrying functional or nonfunctional COI1 alleles worked well. Furthermore, expression of wild type COI1 complemented fully (root lengths of $14.9 \pm 4.0 \mathrm{~mm}$ ), whereas an empty vector control did not (root length of $57.2 \pm 21.8 \mathrm{~mm}$ ). The complementation with single exchange coi $1_{\text {mut }}$ variants 
A

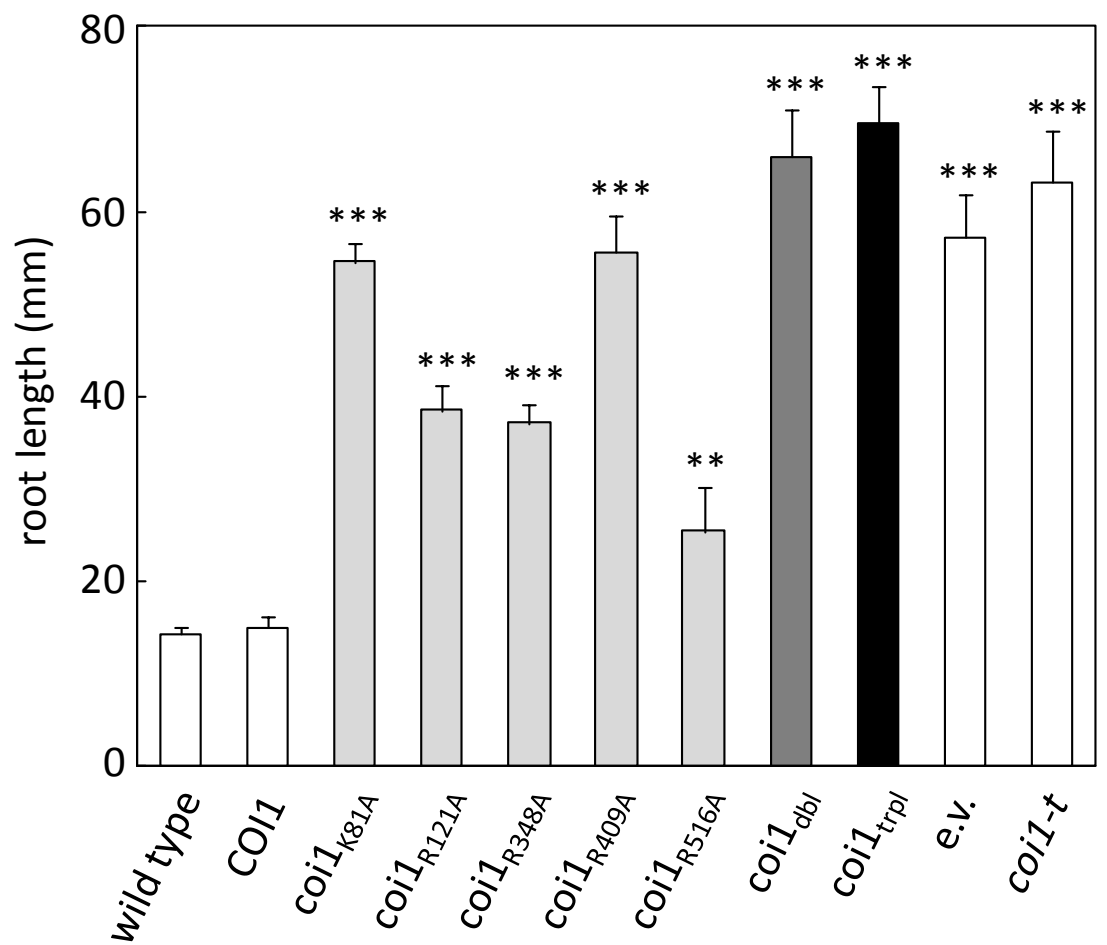

B

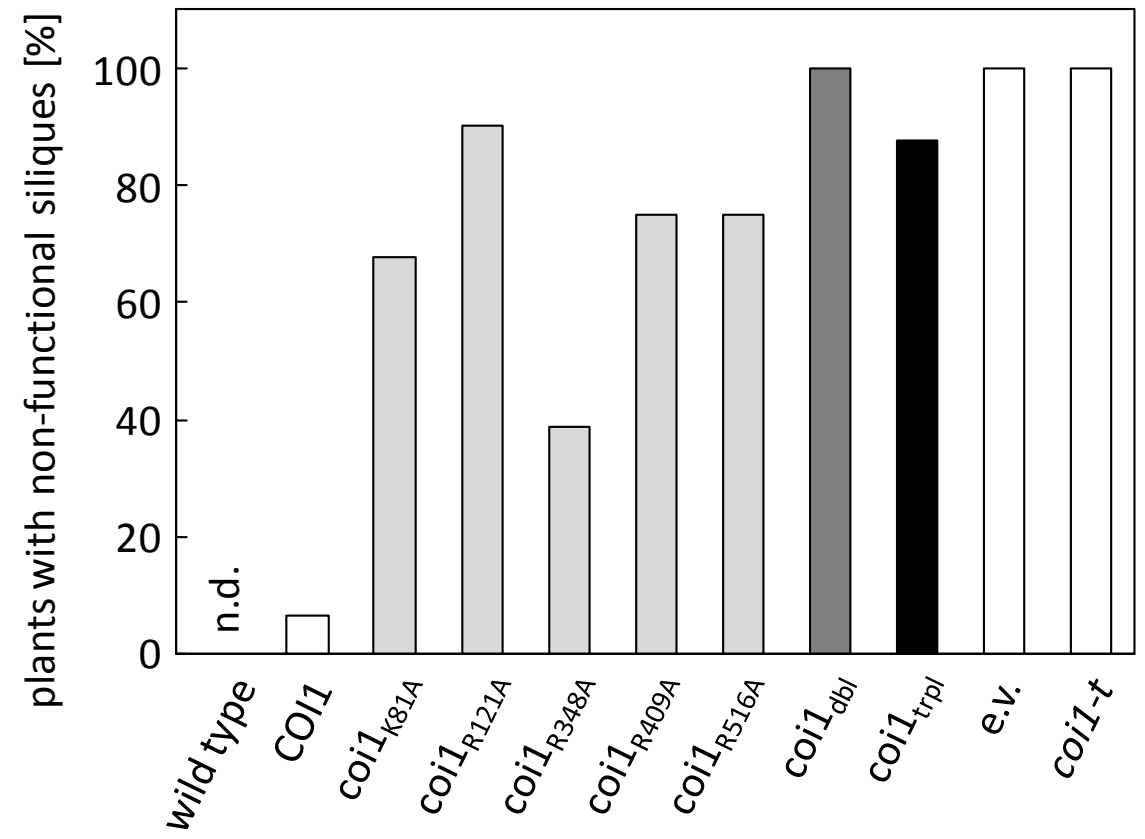

Fig. 14. Reduced in planta functionality of COI1 variants lacking putative inositol polyphosphate binding residues. The coi $1_{\text {mut }}$ variants carrying single or multiple exchanges were tested for their capability to rescue Arabidopsis coil-t mutant phenotypes. (A) Root growth sensitivity against $50 \mu \mathrm{M}$ MeJA was tested using 3-week-old vertically grown plants expressing different rescue constructs, as indicated. The empty vector (e.v.) control carried the DsRed sequence only; 10-66 plants per transformation construct were analyzed. Root lengths are shown in $\mathrm{mm} \pm \mathrm{SE}$. (B) Male fertility was assessed by growing the same individuals assayed for root length on soil until seed set and categorizing plants producing functional or non-functional siliques. The percentage of plants generating nonfunctional siliques is shown; 8-60 plants were taken into account per transformation construct. White bars, controls; grey and black bars, coi1-t plants expressing coi1 mut variants with single (light grey), double (dark grey) or triple exchanges (black). Asterisks indicate significant differences of root length compared to untransformed wild type, according to a student's $t$-test $(* *, p \leq 0.01 ; * * *, p \leq 0.001)$. 
resulted in varying root lengths, indicating different degrees of complementation when different amino acid positions were altered (Fig. 14 A). While plants complemented with the coi1 $_{\text {R516A }}$ variant showed the shortest roots similar to complementation with wild type COI1, variants coi $1_{\mathrm{R} 348 \mathrm{~A}}$ and $\operatorname{coi}_{\mathrm{R} 121 \mathrm{~A}}$ displayed intermediate root lengths with $37.1 \pm 12.7 \mathrm{~mm}$ and $38.5 \pm 16.1 \mathrm{~mm}$, respectively (Fig. $14 \mathrm{~A}$ ). Complementation with variants $\operatorname{coi} 1_{\mathrm{K} 81 \mathrm{~A}}$ and $\operatorname{coi}_{\mathrm{R} 409 \mathrm{~A}}$ revealed the longest roots among the single exchange mutants with mean values of $54.6 \pm 16.4 \mathrm{~mm}$ and $55.6 \pm 12.8 \mathrm{~mm}$, respectively (Fig. 14 A). While the single exchange variants displayed reduced complementation capability, effects observed with variants carrying multiple exchanges were even more pronounced, resulting in complete loss of complementation potential, indicated by root lengths of $66.0 \pm 17.8 \mathrm{~mm}$ and $69.6 \pm 25.9 \mathrm{~mm}$, which even slightly exceeded root lengths recorded for the coi1-t control, possibly due to dominant negative effects. The data indicate that the exchanged amino acids are important for COI1 function and affect JA sensitivity pertaining to root growth.

To test, if other JA-mediated response were also affected, silique development was monitored in the same plants previously assessed in the root growth assay. Plants were categorized as either producing functional siliques similar to wild type controls, or as producing nonfunctional siliques similar to coi1-t plants (Fig. 14 B). In this tests $0 \%$ of wild type plants, but $100 \%$ of coi1-t plants generated non-functional siliques. Complementation of the coi1- $t$ mutant with wild type COI 1 revealed $6.7 \%$ of plants with non-functional siliques, indicating close to full complementation. The single exchange variants showed reduced complementation capability indicated by an average of $69 \%$ of non-functional siliques, with $\operatorname{coi}_{1_{\mathrm{R} 348 \mathrm{~A}}}$ showing the fewest (39\%) and $\operatorname{coi} 1_{\mathrm{K} 81 \mathrm{~A}}, \operatorname{coi}_{\mathrm{R} 409 \mathrm{~A}}$ and coi $1_{\mathrm{R} 516 \mathrm{~A}}$ showing intermediate proportions of non-functional siliques ( $68 \%, 75 \%$ and $75 \%$, respectively). Complementation with $\operatorname{coi}_{\mathrm{R} 121 \mathrm{~A}}$ resulted in the lowest observed fertility rescue among the single exchange variants, with $90 \%$ of plants showing non-functional siliques. As also seen in the root growth assay, the complementation capability was reduced even stronger with coil $1_{\text {mut }}$ variants carrying multiple exchanges, exhibiting $100 \%$ (coi $\left.1_{\mathrm{dbl}}\right)$ and $88 \%$ (coi $\left.1_{\text {trpl }}\right)$ of non-functional siliques. Together the root growth assay and the determination of fertility rescue show that complementation with wild type COI1 resulted in rescue of JA sensitivity in two independent aspects of the JA response, and the rescue with coi1 $1_{\text {mut }}$ variants displayed similar patterns of complementation capacity between both experiments.

As before in yeast (Fig. 13 B), it was attempted to detect the C-terminal polyHis-tagged COI1 variants in plant extracts, but expression levels were too low for detection (data not shown). To test whether or not differences in rescue capability between constructs were due to positional effects of the genomic insertion loci and resulting variable expression levels, 
fluorescence intensities of the co-integrated DsRed selection marker were determined in transformed seeds before experiments described in Fig. 14 were set up (Fig. 15). Data are shown for plant individuals that exhibited average values in the root length assay. Transformed seeds were grouped into categories of increasing fluorescence intensity. Seeds complemented with wild type COI1 showed DsRed fluorescence in the first (low) intensity categories and mainly in category two (Fig. 15). Single exchange variants showed fluorescence mainly in the intermediate intensity categories three and four, whereas multiple exchange variants were
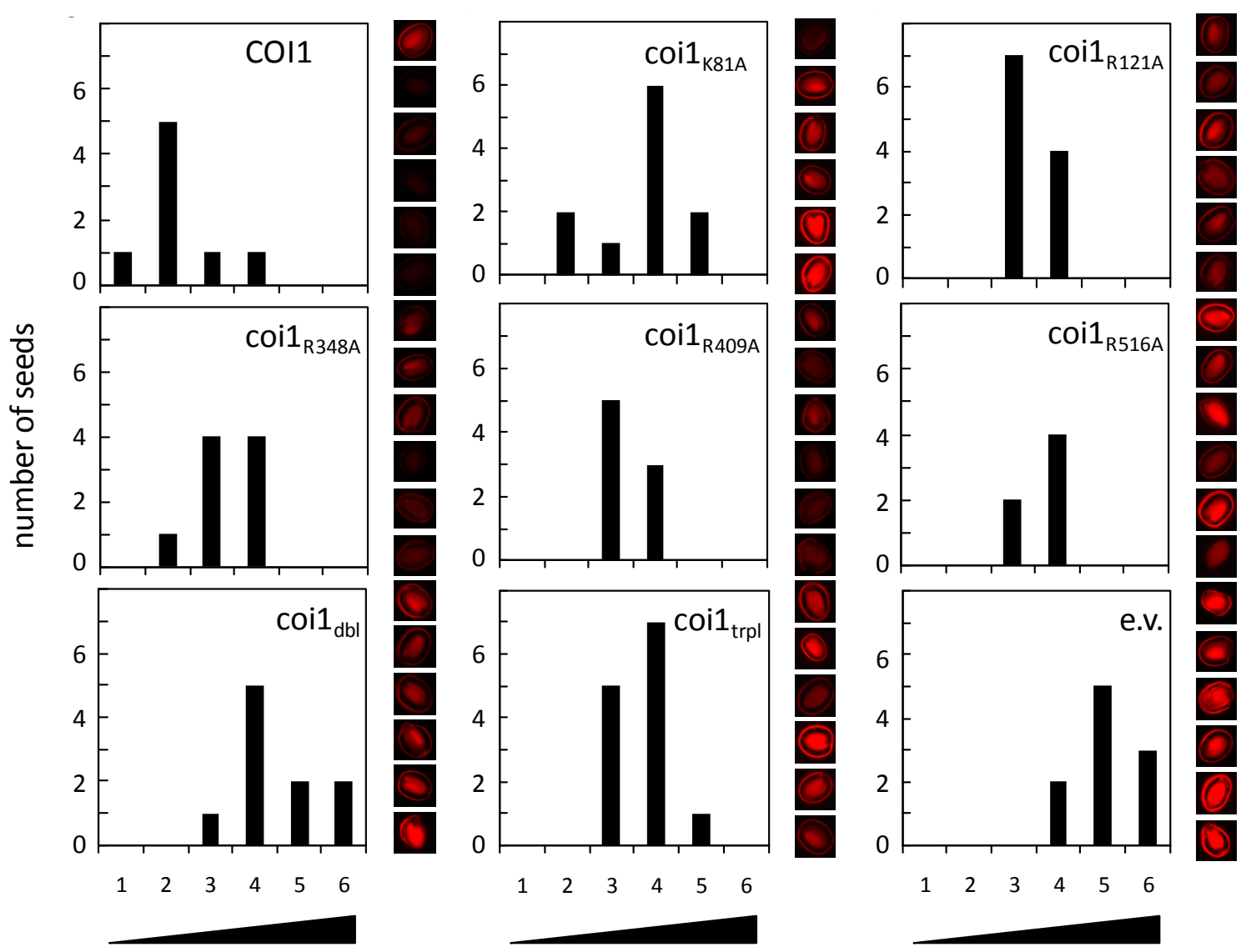

Categories of increasing DsRed fluorescence intensities (arbitrary units)

Fig. 15: Distribution of DsRed fluorescence intensities of transformed coi1-t seeds does not correlate with differences in complementation efficiency. Positive transformants were identified by DsRed fluorescence using the fluorescence stereomicroscope Leica MZ16 FA and a Leica DFC480 camera. Fluorescence intensities were monitored and allocated to six categories of increasing fluorescence. Seeds resulting in seedlings with average root length were taken into account; number of seeds in each category was counted and distributions of fluorescence intensities are depicted for each transformation construct. e.v.: empty vector control carrying DsRed. Representative examples of fluorescing seeds are depicted on the right of each graph. 
found to exhibit fluorescence of higher intensities in categories three, four and five (Fig. 15). The empty vector control showed strongest fluorescence with intensities mainly in categories five and six (Fig. 15).

In addition to the fluorescence intensity plots, mRNA levels of the introduced COI 1 and coil $1_{\text {mut }}$ variants were determined on four plants of each transformation construct via semiquantitative RT-PCR with 27,30 or 34 cycles, using cDNA as a template (Fig. 16). Variants with low complementation capability, such as the multiple exchange variants, displayed expression levels similar to that of wild type COI1, which complemented fully. In contrast, variants with high complementation capability, such as some of the single exchange variants, displayed lower expression levels.
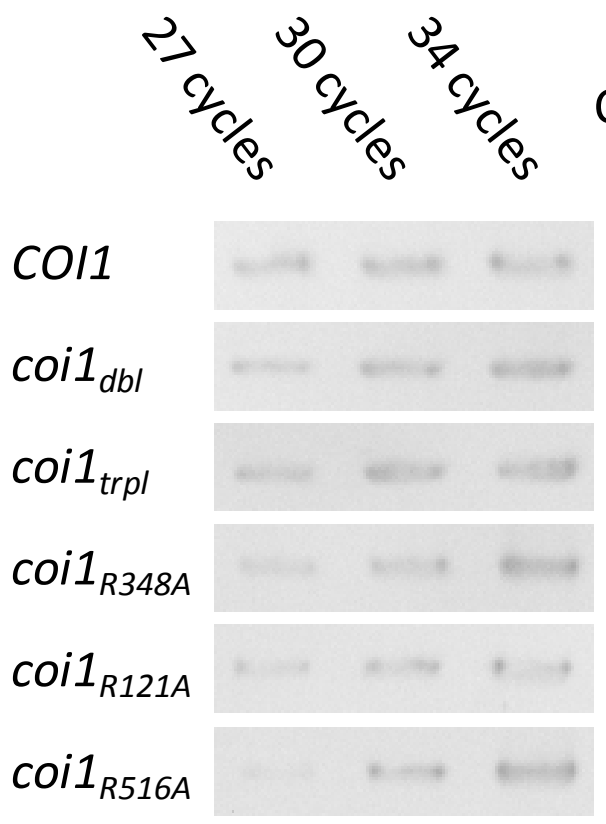

\section{Complementation} capacity

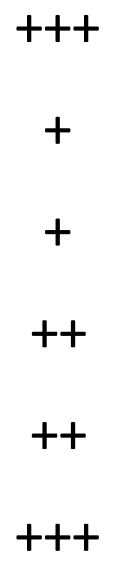

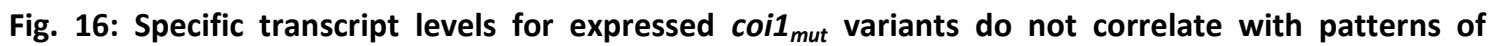
complementation efficiency in coi1-t plants. Transcript levels for COI1 or coil $1_{\text {mut }}$ variants expressed in coi1- $t$ mutants were determined by semi-quantitative RT-PCR. Transcripts were amplified using 27, 30 and 34 PCR cycles, as indicated. Complementation capacity of individual constructs was assessed from the combined results of the root growth assays and the determination of functional siliques (right). + , none to weak complementation; ++, intermediate complementation; +++, very good or full complementation. Variants with low complementation capability, as the multiple exchange variants, displayed expression levels similar to that of wild type COI1, which complemented fully. In contrast, variants with high complementation capability, such as some of the single exchange variants, displayed lower expression levels. Data are shown for a representative set of individual plants. The experiment was performed four times with similar results. 
Even though functional complementation with the C-terminal polyHis-tagged COI1 protein and

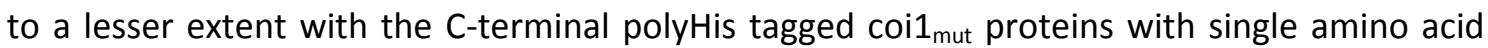
exchanges was detected, immunodetection of the respective COI1 variants in Arabidopsis extracts failed. Semi-quantitative RT-PCR indicated similar RNA levels for all proteins, suggesting that differences observed in the complementation capabilities of coi $1_{\text {mut }}$ variants were not caused by varying expression levels due to positional effects of genomic insertion loci. The data indicate that the introduced mutations in the putative inositol polyphosphate binding sites rendered the protein either unstable or non-functional. The higher abundance of seeds expressing the fluorescent marker gene in transformants carrying the less functional coi $1_{\text {mut }}$ variants suggests that these were tolerated by the plants at higher expression levels than fully functional variants.

\subsection{Modulation of inositol polyphosphate biosynthesis alters COI1/JAZ9 interactions in yeast}

Mutation of putative inositol polyphosphate coordinating residues resulted in reduced interaction of COI1 and JAZ9 (Fig. 13) as well as in reduced complementation capability of COI1 in coi1-t plants (Fig. 14), supporting the hypothesis that an inositol polyphosphate acts as a cofactor in COI1 and is important for COI1 function. As an independent line of evidence, the effects of altered inositol polyphosphate content on the interaction of wild type COI 1 with JAZ9 were investigated. Deletion of the ipk1 gene in yeast results in a strong reduction of InsP levels and concomitant accumulation of its precursor $\operatorname{InsP}_{5}$ (Ponnusamy et al, 2008). Therefore, IPK1 was eliminated by targeted gene disruption in the yeast strain PJ69-4a used for the twohybrid assays. The COI1/JAZ9 interaction was then tested in this background in the presence of coronatine (Fig. 17). Samples without coronatine served as negative controls. It was surprising to find that $\beta$-galactosidase activity resembling the GBD-JAZ9/GAD-COI1 interaction was enhanced in the ipk1 $\Delta$ strain, resulting in activities 2-3 times higher than those in the PJ69-4a background (Fig. 17 A). Western blot analysis indicates close to even levels of COI1 protein present in PJ69-4a and in the ipk1 $\Delta$ strain, respectively (Fig. $17 \mathrm{~B}$ ). 
A

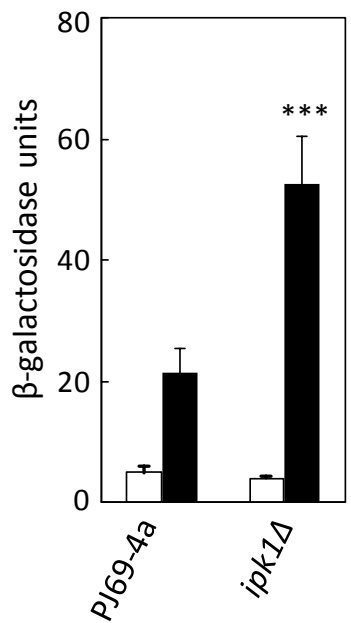

B

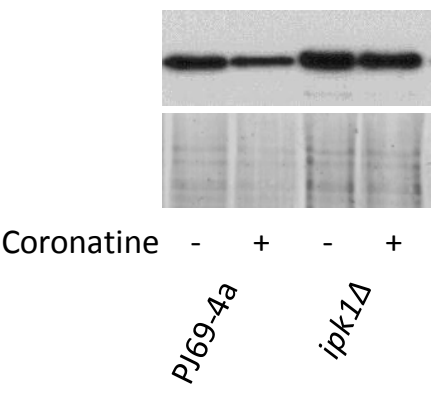

Fig. 17. Modulation of inositol polyphosphate biosynthesis alters COI1/JAZ9 interactions in yeast. The interaction of wild type COI 1 and JAZ9 was assessed in yeast two-hybrid tests using an ipk1 $1 \Delta$ yeast strain, in which the IPK1 gene was deleted. (A) The COI1/JAZ9 interaction was tested in the absence (white bars) or presence of $30 \mu \mathrm{M}$ coronatine (black bars). $\beta$-galactosidase activities indicate the COI1/JAZ9 interaction in controls or ipk1L. Mean values of four replicates \pm SD are shown. Asterisks indicate significant differences of $\beta$-galactosidase activity between the parental strain PJ69-4A and ipk1 $1 \Delta$, according to a student's $t$-test $(* * *, p \leq 0.001)$. (B) Immunodetection of COI1 in the respective yeast strains, as indicated. Top, detection of MYC tags; bottom, coomassie-stained gel. Protein from four cultures was combined for immunodetection. Experiments were repeated in quadruples once with similar results. Yeast two-hybrid experiments and Western blot analysis were kindly performed by Dr. Corinna Thurow and Anna Hermann.

\subsection{Modulation of inositol polyphosphate biosynthesis alters defence responses in ipk1-1 plants}

\subsubsection{Biochemical characterization of ipk1-1 plants}

\subsubsection{Wound-induced PI signalling components in ipk1-1 plants}

To investigate COI 1 function in the corresponding plant system with reduced $\operatorname{InsP}_{6}$ and elevated InsP $_{5}$ levels, the Arabidopsis ikp1-1 mutant (Stevenson-Paulik et al, 2005) was analysed. The Arabidopsis ipk1-1 mutant was originally isolated for feed industrial reasons, because high abundance of $\operatorname{InsP}_{6}$ in feed has detrimental influence on the uptake of phosphate, inositol, and essential minerals by monogastric animals, such as pig and poultry, and furthermore contributes to environmental phosphorus pollution (Brinch-Pedersen et al, 2002; Hamada et al, 2006; Stevenson-Paulik et al, 2005).

Disruption of the IPK1 gene locus in Arabidopsis results in decreased levels of InsP $\mathrm{P}_{6}$ with concomitant accumulation of $\operatorname{InsP}_{4}$ and InsP $\mathrm{P}_{5}$ (Stevenson-Paulik et al, 2005), similar to the 
A

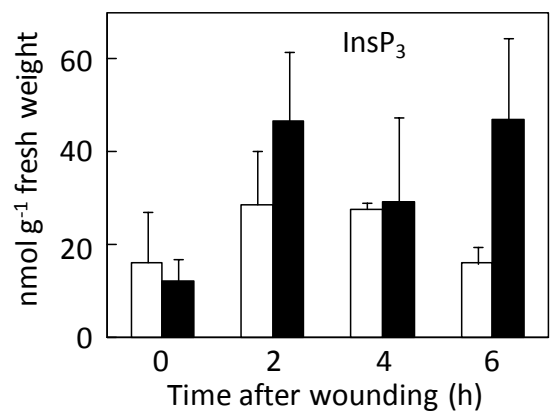

B

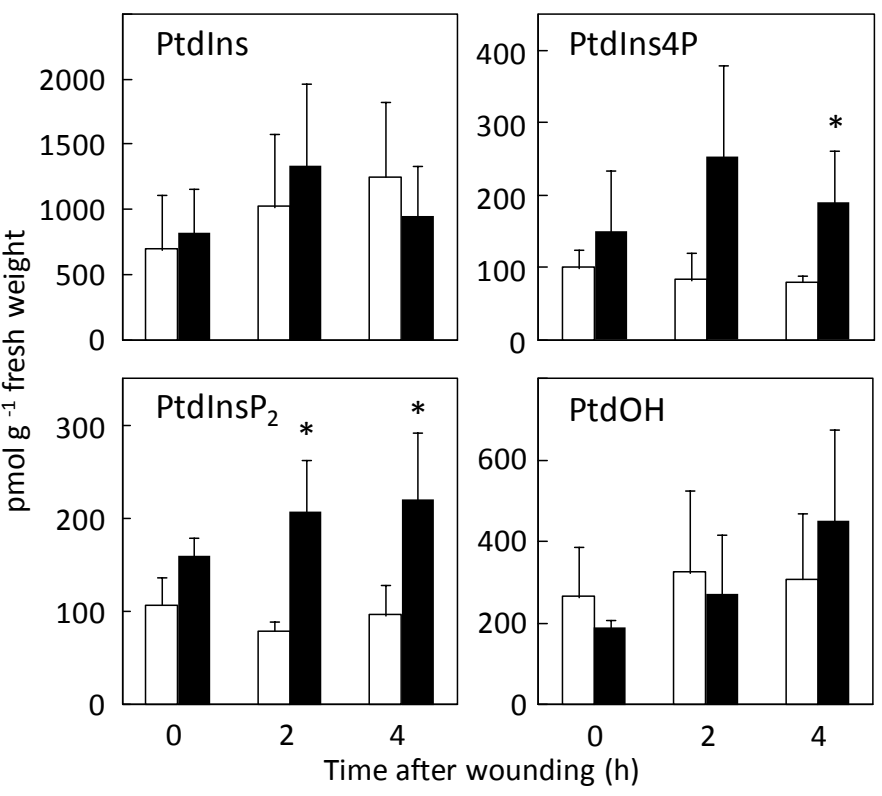

Fig. 18: Wound-induced PI signalling components in ipk1-1 plants. Rosette leaves of 7-week-old plants were wounded with forceps and harvested after indicated time spans. (A) InsP $\mathrm{P}_{3}$ levels were determined by a competitive protein binding assay in wild type (white columns) and ipk1-1 plants (black columns). Data are mean values of one independent wounding experiments assayed in duplicates \pm SD. (B) PI lipids were determined via GC/MS after TLC separation, in wild type (white columns) and ipk1-1 plants (black columns). Lipid data are mean values of three independent wounding experiments assayed in duplicates \pm SD. Asterisks indicate significant differences between level detected in wild type and in ipk1-1 plants at the respective time point, according to a student's $t$-test $(*, p \leq 0.1$ ).

pattern described for yeast ipk1 1 (Ponnusamy et al, 2008). For a deeper biochemical characterization of ipk1-1 plants, wound-induced InsP $\mathrm{P}_{3}$ levels were determined (Fig $18 \mathrm{~A}$ ). As this experiment was only performed once, these data still need to be confirmed. Interestingly, wound induced accumulation of $\operatorname{InsP}_{3}$ was also elevated over wild type controls. By $2 \mathrm{~h}$ after wounding, wild type plants reached maximal $\mathrm{nsP}_{3}$ levels of $28.6 \pm 11.7 \mathrm{nmol} \mathrm{g}^{-1}$ fresh weight, which were clearly exceeded by ipk1-1 plants, increasing to $46.6 . \pm 15.1 \mathrm{nmol} \mathrm{g}{ }^{-1}$ fresh weight (Fig. $18 \mathrm{~A}$ ). ipk1-1 plants reached their maximum with $47.0 \pm 17.3 \mathrm{nmol} \mathrm{g}^{-1}$ fresh weight $6 \mathrm{~h}$ after wounding, by which time wild type controls had declined to $\operatorname{InsP}_{3}$ levels of $16.0 \pm 3.6 \mathrm{nmol} \mathrm{g}^{-1}$ fresh weight. 
Lipid analysis of wound-induced PIs (Fig. $18 \mathrm{~B}$ ) showed that also Ptdlns4P and Ptdlns (4,5) $\mathrm{P}_{2}$ increased over wild type levels. Ptdlns showed only minor differences between wild type and ipk1-1 plants, with both reaching similar maxima (wild type $1253.5 \pm 575.5 \mathrm{nmol} \mathrm{g}^{-1}$ fresh weight $4 \mathrm{~h}$ after wounding, ipk1-1 plants $1332.4 \pm 629.6 \mathrm{pmol} \mathrm{g}^{-1}$ fresh weight $2 \mathrm{~h}$ after wounding). Ptdlns4P levels slightly declined in wild type plants from $100.3 \pm 24.2$ to $79.6 \pm 9.7 \mathrm{pmol} \mathrm{g}^{-1}$ fresh weight within $4 \mathrm{~h}$ of wounding, whereas ipk1-1 plants displayed increasing Ptdlns4P levels from $149.3 \pm 84.3$ to $252.3 \pm 126.1 \mathrm{pmol} \mathrm{g}^{-1}$ fresh weight already $2 \mathrm{~h}$ after wound stimulus. A similar pattern was recorded for $\operatorname{Ptd} \operatorname{lns}(4,5) \mathrm{P}_{2}$ levels, which declined from $107.4 \pm 29.1$ to $79.5 \pm 10.0 \mathrm{pmol} \mathrm{g}^{-1}$ fresh weight in wild type controls, whereas ipk1-1 plants showed an increase from $159.9 \pm 20.1$ to $219.5 \pm 73.2 \mathrm{pmol} \mathrm{g}^{-1}$ fresh weight. The levels of PtdOH displayed only a minor rise in wild type plants from $264.4 \pm 124.6$ to $324.9 \pm 199.8$ pmol g$^{-1}$ fresh weight. In ipk1-1 plants, $\mathrm{PtdOH}$ levels were similar in unwounded plants (188.7 $\pm 18.2 \mathrm{pmol} \mathrm{g}^{-1}$ fresh weight), but rose rather strongly up to $451.0 \pm 224.2 \mathrm{pmol} \mathrm{g}$ ${ }^{1}$ fresh weight.

Taken together, the biochemical characterization of PI metabolites confirmed that ipk1-1 plants displayed elevated levels of $\mathrm{InsP}_{3}$ compared to wild type controls and furthermore also accumulate PI lipids over wild type levels, indicating that interruption of IPK1 influences the whole PI signalling pathway.

\subsubsection{Altered oxylipin patterns in ipk1-1 plants}

As InsP 5-ptase plants with global reduction of the PI pathway displayed increased wound induction of jasmonates, the impact of $\mathrm{PI}$ accumulation and the loss of InsP $_{6}$ in ipk1-1 plants on wound induction of OPDA, dn-OPDA, JA and JA-lle was tested. Levels of wound-induced oxylipins were monitored via LC/MS over a period of $6 \mathrm{~h}$ (Fig. 19). oPDA levels of ipk1-1 plants did not show pronounced differences to wild type levels. While early after wounding ipk1-1 plants slightly exceeded wild type levels ( $0.5 \mathrm{~h}$ after wounding, wild type $5.45 \pm 1.10$, ipk1-1 $8.92 \pm 1.72 \mathrm{nmol} \mathrm{g}^{-1}$ fresh weight), the opposite pattern could be observed at most later time points ( $6 \mathrm{~h}$ after wounding, wild type $11.71 \pm 7.89$, ipk1-1 $7.67 \pm 3.23 \mathrm{nmol} \mathrm{g}{ }^{-1}$ fresh weight). A similar but more pronounced pattern was depicted in dn-oPDA levels, which were about twice as high in ipk1-1 plants early after wounding $(0.5 \mathrm{~h}$ after wounding, wild type $10.71 \pm 3.50$, ipk1-1 $23.15 \pm 8.12 \mathrm{nmol} \mathrm{g}^{-1}$ fresh weight) and only decreased below wild type levels beyond $5 \mathrm{~h}$ of wounding (wild type $9.18 \pm 7.24$, ipk1-1 $6.48 \pm 3.57 \mathrm{nmol} \mathrm{g}^{-1}$ fresh weight). The time course of JA levels was very similar between wild type and ipk1-1 plants, but ipk1-1 plants 


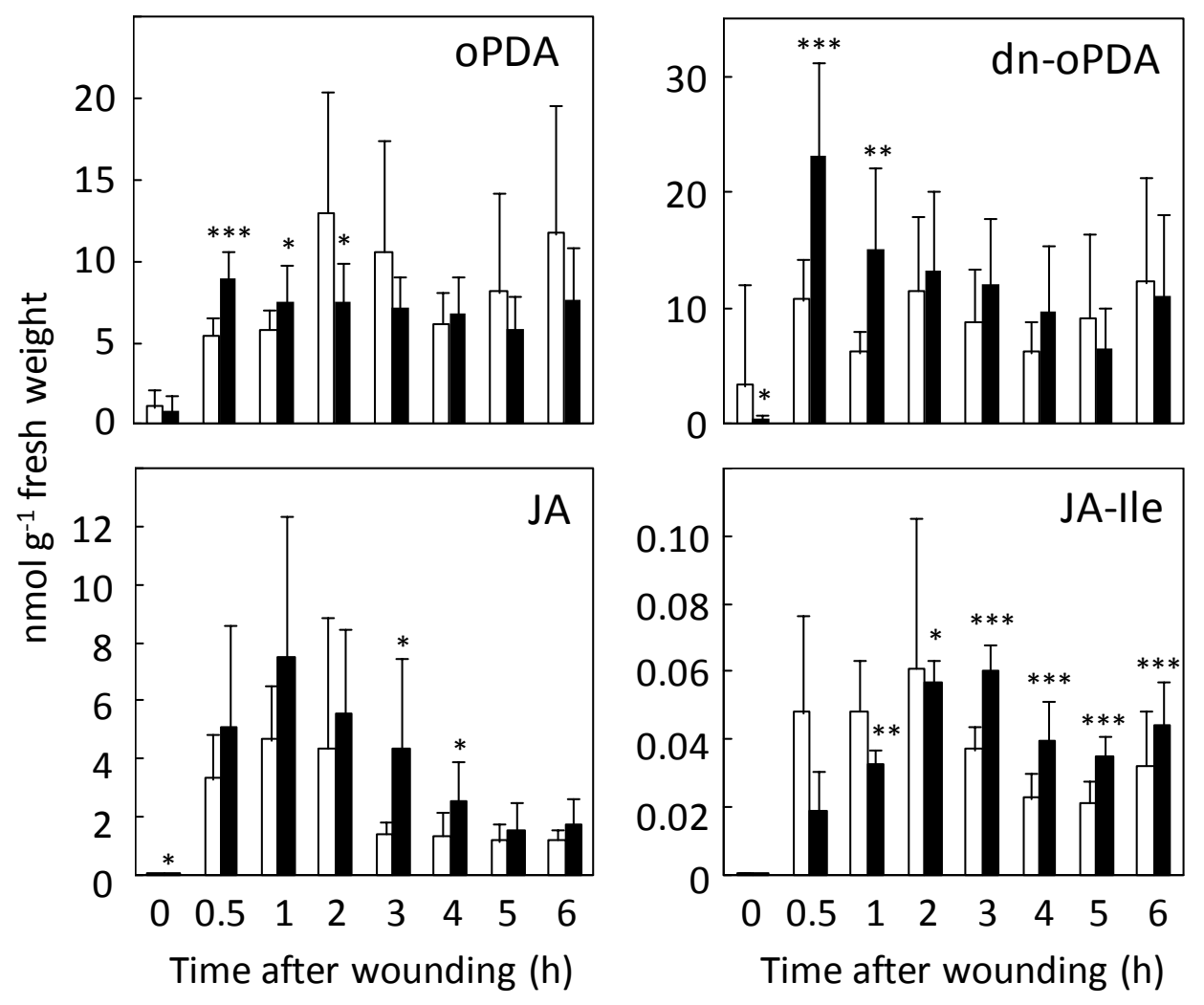

Fig. 19: Wound-induced oxylipins in wild type and ipk1-1 plants with high Ins $\mathrm{P}_{5}$ and low Ins $\mathrm{P}_{6}$ levels. Rosette leaves of 7-week-old plants were wounded with forceps and harvested after the indicated times. Oxylipins were determined via LC/MS in wild type plants (white columns) and InsP 5-ptase (black columns) over $24 \mathrm{~h}$. The mean values of two independent wounding experiments are shown, each assayed in duplicates, and each duplicate measured twice, \pm SD. Asterisks indicate significant differences between level detected in wild type and in ipk1-1 plants at the respective time point, according to a student's $t$-test $\left(*, \mathrm{p} \leq 0.1{ }^{* *}, \mathrm{p} \leq 0.01 ; * *, \mathrm{p} \leq 0.001\right)$.

displayed elevated absolute levels compared to wild type at all time points monitored (Fig. 19). Both reached a maximum $1 \mathrm{~h}$ after wounding (wild type $4.67 \pm 1.86$, ipk1-1 $7.50 \pm 4.83 \mathrm{nmol} \mathrm{g}^{-1}$ fresh weight) and declined constantly afterwards. Whereas OPDA and dn-oPDA values were somewhat higher than wild type in early time points and lower than wild type at later time points, the opposite pattern was observed in JA-lle time courses (Fig. 19). Wound induction of JA-lle seemed to be delayed in ipk1-1 plants, indicated by a postponed increase (wild type maximum $2 \mathrm{~h}$ after wounding of $0.061 \pm 0.044 \mathrm{nmol} \mathrm{g}^{-1}$ fresh weight, ipk1-1 maximum $3 \mathrm{~h}$ after wounding of $0.060 \pm 0.008 \mathrm{nmol} \mathrm{g}^{-1}$ fresh weight) as well as a postponed decrease afterwards (wild type decreased to $0.037 \pm 0.007 \mathrm{nmol} \mathrm{g}^{-1}$ fresh weight $3 \mathrm{~h}$ after wounding, ipk1-1 decreased to comparable $0.039 \pm 0.012 \mathrm{nmol} \mathrm{g}^{-1}$ fresh weight only $4 \mathrm{~h}$ after wounding). In general, oxylipin patterns of ipk1-1 plants were less different from wild type patterns than those previously observed for InsP 5-ptase plants. 


\subsubsection{Arabidopsis ipk1-1 mutants are hypersensitive to JA}

\subsubsection{Enhanced wound-induced gene expression in ipk1-1 mutants}

It was already shown further up that InsP 5-ptase plants exhibit attenuated wound-induced transcript levels of T18K17.7, AOS and WRKY7O (Mosblech et al, 2008). These genes were now also tested by quantitative real-time RT-PCR for wound induction in ipk1-1 plants (Fig. 20). In contrast to the situation in InsP 5-ptase plants, wound-induced gene expression was not abolished in ipk1-1 plants, but was clearly increased over wild type levels. Whereas all genes tested were induced by wounding in both wild type controls and in the ipk1-1 mutant, the level of induction was substantially higher in the ipk1-1 mutant. Relative expression levels of T18K17.7 transcript were 2-4 times higher in ipk1-1 plants for most time points monitored than in the corresponding wild type controls (Fig. 20).

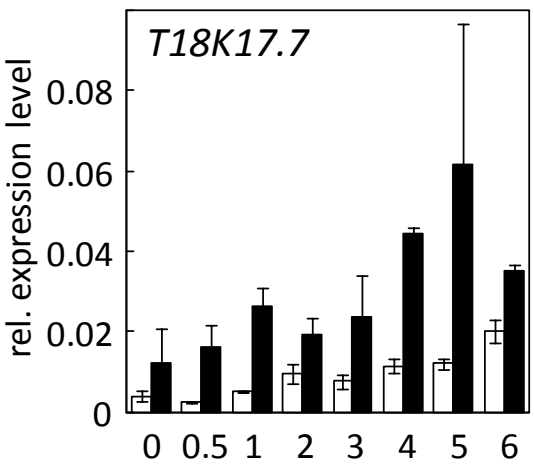

Time after wounding (h)

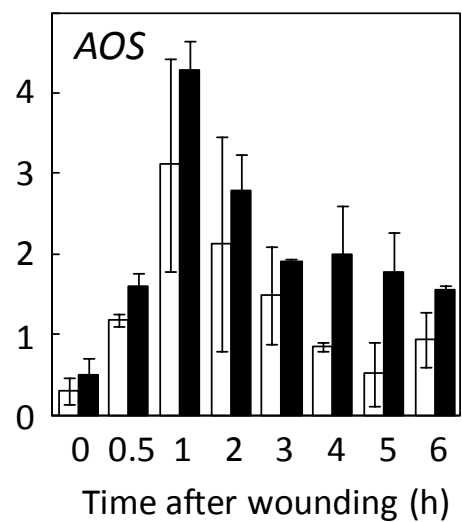

Fig. 20: Wound-induced transcript levelsof T18K17.7, AOS and WRKY7O in wild type and ipk1-1 plants. 7-week-old plants were wounded with forceps and harvested after the indicated times. For expression analysis of wound-inducible genes, quantitative real-time RT-PCR analysis of allene oxide synthase (AOS), the WRKY-family transcription factor WRKY7O and the Kunitz-family trypsin and protease inhibitor T18K17.7 was performed using material from wild type (white bars) or ipk1-1 plants (black bars). The mean values of two independent wounding experiments each analyzed in duplicates \pm SD are shown. Missing error bars are too small to appear.

Similarly, AOS transcript levels increased with a maximum $1 \mathrm{~h}$ after wounding and declined afterwards in both wild type and ipk1-1 plants, with ipk1-1 plants showing higher transcript levels compared to wild type at all time points tested. WRKY7O transcript levels were up to three times higher in ipk1-1 plants (Fig. 20). The data indicate that the induction of woundinduced gene expression was more pronounced in ipk1-1 than in wild type plants. 


\subsubsection{Increased defence against caterpillars of ipk1-1 plants}

As another downstream effect of wound signalling, resistance to insect feeding was tested in the same experimental set up as was used for investigation of InsP 5-ptase plants (Fig. 8). P. xylostella caterpillars of approximately equal developmental stage and weight were placed either on wild type or on ipk1-1 plants and were allowed to feed. Caterpillar weight gain was then monitored over several days. Fig. 21 illustrates the relative caterpillar weight increase over 56 h; absolute values are summarized in Table 2.

Importantly, the rate of weight gain of caterpillars feeding on ipk1-1 plants was lower than that of caterpillars feeding on wild type controls, exhibiting $51 \pm 7$ and $61 \pm 7 \mu$ g weight increase per hour, respectively. A significant difference was observed after $56 \mathrm{~h}$ of feeding, when caterpillars feeding on wild type plants reached a weight increase of $404.6 \pm 22.7 \%$ of initial weight, while caterpillars feeding on ipk1-1 plants attained a weight increase of $320.3 \pm 29.1 \%$ of initial weight.

The data indicate that both the induction of defence gene expression and the defensive capabilities of the Arabidopsis ipk1-1 mutant against caterpillars were increased over that of wild type plants.

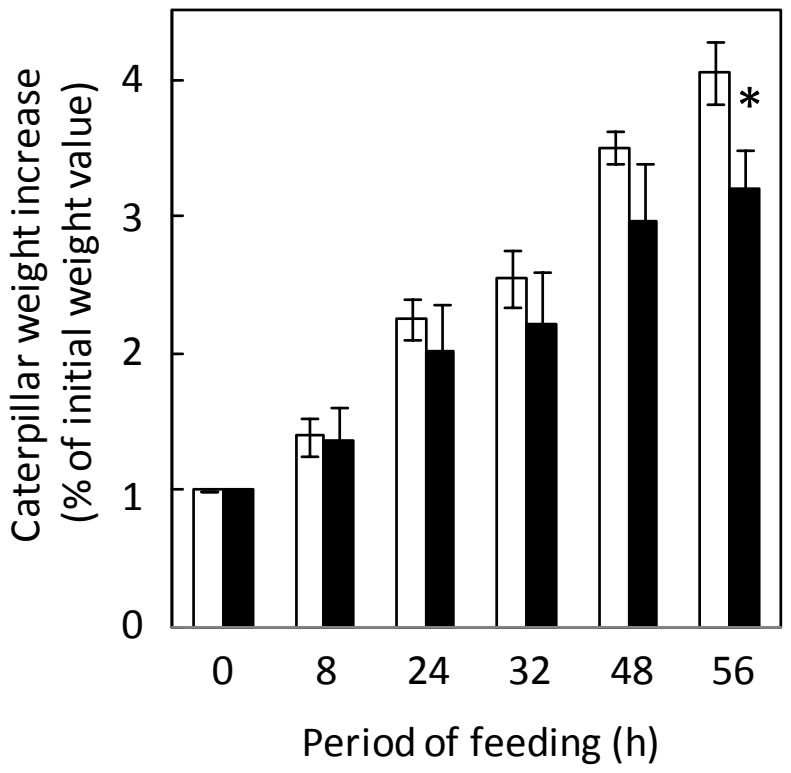

Fig. 21: Caterpillar growth performance feeding on wild type or ipk1-1 plants. $P$. xylostella larvae of $\sim 1 \mathrm{mg}$ were allowed to feed on wild type plants (white bars) or on ipk1-1 plants (black bars). Caterpillar weight was determined at the times indicated, and caterpillars were allowed to continue feeding. Data were normalized against caterpillar weights at time zero and are given as percent increase over the time zero value \pm SD. Data are from three independent biological experiments wherein each experiment corresponds to the examination of $27-40$ caterpillars for each plant line. Asterisk indicates significant increase in caterpillar growth feeding on ipk1-1 plants compared with feeding on wild type plants according to a student's $t$-test $(*, p \leq 0.05)$. 
Table 2. Weight increase of Plutella xylostella caterpillars feeding on Arabidopsis wild type or ipk1-1 plants. Plutella xylostella larvae of $\sim 1 \mathrm{mg}$ were allowed to feed on wild type or ipk1-1 plants. Caterpillar weight was determined at the times indicated, and caterpillars were allowed to continue feeding. Data are from three independent biological experiments, wherein each experiment corresponds to the examination of 27-40 caterpillars for each plant line. Numbers represent mean weight in $\mathrm{mg} \pm \mathrm{SD}$, rates of weight increase calculated from caterpillar net weight increases are given as $\mu \mathrm{g} \mathrm{h}^{-1}$.

\begin{tabular}{cccccccc}
\hline $\begin{array}{c}\text { Period } \\
\text { of } \\
\text { feeding }\end{array}$ & 0 & $8 \mathrm{~h}$ & $24 \mathrm{~h}$ & $32 \mathrm{~h}$ & $48 \mathrm{~h}$ & $56 \mathrm{~h}$ & $\begin{array}{c}\text { Rate of } \\
\text { increase } \\
{\left[\mu \mathrm{h} \mathrm{h}^{-1}\right]}\end{array}$ \\
\hline $\begin{array}{c}\text { wild } \\
\text { type }\end{array}$ & $1.12 \pm 0.05$ & $1.57 \pm 0.17$ & $2.52 \pm 0.21$ & $2.85 \pm 0.27$ & $3.93 \pm 0.28$ & $4.54 \pm 0.42$ & $61 \pm 7$ \\
ipk1-1 & $1.32 \pm 0.26$ & $1.74 \pm 0.12$ & $2.59 \pm 0.19$ & $2.83 \pm 0.21$ & $3.82 \pm 0.25$ & $4.19 \pm 0.60$ & $51 \pm 7$ \\
\hline
\end{tabular}

\subsubsection{Enhanced root length reduction on MeJA in ipk1-1 plants}

To test whether also JA-mediated processes other than defence responses were affected in ipk1-1 plants, root length reduction was monitored between 4-week-old seedlings vertically grown either on normal MS media or on MS media containing $50 \mu \mathrm{M}$ MeJA (Fig. 22). Root length reduction was more pronounced in ipk1-1 plants, exhibiting a reduction of $32.3 \mathrm{~mm}$. This equals an approximately $30 \%$ stronger reduction than that observed with wild type seedlings, which displayed only $24.9 \mathrm{~mm}$ of reduction. The enhanced sensitivity of roots to MeJA is consistent with results previously mentioned by Murphy et al (2008).

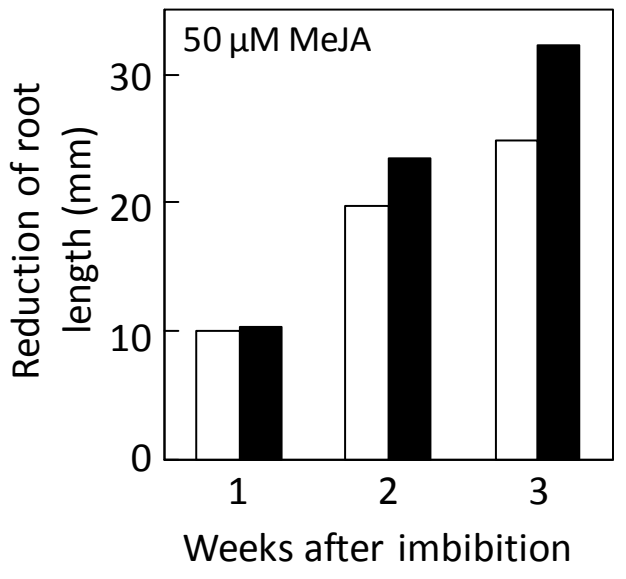

Fig. 22: Root sensitivity of wild type and ipk1-1 seedlings against $50 \mu \mathrm{M}$ MeJA. Reductions in root length of 4-week-old wild type (white bars) or ipk1-1 (black bars) seedlings are shown as differences between root lengths of seedlings grown on vertically oriented MS agar plates with and without $50 \mu \mathrm{M}$ MeJA. The difference was calculated from mean values of 85-130 root lengths with standard errors of $0.02-0.2$. 
Taken together the data of wound induced gene expression, caterpillar feeding performance and root growth on MeJA suggest that perturbed metabolism of inositol polyphosphates in ipk1-1 plants results in hypersensitivity to JA either because of a lack of InsP $\mathrm{P}_{6}$ or due to an accumulation of $\operatorname{InsP}_{5}$ and upstream PI metabolites. The comparison between ipk1-1 plants and InsP 5-ptase plants suggests that the increase in $\operatorname{InsP}_{5}$ rather than a decrease in $\operatorname{Ins}_{6}$ is the cause for the JA hypersensitivity of the Arabidopsis ipk1-1 mutant.

\subsection{SA is relevant for JA as well as for PI signalling}

While the focus of this study was on crosstalk between oxylipin and inositol signalling metabolites, the relevance of SA in wound responses in relation to PI signals was also investigated. JA and SA, both play important roles in plant defence against pathogens, and an antagonistic relation was previously reported in studies concerning responses to biotrophic and necrotrophic pathogens (Glazebrook, 2005; Kessler \& Baldwin, 2002; Thomma et al, 2001). To investigate the role of SA in the observed crosstalk between JA and PI signals during the Arabidopsis wound response, two independent SA-deficient lines, sid2 and NahG, were tested for wound induced levels of JAs and InsP $\mathrm{P}_{3}$. Furthermore, InsP 5-ptase plants, globally reduced in $\mathrm{PI}$ signalling, and ipk1-1 plants, with high InsP $_{5}$ and low $\operatorname{lns}_{6}$ levels, were tested for their wound induced SA content. To validate that both the Arabidopsis sid2 mutant and the NahG transgenic line exhibited their respective biochemical phenotypes, SA levels were determined with and without wounding (Fig. 23). In both cases, SA levels were strongly reduced compared to those observed in wild type controls, as was expected. While SA levels increased in wild type plants with wounding from $0.44 \pm 0.06$ to $0.97 \pm 0.08 \mathrm{nmol} \mathrm{g}^{-1}$ fresh weight, there was no clear increase in both SA related mutants. sid2 mutants displayed SA levels between $0.20 \pm 0.05$ and $0.25 \pm 0.02 \mathrm{nmol} \mathrm{g}^{-1}$ fresh weight, without or with wounding. SA levels in NahG plant were even more strongly reduced, varying between $0.06 \pm 0.01$ and $0.10 \pm 0.03 \mathrm{nmol} \mathrm{g}^{-1}$ fresh weight without or with wounding. Wound induction of OPDA was delayed in both SA related mutants (Fig. 23). While unwounded oPDA levels showed only minor differences in SA related mutants to wild type levels (wild type $0.39 \pm 0.12$, sid2 $0.98 \pm 0.58$ and NahG $0.41 \pm 0.22 \mathrm{nmol} \mathrm{g}^{-1}$ fresh weight), the wound-induced increase observed in wild type plants $2 \mathrm{~h}$ after wounding (to $6.02 \pm 1.04 \mathrm{nmol} \mathrm{g}^{-1}$ fresh weight) was considerably lower in both mutants (sid2 $2.88 \pm 0.18$, NahG $2.04 \pm 0.13 \mathrm{nmol} \mathrm{g}^{-1}$ fresh weight). Nevertheless, oPDA levels of sid 2 and NahG even exceeded wild type levels $4 \mathrm{~h}$ after wounding by 


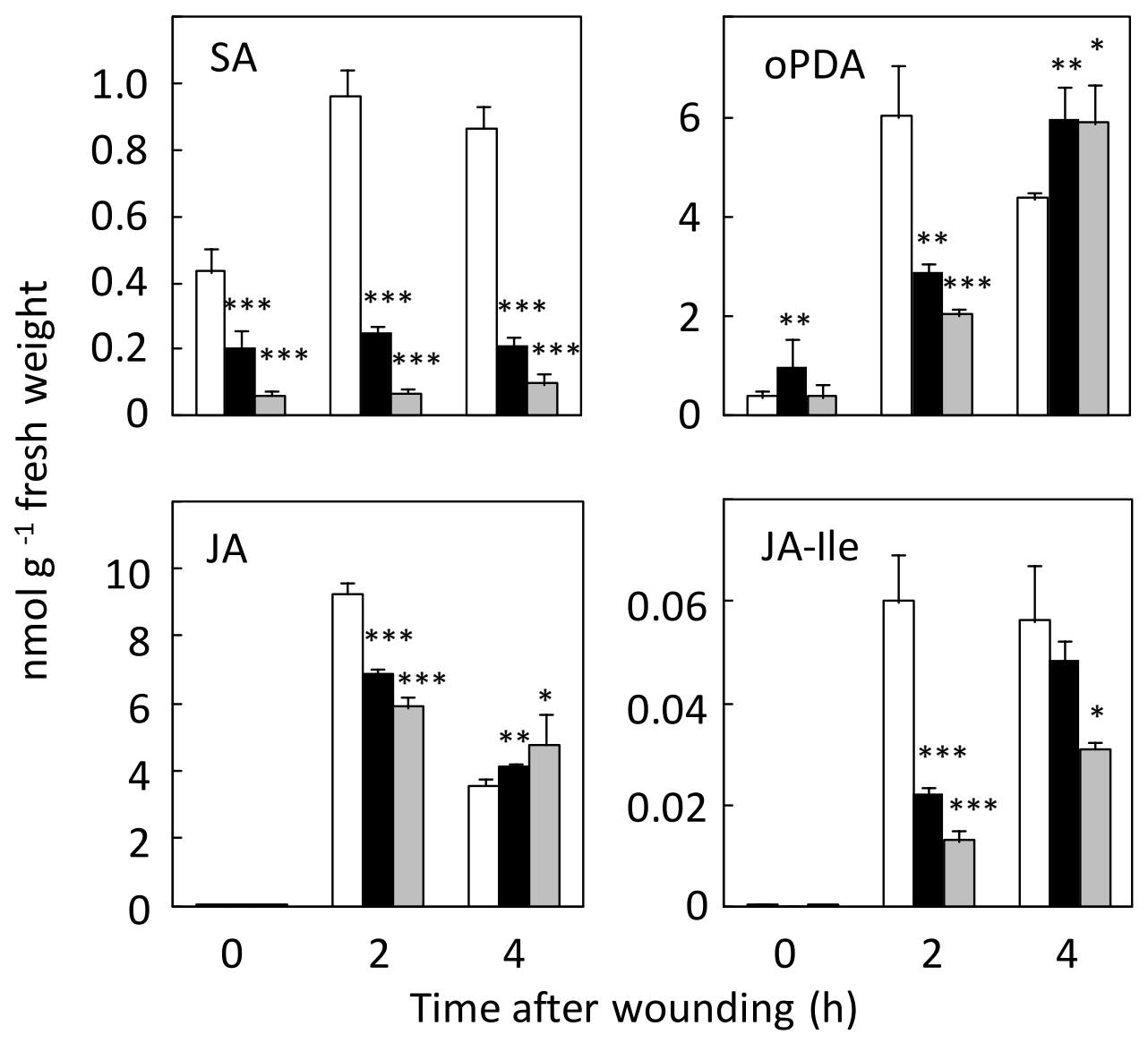

Fig.23: Wound-induced levels of SA and oxylipins in Arabidopsis mutants abolished in SA signalling. Rosette leaves of 7-week-old plants were wounded with forceps and harvested after the indicated times. Phytohormones were determined via LC/MS in wild type plants (white columns) and sid2 (black columns) and NahG (grey columns). Data of one wounding experiment are shown, each assayed in duplicates, and each duplicate measured twice, \pm SD. Missing error bars are too small to appear. The experiment was repeated once using GC/MS, obtaining similar results. Asterisks indicate significant differences between levels detected in wild type and sid2 plants or NahG plants, respectively, at the indicated time point, according to a student's $t$-test $\left(*, p \leq 0.1 *^{* *}, \mathrm{p} \leq 0.01 ; * * *, p \leq 0.001\right)$.

more than $25 \%$. Wound-induced JA levels were only slightly affected by SA alteration (Fig. 23) with lowered wound induction by about one fourth in sid2 (6.85 \pm 0.21 versus $9.25 \pm 0.32 \mathrm{nmol}$ $\mathrm{g}^{-1}$ fresh weight in wild type) and about one third in NahG $\left(5.89 \pm 0.33 \mathrm{nmol} \mathrm{g}{ }^{-1}\right.$ fresh weight) $2 \mathrm{~h}$ after wounding, and similar levels to wild type $4 \mathrm{~h}$ after wounding. However, levels of JAlle, representing the bioactive form of JA, were strongly reduced in both mutants $2 \mathrm{~h}$ after wounding (Fig. 23) with wild type showing $0.06 \pm 0.01$, sid2 $0.02 \pm 0.01$ and NahG $0.05 \pm 0.01 \mathrm{nmol} \mathrm{g}^{-1}$ fresh weight. This difference was less pronounced $4 \mathrm{~h}$ after wounding, with sid2 showing only a minor reduction and NahG a reduction of about $45 \%$.

Because SA-deficient mutants exhibited reduced wound-induced levels of JA-lle as well as of its precursors, $\mathrm{InsP}_{3}$ levels were determined after wounding in these plants (Fig. 24). Whereas wild type plants exhibited an increase in InsP $\mathrm{P}_{3}$ levels from $3.9 \pm 2.3$ to $17.4 \pm 8.5 \mathrm{nmol} \mathrm{g}^{-1}$ fresh 
weight, sid2 plants showed no increase but rather constant levels of $3.4 \pm 1.7$ and $4.3 \pm 2.9 \mathrm{nmol} \mathrm{g}^{-1}$ fresh weight (Fig. 24). NahG plants displayed an increase from $3.5 \pm 3.4$ to $11.3 \pm 5.8 \mathrm{nmol} \mathrm{g}^{-1}$ fresh weight $2 \mathrm{~h}$ after wounding, but deceeded wild type levels by about one third. $4 \mathrm{~h}$ after wounding the increase in NahG plants was declined below untreated levels (2.7 $\pm 0.3 \mathrm{nmol} \mathrm{g}^{-1}$ fresh weight), whereas wild type levels were still elevated clearly over control levels (10.7 $\pm 1.5 \mathrm{nmol} \mathrm{g}^{-1}$ fresh weight).

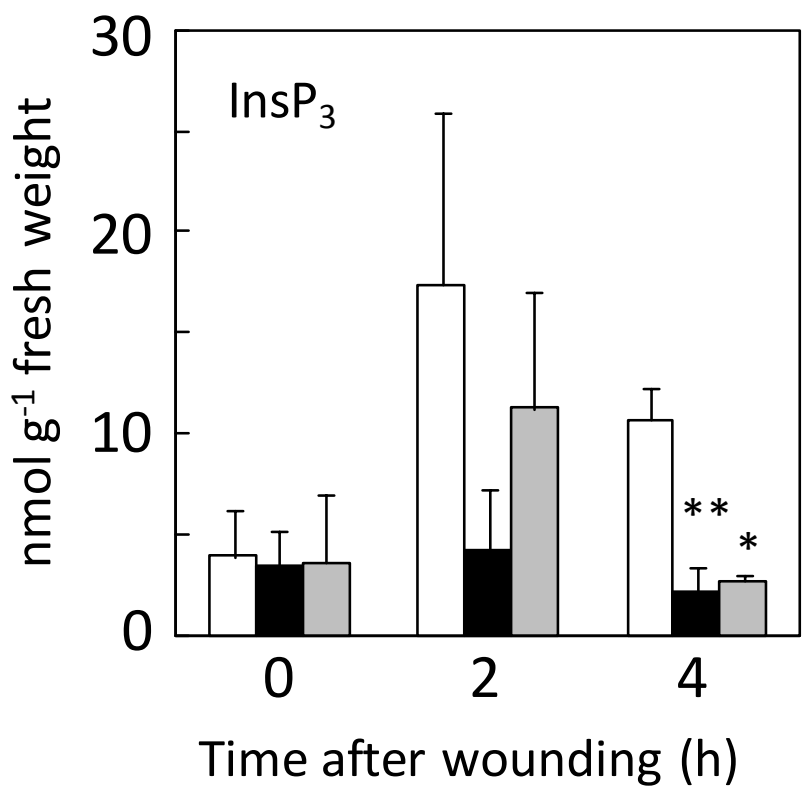

Fig. 24: Wound-induced InsP $\mathrm{P}_{3}$ levels in SA-deficient mutants sid2 and NahG. Rosette leaves of 7-weekold plants were wounded with forceps and harvested after the indicated times. Ins $\mathrm{P}_{3}$ levels were determined via a competitive protein binding assay in wild type plants (white columns) and sid2 (black columns) and NahG (grey columns). Mean values of two wounding experiment are shown, assayed in duplicates, \pm SD. Asterisks indicate significant differences between levels detected in wild type and in sid2 plants or in NahG plants, respectively, at the indicated time point, according to a student's $t$-test (*, $\mathrm{p} \leq 0.1 ; * *, \mathrm{p} \leq 0.01)$.

Taken together, both SA-deficient plant lines exhibited reduced or even abolished $\operatorname{InsP}_{3}$ induction with wounding. Whether this is a direct consequence of interference with SA content or rather has an indirect cause, possibly including lowered JA-Ile levels, remains unclear at this point.

After indicating $\mathrm{SA}$ signals to be relevant for proper $\operatorname{InsP}_{3}$ accumulation with wounding, reciprocally the requirement of $\mathrm{PI}$ signals for SA formation with wounding was tested. SA levels were determined in unwounded and wounded InsP 5-ptase and ipk1-1 plants, both differently impaired in PI signalling (Fig. 25). The measurement of SA content in InsP 5-ptase and wild type 


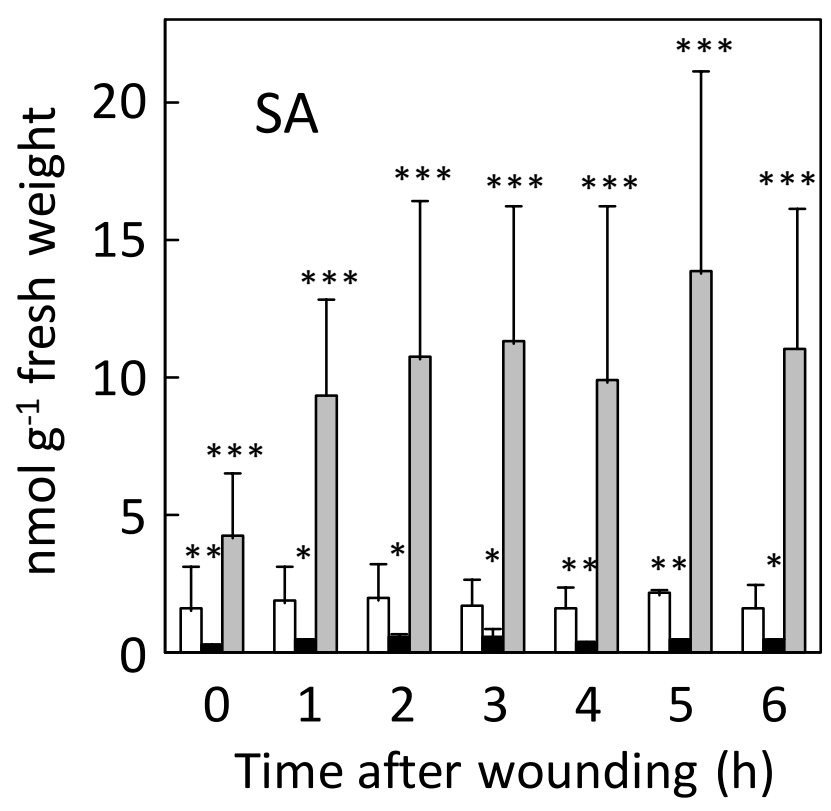

Fig. 25: Wound-induced SA levels in plants disturb in PI signalling. Rosette leaves of 7-week-old plants were wounded with forceps and harvested after the indicated times. SA levels were determined in wild type plants (white columns) and InsP 5-ptase (black columns) and ipk1-1 (grey columns). Mean values of two wounding experiment are shown, assayed in duplicates, and each duplicate measured twice, \pm SD. Missing error bars are too small to appear. Asterisks indicate significant differences between levels detected in wild type and in sid2 plants or in NahG plants, respectively, at the indicated time point, according to a student's $t$-test $(*, p \leq 0.1 ; * *, p \leq 0.01 ; * * *, p \leq 0.001)$.

plants was conducted by GC/MS and in ipk1-1 and wild type plants via LC/MS. As wild type SA levels matched between the two different methods, both results were joined in one figure (Fig. 25).

While global reduction of PI signalling components in InsP 5-ptase plants resulted in reduced levels of SA compared to wild type (wild type average levels of $1.8 \pm 0.2 \mathrm{nmol} \mathrm{g}^{-1}$ fresh weight, InsP 5-ptase average levels of about $0.5 \pm 0.1 \mathrm{nmol} \mathrm{g}^{-1}$ fresh weight), interruption of InsP $\mathrm{P}_{5}$ to Ins $\mathrm{P}_{6}$ conversion in ipk1-1 plants resulted in a pronounced accumulation of SA with its maximum of $17.4 \pm 8.5 \mathrm{nmol} \mathrm{g}^{-1}$ fresh weight $5 \mathrm{~h}$ after wounding, strongly exceeding wild type levels. Furthermore, SA levels were wound-inducible in ipk1-1 plants, whereas SA levels proceeded rather constant in wild type and InsP 5-ptase plants. The effects observed in ipk1-1 plants may be either caused by the absence of $\operatorname{lns}_{6}$, or by accumulation of precursors as $\operatorname{lns} \mathrm{P}_{5}$ or $\operatorname{InSP}_{4}$. 


\section{Discussion}

Previous experiments have demonstrated that PI signals are implicated in the Arabidopsis wounding response, indicated by an increase in $\operatorname{InsP}_{3}$ levels over a period of $6 \mathrm{~h}$ after wounding. Furthermore, wound-induced JA was indicated as an upstream factor of PI signals, as JA deficient dde2-2 plants failed to accumulate wound-induced Ins $\mathrm{P}_{3}$ (Mosblech et al, 2008).

\subsection{JA as an upstream factor of PI signals}

To test, if JA is sufficient for $\operatorname{InSP}_{3}$ induction, Arabidopsis rosette leaves were floated on MeJA solution (Fig. 6 A). Whereas this exogenous MeJA application did not induce $\operatorname{InsP}_{3}$ accumulation, sorbitol treatment known to trigger endogenous JA formation caused a substantial $\operatorname{InsP}_{3}$ induction (Fig. 6 B). Assuming that exogenous sorbitol treatment triggers the endogenous production of JA in plants, as has been suggested before (Reinbothe et al, 1994; Stenzel et al, 2003b; Weichert et al, 2000), these data are consistent with a role of JA upstream of InsP $\mathrm{P}_{3}$ in a linear signalling pathway. However, it cannot be differentiated, if sorbitol itself or $\mathrm{JA}$ or another factor induced by sorbitol treatment caused the accumulation of $\operatorname{InsP}_{3}$. Importantly, the mechanism by which sorbitol treatment influences JA signals has not been delineated, and therefore these data must be interpreted with caution.

DNA chip-based analysis of gene expression in Arabidopsis by Lin et al (2004b) revealed that PI signalling-related genes were induced by a variety of stimuli. Among those upregulated by MeJA treatment were inositol 1,4,5-trisphosphate 3-kinase and PLC, both involved in the formation of InsP $_{4}$ and InsP $\mathrm{P}_{5}$, supporting the hypothesis that JA is an upstream factor of inositol polyphosphate signals.

\subsection{PI signals required for wound responses and defence}

Alteration of gene expression patterns is the key to the manifestation of specific stress responses. In order to elucidate the impact of PI signals on Arabidopsis wound responses, wound-inducible gene expression was monitored in wild type and InsP 5-ptase plants (Fig. 7). Transcript accumulation upon wounding was lowered or delayed for various genes in InsP 5 - 
ptase plants, including COI1-dependent (AOS or VSP1) as well as COI1-independent genes (e.g. $R N S 1$ or OPR1), suggesting that PI signals influence wound-induced gene expression in a JAdependent as well as in a JA-independent manner. Moreover, the different expression patterns in InsP 5-ptase plants, displaying attenuation of early (AOS) or late expression (RNS1) or an overall delay in expression (OPR1), imply a complex network of Pl-dependent mechanisms for the regulation of gene expression. This interpretation is supported by biochemical results, indicating that $\mathrm{PI}$ signals not only play a role in JA signalling but are also involved in auxin signalling (Mosblech et al, 2008) as well as in SA signalling (Fig. 24 and 25). The strongly reduced expression of WRKY70 in InsP 5-ptase plants furthermore enhances the effect of PI signals in SA signalling or possibly within the crosstalk between JA and SA signals, since WRKY70 represents a regulatory node between both, as it positively regulates SAmediated defences while repressing JA-mediated responses ( $\mathrm{Li}$ et al, 2006; Li et al, 2004). In addition, altered WRKY70 expression suggests effects of PIs on the induction of cis-regulatory elements. So far, there are few examples for effects of PIs on transcription factors. An example for directly PI-dependent regulation of gene expression is presented by the mammalian transcription factor TUBBY, which binds to the plasma membrane in the presence of Ptdlns $(4,5) P_{2}$ and translocates to the nucleus upon Ptdlns $(4,5) P_{2}$ hydrolysis (Santagata et al, 2001).

To further delineate the impact of PI signals on plant defence responses, resistance to insect feeding was assessed by caterpillar growth performance tests (Fig. 8). Caterpillar growth with feeding on InsP 5-ptase plants was significantly faster than that on wild type plants and resembled that observed with feeding on dde2-2 plants (Fig. 8), suggesting that PI signals are of similar importance for Arabidopsis defence against herbivores as JA. Wound-induced production of defensins, which affect caterpillars' digestion of plant material, has been shown before to be JA-dependent, as caterpillars feeding on JA-deficient plants grew larger compared to those feeding on wild type plants (Chen et al, 2005; Kessler et al, 2004; Liu et al, 2005). The outcome of the feeding performance test on dde2-2 plants in this thesis (Fig. 8) closely resembled these earlier studies. The observations of this experiment support the notion that $\mathrm{PI}$ and JA signals act in the same signalling cascade. Moreover, the enhanced caterpillar performance on InsP 5-ptase plants implicates ecophysiological relevance of PI signals in mediating wound-induced plant defence reactions. 


\subsection{Are PI signals required for sensitivity towards JA-Ile?}

Interestingly, JA as well as its precursors and also the bioactive form JA-lle were elevated over wild type levels upon wounding in InsP 5-ptase plants over a $24 \mathrm{~h}$ period (Fig. 9), a time span within which the first differences of caterpillar growth performance on different plant lines became obvious (Fig. 8). This observation strengthens the impact of PI signals in plant defence responses, as wound-inducible gene expression and also defence against caterpillars was weakened in InsP 5-ptase plants, despite of elevated levels of JAs and JA-lle. Furthermore, the combination of reduced wound response together with high levels of JA-lle points towards the hypothesis that InsP 5-ptase plants impaired in PI signalling exhibit a partial insensitivity towards JA signals.

To compare InsP 5-ptase plants with established JA-insensitive plants, coi1 mutants were tested for their wound-induced oxylipin pattern (Fig. 11). The here newly established T-DNA insertion line coi1- $t$ exhibited JA-insensitive features known for the commonly used EMS line coi1-1 (Fig. 10). When tested for wound-induced oxylipins, both coi1-1 and coi1-t displayed reduced induction of JA and precursors, but elevated levels of JA-lle, clearly exceeding wild type levels (Fig. 11). However, while JA-lle levels of InsP 5-ptase plants displayed a similar pattern (Fig. 9), the wound induction of JA and JA precursors showed opposite patterns between coi1 mutants (Fig. 11) and InsP 5-ptase plants (Fig. 9), as the latter accumulated these jasmonates as well over wild type levels. This may indicate that the conversion of JA to JA-Ile is either negatively regulated by COI1 or independently of COI1 by another factor. As several enzymes of JA biosynthesis are known to be COl1-dependently expressed (Reymond et al, 2000), it is comprehensible that levels of JA and JA precursors are reduced in coi1 plants. However, the elevated levels of these compounds in InsP 5-ptase plants may be caused by a COI1-independent but PI-regulated mechanism.

The notion of partial insensitivity of InsP 5-ptase plants towards JA-lle raised the question why a reduction of inositol-containing signalling factors would affect JA sensitivity. Based on the information that an $\operatorname{InsP}_{6}$ is bound as a cofactor in the auxin receptor TIR1, it was a key working hypothesis of this thesis that an inositol polyphosphate is required as a cofactor also in the JA receptor COI1. 


\subsection{Exchange of putative inositol polyphosphate coordinating amino acids reduces COI1 functionality}

To test the hypothesis of a direct influence of an inositol polyphosphate on COI1 function, different coi $1_{\text {mut }}$ variants were created (Fig. 12 B). The results of the yeast two-hybrid experiments (Fig. 13) specified the mutated amino acid residues as being important for COI1 interaction with JAZ9, and even the exchange of single amino acids already impaired the coi $1_{\text {mut }} /$ JAZ9 interaction. Manipulation of amino acid residues may result in protein misfolding and subsequent protein degradation. Western blot analysis (Fig. 13 B) showed that all coi $1_{\text {mut }}$ variants were expressed to similar levels and not degraded, suggesting that reduced proteinprotein interactions of coi $1_{\text {mut }}$ and JAZ9 were due to reduced inositol polyphosphate binding rather than lower expression levels of the transgenes.

Since yeast is an artificial system to investigate the interaction of plant proteins, it was tested whether the reduced interaction of coil $1_{\text {mut }}$ variants with JAZ9 as determined in the yeast system translated into a reduced functionality of the COI1 protein in planta. Therefore, the coil $1_{\text {mut }}$ variants were tested for altered functionality in Arabidopsis mutant complementation tests of the coi1-t mutant. Data presented in Fig. 14 demonstrate that the exchange of single amino acids resulted in reduced complementation ability, depending on the exchanged amino acid position. As was the case for the coi $1_{\text {mut }} /$ JAZ9 interaction in yeast (Fig. 13), multiple exchanges led to severe reduction or complete loss of complementation ability also in Arabidopsis. It is important to note that with the exception of coi $1_{\mathrm{K} 81 \mathrm{~A}}$ and $\operatorname{coi}_{\mathrm{R} 121 \mathrm{~A}}$ single exchange variants completely lost their interaction potential with JAZ9 in yeast, but some single exchange variants still showed complementation potential in Arabidopsis, for example $\operatorname{coi}_{1} 516 \mathrm{~A}$ and $\operatorname{coi} 1_{\mathrm{R} 348 \mathrm{~A}}$. This observation may be explained by the higher complexity of the plant model and in particular by the existence of other JAZ proteins, which can possibly still interact with some of the coi $1_{\text {mut }}$ variants. Furthermore, the JA-lle analogue coronatine used in the yeast two-hybrid tests may influence the interaction of COI1 with its target proteins differently than the plant endogenous JA-lle. Although JA-lle is the proposed bioactive form of JA (Fonseca et al, 2009), other JA-amino acid conjugates, such as JA-leucin and JA-valin, can also promote the COI1/JAZ interaction (Katsir et al, 2008), and different JA-amino acid conjugates may, therefore, influence COI1/JAZ binding differently in different aspects of plant life.

To confirm that the function of the coil $1_{\text {mut }}$ variants was not only abolished in the artificial situation of exposing the seedlings to exogenous MeJA (Fig. 14 A), the development of functional siliques was determined (Fig. 14 B). There were slight differences upon complementation of the coi1-t mutant with coil $1_{\text {mut }}$ variants carrying single exchanges between 
complementation of the root growth phenotype and that restoring fertility. For instance,

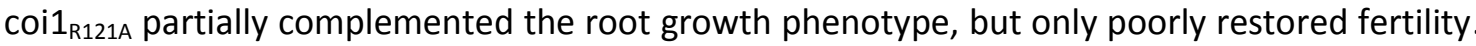
The opposite effect was observed for $\operatorname{coi}_{\mathrm{R} 516 \mathrm{~A}}$, which resulted in only partial complementation of seed development but exhibited close to full complementation of the root growth phenotype (Fig. 14 A). With regard to root growth and reproduction, different JAZ proteins as well as different downstream signalling elements, such as MAP kinases (MPK6) or transcription factors may be involved (Memelink, 2009). Besides slight differences in the two single amino acid exchange variants mentioned, the overall outcome of the silique analysis closely resembled the results from the root growth assays. Furthermore, with only minor differences in the details between the yeast two-hybrid tests and the Arabidopsis mutant complementation experiments, the results display similar patterns in these two independent model systems, thus, strongly supporting the notion that interfering with inositol polyphosphate binding in COI1 impairs COI1 function.

Whereas variable expression levels could be ruled out for the yeast experiments (Fig. 13), none of the COI1-derived protein variants were directly detectable in Western blots using Arabidopsis extracts. The analysis of mRNA levels by semi-quantitative RT-PCR revealed no correlation between specific transcript levels and complementation efficiency (Fig. 16). Furthermore, the analysis of fluorescence intensities of the marker protein DsRed suggests that differences in expression levels arising from positional effects of the genomic insertion loci did not contribute to the complementation patterns observed (Fig. 15). Importantly, DsRed intensities were strongest with constructs displaying the lowest complementation capabilities, an observation in line with the results from mRNA analysis. The observation that weak functional alleles of COI1 were expressed to high levels indicates that high COI1 expression is not readily tolerated by the plants. The control experiments performed indicate that differences observed in complementation capability between different coi $1_{\text {mut }}$ variants were not a result of varying expression levels but rather originated from the manipulation of the COI1 protein.

\subsection{Reduced function of $\mathrm{COI} 1$ in backgrounds with high $\operatorname{lns} \mathrm{P}_{5}$ and low $\operatorname{lns} \mathrm{P}_{6}$}

As an alternative approach to the analysis of coi $1_{\text {mut }}$ variants, and to rule out the possibility of incorrect folding or uneven expression of the altered COI1 variants, wild type COI 1 was tested for its functionality in yeast and plant backgrounds with altered inositol polyphosphate composition. In both yeast and Arabidopsis the enzyme IPK1 catalyzes a key step in the 
production of $\operatorname{InsP}_{6}$. Yeast and Arabidopsis mutants deficient in IPK1 have reduced levels of InsP $\mathrm{P}_{6}$ and instead accumulate precursors as Ins $\mathrm{P}_{5}$ (Ponnusamy et al, 2008; Stevenson-Paulik et al, 2005). This situation is markedly different from that reported for InsP 5-ptase plants, which have reduced levels of both $\operatorname{InsP}_{6}$ and $\operatorname{InsP}_{5}$ (Perera et al, 2008), as was already stressed in the introduction.

\subsubsection{COI1/JAZ9 interaction in ipk1 $1 \triangle$ yeast}

Data from yeast two-hybrid tests show that the COI1/JAZ9 interaction was stronger in the ipk1 $\Delta$ yeast strain than in the corresponding parental strain PJ69-4a (Fig. 17). Importantly, the Arabidopsis ipk1-1 mutant displayed enhanced responses to JA-mediated processes, including wound responses, defensive capabilities against caterpillar feeding and growth (Figs. 18-22). Preliminary microarray data indicate that COI1 expression levels were not elevated in Arabidopsis ipk1-1 plants (data not shown). As immunodetection of COI1 or coil $1_{\text {mut }}$ variants in plants failed, it cannot be conclusively decided whether the enhanced defence response in ipk1-1 plants was due to altered COI1 functionality or, possibly, protein stability.

\subsubsection{Biochemical characterization of ipk1-1 plants}

\subsubsection{PI signals in ipk1-1 plants}

When ipk1-1 plants were investigated in more detail for their wound-induced levels of InsP $\mathrm{P}_{3}$ and PI lipids, elevated levels of InsP $\mathrm{P}_{3}$ as well as of PtdIns4P and PtdIns(4,5) $\mathrm{P}_{2}$ over wild type levels were detected (Fig. 18). Without wounding, only minor differences between ipk1-1 and wild type were monitored, indicating that especially upon wounding these signalling compounds accumulated in ipk1-1 plants. These data indicate that the interruption of $\operatorname{InsP}_{6}$ biosynthesis not only results in accumulation of $\operatorname{InsP}_{5}$ and InsP $\mathrm{P}_{4}$ (Stevenson-Paulik et al, 2005), but that intermediates build up, at least under stress conditions. A feature shared by both plant lines ipk1-1 and InsP 5-ptase is the reduction of InsP $_{6}$ levels. The Arabidopsis ipk1-1 mutant is not only affected in the composition of soluble inositol polyphosphates, but displays elevated wound-induced accumulation of all PI pathway compounds, and therefore can be viewed as a tool with opposite conditions to InsP 5-ptase plants, which are reduced in the whole PI signalling pathway. 


\subsubsection{JA signals in ipk1-1 plants}

Wound-induced oxylipin levels were in general slightly enhanced in ipk1-1 plants compared to wild type controls (Fig. 19), except for oPDA levels, which were reduced. JA-lle levels in ipk1-1 plants displayed delayed wound induction. The course of early accumulation of oPDA and dnoPDA accompanied by increased JA levels and delayed JA-lle formation may reflect an early block of JA conversion to JA-lle, which results in accumulation of precursors. At later time points, JA-lle formation seems to proceed, decreasing OPDA and dn-oPDA levels and also lowering JA accumulation. If JA-lle perception is more pronounced in ipk1-1 plants due to elevated InsP $\mathrm{P}_{5}$ levels, this may cause an intensified feedback inhibition of JA-lle synthesis. Why JA-lle exceeds wild type levels at later time points is still unclear.

When oxylipin levels of InsP 5-ptase plants with a globally reduced PI pathway and ipk1-1 with accumulation of PI components upstream of $\mathrm{InsP}_{6}$ are compared (Fig. 9 and 19), clearly a reduction of $\mathrm{PI}$ signals results in accumulation of oxylipins, especially JA-Ile, whereas accumulation of most PI signals in ipk1-1 plants has only minor effects on oxylipin levels and results only in a slight elevation. Taking into account that JA-lle is the relevant bioactive form of JA, accumulation of PI components upstream of InsP $\mathrm{P}_{6}$ in ipk1-1 plants caused a delay in JA signals, whereas the global reduction of the PI pathway in InsP 5-ptase plants resulted in accumulation of JA signals. Considering that in both plant lines $\operatorname{InsP}_{6}$ levels are reduced, whereas other PI components are manipulated in opposite patterns, the different effects monitored in both plant lines are likely due to the up or down regulation of the remaining PI signalling components, rather than a consequence of altered $\operatorname{InsP}_{6}$ levels.

Thus, it may be assumed that reduction of PI signals results in accumulation of wound-induced oxylipins while increased PI signals only slightly enhanced biosynthesis of jasmonates and rather delayed JA-Ile signals.

\subsubsection{COI1-mediated responses in ipk1-1 plants}

As ipk1-1 plants displayed enhanced wound-inducible gene expression and increased resistance against caterpillar feeding (Fig. 20 and 21), these plants were suggested to be hypersensitive towards jasmonates.

The increased JA sensitivity in ipk1-1 plants may be a result of the slight elevation of jasmonates with wounding in these plants (Fig. 19). However, InsP 5-ptase plants with reduced JA sensitivity displayed pronounced increases in wound-induced jasmonates over wild type levels (Fig. 9), suggesting that increases in JA-lle levels do not per se correlate with increased JA sensitivity. Furthermore, the JA-insensitive coil mutants accumulate JA-lle over wild type 
levels, indicating that levels of jasmonates and JA sensitivity are not linked. The impact of PI signals on JA sensitivity is stressed by the fact that the levels of JA-lle in ipk1-1 plants were rather delayed than enhanced.

The enhanced JA sensitivity in ipk1-1 plants may either result from reduced Ins $\mathrm{P}_{6}$ levels or from accumulation of $\mathrm{InsP}_{5}$ or other upstream components of the PI pathway. Differences between ipk1-1 and wild type plants were most pronounced in the levels of InsP $_{5}$ (about 30 times higher without stimulus; Stevenson-Paulik et al, 2005) and lower phosphorylated inositols, while differences in PI lipid levels were less distinct (with wound stimulus not exceeding three times increases over wild type levels; Fig. 18 B). Thus, it is more likely that the observed increased wound response and defence in ipk1-1 plants results from increased inositol polyphosphates rather than from increases in PI lipids. Alteration of putative inositol polyphosphate binding residues resulted in clearly lowered COI1 functionality (Figs. 13 and 14), rather than increasing it, and it appears unlikely that reduced InsP $_{6}$ production would enhance responses to JAmediated processes. Furthermore, the comparison with data from experiments on InsP 5ptase plants, in which both Ins $\mathrm{P}_{6}$ and $\operatorname{Ins}_{5}$ are reduced and which showed attenuated wound responses (Fig. 7 and 8; Mosblech et al, 2008), suggests that accumulation of InsP $_{5}$, not a lack of InsP $\mathrm{P}_{6}$, might be the relevant factor. The patterns of complementation of the Arabidopsis coi1- $t$ mutant by different coi $1_{\text {mut }}$ variants is also consistent with the hypothesis that the increased JA sensitivity observed in ipk1-1 plants is a direct effect of alterations in inositol polyphosphates influencing COI1 functionality rather than having an indirect cause. In conclusion, the data indicate that the inositol polyphosphate required for COI 1 function is likely InsP $P_{5}$.

\subsection{InsP 5 as a cofactor of COI1}

The hypothesis of $\operatorname{InsP}_{5}$ supporting COI1 function is additionally supported by studies performed on the CSN of mammalian cells. The inositol 1,3,4-trisphosphate 5/6 kinase (5/6 kinase) phosphorylates $\operatorname{InsP}_{3}$ to form $\operatorname{InsP}_{4}$, the rate limiting step of $\operatorname{InsP}_{5}$ and $\operatorname{InsP_{6}}$ biosynthesis in mammals (Wilson et al, 2001). Interestingly, the 5/6 kinase co-purifies with the CSN from cow brain (Wilson et al, 2001) and is conserved in sequence between kingdoms from plants to humans. It is conceivable that the association of such an enzyme with the CSN, which assembles with SCF ${ }^{\mathrm{CO} 11}$ also in Arabidopsis (Feng et al, 2003), provides the catalytic activity for synthesis of an inositol polyphosphate in close proximity to the COI1 protein. 
Wounding-induced biosynthesis of inositol polyphosphates raises the question for the benefit of a transiently produced cofactor. In wild type yeast as well as in wild type plants the reported basal InsP $P_{5}$ levels are very low (Stevenson-Paulik et al, 2005; York et al, 1999). However, the published data only report inositol polyphosphate levels for non-stimulated cells. While there is currently no information about $\mathrm{InsP}_{5}$ levels after wounding or other JA-inducing stimuli, we have previously shown that $\mathrm{InsP}_{3}$ levels strongly increase in Arabidopsis upon wounding (Mosblech et al, 2008), which may provide intermediates for further phosphorylation and production of InsP $P_{5}$. This $\operatorname{InsP}_{3}$ accumulation was even enhanced in ipk1-1 plants (Fig. 18 A). Considering the effects of $\mathrm{InSP}_{5}$ on COI1 function described here, increased production of $\mathrm{InsP}_{5}$ might be part of an activating mechanism for COI1, which might enhance its affinity to JA-lle or its target proteins.

While all data presented can be explained by focusing on known information on COI1, it is clear that plant signalling is highly complex and COI1 will not be the only player influenced by perturbed inositol polyphosphate metabolism. In this context, it should be noted that the increased complexity of the plant systems is not present in the yeast model, which served as an independent control to support reported findings made in Arabidopsis. In any case, indirect effects of altered inositol polyphosphate levels must also be considered when explaining the observations made. Since ipk1-1 plants display low levels of InsP $_{6}$ (Stevenson-Paulik et al, 2005 ) it is likely that, for instance, auxin signalling is affected, because $\operatorname{Ins}_{6}$ is bound as a cofactor to TIR1 (Tan et al, 2007). Manipulations in InsP $\mathrm{P}_{6}$ content can possibly lead to altered auxin signals, which could then directly or indirectly influence JA signals. Furthermore, cation balance may be influenced by $\mathrm{InsP}_{6}$ reduction, as $\mathrm{Ca}^{2+}$ release was reported upon $\operatorname{InsP}_{6}$ formation (Lemtiri-Chlieh et al, 2003), which might also be relevant for wound responses (Howe \& Jander, 2008). Additionally, $\mathrm{InsP}_{6}$ may build complexes with divalent cations and also affect $\mathrm{K}^{+}$ion channels (Nagy et al, 2009), and cation imbalances may have multiple consequences for various cellular processes including stress responses. However, such scenarios are not supported by current data and must remain speculative at this point.

The data obtained on InsP $_{5}$ function in COI1 in this thesis are strongly supported by a concurrent study from Sheared et al (John Browse, personal communication; data submitted to nature). Besides demonstrating that COI1 together with JAZ proteins build the receptor for JA-lle, their data on the COI1 crystal structure together with MS data and additional pharmacological results also indicate $\mathrm{InsP}_{5}$ as a cofactor of COI1. When InsP $\mathrm{P}_{5}$ was removed from purified COI1 protein, only trace activity of JA-Ile binding in the presence of JAZ1 protein was revealed, but this activity was restored by the addition of exogenous $\operatorname{InsP}_{5}$. Interestingly, only the isomer $\operatorname{Ins}(1,2,4,5,6) \mathrm{P}_{5}$ was found to copurify with COI1. The InsP $\mathrm{P}_{5}$ isomer 
accumulating in ipk1-1 mutants is Ins $(1,3,4,5,6) \mathrm{P}_{5}$, whereas the isomer detectable in wild type Arabidopsis is Ins $(1,2,4,5,6) \mathrm{P}_{5}$ (Stevenson-Paulik et al, 2005). Possibly, COI1 also interacts with non-favoured isomers of $\operatorname{InsP}_{5}$ if they are supplied in high concentrations, as it is the case in ipk1 mutants.

Sheared et al. also identified positions K81, R121, R348 and R409 but not R516 as being likely involved in inositol phosphate binding, and additionally they identified 14 other residues to have contact to phosphate groups. This on one hand confirms four of the five residues that were tested in this thesis for their role in InsP $\mathrm{P}_{5}$ binding, and on the other hand highlights that $\mathrm{InsP}_{5}$ binding of COI1 is far more complex than expected. Nonetheless, the study by Sheared at al. strongly supports the findings of this thesis. While their protein biochemical data represent proof that $\operatorname{InsP}_{5}$ is bound to COI1, the experiments conducted in this thesis depict the physiological importance of this cofactor for plant defence as well as plant development.

In conclusion, the combined data from yeast and plant models as well as the comparison of relevant transgenic and mutant lines of Arabidopsis presented in this thesis give a well-defined picture of how $\mathrm{InsP}_{5}$ is important for the regulation of COI1 functionality. The emerging view suggests that upon wounding the formation of $\operatorname{InsP}_{5}$ commences, which might act as a cofactor in COI1 to mediate increased affinity to COI1 substrates. This notion is in line with previously proposed concepts (Heilmann et al, 2001; Perera et al, 2001) suggesting that upon stress an initial "wake up call" activates a whole set of internal signals, which are afterwards further integrated to establish a specific signal signature initiating an appropriate response for each stimulus perceived.

\subsection{Integrating PI signals into a greater signalling network: a switch between JA and SA signalling?}

Having addressed the detailed mode of action of inositol polyphosphates in JA-lle perception by COI1, the question remains how this information must be interpreted in a greater view of plant signalling.

Analysis of jasmonates in SA-deficient Arabidopsis lines revealed that wound-induced oxylipin formation was reduced or delayed, with JA-lle levels showing the most pronounced reduction compared to wild type induction (Fig. 23). This may indicate that JA and SA signals act synergistically during wound responses, a concept in contrast to results observed upon pathogen infection. Spoel et al (2003) reported strongly elevated JA accumulation in NahG 
plants after inoculation with $P$. syringae, while in wild type plants only minor increases of JA were detectable. Whereas JA and SA seem to antagonize one another during responses to pathogen infection, responses to wounding may require both JA and SA, with SA acting upstream of JA signals. Synergistic effects were reported upon JA and SA application at low concentrations (Loake \& Grant, 2007; Mur et al, 2006).

To elucidate the relation between PI and SA signals during wound responses, wound-induced Ins $_{3}$ levels were determined in sid2 and NahG plants (Fig. 24) and, reciprocally, woundinduced SA-levels were determined in InsP 5-ptase and ipk1-1 plants (Fig. 25). InsP accumulation was reduced in both sid 2 and $N a h G$, indicating that SA signals are relevant for PI signal induction upon wounding. This observation is in line with reports on Arabidopsis cell suspension cultures, in which PtdlnsP(4,5) $\mathrm{P}_{2}$ formation driven by increased PI4-kinase activity was inducible by SA treatment (Krinke et al, 2007b). However, InsP $\mathrm{P}_{3}$ accumulation was not SAinducible in the cell culture, which may specify PI lipids as a factor being induced by SA alone. The wound stimulus may then induce further metabolism of PI lipids to form InsP $\mathrm{P}_{3}$ and other soluble inositol polyphosphates. As InsP $\mathrm{P}_{3}$ accumulation also failed in JA-deficient $d d e 2-2$ plants (Mosblech et al, 2008), it is conceivable that both SA and JA are required in combination for PI induction upon wounding.

In a reciprocal experiment, when InsP 5-ptase and ipk1-1 plants were tested for their woundinduced SA contents (Fig. 25), PI signals seemed to be required for SA formation. InsP 5-ptase plants with reduced PI signals displayed strongly reduced SA levels, whereas ipk1-1 plants exhibited SA amounts strongly elevated over those of wild type controls (Fig. 25). This pattern indicates that $\mathrm{PI}$ signalling components other than $\operatorname{Ins}_{6}$, which accumulate in ipk1-1 plants, may boost SA accumulation upon wounding.

The results allow speculation on a self-reinforcing loop of JA, SA and PI signals in the Arabidopsis wound response. A possible network is depicted as a simplified model in Fig. 26. Upon wounding, in the first place JA-lle is rapidly formed (Fig. 26, point 1; Glauser et al, 2008) and required for induction of $\mathrm{PI}$ signals, as indicated by JA-deficient dde2-2 plants, which do not accumulate $\mathrm{InSP}_{3}$ upon wounding (Fig. 26, point 2; Mosblech et al, 2008). PI signals in turn promote SA formation (Fig. 26, point 3). This notion is supported by the finding that InsP 5ptase plants exhibited reduced SA-levels, whereas ipk1-1 plants exhibit elevated SA levels (Fig. 25). SA accumulation then further induces JA-lle signals or promotes the maintenance of the JA-lle signal (Fig. 26, point 4), as SA-deficient mutants contained reduced levels of JA-lle upon wounding (Fig. 23). Furthermore, the reduced wound induction of InsP $\mathrm{P}_{3}$ signals in SAdeficient mutants (Fig. 24) suggests that SA is required for the induction of the PI pathway or 


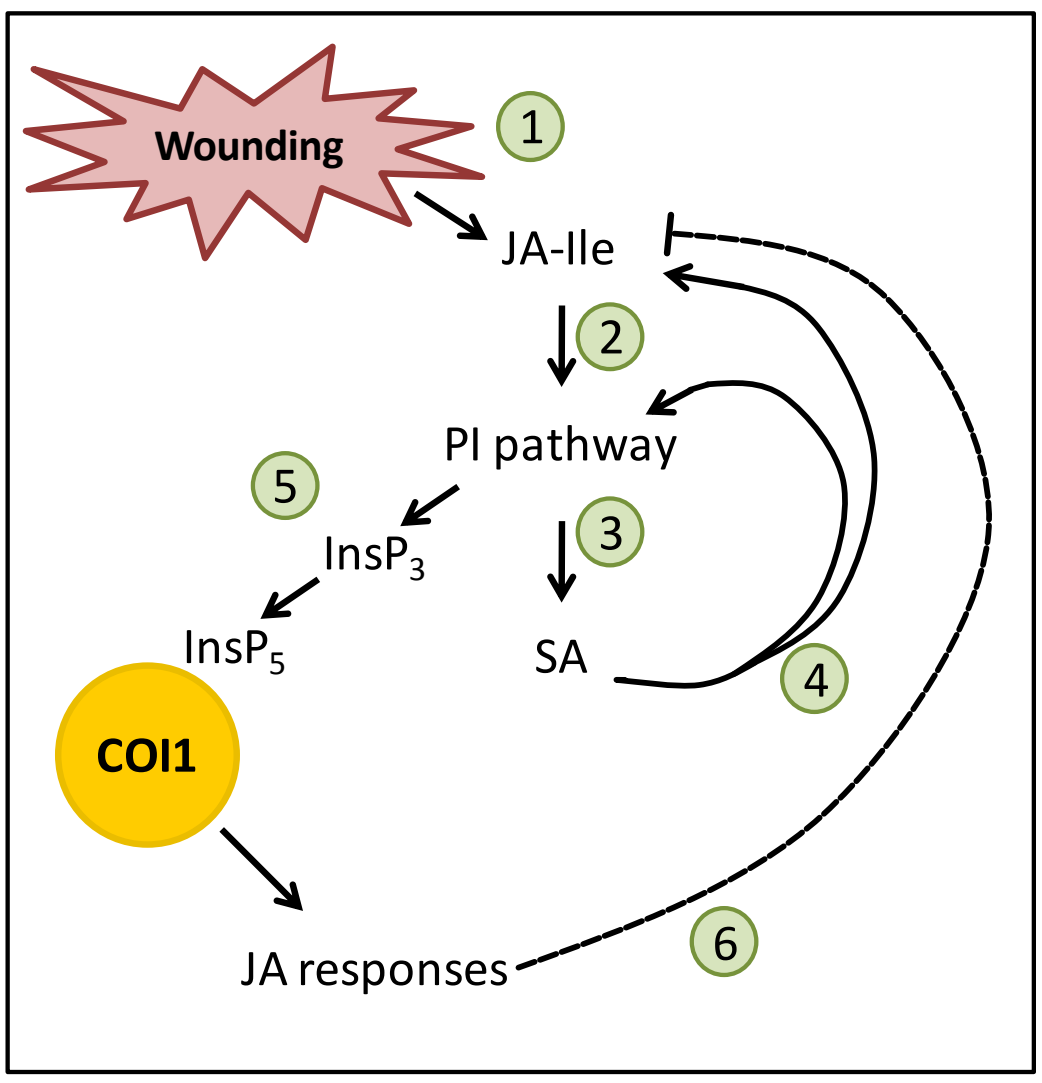

Fig. 26: Simplified model of JA/SA/PI action in Arabidopsis wound response. Black arrows indicate synergistic effects, dashed line indicates antagonistic effect. Explanation of numbers 1-6 see text.

to maintain PI signalling (Fig. 26, point 4). Data represented in this thesis suggest that JA-lle can best be perceived with $\mathrm{InSP}_{5}$ present in the COI1 protein. To allocate sufficient amounts of InsP $_{5}$, SA may activate a PI4-kinase and the PI pathway is put into operation (Fig. 26, point 4;

Krinke et al, 2007b). With InsP $P_{5}$ bound in the COI1 protein (Fig. 26, point 5), JA responses may proceed and induce appropriate gene expression as well as a repression of JA-lle signals (Fig. 26, point 6), as coi1 mutants and also InsP 5-ptase plants exhibit increased woundinduced accumulation of JA-lle. In this model, the role of SA would be to potentiate the wound-induced JA signal in close interaction with PI signals. A process like this would offer various points to fine tune the signal composition in order to achieve a specific and targeted defence response.

The model presented in Fig. 26 is based on a limited volume of data and must remain largely speculative. As potato plants with altered inositol polyphosphate metabolism and deficient in InsP $\mathrm{P}_{6}$ formation exhibited reduced resistance to viruses, bacteria and fungal pathogens (Murphy et al, 2008), it may be speculated that $\operatorname{Ins}_{6}$ is also involved in SA-mediated defence, whereas $\operatorname{InsP}_{5}$ supports JA-mediated defence. The balance between InsP $\mathrm{P}_{5}$ and $\operatorname{Ins} \mathrm{P}_{6}$ might display a switch to push the defence reaction in one or the other direction, and possibly there is a link to auxin signalling via TIR1. JA and auxin signals are both perceived via similar 
machineries, including F-box protein receptors that are part of SCF E3 ubiquitin ligase complexes. Importantly, the auxin receptor TIR1 carries an InsP $\mathrm{P}_{6}$ as cofactor, whereas the JA receptor COI1 requires an $\mathrm{InsP}_{5}$ cofactor, as demonstrated in this thesis. Truman et al (2010) have proposed a model, in which JA signals induced by pathogen infection are followed by a phase of auxin signals, which in turn initiate SA signalling. In such a model, the transition from $J A$ to auxin signals could be supported by a change in $\operatorname{InsP}_{5} / \operatorname{InsP}_{6}$ balance, which would influence the sensitivity of either the JA or the auxin receptor. In fact, this suggestion does not interfere with the proposed scheme presented in Fig. 26, but would rather complete the suggested model.

Future analysis may fill some of the informational gaps and reveal even more links between signalling pathways that should be viewed as an integrated and interdependent signalling network of exceeding complexity.

\subsection{Conclusions}

The data presented in this thesis indicate that the production of inositol polyphosphates in Arabidopsis is important for sensitivity of JA perception. The proposed mechanism for this effect involves binding of $\operatorname{InSP}_{5}$ as a cofactor to $\mathrm{COI} 1$, which is altered by this interaction either in its affinity to JA-lle itself, its target protein, JAZ, or in its inherent stability. Stress-induced increases in inositol polyphosphates might be part of a fine-tuning mechanism for phytohormone receptors, including COI1 and TIR1. By redeploying the production of InsP $\mathrm{P}_{5}$ or InsP $\mathrm{P}_{6}$, different stress consitions may influence the plant's signalling network towards effects mediated by JA or auxin. At this point it is clear that other mediators, such as SA, are also involved in this regulation; the precise contribution of these factors, however, remains open for future investigations. 


\section{SUMMARY}

Plant responses to wounding are of central importance during defence against herbivores and therefore tightly regulated. Hereby the isoleucin conjugate of jasmonic acid (JA-lle) is a major regulatory molecule. In this thesis, phosphoinositide (PI) signals not previously implicated in plant wound responses have been studied and are introduced as new components active in the signalling network regulating plant defence responses.

Transgenic Arabidopsis InsP 5-ptase plants that are attenuated in PI signalling exhibited decreased wound-induced gene expression as well as reduced defence against caterpillar feeding. These results indicate that wound-induced accumulation of PI signals is required for full wounding and defence responses. Besides their attenuated defence, InsP 5-ptase plants accumulated JA-Ile in a pattern also found for JA-insensitive Arabidopsis coi1 mutants. These data suggest that InsP 5-ptase plants are partially insensitive towards JA-Ile. To explain the interdependency of PI-derived signals and JA-lle perception, the Arabidopsis JA-lle receptor, COI1, was compared with the auxin receptor, TIR1, which contains an inositol hexakisphosphate $\left(\mathrm{InsP}_{6}\right)$ cofactor. Based on the structural similarity of COI1 and TIR1 the possibility was explored that an inositol polyphosphate cofactor is required for COI1 function. COI1 variants, in which putative inositol polyphosphate coordinating amino acids were exchanged for alanines, exhibited reduced interaction with the COI1 target, JAZ9, in yeast twohybrid tests. Consistent with the yeast two-hybrid data, the same COI1 variants displayed reduced capability to rescue jasmonate-mediated root growth inhibition or silique development in Arabidopsis coi1 mutants. Further yeast two-hybrid tests using wild type COI1 in an ipk1 $1 \Delta$ yeast strain with increased levels of inositol pentakisphosphate $\left(\operatorname{InsP}_{5}\right)$ and reduced levels of InsP $_{6}$ indicated an enhanced COI1/JAZ9 interaction. Consistent with these findings, Arabidopsis ipk1-1 mutants, also with increased $\operatorname{InsP}_{5}$ and reduced $\operatorname{InsP}_{6}$ levels, showed increased defensive capabilities via COI1-mediated processes, including wound-induced gene expression, defence against caterpillars, or root growth inhibition by jasmonate. The combined data from yeast and Arabidopsis experiments indicate that an inositol polyphosphate and likely InsP $_{5}$ is required for COI1 function in Arabidopsis. Experiments on salicylic acid (SA)-deficient Arabidopsis mutants suggest a further interrelation between SA and PI signals in wounding responses, establishing PI-derived signals as a central component of the regulatory network controlling Arabidopsis responses to wounding. 


\section{LITERATURE}

Alcazar-Roman AR, Tran EJ, Guo S, Wente SR (2006) Inositol hexakisphosphate and Gle1 activate the DEAD-box protein Dbp5 for nuclear mRNA export. Nat Cell Bio/ 8(7): 711-716

Anderson JP, Badruzsaufari E, Schenk PM, Manners JM, Desmond OJ, Ehlert C, Maclean DJ, Ebert PR, Kazan K (2004) Antagonistic interaction between abscisic acid and jasmonateethylene signaling pathways modulates defense gene expression and disease resistance in Arabidopsis. Plant Cell 16(12): 3460-3479

Balbi V, Devoto A (2008) Jasmonate signalling network in Arabidopsis thaliana: crucial regulatory nodes and new physiological scenarios. New Phytol 177(2): 301-318

Bargmann BO, Laxalt AM, ter Riet B, Testerink C, Merquiol E, Mosblech A, Leon-Reyes A, Pieterse CM, Haring MA, Heilmann I, Bartels D, Munnik T (2009) Reassessing the role of phospholipase D in the Arabidopsis wounding response. Plant Cell Environ 32(7): 837-850

Bauw G, Nielsen HV, Emmersen J, Nielsen KL, Jorgensen M, Welinder KG (2006) Patatins, Kunitz protease inhibitors and other major proteins in tuber of potato cv. Kuras. Febs $J$ 273(15): 3569-3584

Beckers GJ, Spoel SH (2006) Fine-Tuning Plant Defence Signalling: Salicylate versus Jasmonate. Plant Biol (Stuttg) 8(1): 1-10

Benedetti CE, Xie D, Turner JG (1995) Coi1-dependent expression of an Arabidopsis vegetative storage protein in flowers and siliques and in response to coronatine or methyl jasmonate. Plant Physiol 109(2): 567-572

Berridge MJ, Irvine RF (1984) Inositol trisphosphate, a novel second messenger in cellular signal transduction. Nature 312(5992): 315-321

Berwin B, Floor E, Martin TF (1998) CAPS (mammalian UNC-31) protein localizes to membranes involved in dense-core vesicle exocytosis. Neuron 21(1): 137-145

Bostock RM (2005) Signal crosstalk and induced resistance: straddling the line between cost and benefit. Annu Rev Phytopathol 43: 545-580

Boter M, Ruiz-Rivero O, Abdeen A, Prat S (2004) Conserved MYC transcription factors play a key role in jasmonate signaling both in tomato and Arabidopsis. Genes Dev 18(13): 1577-1591

Braun M, Baluska F, von Witsch M, Menzel D (1999) Redistribution of actin, profilin and phosphatidylinositol-4, 5-bisphosphate in growing and maturing root hairs. Planta 209(4): 435443

Brinch-Pedersen H, Sorensen LD, Holm PB (2002) Engineering crop plants: getting a handle on phosphate. Trends Plant Sci 7(3): 118-125 
Brodersen P, Petersen M, Bjorn Nielsen H, Zhu S, Newman MA, Shokat KM, Rietz S, Parker J, Mundy J (2006) Arabidopsis MAP kinase 4 regulates salicylic acid- and jasmonic acid/ethylenedependent responses via EDS1 and PAD4. Plant J 47(4): 532-546

Brooks DM, Bender CL, Kunkel BN (2005) The Pseudomonas syringae phytotoxin coronatine promotes virulence by overcoming salicylic acid-dependent defences in Arabidopsis thaliana. Mol Plant Pathol 6(6): 629-639

Browse J, Howe GA (2008) New weapons and a rapid response against insect attack. Plant Physiol 146(3): 832-838

Bullock WO, Fernandez JM, Short JM (1987) XL1-Blue: a high efficiency plasmid transforming recA Escherichia coli strain with beta-galactosidase selection. Biotechniques 5: 376-378

Cao H, Glazebrook J, Clarke JD, Volko S, Dong X (1997) The Arabidopsis NPR1 gene that controls systemic acquired resistance encodes a novel protein containing ankyrin repeats. Cell 88(1): 57-63

Chen H, Wilkerson CG, Kuchar JA, Phinney BS, Howe GA (2005) Jasmonate-inducible plant enzymes degrade essential amino acids in the herbivore midgut. Proc Natl Acad Sci U S A 102(52): 19237-19242

Chen Z, Zheng Z, Huang J, Lai Z, Fan B (2009) Biosynthesis of salicylic acid in plants. Plant Signal Behav 4(6): 493-496

Chini A, Boter M, Solano R (2009a) Plant oxylipins: COI1/JAZs/MYC2 as the core jasmonic acidsignalling module. FEBS J 276(17): 4682-4692

Chini A, Fonseca S, Chico JM, Fernandez-Calvo P, Solano R (2009b) The ZIM domain mediates homo- and heteromeric interactions between Arabidopsis JAZ proteins. Plant J 59(1): 77-87

Chini A, Fonseca S, Fernandez G, Adie B, Chico JM, Lorenzo O, Garcia-Casado G, Lopez-Vidriero I, Lozano FM, Ponce MR, Micol JL, Solano R (2007) The JAZ family of repressors is the missing link in jasmonate signalling. Nature 448(7154): 666-671

Cho MH, Chen Q, Okpodu CM, Boss WF (1992) Separation and quantification of of $\left.{ }^{3} \mathrm{H}\right]$ inositol phospholipids using thin-layer-chromatography and a computerized ${ }^{3} \mathrm{H}$ imaging scanner. LC-GC 10: $464-468$

Chomczynski P, Mackey K (1995) Short technical reports. Modification of the TRI reagent procedure for isolation of RNA from polysaccharide- and proteoglycan-rich sources. Biotechniques 19(6): 942-945

Christie WW (2003) Thin-layer chromatography. In Lipid analysis Vol. 15, pp 142-152. Bridgwater: The Oily Press

Chung HS, Howe GA (2009) A critical role for the TIFY motif in repression of jasmonate signaling by a stabilized splice variant of the JASMONATE ZIM-domain protein JAZ10 in Arabidopsis. Plant Cell 21(1): 131-145 
Chung HS, Koo AJ, Gao X, Jayanty S, Thines B, Jones AD, Howe GA (2008) Regulation and function of Arabidopsis JASMONATE ZIM-domain genes in response to wounding and herbivory. Plant Physiol 146(3): 952-964

Cope GA, Suh GS, Aravind L, Schwarz SE, Zipursky SL, Koonin EV, Deshaies RJ (2002) Role of predicted metalloprotease motif of Jab1/Csn5 in cleavage of Nedd8 from Cul1. Science 298(5593): 608-611

Creelman RA, Mullet JE (1995) Jasmonic acid distribution and action in plants: regulation during development and response to biotic and abiotic stress. Proc Natl Acad Sci U S A 92(10): 4114-4119

Creelman RA, Mullet JE (1997) Biosynthesis and action of jasmonates in plants. Annu Rev Plant Physiol Plant Mol Biol 48: 355-381

Cui J, Bahrami AK, Pringle EG, Hernandez-Guzman G, Bender CL, Pierce NE, Ausubel FM (2005) Pseudomonas syringae manipulates systemic plant defenses against pathogens and herbivores. Proc Natl Acad Sci U S A 102(5): 1791-1796

del Pozo O, Pedley KF, Martin GB (2004) MAPKKKalpha is a positive regulator of cell death associated with both plant immunity and disease. EMBO J 23(15): 3072-3082

Delaney TP, Uknes S, Vernooij B, Friedrich L, Weymann K, Negrotto D, Gaffney T, Gut-Rella M, Kessmann H, Ward E, Ryals J (1994) A central role of salicylic Acid in plant disease resistance. Science 266(5188): 1247-1250

Delker C, Stenzel I, Hause B, Miersch O, Feussner I, Wasternack C (2006) Jasmonate biosynthesis in Arabidopsis thaliana--enzymes, products, regulation. Plant Biol (Stuttg) 8(3): 297-306

Demarsy E, Fankhauser C (2009) Higher plants use LOV to perceive blue light. Curr Opin Plant Biol 12(1): 69-74

Devoto A, Turner JG (2003) Regulation of jasmonate-mediated plant responses in arabidopsis. Ann Bot 92(3): 329-337

Dewdney J, Reuber TL, Wildermuth MC, Devoto A, Cui J, Stutius LM, Drummond EP, Ausubel FM (2000) Three unique mutants of Arabidopsis identify eds loci required for limiting growth of a biotrophic fungal pathogen. Plant J 24(2): 205-218

Doares SH, Narvaez-Vasquez J, Conconi A, Ryan CA (1995) Salicylic acid inhibits synthesis of proteinase inhibitors in tomato leaves induced by systemin and jasmonic acid. Plant Physiol 108(4): 1741-1746

Dohmen RJ, Wu P, Varshavsky A (1994) Heat-inducible degron: a method for constructing temperature-sensitive mutants. Science 263(5151): 1273-1276

Dombrecht B, Xue GP, Sprague SJ, Kirkegaard JA, Ross JJ, Reid JB, Fitt GP, Sewelam N, Schenk PM, Manners JM, Kazan K (2007) MYC2 differentially modulates diverse jasmonate-dependent functions in Arabidopsis. Plant Cell 19(7): 2225-2245 
Dong CH, Xia GX, Hong Y, Ramachandran S, Kost B, Chua NH (2001) ADF proteins are involved in the control of flowering and regulate F-actin organization, cell expansion, and organ growth in Arabidopsis. Plant Cell 13(6): 1333-1346

Dong X (2004) NPR1, all things considered. Curr Opin Plant Biol 7(5): 547-552

Drobak BK, Dewey RE, Boss WF (1999) Phosphoinositide kinases and the synthesis of polyphosphoinositides in higher plant cells. Int Rev Cytol 189: 95-130

Drobak BK, Watkins PA $(2000)$ Inositol(1,4,5)trisphosphate production in plant cells: an early response to salinity and hyperosmotic stress. FEBS Lett 481(3): 240-244

Fammartino A, Cardinale F, Gobel C, Mene-Saffrane L, Fournier J, Feussner I, Esquerre-Tugaye MT (2007) Characterization of a divinyl ether biosynthetic pathway specifically associated with pathogenesis in tobacco. Plant Physiol 143(1): 378-388

Feng S, Ma L, Wang X, Xie D, Dinesh-Kumar SP, Wei N, Deng XW (2003) The COP9 signalosome interacts physically with SCF COI1 and modulates jasmonate responses. Plant Cell 15(5): 10831094

Fenn JB, Mann M, Meng CK, Wong SF, Whitehouse CM (1989) Electrospray ionization for mass spectrometry of large biomolecules. Science 246(4926): 64-71

Feussner I, Wasternack C, Kindl H, Kuhn H (1995) Lipoxygenase-catalyzed oxygenation of storage lipids is implicated in lipid mobilization during germination. Proc Natl Acad Sci U S A 92(25): 11849-11853

Feys B, Benedetti CE, Penfold CN, Turner JG (1994) Arabidopsis Mutants Selected for Resistance to the Phytotoxin Coronatine Are Male Sterile, Insensitive to Methyl Jasmonate, and Resistant to a Bacterial Pathogen. Plant Cell 6(5): 751-759

Fitzgerald HA, Chern MS, Navarre R, Ronald PC (2004) Overexpression of (At)NPR1 in rice leads to a $\mathrm{BTH}$ - and environment-induced lesion-mimic/cell death phenotype. Mol Plant Microbe Interact 17(2): 140-151

Fode B, Siemsen T, Thurow C, Weigel R, Gatz C (2008) The Arabidopsis GRAS protein SCL14 interacts with class II TGA transcription factors and is essential for the activation of stressinducible promoters. Plant Cell 20(11): 3122-3135

Fonseca S, Chico JM, Solano R (2009) The jasmonate pathway: the ligand, the receptor and the core signalling module. Curr Opin Plant Biol 12(5): 539-547

Ford MG, Pearse BM, Higgins MK, Vallis $Y$, Owen DJ, Gibson A, Hopkins CR, Evans PR, McMahon HT (2001) Simultaneous binding of Ptdlns(4,5)P2 and clathrin by AP180 in the nucleation of clathrin lattices on membranes. Science 291(5506): 1051-1055

Gagne JM, Smalle J, Gingerich DJ, Walker JM, Yoo SD, Yanagisawa S, Vierstra RD (2004) Arabidopsis EIN3-binding F-box 1 and 2 form ubiquitin-protein ligases that repress ethylene action and promote growth by directing EIN3 degradation. Proc Natl Acad Sci U S A 101(17): 6803-6808 
Georges F, Das S, Ray H, Bock C, Nokhrina K, Kolla VA, Keller W (2009) Over-expression of Brassica napus phosphatidylinositol-phospholipase $\mathrm{C} 2$ in canola induces significant changes in gene expression and phytohormone distribution patterns, enhances drought tolerance and promotes early flowering and maturation. Plant Cell Environ 32(12): 1664-1681

Glauser G, Grata E, Rudaz S, Wolfender JL (2008) High-resolution profiling of oxylipincontaining galactolipids in Arabidopsis extracts by ultra-performance liquid chromatography/time-of-flight mass spectrometry. Rapid Commun Mass Spectrom 22(20): 3154-3160

Glazebrook J (2005) Contrasting mechanisms of defense against biotrophic and necrotrophic pathogens. Annu Rev Phytopathol 43: 205-227

Guex N, Peitsch MC (1997) SWISS-MODEL and the Swiss-PdbViewer: an environment for comparative protein modeling. Electrophoresis 18(15): 2714-2723

Gungabissoon RA, Jiang C-J, Drobak BK, Maciver SK, Hussey PJ (1998) Interaction of maize actin-depolymerising factor with actin and phosphoinositides and its inhibition of plant phospholipase C. Plant J 16: 689-696

Guo H, Ecker JR (2003) Plant responses to ethylene gas are mediated by SCF(EBF1/EBF2)dependent proteolysis of EIN3 transcription factor. Cell 115(6): 667-677

Hamada A, Yamaguchi K, Harada M, Horiguchi K, Takahashi T, Honda H (2006) Recombinant, rice-produced yeast phytase shows the ability to hydrolyze phytate derived from seed-based feed, and extreme stability during ensilage treatment. Biosci Biotechnol Biochem 70(6): 15241527

Hamberg M, Fahlstadius P (1990) Allene oxide cyclase: a new enzyme in plant lipid metabolism. Arch Biochem Biophys 276(2): 518-526

Hay JC, Fisette PL, Jenkins GH, Fukami K, Takenawa T, Anderson RA, Martin TF (1995) ATPdependent inositide phosphorylation required for $\mathrm{Ca}(2+)$-activated secretion. Nature 374(6518): 173-177

Hay JC, Martin TF (1993) Phosphatidylinositol transfer protein required for ATP-dependent priming of $\mathrm{Ca}(2+)$-activated secretion. Nature 366(6455): 572-575

Heilmann I, Perera IY, Gross W, Boss WF (1999) Changes in phosphoinositide metabolism with days in culture affect signal transduction pathways in Galdieria sulphuraria. Plant Physiol 119(4): 1331-1339

Heilmann I, Perera IY, Gross W, Boss WF (2001) Plasma membrane phosphatidylinositol 4,5bisphosphate levels decrease with time in culture. Plant Physiol 126(4): 1507-1518

Hilgemann DW, Ball R (1996) Regulation of cardiac Na+,Ca2+ exchange and KATP potassium channels by PIP2. Science 273(5277): 956-959

Hirayama T, Mitsukawa N, Shibata D, Shinozaki K (1997) AtPLC2, a gene encoding phosphoinositide-specific phospholipase $C$, is constitutively expressed in vegetative and floral tissues in Arabidopsis thaliana. Plant Mol Biol 34(1): 175-180 
Hofgen R, Willmitzer L (1988) Storage of competent cells for Agrobacterium transformation. Nucleic Acids Res 16(20): 9877

Hood EE, Gelvin SB, Melchers LS, Hoekema A (1993) New Agrobacterium helper plasmids for gene transfer to plants. Transgenic Res 2: 208-218

Hornung E, Pernstich C, Feussner I (2002) Formation of conjugated Delta11Delta13-double bonds by Delta12-linoleic acid $(1,4)$-acyl-lipid-desaturase in pomegranate seeds. Eur J Biochem 269(19): 4852-4859

Howe GA, Jander G (2008) Plant immunity to insect herbivores. Annu Rev Plant Biol 59: 41-66

Inoue $\mathrm{H}$, Nojima H, Okayama H (1990) High efficiency transformation of Escherichia coli with plasmids. Gene 96(1): 23-28

Ischebeck T, Stenzel I, Heilmann I (2008) Type B phosphatidylinositol-4-phosphate 5-kinases mediate pollen tube growth in Nicotiana tabacum and Arabidopsis by regulating apical pectin secretion. Plant Cell 20: 3312-3330

Ischebeck T, Vu LH, Jin X, Stenzel I, Lofke C, Heilmann I (2010) Functional cooperativity of enzymes of phosphoinositide conversion according to synergistic effects on pectin secretion in tobacco pollen tubes. Mol Plant: (in press)

Itoh A, Howe GA (2001) Molecular cloning of a divinyl ether synthase. Identification as a CYP74 cytochrome P-450. J Biol Chem 276(5): 3620-3267

James P, Halladay J, Craig EA (1996) Genomic libraries and a host strain designed for highly efficient two-hybrid selection in yeast. Genetics 144(4): 1425-1436

Johnson PR, Ecker JR (1998) The ethylene gas signal transduction pathway: a molecular perspective. Annu Rev Genet 32: 227-254

Jones JD, Dangl JL (2006) The plant immune system. Nature 444(7117): 323-329

Jost M, Simpson F, Kavran JM, Lemmon MA, Schmid SL (1998) Phosphatidylinositol-4,5bisphosphate is required for endocytic coated vesicle formation. Curr Biol 8(25): 1399-1402

Katsir L, Schilmiller AL, Staswick PE, He SY, Howe GA (2008) COI1 is a critical component of a receptor for jasmonate and the bacterial virulence factor coronatine. Proc Natl Acad Sci U S A 105(19): 7100-7105

Kernan A, Thornburg RW (1989) Auxin levels regulate the expression of a wound-inducible proteinase inhibitor II-chloramphenicol acetyl transferase gene fusion in vitro and in vivo. Plant Physiol 91(1): 73-78

Kessler A, Baldwin IT (2002) Plant responses to insect herbivory: the emerging molecular analysis. Annu Rev Plant Biol 53: 299-328

Kessler A, Halitschke R, Baldwin IT (2004) Silencing the jasmonate cascade: induced plant defenses and insect populations. Science 305(5684): 665-668

Kipreos ET, Pagano M (2000) The F-box protein family. Genome Biol 1(5): REVIEWS3002 
Kirch G (2006) Auftreten und Bekämpfung phytophager Insekten an Getreide und Raps in Schleswig-Holstein. Justus-Liebig-Universität Gießen, Gießen

Kloek AP, Verbsky ML, Sharma SB, Schoelz JE, Vogel J, Klessig DF, Kunkel BN (2001) Resistance to Pseudomonas syringae conferred by an Arabidopsis thaliana coronatine-insensitive (coi1) mutation occurs through two distinct mechanisms. Plant J 26(5): 509-522

König S, Ischebeck T, Lerche J, Stenzel I, Heilmann I (2008) Salt stress-induced association of phosphatidylinositol-4,5-bisphosphate with clathrin-coated vesicles in plants. Biochem J 415: 387-399

König S, Mosblech A, Heilmann I (2007) Stress-inducible and constitutive phosphoinositide pools have distinct fatty acid patterns in Arabidopsis thaliana. FASEB J 21: 1958-1967

Koornneef A, Pieterse CM (2008) Cross talk in defense signaling. Plant Physio/ 146(3): 839-844

Krinke O, Novotna Z, Valentova O, Martinec J (2007a) Inositol trisphosphate receptor in higher plants: is it real? J Exp Bot 58(3): 361-376

Krinke O, Ruelland E, Valentova O, Vergnolle C, Renou JP, Taconnat L, Flemr M, Burketova L, Zachowski A (2007b) Phosphatidylinositol 4-kinase activation is an early response to salicylic acid in Arabidopsis suspension cells. Plant Physiol 144(3): 1347-1359

Laurie-Berry N, Joardar V, Street IH, Kunkel BN (2006) The Arabidopsis thaliana JASMONATE INSENSITIVE 1 gene is required for suppression of salicylic acid-dependent defenses during infection by Pseudomonas syringae. Mol Plant Microbe Interact 19(7): 789-800

Lee $\mathrm{S}$, Hirt H, Lee $Y$ (2001) Phosphatidic acid activates a wound-activated MAPK in Glycine max. Plant J 26(5): 479-486

Lee Y, Choi YB, Suh S, Lee J, Assmann SM, Joe CO, Kelleher JF, Crain RC (1996) Abscisic AcidInduced Phosphoinositide Turnover in Guard Cell Protoplasts of Vicia faba. Plant Physiol 110(3): 987-996

Lemmon MA, Ferguson KM (2000) Signal-dependent membrane targeting by pleckstrin homology (PH) domains. Biochem J 350 Pt 1: 1-18

Lemtiri-Chlieh F, MacRobbie EA, Webb AA, Manison NF, Brownlee C, Skepper JN, Chen J, Prestwich GD, Brearley CA (2003) Inositol hexakisphosphate mobilizes an endomembrane store of calcium in guard cells. Proc Natl Acad Sci U S A 100(17): 10091-10095

Leon J, Rojo E, Sanchez-Serrano JJ (2001) Wound signalling in plants. J Exp Bot 52(354): 1-9

Li C, Schilmiller AL, Liu G, Lee GI, Jayanty S, Sageman C, Vrebalov J, Giovannoni JJ, Yagi K, Kobayashi Y, Howe GA (2005) Role of beta-oxidation in jasmonate biosynthesis and systemic wound signaling in tomato. Plant Cell 17(3): 971-986

Li J, Brader G, Kariola T, Palva ET (2006) WRKY70 modulates the selection of signaling pathways in plant defense. Plant J 46(3): 477-491

Li J, Brader G, Palva ET (2004) The WRKY70 transcription factor: a node of convergence for jasmonate-mediated and salicylate-mediated signals in plant defense. Plant Cell 16(2): 319-331 
Li L, Li C, Howe GA (2001) Genetic analysis of wound signaling in tomato. Evidence for a dual role of jasmonic acid in defense and female fertility. Plant Physiol 127(4): 1414-1417

Lin WC, Lu CF, Wu JW, Cheng ML, Lin YM, Yang NS, Black L, Green SK, Wang JF, Cheng CP (2004a) Transgenic tomato plants expressing the Arabidopsis NPR1 gene display enhanced resistance to a spectrum of fungal and bacterial diseases. Transgenic Res 13(6): 567-581

Lin WH, Ye R, Ma H, Xu ZH, Xue HW (2004b) DNA chip-based expression profile analysis indicates involvement of the phosphatidylinositol signaling pathway in multiple plant responses to hormone and abiotic treatments. Cell Res 14(1): 34-45

Liu Y, Ahn JE, Datta S, Salzman RA, Moon J, Huyghues-Despointes B, Pittendrigh B, Murdock LL, Koiwa $\mathrm{H}$, Zhu-Salzman K (2005) Arabidopsis vegetative storage protein is an anti-insect acid phosphatase. Plant Physiol 139(3): 1545-1556

Loake G, Grant M (2007) Salicylic acid in plant defence--the players and protagonists. Curr Opin Plant Biol 10(5): 466-472

Lorenzo O, Chico JM, Sanchez-Serrano JJ, Solano R (2004) JASMONATE-INSENSITIVE1 encodes a MYC transcription factor essential to discriminate between different jasmonate-regulated defense responses in Arabidopsis. Plant Cell 16(7): 1938-1950

Lorenzo O, Piqueras R, Sanchez-Serrano JJ, Solano R (2003) ETHYLENE RESPONSE FACTOR1 integrates signals from ethylene and jasmonate pathways in plant defense. Plant Cell 15(1): $165-178$

Lorenzo O, Solano R (2005) Molecular players regulating the jasmonate signalling network. Curr Opin Plant Biol 8(5): 532-540

Lu H, Salimian S, Gamelin E, Wang G, Fedorowski J, LaCourse W, Greenberg JT (2009) Genetic analysis of acd6-1 reveals complex defense networks and leads to identification of novel defense genes in Arabidopsis. Plant J 58(3): 401-412

Makandar R, Essig JS, Schapaugh MA, Trick HN, Shah J (2006) Genetically engineered resistance to Fusarium head blight in wheat by expression of Arabidopsis NPR1. Mol Plant Microbe Interact 19(2): 123-129

Maleck K, Levine A, Eulgem T, Morgan A, Schmid J, Lawton KA, Dangl JL, Dietrich RA (2000) The transcriptome of Arabidopsis thaliana during systemic acquired resistance. Nat Genet 26(4): 403-410

Mandaokar A, Browse J (2009) MYB108 acts together with MYB24 to regulate jasmonatemediated stamen maturation in Arabidopsis. Plant Physiol 149(2): 851-862

Matyash V, Liebisch G, Kurzchalia TV, Shevchenko A, Schwudke D (2008) Lipid extraction by methyl-tert-butyl ether for high-throughput lipidomics. J Lipid Res 49(5): 1137-1146

McConn M, Creelman RA, Bell E, Mullet JE, Browse J (1997) Jasmonate is essential for insect defense in Arabidopsis. Proc Natl Acad Sci U S A 94(10): 5473-5477 
McGinnis KM, Thomas SG, Soule JD, Strader LC, Zale JM, Sun TP, Steber CM (2003) The Arabidopsis SLEEPY1 gene encodes a putative F-box subunit of an SCF E3 ubiquitin ligase. Plant Cell 15(5): 1120-1130

McGrath KC, Dombrecht B, Manners JM, Schenk PM, Edgar Cl, Maclean DJ, Scheible WR, Udvardi MK, Kazan K (2005) Repressor- and activator-type ethylene response factors functioning in jasmonate signaling and disease resistance identified via a genome-wide screen of Arabidopsis transcription factor gene expression. Plant Physiol 139(2): 949-959

Meijer HJ, Munnik T (2003) Phospholipid-based signaling in plants. Annu Rev Plant Biol 54: 265306

Memelink J (2009) Regulation of gene expression by jasmonate hormones. Phytochemistry 70(13-14): 1560-1570

Menke FL, van Pelt JA, Pieterse CM, Klessig DF (2004) Silencing of the mitogen-activated protein kinase MPK6 compromises disease resistance in Arabidopsis. Plant Cell 16(4): 897-907

Michell RH (2008) Inositol derivatives: evolution and functions. Nat Rev Mol Cell Biol 9(2): 151161

Moon J, Parry G, Estelle M (2004) The ubiquitin-proteasome pathway and plant development. Plant Cell 16(12): 3181-3195

Mosblech A, Feussner I, Heilmann I (2009) Oxylipins: structurally diverse metabolites from fatty acid oxidation. Plant Physiol Biochem 47(6): 511-517

Mosblech A, Feussner I, Heilmann I (2010) Oxylipin signaling and plant growth. In Plant Lipid Signaling, Munnik T (ed), pp 1861-1870. Berlin, Germany: Springer

Mosblech A, König S, Stenzel I, Grzeganek P, Feussner I, Heilmann I (2008) Phosphoinositide and inositolpolyphosphate-signaling in defense responses of Arabidopsis thaliana challenged by mechanical wounding. Molecular Plant 1: 249-261

Mou Z, Fan W, Dong X (2003) Inducers of plant systemic acquired resistance regulate NPR1 function through redox changes. Cell 113(7): 935-944

Mueller-Roeber B, Pical C (2002) Inositol phospholipid metabolism in Arabidopsis. Characterized and putative isoforms of inositol phospholipid kinase and phosphoinositidespecific phospholipase C. Plant Physiol 130(1): 22-46

Mueller MJ, Brodschelm W (1994) Quantification of jasmonic acid by capillary gas chromatography-negative chemical ionization-mass spectrometry. Anal Biochem 218(2): 425435

Mukhopadhyay D, Riezman H (2007) Proteasome-independent functions of ubiquitin in endocytosis and signaling. Science 315(5809): 201-205

Munnik T (2001) Phosphatidic acid: an emerging plant lipid second messenger. Trends Plant Sci 6(5): 227-233 
Munnik T, Irvine RF, Musgrave A (1998) Phospholipid signalling in plants. Biochim Biophys Acta 1389(3): 222-272

Mur LA, Kenton P, Atzorn R, Miersch O, Wasternack C (2006) The outcomes of concentrationspecific interactions between salicylate and jasmonate signaling include synergy, antagonism, and oxidative stress leading to cell death. Plant Physiol 140(1): 249-262

Murphy AM, Otto B, Brearley CA, Carr JP, Hanke DE (2008) A role for inositol hexakisphosphate in the maintenance of basal resistance to plant pathogens. Plant J 56(4): 638-652

Musser RO, Farmer E, Peiffer M, Williams SA, Felton GW (2006) Ablation of caterpillar labial salivary glands: technique for determining the role of saliva in insect-plant interactions. $J$ Chem Ecol 32(5): 981-992

Nagy R, Grob H, Weder B, Green P, Klein M, Frelet-Barrand A, Schjoerring JK, Brearley C, Martinoia E (2009) The Arabidopsis ATP-binding cassette protein AtMRP5/AtABCC5 is a high affinity inositol hexakisphosphate transporter involved in guard cell signaling and phytate storage. J Biol Chem 284(48): 33614-33622

Nakagami H, Pitzschke A, Hirt H (2005) Emerging MAP kinase pathways in plant stress signalling. Trends Plant Sci 10(7): 339-346

Nawrath C, Metraux JP (1999) Salicylic acid induction-deficient mutants of Arabidopsis express PR-2 and PR-5 and accumulate high levels of camalexin after pathogen inoculation. Plant Cell 11(8): 1393-1404

Niggeweg R, Thurow C, Weigel R, Pfitzner U, Gatz C (2000) Tobacco TGA factors differ with respect to interaction with NPR1, activation potential and DNA-binding properties. Plant Mol Biol 42(5): 775-788

Nomura K, Melotto M, He SY (2005) Suppression of host defense in compatible plantPseudomonas syringae interactions. Curr Opin Plant Bio/ 8(4): 361-368

O'Donnell PJ, Schmelz E, Block A, Miersch O, Wasternack C, Jones JB, Klee HJ (2003) Multiple hormones act sequentially to mediate a susceptible tomato pathogen defense response. Plant Physiol 133(3): 1181-1189

Park JH, Halitschke R, Kim HB, Baldwin IT, Feldmann KA, Feyereisen R (2002) A knock-out mutation in allene oxide synthase results in male sterility and defective wound signal transduction in Arabidopsis due to a block in jasmonic acid biosynthesis. Plant J 31(1): 1-12

Parre E, Ghars MA, Leprince AS, Thiery L, Lefebvre D, Bordenave M, Richard L, Mazars C, Abdelly C, Savoure A (2007) Calcium signaling via phospholipase $C$ is essential for proline accumulation upon ionic but not nonionic hyperosmotic stresses in Arabidopsis. Plant Physiol 144(1): 503-512

Pauwels L, Barbero GF, Geerinck J, Tilleman S, Grunewald W, Perez AC, Chico JM, Bossche RV, Sewell J, Gil E, Garcia-Casado G, Witters E, Inze D, Long JA, De Jaeger G, Solano R, Goossens A (2010) NINJA connects the co-repressor TOPLESS to jasmonate signalling. Nature 464(7289): 788-791 
Pauwels L, Morreel K, De Witte E, Lammertyn F, Van Montagu M, Boerjan W, Inze D, Goossens A (2008) Mapping methyl jasmonate-mediated transcriptional reprogramming of metabolism and cell cycle progression in cultured Arabidopsis cells. Proc Natl Acad Sci U S A 105(4): 13801385

Pearce G, Strydom D, Johnson S, Ryan CA (1991) A polypeptide from tomato leaves induces wound-inducible proteinase inhibitor proteins. Science 253(5022): 895-897

Perera IY, Davis AJ, Galanopoulou D, Im YJ, Boss WF (2005) Characterization and comparative analysis of Arabidopsis phosphatidylinositol phosphate 5-kinase 10 reveals differences in Arabidopsis and human phosphatidylinositol phosphate kinases. FEBS Lett 579(16): 3427-3432

Perera IY, Heilmann I, Boss WF (1999) Transient and sustained increases in inositol 1,4,5trisphosphate precede the differential growth response in gravistimulated maize pulvini. Proc Natl Acad Sci U S A 96(10): 5838-5843

Perera IY, Heilmann I, Chang SC, Boss WF, Kaufman PB (2001) A role for inositol 1,4,5trisphosphate in gravitropic signaling and the retention of cold-perceived gravistimulation of oat shoot pulvini. Plant Physiol 125(3): 1499-1507

Perera IY, Hung CY, Brady S, Muday GK, Boss WF (2006) A universal role for inositol 1,4,5trisphosphate-mediated signaling in plant gravitropism. Plant Physiol 140(2): 746-760

Perera IY, Hung CY, Moore CD, Stevenson-Paulik J, Boss WF (2008) Transgenic Arabidopsis Plants Expressing the Type 1 Inositol 5-Phosphatase Exhibit Increased Drought Tolerance and Altered Abscisic Acid Signaling. Plant Cell 20: 2876-2893

Perera IY, Love J, Heilmann I, Thompson WF, Boss WF (2002) Up-regulation of phosphoinositide metabolism in tobacco cells constitutively expressing the human type I inositol polyphosphate 5-phosphatase. Plant Physiol 129(4): 1795-1806

Petersen $M$, Brodersen $P$, Naested $H$, Andreasson $E$, Lindhart $U$, Johansen $B$, Nielsen HB, Lacy M, Austin MJ, Parker JE, Sharma SB, Klessig DF, Martienssen R, Mattsson O, Jensen AB, Mundy J (2000) Arabidopsis map kinase 4 negatively regulates systemic acquired resistance. Cell 103(7): 1111-1120

Pical C, Westergren T, Dove SK, Larsson C, Sommarin M (1999) Salinity and hyperosmotic stress induce rapid increases in phosphatidylinositol 4,5-bisphosphate, diacylglycerol pyrophosphate, and phosphatidylcholine in Arabidopsis thaliana cells. J Biol Chem 274(53): 38232-38240

Pichersky E, Gershenzon J (2002) The formation and function of plant volatiles: perfumes for pollinator attraction and defense. Curr Opin Plant Biol 5(3): 237-243

Pickart CM (2001) Mechanisms underlying ubiquitination. Annu Rev Biochem 70: 503-533

Pieterse CM, Dicke M (2007) Plant interactions with microbes and insects: from molecular mechanisms to ecology. Trends Plant Sci 12(12): 564-569

Pieterse CM, van Loon LC (1999) Salicylic acid-independent plant defence pathways. Trends Plant Sci 4(2): 52-58 
Ponnusamy S, Alderson NL, Hama H, Bielawski J, Jiang JC, Bhandari R, Snyder SH, Jazwinski SM, Ogretmen B (2008) Regulation of telomere length by fatty acid elongase 3 in yeast. Involvement of inositol phosphate metabolism and Ku70/80 function. J Biol Chem 283(41): 27514-27524

Potuschak T, Lechner E, Parmentier Y, Yanagisawa S, Grava S, Koncz C, Genschik P (2003) EIN3dependent regulation of plant ethylene hormone signaling by two arabidopsis $\mathrm{F}$ box proteins: EBF1 and EBF2. Cell 115(6): 679-689

Pre M, Atallah M, Champion A, De Vos M, Pieterse CM, Memelink J (2008) The AP2/ERF domain transcription factor ORA59 integrates jasmonic acid and ethylene signals in plant defense. Plant Physiol 147(3): 1347-1357

Raboy V (2003) myo-Inositol-1,2,3,4,5,6-hexakisphosphate. Phytochemistry 64(6): 1033-1043

Randall PJ, Bouma D (1973) Zinc deficiency, carbonic anhydrase, and photosynthesis in leaves of spinach. Plant Physiol 52(3): 229-232

Reinbothe S, Reinbothe C, Lehmann J, Becker W, Apel K, Parthier B (1994) JIP60, a methyl jasmonate-induced ribosome-inactivating protein involved in plant stress reactions. Proc Natl Acad Sci U S A 91(15): 7012-7016

Reymond P, Weber H, Damond M, Farmer EE (2000) Differential gene expression in response to mechanical wounding and insect feeding in Arabidopsis. Plant Cell 12(5): 707-720

Robert-Seilaniantz A, Navarro L, Bari R, Jones JD (2007) Pathological hormone imbalances. Curr Opin Plant Biol 10(4): 372-379

Rochon A, Boyle P, Wignes T, Fobert PR, Despres C (2006) The coactivator function of Arabidopsis NPR1 requires the core of its $\mathrm{BTB} / \mathrm{POZ}$ domain and the oxidation of C-terminal cysteines. Plant Cell 18(12): 3670-3685

Ruegger M, Dewey E, Gray WM, Hobbie L, Turner J, Estelle M (1998) The TIR1 protein of Arabidopsis functions in auxin response and is related to human SKP2 and yeast grr1p. Genes Dev 12(2): 198-207

Rushton PJ, Macdonald H, Huttly AK, Lazarus CM, Hooley R (1995) Members of a new family of DNA-binding proteins bind to a conserved cis-element in the promoters of alpha-Amy2 genes. Plant Mol Biol 29(4): 691-702

Saiardi A, Resnick AC, Snowman AM, Wendland B, Snyder SH (2005) Inositol pyrophosphates regulate cell death and telomere length through phosphoinositide 3-kinase-related protein kinases. Proc Natl Acad Sci U S A 102(6): 1911-1914

Sansom MS, Bond PJ, Deol SS, Grottesi A, Haider S, Sands ZA (2005) Molecular simulations and lipid-protein interactions: potassium channels and other membrane proteins. Biochem Soc Trans 33(Pt 5): 916-920

Santagata S, Boggon TJ, Baird CL, Gomez CA, Zhao J, Shan WS, Myszka DG, Shapiro L (2001) Gprotein signaling through tubby proteins. Science 292(5524): 2041-2050 
Santner A, Estelle M (2010) The ubiquitin-proteasome system regulates plant hormone signaling. Plant J 61(6): 1029-1040

Schmelz EA, Engelberth J, Tumlinson JH, Block A, Alborn HT (2004) The use of vapor phase extraction in metabolic profiling of phytohormones and other metabolites. Plant J 39(5): 790808

Schwechheimer C, Deng XW (2001) COP9 signalosome revisited: a novel mediator of protein degradation. Trends Cell Biol 11(10): 420-426

Schwechheimer C, Isono E The COP9 signalosome and its role in plant development. Eur J Cell Biol 89(2-3): 157-162

Seeds AM, York JD (2007) Inositol polyphosphate kinases: regulators of nuclear function. Biochem Soc Symp(74): 183-197

Shen X, Xiao H, Ranallo R, Wu WH, Wu C (2003) Modulation of ATP-dependent chromatinremodeling complexes by inositol polyphosphates. Science 299(5603): 112-114

Spoel SH, Johnson JS, Dong X (2007) Regulation of tradeoffs between plant defenses against pathogens with different lifestyles. Proc Natl Acad Sci U S A 104(47): 18842-18847

Spoel SH, Koornneef A, Claessens SM, Korzelius JP, Van Pelt JA, Mueller MJ, Buchala AJ, Metraux JP, Brown R, Kazan K, Van Loon LC, Dong X, Pieterse CM (2003) NPR1 modulates cross-talk between salicylate- and jasmonate-dependent defense pathways through a novel function in the cytosol. Plant Cell 15(3): 760-770

Staswick PE (2008) JAZing up jasmonate signaling. Trends Plant Sci 13(2): 66-71

Staswick PE, Su W, Howell SH (1992) Methyl jasmonate inhibition of root growth and induction of a leaf protein are decreased in an Arabidopsis thaliana mutant. Proc Natl Acad Sci U S A 89(15): 6837-6840

Staswick PE, Tiryaki I, Rowe ML (2002) Jasmonate response locus JAR1 and several related Arabidopsis genes encode enzymes of the firefly luciferase superfamily that show activity on jasmonic, salicylic, and indole-3-acetic acids in an assay for adenylation. Plant Cell 14(6): 14051415

Stenzel I, Hause B, Maucher H, Pitzschke A, Miersch O, Ziegler J, Ryan CA, Wasternack C (2003a) Allene oxide cyclase dependence of the wound response and vascular bundle-specific generation of jasmonates in tomato - amplification in wound signalling. Plant J 33(3): 577-589

Stenzel I, Hause B, Miersch O, Kurz T, Maucher H, Weichert H, Ziegler J, Feussner I, Wasternack $\mathrm{C}$ (2003b) Jasmonate biosynthesis and the allene oxide cyclase family of Arabidopsis thaliana. Plant Mol Biol 51(6): 895-911

Stevenson-Paulik J, Bastidas RJ, Chiou ST, Frye RA, York JD (2005) Generation of phytate-free seeds in Arabidopsis through disruption of inositol polyphosphate kinases. Proc Natl Acad Sci U S A 102(35): 12612-12617

Stevenson JM, Perera IY, Heilmann I, Persson S, Boss WF (2000) Inositol signaling and plant growth. Trends Plant Sci 5(6): 252-258 
Stout MJ, Thaler JS, Thomma BP (2006) Plant-mediated interactions between pathogenic microorganisms and herbivorous arthropods. Annu Rev Entomol 51: 663-689

Strahl T, Thorner J (2007) Synthesis and function of membrane phosphoinositides in budding yeast, Saccharomyces cerevisiae. Biochim Biophys Acta 1771(3): 353-404

Tada Y, Spoel SH, Pajerowska-Mukhtar K, Mou Z, Song J, Wang C, Zuo J, Dong X (2008) Plant immunity requires conformational changes [corrected] of NPR1 via S-nitrosylation and thioredoxins. Science 321(5891): 952-956

Tan X, Calderon-Villalobos LI, Sharon M, Zheng C, Robinson CV, Estelle M, Zheng N (2007) Mechanism of auxin perception by the TIR1 ubiquitin ligase. Nature 446(7136): 640-645

Thines B, Katsir L, Melotto M, Niu Y, Mandaokar A, Liu G, Nomura K, He SY, Howe GA, Browse J (2007) JAZ repressor proteins are targets of the SCF(COI1) complex during jasmonate signalling. Nature 448(7154): 661-665

Thomma BP, Eggermont K, Tierens KF, Broekaert WF (1999) Requirement of functional ethylene-insensitive 2 gene for efficient resistance of Arabidopsis to infection by Botrytis cinerea. Plant Physiol 121(4): 1093-1102

Thomma BP, Penninckx IA, Broekaert WF, Cammue BP (2001) The complexity of disease signaling in Arabidopsis. Curr Opin Immuno/ 13(1): 63-68

Traw MB, Bergelson J (2003) Interactive effects of jasmonic acid, salicylic acid, and gibberellin on induction of trichomes in Arabidopsis. Plant Physiol 133(3): 1367-1375

Truman WM, Bennett MH, Turnbull CG, Grant MR (2010) Arabidopsis auxin mutants are compromised in systemic acquired resistance and exhibit aberrant accumulation of various indolic compounds. Plant Physiol 152(3): 1562-1573

Turner JG, Ellis C, Devoto A (2002) The jasmonate signal pathway. Plant Cell 14 Suppl: S153164

Vernooij B, Uknes S, Ward E, Ryals J (1994) Salicylic acid as a signal molecule in plant-pathogen interactions. Curr Opin Cell Biol 6(2): 275-279

Vick BA, Zimmerman DC (1984) Biosynthesis of jasmonic Acid by several plant species. Plant Physiol 75(2): 458-461

Vierstra RD (2009) The ubiquitin-26S proteasome system at the nexus of plant biology. Nat Rev Mol Cell Biol 10(6): 385-397

Voges D, Zwickl P, Baumeister W (1999) The 26S proteasome: a molecular machine designed for controlled proteolysis. Annu Rev Biochem 68: 1015-1068

von Dahl CC, Winz RA, Halitschke R, Kuhnemann F, Gase K, Baldwin IT (2007) Tuning the herbivore-induced ethylene burst: the role of transcript accumulation and ethylene perception in Nicotiana attenuata. Plant J 51(2): 293-307 
von Malek B, van der Graaff E, Schneitz K, Keller B (2002) The Arabidopsis male-sterile mutant dde2-2 is defective in the allene oxide synthase gene encoding one of the key enzymes of the jasmonic acid biosynthesis pathway. Planta 216(1): 187-192

Wach A, Brachat A, Pohlmann R, Philippsen P (1994) New heterologous modules for classical or PCR-based gene disruptions in Saccharomyces cerevisiae. Yeast 10(13): 1793-1808

Wang C, Zien CA, Afitlhile M, Welti R, Hildebrand DF, Wang X (2000) Involvement of phospholipase $D$ in wound-induced accumulation of jasmonic acid in arabidopsis. Plant Cell 12(11): 2237-2246

Wang D, Amornsiripanitch N, Dong X (2006) A genomic approach to identify regulatory nodes in the transcriptional network of systemic acquired resistance in plants. PLoS Pathog 2(11): e123

Wasternack C (2007) Jasmonates: an update on biosynthesis, signal transduction and action in plant stress response, growth and development. Ann Bot (Lond) 100(4): 681-697

Weichert H, Kohlmann M, Wasternack C, Feussner I (2000) Metabolic profiling of oxylipins upon sorbitol treatment in barley leaves. Biochem Soc Trans 28: 861-862

Weirich CS, Erzberger JP, Flick JS, Berger JM, Thorner J, Weis K (2006) Activation of the $\mathrm{DExD} / \mathrm{H}$-box protein Dbp5 by the nuclear-pore protein Gle1 and its coactivator InsP6 is required for mRNA export. Nat Cell Biol 8(7): 668-676

Wigoda N, Ma X, Moran N (2010) Phosphatidylinositol 4,5-bisphosphate regulates plant $\mathrm{K}(+)$ channels. Biochem Soc Trans 38(2): 705-709

Wildermuth MC, Dewdney J, Wu G, Ausubel FM (2001) Isochorismate synthase is required to synthesize salicylic acid for plant defence. Nature 414(6863): 562-565

Wilson MP, Sun Y, Cao L, Majerus PW (2001) Inositol 1,3,4-trisphosphate 5/6-kinase is a protein kinase that phosphorylates the transcription factors c-Jun and ATF-2. J Biol Chem 276(44): 40998-41004

Witke W (2004) The role of profilin complexes in cell motility and other cellular processes. Trends Cell Biol 14(8): 461-469

Xie DX, Feys BF, James S, Nieto-Rostro M, Turner JG (1998) COI1: an Arabidopsis gene required for jasmonate-regulated defense and fertility. Science 280(5366): 1091-1094

Xu L, Liu F, Lechner E, Genschik P, Crosby WL, Ma H, Peng W, Huang D, Xie D (2002) The SCF(COI) ubiquitin-ligase complexes are required for jasmonate response in Arabidopsis. Plant Cell 14(8): 1919-1935

Xu X, Chen C, Fan B, Chen Z (2006) Physical and functional interactions between pathogeninduced Arabidopsis WRKY18, WRKY40, and WRKY60 transcription factors. Plant Cell 18(5): $1310-1326$

Yamamoto YT, Conkling MA, Sussex IM, Irish VF (1995) An Arabidopsis cDNA related to animal phosphoinositide-specific phospholipase C genes. Plant Physiol 107(3): 1029-1230 
Yan J, Zhang C, Gu M, Bai Z, Zhang W, Qi T, Cheng Z, Peng W, Luo H, Nan F, Wang Z, Xie D (2009) The Arabidopsis CORONATINE INSENSITIVE1 protein is a jasmonate receptor. Plant Cell 21(8): 2220-2236

Yan Y, Stolz S, Chetelat A, Reymond P, Pagni M, Dubugnon L, Farmer EE (2007) A downstream mediator in the growth repression limb of the jasmonate pathway. Plant Cell 19(8): 2470-2483

York JD, Odom AR, Murphy R, Ives EB, Wente SR (1999) A phospholipase C-dependent inositol polyphosphate kinase pathway required for efficient messenger RNA export. Science 285(5424): 96-100

Zhang Y, Xu W, Li Z, Deng XW, Wu W, Xue Y (2008) F-box protein DOR functions as a novel inhibitory factor for abscisic acid-induced stomatal closure under drought stress in Arabidopsis. Plant Physiol 148(4): 2121-2133

Zhao Y, Thilmony R, Bender CL, Schaller A, He SY, Howe GA (2003) Virulence systems of Pseudomonas syringae pv. tomato promote bacterial speck disease in tomato by targeting the jasmonate signaling pathway. Plant J 36(4): 485-499 


\section{APPENDIX}

\subsection{List of oligonucleotides}

\begin{tabular}{|c|c|c|}
\hline No. & Oligonucleotide sequence & Purpose \\
\hline P1 & 5'-tggaccatataaattcatgcagtc-3' & Genotyping Arabidopsis: coi1, for \\
\hline $\mathrm{P} 2$ & 5'-ctgcagtgtgtaacgatgctc-3' & Genotyping Arabidopsis: coi1, rev \\
\hline P3 & 5'-tcatcatcaatgtggctgct-3' & Genotyping yeast: ipk1, for \\
\hline P4 & 5'-gatacatcgggcaaagcaag-3' & Genotyping yeast: ipk1, rev \\
\hline P5 & 5'-gattccatggaggatcctgatatcaagaggtgtaaattg-3' & coil for, introducing Ncol \\
\hline P6 & $\begin{array}{l}\text { 5'-gattcccgggtcagtggtggtggtggtggtgtattggctccttc } \\
\text { aggactcta-3' }\end{array}$ & $\begin{array}{l}\text { coi1 rev, introducing Xmal and } \\
6 x \mathrm{His} \text { tag }\end{array}$ \\
\hline P7 & 5'-ggtcgctcaaacttgcaggcaagcctagag-3’ & $\begin{array}{l}\text { QuickChange site-directed } \\
\text { mutagenesis, coi1 K81A_for }\end{array}$ \\
\hline P8 & 5'-ctctaggcttgcctgcaagtttgagcgacc-3' & $\begin{array}{l}\text { QuickChange site-directed } \\
\text { mutagenesis, coi1 K81A_rev }\end{array}$ \\
\hline P9 & 5'-cagttgaagcggctggcgattgaacgcggtgc-3' & $\begin{array}{l}\text { QuickChange site-directed } \\
\text { mutagenesis, coi1 R348A_for }\end{array}$ \\
\hline P10 & 5'-gcaccgcgttcaatcgccagccgcttcaactg-3' & $\begin{array}{l}\text { QuickChange site-directed } \\
\text { mutagenesis, coi1 R348A_rev }\end{array}$ \\
\hline P11 & 5'-gccttcactggcatacttgtgggtacaagg-3’ & $\begin{array}{l}\text { QuickChange site-directed } \\
\text { mutagenesis, coi1 R516A_for }\end{array}$ \\
\hline P12 & 5'-ccttgtacccacaagtatgccagtgaaggc-3’ & $\begin{array}{l}\text { QuickChange site-directed } \\
\text { mutagenesis, coi1 R516A_rev }\end{array}$ \\
\hline P13 & 5'-cggtgcacttccgagcgatgattgtcagtg-3' & $\begin{array}{l}\text { QuickChange site-directed } \\
\text { mutagenesis, coi1 R121A_for }\end{array}$ \\
\hline P14 & $5^{\prime}$-cactgacaatcatcgctcggaagtgcaccg-3' & $\begin{array}{l}\text { QuickChange site-directed } \\
\text { mutagenesis, coi1 R121A_rev }\end{array}$ \\
\hline P15 & $5^{\prime}$-cctctgtgacttcgcccttgtcttactcg-3' & $\begin{array}{l}\text { QuickChange site-directed } \\
\text { mutagenesis, coi1 R409A_for }\end{array}$ \\
\hline P16 & 5'-cgagtaagacaagggcgaagtcacagagg-3’ & $\begin{array}{l}\text { QuickChange site-directed } \\
\text { mutagenesis, coi1 R409A_rev }\end{array}$ \\
\hline P17 & 5'-gatcaagcttggccgcaacagaggtggatg-3' & DsRed for, introducing HindIII \\
\hline P18 & 5'-gatcaagcttagaaggtaattatccaagat-3’ & DsRed rev, introducing HindIII \\
\hline P19 & 5'-gaaagtggatcgaaacgatggcctcctccgag-3' & Delet Ncol in DsRed 1, for \\
\hline P20 & 5'-ctcggaggaggccatcgtttcgatccactttc-3' & Delet Ncol in DsRed 1, rev \\
\hline $\mathrm{P} 21$ & 5'-gatgcagaagaagacgatgggctgggaggcc-3’ & Delet Ncol in DsRed 2, for \\
\hline $\mathrm{P} 22$ & $5^{\prime}$-ggcctcccagcccatcgtcttcttctgcatc-3' & Delet Ncol in DsRed 2, rev \\
\hline P23 & 5'-gatcgtcgactcagtggtggtggtggtggtgtattggc $-3^{\prime}$ & Coi1 rev, introducing Sall \\
\hline P24 & $\begin{array}{l}\text { 5'-aaaattgtcagagataagttccttttttgaaaagaaagatcga } \\
\text { tgcgtacgctgcaggtcgac-3' }\end{array}$ & Yeast ko, ipk1, for \\
\hline
\end{tabular}




\subsection{List of oligonucleotides (continued)}

\begin{tabular}{|c|c|c|}
\hline No. & Oligonucleotide sequence & Purpose \\
\hline $\mathrm{P} 25$ & $\begin{array}{l}\text { 5'-gtgcatctgccagtaccaaaggtggaaagaaaagtatacag } \\
\text { tttaatcgatgaattcgagctcg-3' }\end{array}$ & Yeast ko, ipk1, rev \\
\hline $\mathrm{P} 26$ & 5'-gtcgcgacggttgatgat-3' & $\begin{array}{l}\text { Detection of coi } 1_{\text {mut }} \text { in coi1-t plants, } \\
\text { semi-quantitative RT-PCR, for }\end{array}$ \\
\hline $\mathrm{P} 27$ & 5'-ggtggtggtggtggtgtatt-3' & $\begin{array}{l}\text { Detection of coil }{ }_{\text {mut }} \text { in coil-t } \text { plants, } \\
\text { semi-quantitative RT-PCR, rev }\end{array}$ \\
\hline $\mathrm{P} 28$ & 5'-gattatggaggatcctgatatcaagaggt-3' & $\begin{array}{l}\text { Detection of coi1 in coi1-t plants, } \\
\text { semi-quantitative RT-PCR, for }\end{array}$ \\
\hline P29 & $5^{\prime}$-gatttcatattggctccttcaggactcta-3' & $\begin{array}{l}\text { Detection of coi1 in coi1- } t \text { plants, } \\
\text { semi-quantitative RT-PCR, for }\end{array}$ \\
\hline
\end{tabular}

\subsection{List of abbreviations}

5/6 kinase Inositol 1,3,4-trisphosphate 5/6 kinase

A. tumefaciens Agrobacterium tumefaciens

$\begin{array}{ll}\text { ABA } & \text { Abscisic acid } \\ \mathrm{Amp}^{\mathrm{R}} & \text { Ampicillin } \\ \mathrm{AOC} & \text { Allene oxide cyclase } \\ \mathrm{AOS} & \text { Allene oxide synthase } \\ \mathrm{ASK} & \text { ARABIDOPSIS SKP1-LIKE } \\ \mathrm{ATP} & \text { Adenosine trisphosphate } \\ \mathrm{Ca}\left(\mathrm{NO}_{3}\right)_{2} & \text { Calcium nitrate } \\ \mathrm{CaCl} & \text { Calcium chloride } \\ \mathrm{CDNA}^{2} & \text { Complementary desoxyribonucleic acid } \\ \mathrm{CH}_{3} \mathrm{OH} & \text { Methanol } \\ \mathrm{CHCl}_{3} & \text { Chloroform } \\ \mathrm{CoCl} & \text { Cobalt chlorite } \\ \mathrm{COI}_{2} & \text { CORONATINE INSENSITIVE 1 } \\ \mathrm{coil}^{-1} & \text { Coronatine insensitive 1-1 } \\ \mathrm{coi1-t} & \text { Coronatine insensitive 1 T-DNA insertion line }\end{array}$




\begin{tabular}{|c|c|}
\hline CSN & COP9 signalosome \\
\hline CSN & COP9 signalosome \\
\hline CTAB & Cetyltrimethylammoniumbromid \\
\hline CUL1 & CULLIN 1 \\
\hline $\mathrm{CuSO}_{4}$ & Copper sulfate \\
\hline DAG & Diacyl glycerol \\
\hline dde2-2 & Delayed dehiscence 2-2 \\
\hline $\mathrm{ddH}_{2} \mathrm{O}$ & Double distilled water \\
\hline DEPC & Diethylpyrocarbonate \\
\hline DNA & Desoxyribonucleic acid \\
\hline dn-oDPA & Dinor-oPDA \\
\hline dNTPs & Desoxyribonucleotide \\
\hline E. coli & Escherichia coli \\
\hline EDTA & Ethylene diamine tetra acetate \\
\hline EOT & epoxy octadecatrienoic acid \\
\hline ERF & Ethylene response factor \\
\hline ET & Ethylene \\
\hline $\mathrm{FeCl}_{3}$ & Iron chloride \\
\hline GAD & Gal4 activation domain \\
\hline GBD & Gal4 DNA binding domain \\
\hline GC & Gas chromatography \\
\hline $\mathrm{GC} / \mathrm{MS}$ & Gas chromatography coupled to mass spectrometry \\
\hline $\mathrm{H}_{3} \mathrm{BO}_{3}$ & Boric acid \\
\hline $\mathrm{H}_{3} \mathrm{PO}_{4}$ & Phosphoric acid \\
\hline $\mathrm{HCl}$ & Hydrochloric acid \\
\hline HEPES & 4-(2-hydroxyethyl)-1-piperazineethanesulfonic acid \\
\hline HIP & Hexane/isopropanol \\
\hline HPOT & hydroperoxy $\alpha$-linolenic acid \\
\hline IAA & $\beta$-indolyl acetic acid \\
\hline ICS & Isochorismate synthase \\
\hline InsP 5-ptase & Inositol polyphosphate 5-phosphatase \\
\hline $\operatorname{lns} P_{3}$ & Inositol 1,4,5-trisphosphate \\
\hline InsP 4 & Inositol 1,3,4,5-tetrakisphosphate \\
\hline $\operatorname{lnsP}_{5}$ & Inositol 1,3,4,5,6-pentakisphosphate \\
\hline $\operatorname{lnsP}_{6}$ & Inositol 1,2,3,4,5,6-hexakisphosphate \\
\hline
\end{tabular}


IPK

JA

JA-Ile

JAR1

JAZ

$\mathrm{K}_{2} \mathrm{HPO}_{4}$

$\mathrm{Kan}^{\mathrm{R}}$

$\mathrm{KCl}$

$\mathrm{KH}_{2} \mathrm{PO}_{4}$

$\mathrm{KNO}_{3}$

$\mathrm{KOH}$

LC/MS

LOX

LRR

MAP

MeJA

$\mathrm{MeOH}$

$\mathrm{MgCl}_{2}$

$\mathrm{MgSO}_{4}$

$\mathrm{MnSO}_{4}$

MPK

mRNA

MS

MTBE

MYB

MYC2

$\mathrm{Na}_{2} \mathrm{MoO}_{4}$

$\mathrm{NaCl}$

$\mathrm{NaClO}$

NahG

$\mathrm{NaOH}$
Inositol polyphosphate kinases

Jasmonic acid

Jasmonoyl-isoleucin

JASMONIC ACID RESISTANT 1

Jasmonate ZIM-domain

Dipotassium phosphate

Kanamycin

Potassium chloride

Monopotassium phosphate

Potassium nitrate

Potassium hydroxide

Reversed-Phase High Performance Liquid Chromatography coupled to mass spectrometry

Lipoxygenase

Leucin-rich repeat

Mitogen-activated protein

Methyl-JA

Methanol

Magnesium chlorite

Magnesium sulfate

Manganese sulfate

Mitogen-activated protein (MAP) kinase

messenger RNA

Mass spectrometry

Methyl-tert-butyl ether

Transcription factors are named after the symptoms the virus of their first discovery causes: myeloblastosis

JA-responsive transcription factor named after the symptoms the virus of their first discovery causes: myelocytomatosis

Sodium molybdate

Sodium chlorite

Sodium hypochlorite

Salicylate hydroxylase

Sodium hydroxide 


\begin{tabular}{|c|c|}
\hline NEDD & $\begin{array}{l}\text { Neural precursor cell expressed developmentally downregulated } \\
\text { protein }\end{array}$ \\
\hline$\left(\mathrm{NH}_{4}\right)_{2} \mathrm{HPO}_{4}$ & Diammonium phosphate \\
\hline $\mathrm{NH}_{4} \mathrm{OH}$ & Ammonium hydroxide \\
\hline NPR1 & NONEXPRESSOR OF PR GENES 1 \\
\hline ONPG & o-nitrophenyl- $\beta$-D-galactopyranoside \\
\hline OPC 6:0 & oxo pentenyl cyclopentane hexanoic acid \\
\hline OPC 8:0 & oxo pentenyl cyclopentane octanoic acid \\
\hline OPDA & oxo phytodienoic acid \\
\hline OPR & oPDA reductase \\
\hline P. syringae & Pseudomonas syringae \\
\hline PAL & Phenylalanine lyase \\
\hline PCR & Polymerase chain reaction \\
\hline $\mathrm{PH}$ & Pleckstrin homology \\
\hline $\mathrm{PI}$ & Phosphoinositide \\
\hline PI4-kinases & Ptdlns 4-kinases \\
\hline PIP5-kinases & Ptdlns4P 5-kinases \\
\hline PI-PLCs & PI-specific PLCs \\
\hline PKC & Protein kinase $\mathrm{C}$ \\
\hline PLC & Phospholipase C \\
\hline PR & Pathogenesis related \\
\hline Ptdlns & Phosphatidylinositol \\
\hline Ptdlns $4,5 \mathrm{P}_{2}$ & Phosphatidylinositol 4,5-bisphosphate \\
\hline Ptdlns4P & Phosphatidylinositol 4-phosphate \\
\hline $\mathrm{PtdOH}$ & Phosphatidic acid \\
\hline QLIT & Quadrupole-linear ion trap \\
\hline RBX & RING-BOX PROTEIN \\
\hline RNS & Ribonuclease \\
\hline RP-HPLC & Reversed-Phase High Performance Liquid Chromatography \\
\hline RT-PCR & Reverse transcription polymerase chain reaction \\
\hline SA & Salicylic acid \\
\hline SCF & Skip, Cullin, F-box \\
\hline $\operatorname{sid} 2$ & SA induction-defective 2 \\
\hline TRIS & Tris(hydroxymethyl)aminomethane \\
\hline VSP & Vegetative storage protein \\
\hline
\end{tabular}


WRKY

ZIM

$\mathrm{ZnSO}_{4}$

$\alpha-$ LeA
Transcription factor, named after their WRKY domain, defined by the conserved amino acid sequence WRKYGQK

Zinc-finger protein expressed in Inflorescence Meristem

Zinc sulfate

$\alpha$-linolenic acid 


\subsection{Plasmid maps}
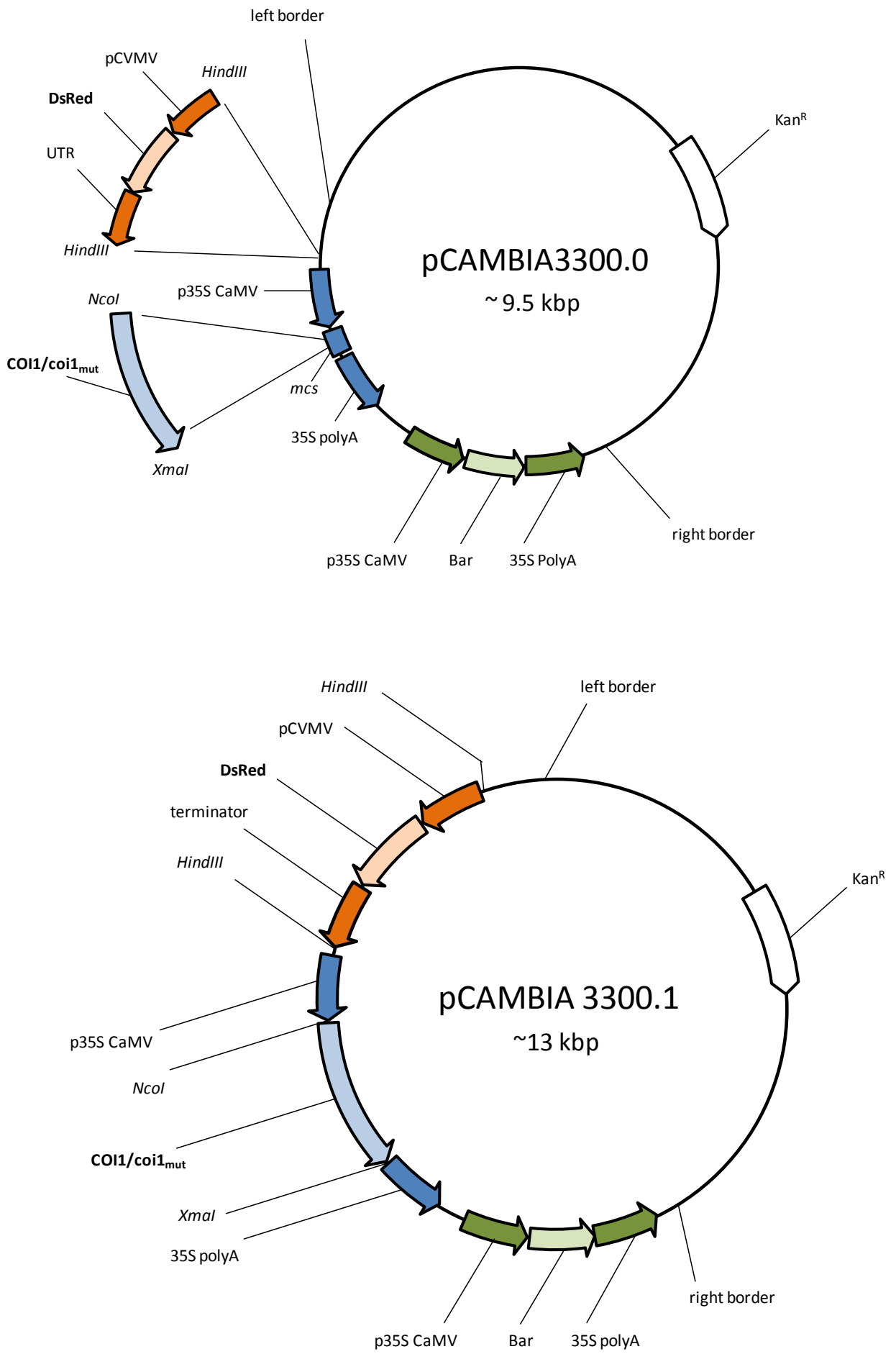

Representation of the pCAMBIA plasmid, used for Arabidopsis transformation. The DsRed cassette consisting of a CVMV promoter, the DsRed coding region and a standard terminator was introduced to pCAMBIA3300.0 via HindIII restriction sites. The COI1 and coi1 $1_{\text {mut }}$ coding regions were introduced into the multiple cloning site via $\mathrm{Ncol}$ and $\mathrm{Xmal}$ restriction sites, behind the 35S CaMV promoter and ahead of the $35 \mathrm{~S}$ polyA terminator. The PCAMBIA vector containing the DsRed cassette and the COI1 or coil $1_{\text {mut }}$ coding regions was named pCAMBIA3300.1 


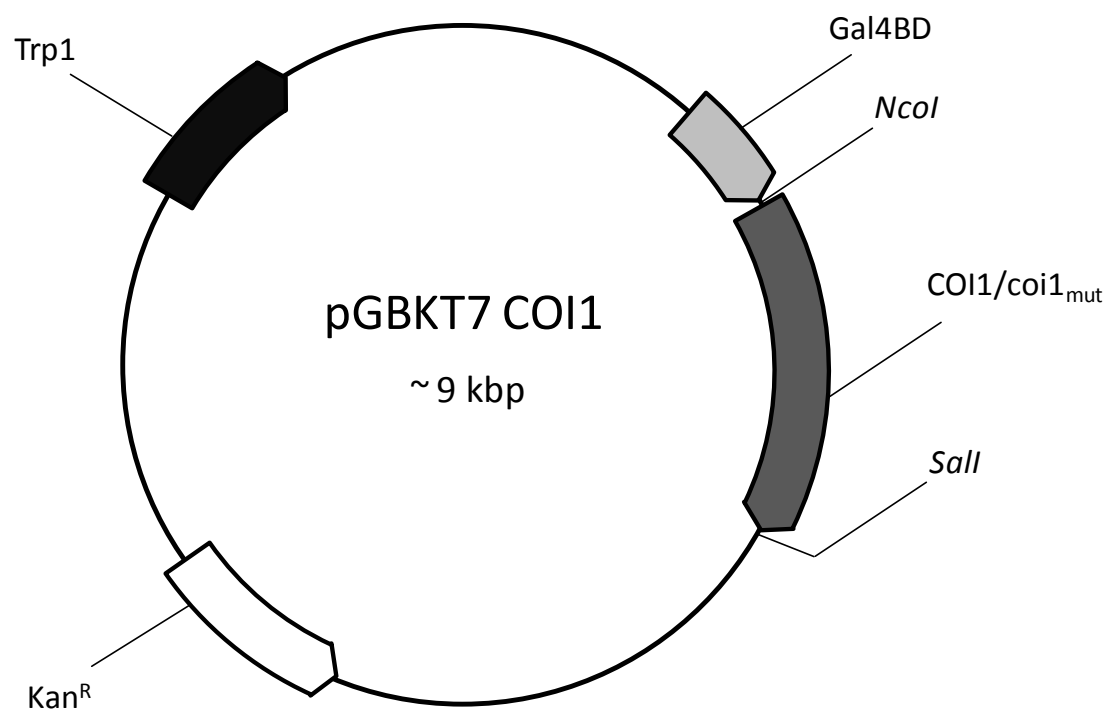

Representation of the pGBKT7 plasmid used for yeast transformation for yeast two-hybrid assays. The COI1 and coil ${ }_{\text {mut }}$ coding regions were introduced via $\mathrm{Ncol}$ and Sall restriction sites, in frame with the Gal4BD coding region. 


\section{ACKNOWLEDGEMENTS - DANKSAGUNG}

An erster Stelle danke ich meinem Doktorvater Prof. Dr. Ingo Heilmann.

Für die Möglichkeit, das faszinierende Projekt meiner Diplomarbeit in ein ebenso faszinierendes Promotionsprojekt fortführen zu dürfen; für eine außergewöhnlich intensive Betreuung während der gesamten Promotionszeit, für seine motivierende und aufmunternde Art, und für die großartige Unterstützung bei der Präsentation eigener Daten, ob Seminar, Tagungsvortrag oder Publikation; für dreieinhalb Jahre, in denen ich viel gelernt habe, jeden Tag gerne ins Labor gekommen bin und mich immer gut aufgehoben gefühlt habe.

Meinem Thesis Komitee, neben Prof. Dr. Ingo Heilmann bestehend aus Prof. Dr. Andrea Polle und Prof. Dr. Gerhard Braus, danke ich für das Interesse an meiner Arbeit, die guten Ratschläge und anregenden Diskussionen.

Insbesondere danke ich Prof. Dr. Andrea Polle für die Übernahme des Korreferates.

Prof. Dr. Ivo Feußner danke ich für die Möglichkeit, in seiner Abteilung arbeiten und die hervorragende Ausstattung nutzen zu dürfen, sowie für interessante und konstruktive Diskussionen. Des Weiteren bedanke ich mich für die Zwischenfinanzierung im ersten Promotionsjahr.

Bei Prof. Dr. Ivo Feußner sowie Prof. Dr. Jan Schirawski und Dr. Thomas Teichmann bedanke ich mich für die Bereitschaft, zusammen mit meinem Thesis Komitee meine Prüfungskommission zu bilden.

Der Göttinger Graduiertenschule für Neurowissenschaften und Molekulare Biowissenschaften (GGNB) danke ich für das interessante Angebot an Methodenkursen, Soft-Skill-Kursen und Freizeitaktivitäten sowie besonders für die Finanzierung meiner Promotion in Form eines Jahresstipendiums sowie eines 3-monatigen Brückenstipendiums.

Ebenso danke ich der Deutschen Forschungsgemeinschaft (DFG) für die Finanzierung meines dritten Promotionsjahres.

Ganz besonders möchte ich mich bei Dr. Corinna Thurow und ihrer technischen Assistentin Anna Hermann für die Durchführung der Yeast two-hybrid Experimente danken, sowie bei Corinna für hilfreiche Diskussionen und gute Ratschläge.

Prof. Dr. Christiane Gatz und der gesamten Abteilung "Molekularbiologie und Physiologie der Pflanze" sei gedankt für die Möglichkeit, das Equipment für die real-time RT-PCR nutzen zu dürfen sowie für die ständige Hilfsbereitschaft bei allen real-time Fragen, insbesondere Dr. Guido Kriete, Katrin Gärtner und Mark Zander.

Ich danke verschiedenen Personen in aller Welt für das zur Verfügung stellen verschiedener Arabidopsis-Samen: Dr. John York für ipk1-1 Saatgut, Dr. Imara Perera für InsP 5-ptase Saatgut, Dr. Jane Glazebrook für coi1-1 Saatgut, Dr. Michael Stumpe für das Überlassen von dde2-2 
Saatgut, Dr. Hella Tappe für das Überlassen von sid2 und Jan-Gerrit Carsjens für das Überlassen von NahG Saatgut.

Ronald Scholz danke ich für das Überlassen von coi1-1 gl-1 Saatgut und die hilfreichen Tipps zur coi1 Selektion.

Bei der Abteilung Agrarentomologie, Prof. Dr. Vidal, bedanke ich mich für die Versorgung mit Plutella xylostella Raupen. Hier gilt mein besonderer Dank Frau Dorothea Mennerich.

Dr. Cornelia Göbel danke ich für das Messen zahlreicher Phytohormonproben per GC/MS und LC/MS und ihre Geduld, mir die großen Maschinen immer wieder aufs Neue zu erklären.

Dr. Otto Miersch stellte freundlicher Weise $D_{5}$-Jasmonat- und $D_{6}$-OPDA-Standards für die Phytohormonbestimmung zur Verfügung.

Dr. Peter Grzeganek danke ich für die Hilfe bei meinen ersten Phytohormonbestimmungen per Evaporationsmethode.

Dr. Martin Fulda danke ich für viele schlaue Tips und zusammen mit Dr. Michael Scharnewski für die Hilfe beim Hefe-knock-out.

Prof. Wodarz und seiner Arbeitsgruppe danke ich dafür, dass ich das FluoreszenzStereomikroskop benutzen durfte.

Dr. John Shanklin danke ich für das pHAS DsRed-Plasmid.

Dr. Ellen Hornung danke ich für den pCAMBIA-Vektor, für das Korrekturlesen meiner Arbeit sowie ihr immer offenes Ohr, ihr stete Hilfsbereitschaft und das ein oder andere Mittagessen.

Bei unserer Gärtnerin Susanne Mester bedanke ich mich für die gewissenhafte Pflege meiner Pflanzen, die geduldige Hilfe beim Pikieren zahlreicher Keimlinge und das Aussieben von Saatgut, aber auch für die Versorgung mit guter hausgeschlachteter Wurst.

Bei unseren technischen Assistentinnen Sabine Freitag und Pia Meyer bedanke ich mich für ihre große Hilfsbereitschaft, die gute Stimmung und den vielen Spaß in zahlreichen Mittagspausen. Und Sabein, danke fürs Göttinger Tageblatt.

Bei meinen Praktikanten Christian Opitz, Georg Wiesner und Cornelius Schneider bedanke ich mich für ihre fleißige Mitarbeit.

Desweiteren bedanke ich mich bei allen Kollegen der Abteilung Biochemie der Pflanze für die ständige Hilfsbereitschaft bei den Tücken des Alltags, die angenehmen Arbeitsatmosphäre und die vielen fröhlichen Feste.

Ganz spezieller Dank gilt dabei der AG Heilmann, in der jeder auf seine Weise zum familiären Arbeitsklima und der lebhaften Arbeitskulisse beigetragen hat. Bei Dr. Till Ischebeck und Dr. Irene Stenzel bedanke ich mich besonders für die Hilfe bei allen Fragen rund ums Klonieren. 


\section{CURRICULUM VITAE}

$\begin{array}{ll}\text { Name } & \text { Alina Mosblech } \\ \text { Address } & \text { Department of Plant Biochemistry } \\ & \text { Albrecht-von-Haller-Institute of Plant Sciences } \\ & \text { Georg August University Göttingen } \\ \text { Justus-von-Liebig-Weg 11, 37077 Göttingen, Germany } & \\ \text { Phone } & \\ \text { Home address } & \\ \text { Email } & \\ \text { Nationality } & \text { German } \\ \text { Status } & \\ \text { Date and place of birth } & \text { July } 7^{\text {th }}, 1980, \text { in Paderborn, Germany }\end{array}$

\section{Scientific Education and Qualifications}

\section{Studies}

2007-2010

Doctoral thesis at the Albrecht-von-Haller-Institute for Plant Sciences (with Prof. Dr. Ingo Heilmann)

Thesis title: "Requirement of phosphoinositide-derived signals in the wounding response of Arabidopsis thaliana"

since 2008 Accepted to the Göttingen Graduate School for Neurosciences and Molecular Biosciences (GGNB), an interdisciplinary training platform for excellent doctoral students in neurosciences and molecular biosciences

$2000-2007$

Studies of Biology at Georg August University Göttingen;

Degree: Diploma (grade "very good with distinction" / 1.0)

Major subject: Biochemistry

Minor subjects: Botany and Developmental Biology

Diploma thesis at the Albrecht-von-Haller-Institute for Plant Sciences (with Prof. Dr. Ivo Feussner/Prof. Dr. Ingo Heilmann) 
Thesis title: "Inositol 1,4,5-trisphosphate and jasmonic acid signal transduction during the wound response of Arabidopsis thaliana" (in German)

$2002-2003$

ERASMUS exchange, University of Oulu, Finland

$1999-2000$

German language and literature studies and education science at Georg August University Göttingen

\section{Presentations at International Conferences}

2010

2009

2008

2007
Oral presentation at the $23^{\text {rd }}$ Conference of Plant Molecular Biology (Dabringhausen, Germany)

Oral presentation at the $4^{\text {th }}$ European Symposium on Plant Lipids (Göttingen, Germany)

Poster at the International Botanical Congress (Leipzig, Germany)

Oral presentation at the $18^{\text {th }}$ International Symposium on Plant Lipids (Bordeaux, France)

Oral presentation at the $3^{\text {rd }}$ European Symposium on Plant Lipids (York, UK)

Poster at the International Botanical Congress (Hamburg, Germany)

\section{Scholarships}

2010

$2008-2009$

$2002-2003$
GGNB Bridging Fund to finalize Ph.D. studies

GGNB Scholarship for Ph.D. studies

ERASMUS grant for a one-year stay in Oulu, Finland 


\section{Publications}

\section{Journal articles}

Bargmann BO, Laxalt AM, Riet B, Testerink C, Merquiol E, Mosblech A, Reyes AL, Pieterse CM, Haring MA, Heilmann I, Bartels D, Munnik T (2009) Reassessing the role of phospholipase $D$ in the Arabidopsis wounding response. Plant Cell Environ 32: 837-850

Mosblech A, Feussner I, Heilmann I (2009) Oxylipins: Structurally diverse metabolites from fatty acid oxidation. Plant Physiol Biochem 47: 511-517

Mosblech A, König S, Stenzel I, Grzeganek P, Feussner I, Heilmann I (2008) Phosphoinositide and inositolpolyphosphate-signalling in defence responses of Arabidopsis thaliana challenged by mechanical wounding. Mol Plant 1: 249-261

König S, Hoffmann M, Mosblech A, Heilmann I (2008) Determination of content and fatty acid composition of unlabeled phosphoinositide species by thin layer chromatography and gas chromatography. Anal Biochem 378: 387-399

König S, Mosblech A, Heilmann I (2007) Stress-inducible and constitutive phosphoinositide pools have distinctive fatty acid patterns in Arabidopsis thaliana. FASEB J 21: 1958-1967

\section{Book Chapters}

Mosblech A, Feussner I, Heilmann I (2010) Oxylipin signaling and plant growth. In T Munnik, ed, Plant Lipid Signaling, Plant Cell Monographs. Springer Academic Publishers, Berlin/Heidelberg, pp 1861-1870

\section{In Preparation}

Mosblech A, Thurow C, Gatz C, Feussner I, Heilmann I "Jasmonic acid perception by COI1 requires an inositol polyphosphate cofactor in Arabidopsis thaliana" (currently under review at Proc Natl Acad Sci USA) 